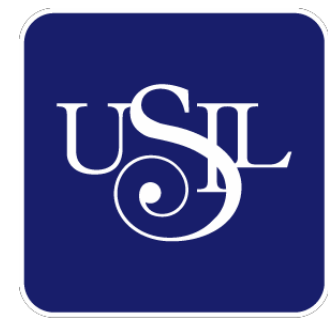

UNIVERSIDAD

SAN IGNACIO

DE LOYOLA

\author{
ESCUELA DE POSTGRADO
}

\title{
COBERTOR SANITARIO PARA INODORO
}

Trabajo de Investigación para optar el grado de:

\author{
DANIEL RICARDO BULLÓN AYALA \\ Maestro en Ciencias Empresariales con Mención en \\ Gestión de Operaciones
}

\section{CHRISTIAN ALEJANDRO CASTILLO FONSECA} Maestro en Ciencias Empresariales con Mención en Gestión Financiera

\section{ISMAEL VARGAS GARCÍA \\ Maestro en Ciencias Empresariales con Mención en Gestión de Operaciones}

Asesor:

Dr. Edmundo Rafael Casavilca Maldonado

Lima - Perú 
AGRADECIMIENTOS

A la Escuela de Post Grado, a los profesores y a nuestros familiares que nos condujeron en este largo camino de trabajo, dedicación y mucho esfuerzo para alcanzar el Grado de Magíster. 


\section{RESUMEN EJECUTIVO}

El presente plan de negocio, proyecta la creación de una empresa dedicada a la producción y comercialización del Cobertor Sanitario para Inodoros. Este producto tiene la característica principal de servir como protección entre la tasa del inodoro y la piel de las personas, durante el uso de los baños públicos. Puesto que, existen estudios que indican que la superficie de los inodoros contiene bacterias y microbios como: estafilococos, psedomonas, Coliform, Escherichia coli, el Norovirus, la Salmonella o las Campylobacter, que podrían atentar contra la salud e higiene de los usuarios.

Por otro lado, el cobertor sanitario para inodoros tiene una mínima presencia en el mercado peruano, lo podemos encontrar en:las góndolas de algunos supermercados en la sección delimpieza del hogar,como parte del servicio que ofrece el Centro comercial Plaza Norte en sus servicios higiénicos y en venta por internet o tiendas especializadas para bebés; lo cual lo convierte en una oportunidad para la prevención y protección de enfermedades. En ese sentido, la producción y comercialización del cobertor sanitario para inodoros se convierte en una oportunidad de negocio que se ubicaría en el segmento de cosmética y productos de aseo personal, debido a su constante crecimiento durante los últimos años. Asimismo, este producto se insertaría en la ruta de consumo de cuidado personal del segmento femenino: toallas higiénicas, pañitos húmedos, tampones, entre otros, completándolo.

Sin embargo, estas afirmaciones deben de validarse, para ello la investigación realizada en el ámbito cualitativo y cuantitativo, han evidenciado un importante nivel de aceptación e intención de compra del cobertor sanitario para inodoros. Por ello, la investigación determinó que el mercado objetivo este constituido por mujeres entre 20 a 54 años de edad, que residen en los distritos de Lima Moderna del NSE A, B y C, pues abarca los distritos con mayor capacidad adquisitiva. Por otro lado, según la clasificación de Arellano estas mujeres siempre están buscando nuevos productos que hagan más fácil su vida diaria y también, que mejoren su salud y la de su familia.

Asimismo, durante la realización de la entrevista de profundidad se eligió a los supermercados como el canal adecuado para el producto, luego de que el experto en supermercados indicará que se puede comercializar en sus puntos de venta en calidad de producto rentable con buena tendencia. Esta afirmación, se terminó de validar durante la realización de la investigación de mercado a través de los Focus Group y las 
encuestas. En ese sentido se pretende introducir el producto en las tiendas de los supermercados Tottus, Metro, Wongy Plaza Vea ubicados en los distritos de Lima Moderna.

Por otro lado, el cobertor sanitario para inodoros necesitará de un plan comunicacional e inversión de marketing fuerte con la finalidad de posicionar el producto en la mente de las consumidoras, como un producto de prevención y protección de la higiene femenina, ante la posibilidad de contraer enfermedades en el uso de los baños públicos.

Otro aspecto importante a evaluar fue la viabilidad del proyecto de producción y comercialización del cobertor sanitario para inodoros, para lo cual se tuvo que definir el precio de éste, el cual se obtuvo mediante la encuesta sugiriendo un precio de S/ 2.50 soles por pack de diez (10) unidades. Con el precio definido se realizó la evaluación financiera del proyecto en un horizonte de cinco (05) años. La evaluación financiera identificó que la inversióninicialdel proyecto asciende a S/. 1, 102,644 con una estructura de financiamiento distribuida de la siguiente forma: aporte propio con un $50.14 \%$ de la inversión inicial y préstamo de la banca con un 49.86\% de la inversión.

Finalmente para realizar la evaluación de la inversión se considera un COK de 18.24\% para la evaluación económica obteniéndose un VANE de 1, 736,672.4,TIRE de $60.98 \%$ un PRKE de 1 Año 10 meses y una relación B/CE de 2.58.Por otro lado, para la evaluación Financiera se utiliza una tasa WACC de 25.75\%, obteniéndose un VANF de1, 184,621.18, un TIRF de 79.29\%, un PRKF de 1 Año 8 meses y una relación B/CF de 3.17, mostrándose con ello que el negocio sería viable y rentable económica y financieramente. 


\section{Tabla de contenido}

CAPITULO I: GENERALIDADES

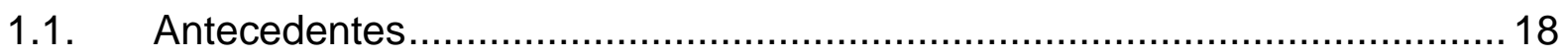

1.2. Determinación del problema u oportunidad ………............................... 19

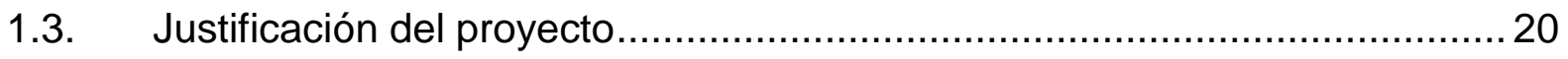

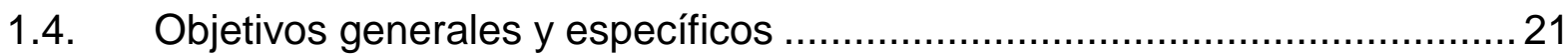

1.5. Alcances y limitaciones de la investigación ............................................... 21

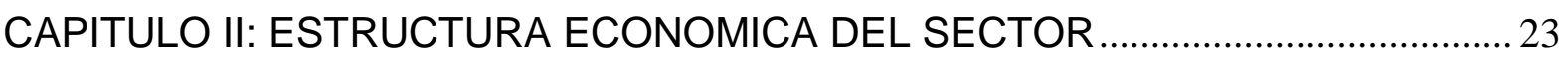

2.1. Descripción del estado actual de la industria..............................................23

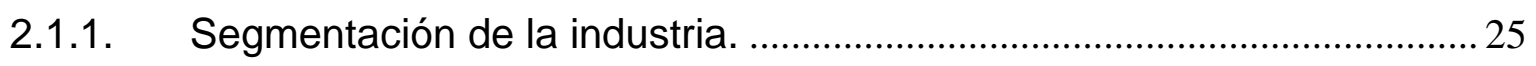

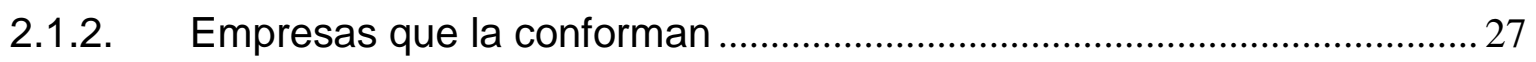

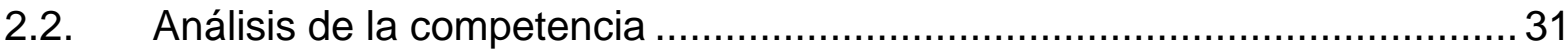

2.2.1. Empresas que ofrecen el mismo producto o servicio, indicando las semejanzas y diferencias que tienen con el proyecto de empresa....................... 32

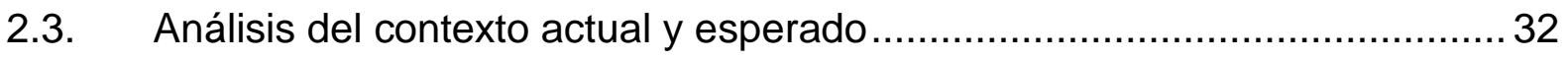

2.3.1. Análisis político - gubernamental - Legal ................................................ 32

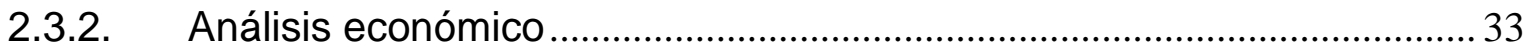

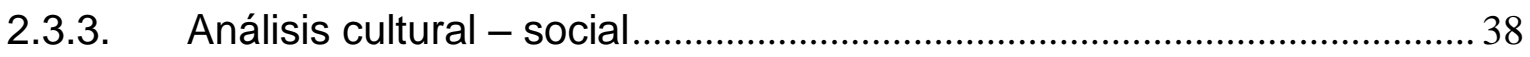

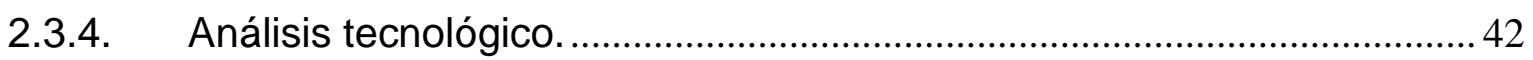

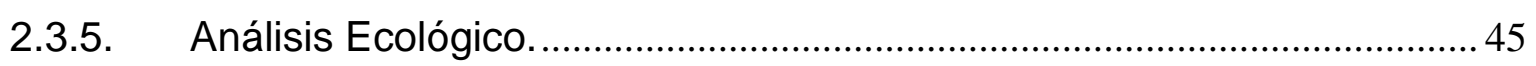

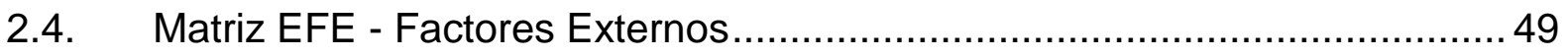

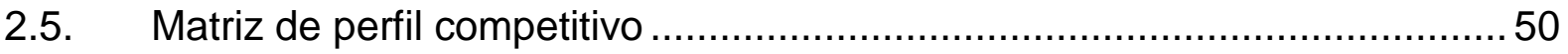

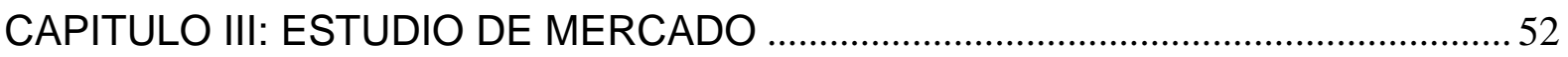

3.1. Descripción del servicio o producto ………......................................... 52

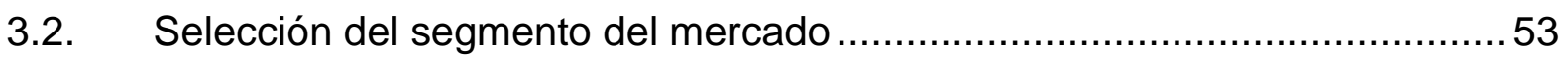

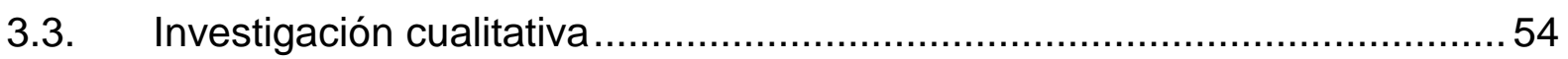

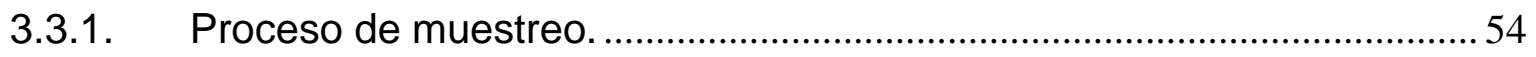

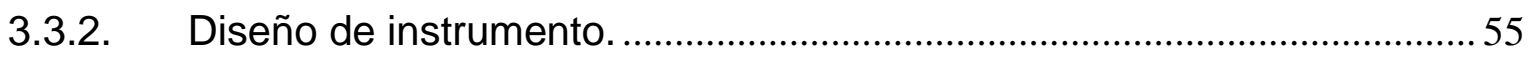

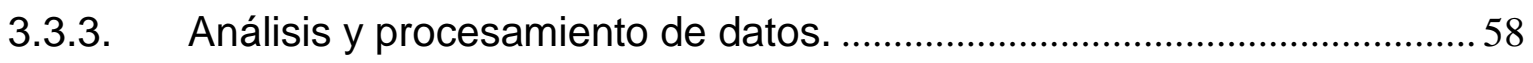

3.3.4. Conclusiones de la investigación cualitativa ...............................................58

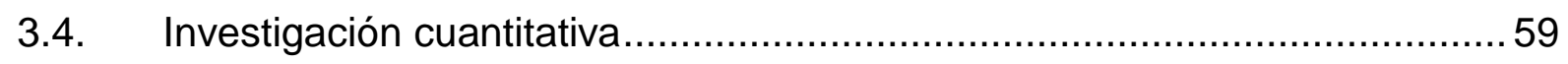

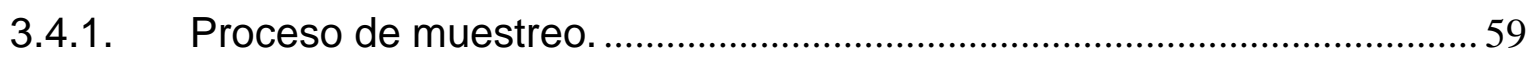

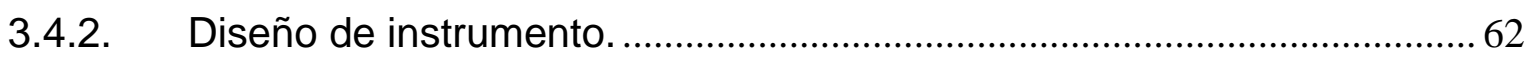


3.4.3. Análisis y procesamiento de datos.

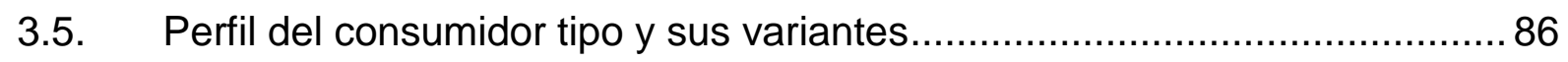

CAPITULO IV: PROYECCION DEL MERCADO OBJETIVO ……………………........87

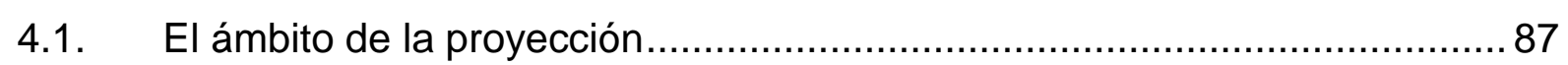

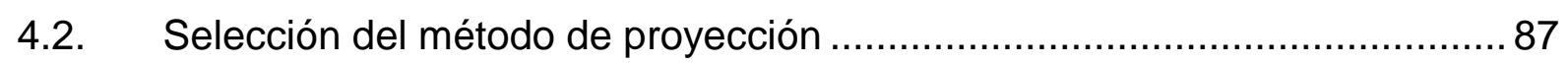

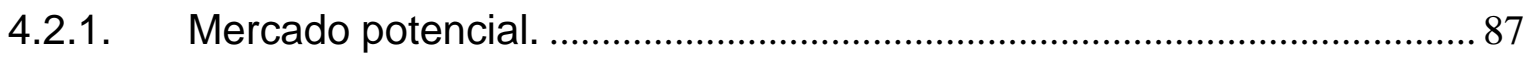

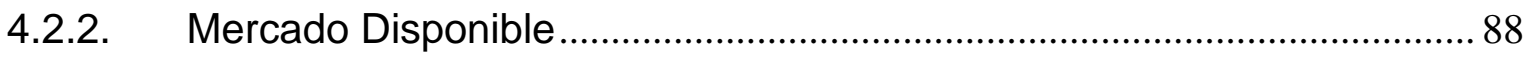

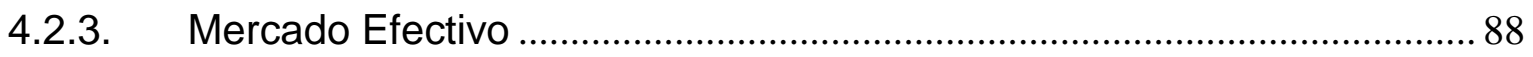

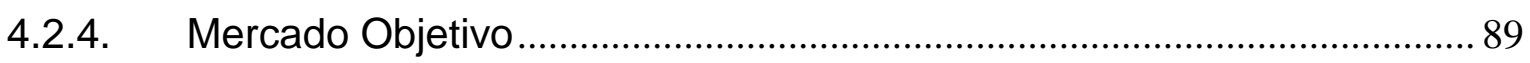

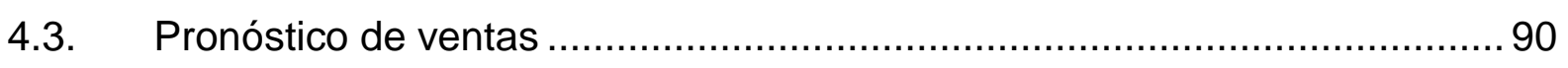

4.4. Aspectos críticos que impactan el pronóstico de ventas ............................ 91

CAPITULO V: INGENIERIA DEL PROYECTO_...........................................................92

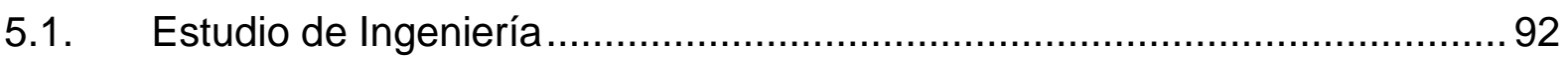

5.1.1. Modelamiento y selección de procesos productivos.................................. 93

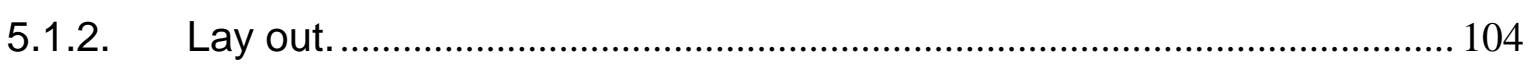

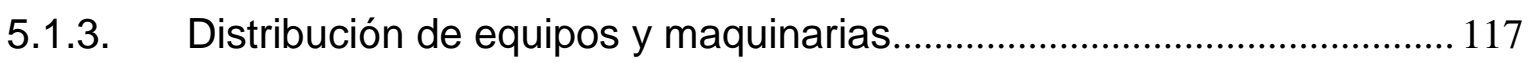

5.2. Determinación del tamaño ............................................................... 117

5.2.1. Proyección de crecimiento ..................................................................... 118

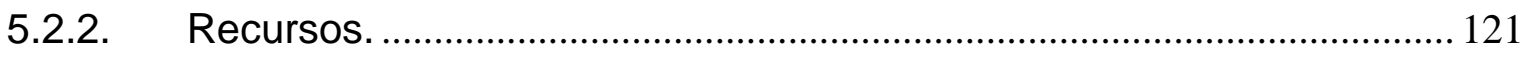

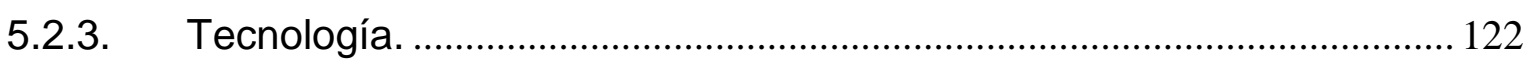

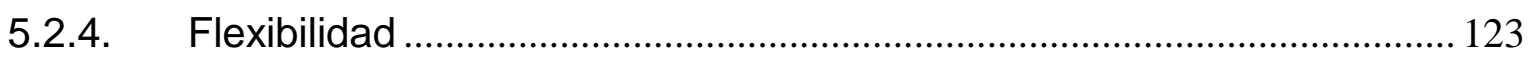

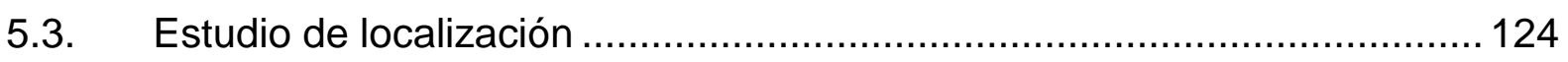

5.3.1. Definición de factores locacionales. ....................................................... 124

5.3.2. Determinación de la localización óptima................................................... 126

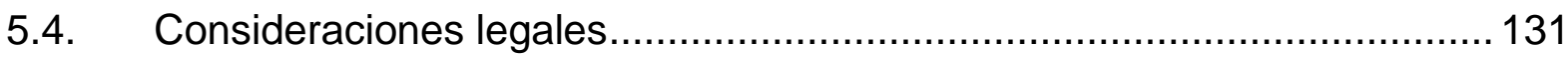

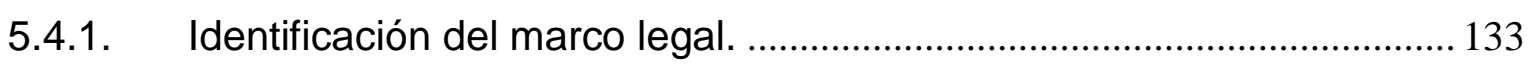

5.4.2. Ordenamiento jurídico de la empresa ...................................................... 135

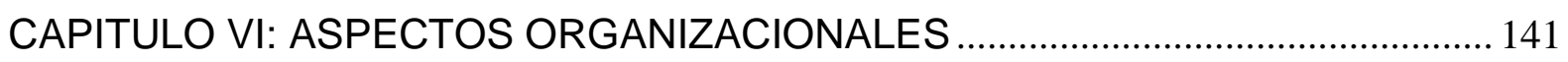

6.1. Caracterización de la cultura organizacional deseada............................. 141

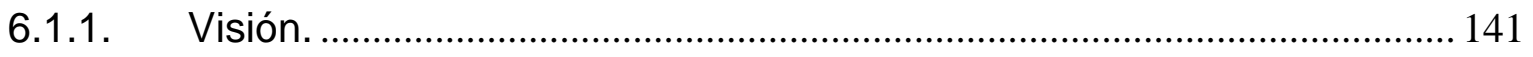

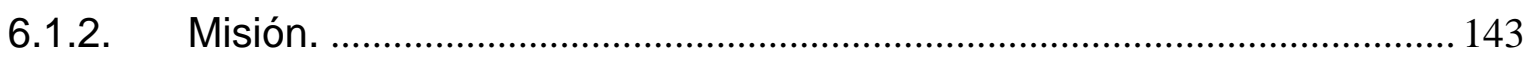

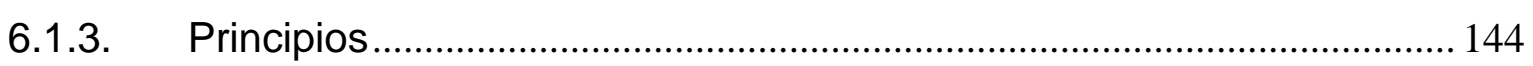

6.2. Formulación de estrategias del negocio ............................................. 145 


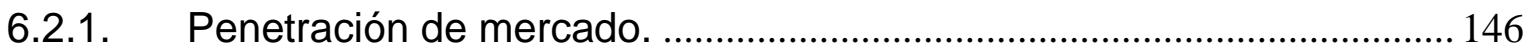

6.2.2. Estrategia para el lanzamiento de producto.............................................. 146

6.3. Diseño de la estructura organizacional deseada ................................... 147

6.4. Diseño de los perfiles de puestos clave............................................... 149

6.5. Remuneraciones, compensaciones e incentivos .................................. 152

6.6. Política de recursos humanos .............................................................. 154

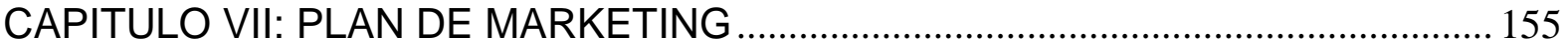

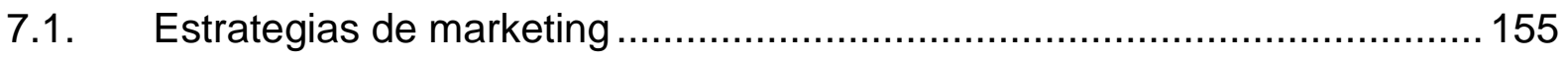

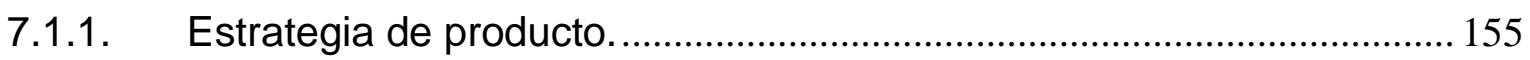

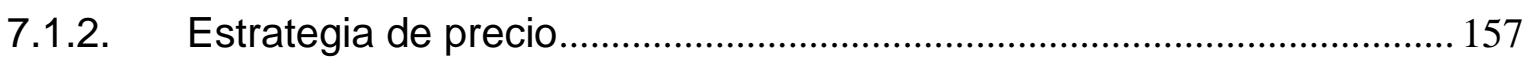

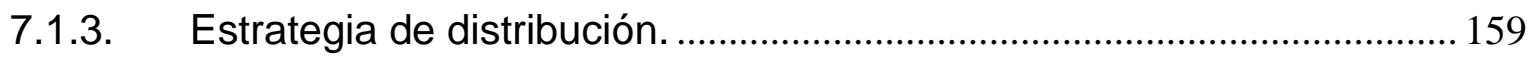

7.1.4. Estrategia de promoción y publicidad. ...................................................... 160

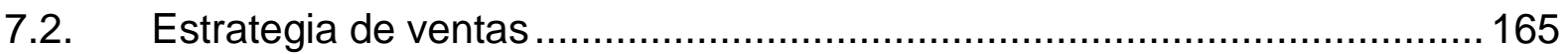

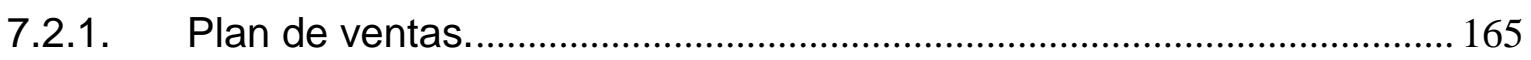

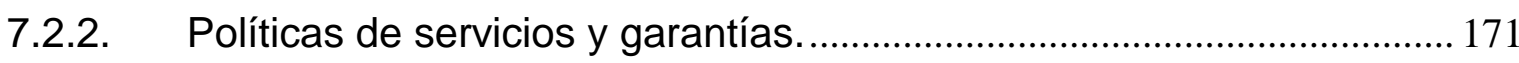

7.2.3. Presupuesto de marketing con un horizonte a 5 años del plan de

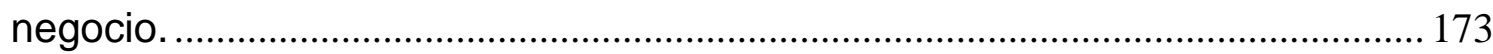

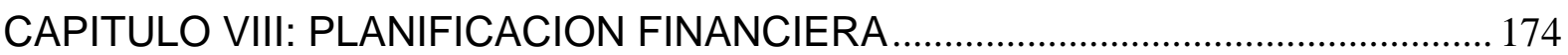

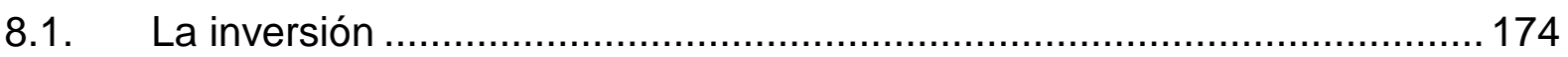

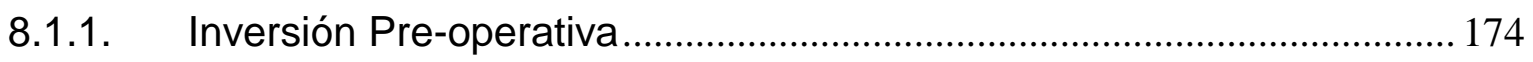

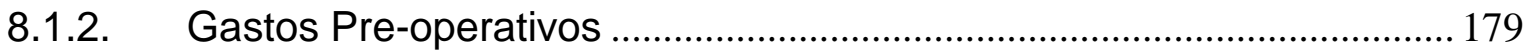

8.1.3. Inversión en capital de trabajo................................................................... 181

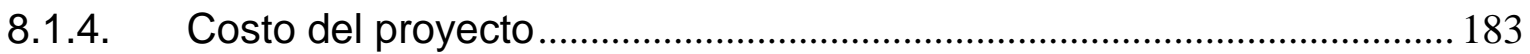

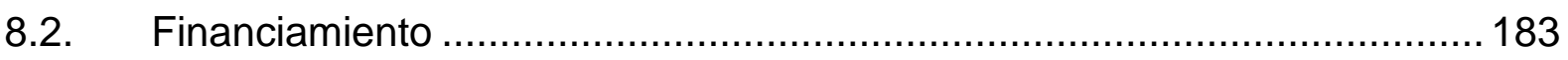

8.2.1. Endeudamiento y condiciones ……………………............................... 183

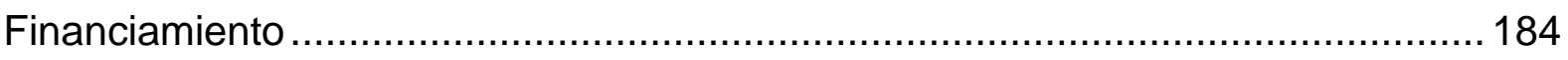

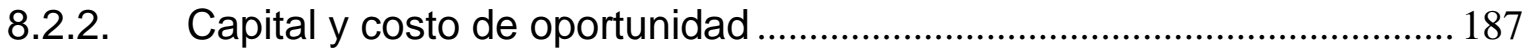

8.2.3. Costo de Capital promedio ponderado..................................................... 188

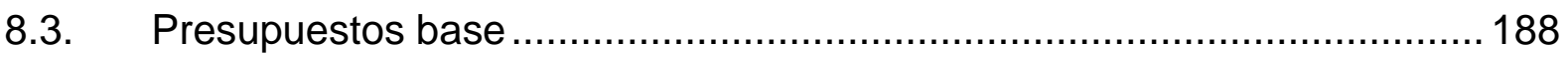

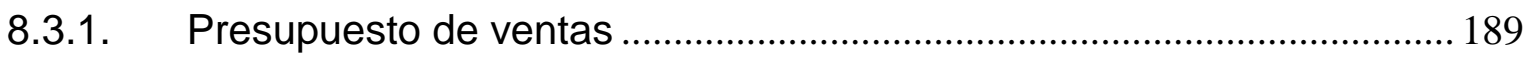

8.3.2. Presupuesto de costos de producción .................................................... 189

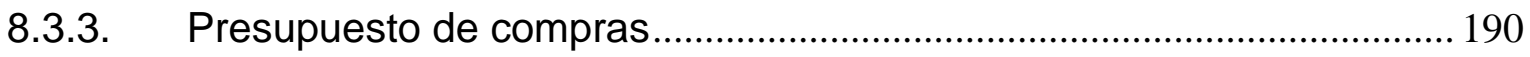

8.3.4. Presupuesto de costo de ventas ............................................................ 191 
8.3.5. Presupuesto de gastos administrativos ................................................... 191

8.3.6. Presupuesto de marketing y ventas ....................................................... 192

8.3.7. Presupuesto de gastos financieros ............................................................ 193

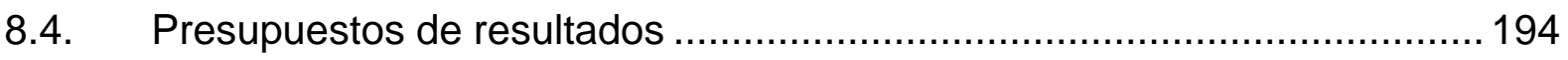

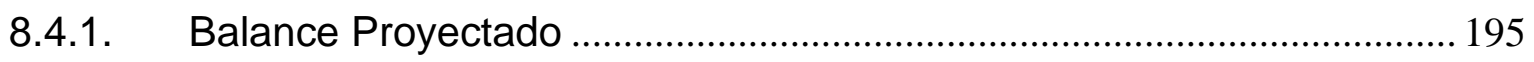

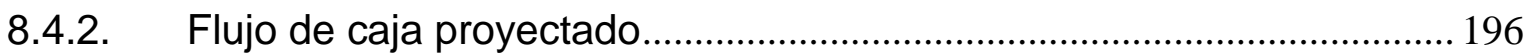

CAPITULO IX: EVALUACION ECONOMICO FINANCIERA ........................................ 197

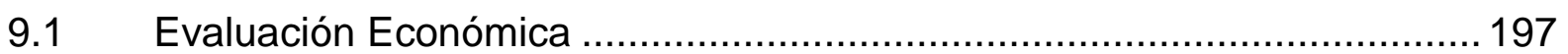

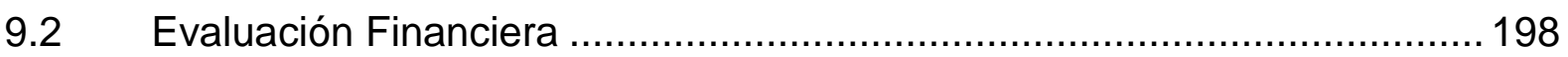

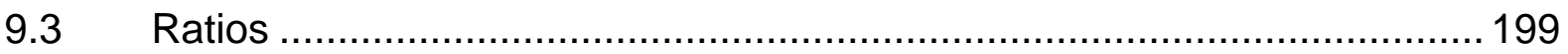

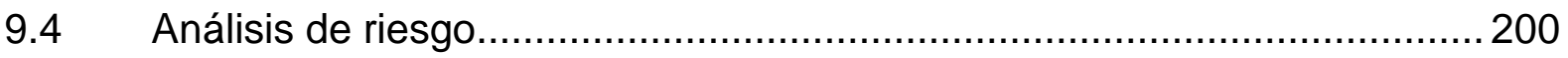

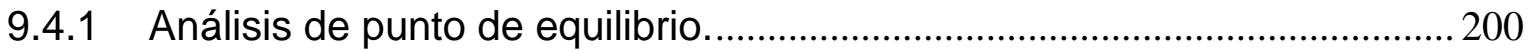

9.4.2 Análisis de sensibilidad. ................................................................................ 200

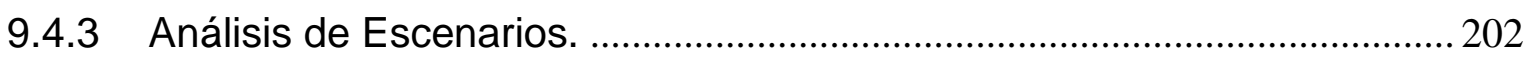

CAPITULO X: CONCLUSIONES Y RECOMENDACIONES ……………………......... 204

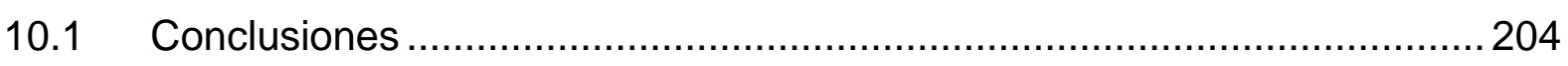

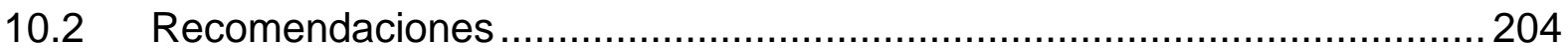

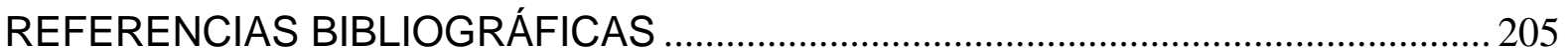

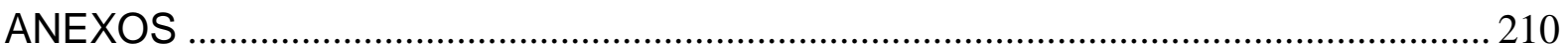




\section{ÍNDICE DE TABLAS}

Tabla 1. Compra Termoencogibles del Perú S.A

Tabla 2. Principales indicadores del país

Tabla3. Hogares con acceso a tecnologías de información y comunicación internet.

Tabla 4. Hogares con acceso a tecnologías de información y comunicación

Tabla 5. Matriz EFE

Tabla 6. Matriz de perfil competitivo

Tabla 7. Perfiles de expertos

Tabla 8. Entrevistas de profundidad

Tabla 9. Ficha Técnica del Focus Group

Tabla 10. Focus Group

Tabla 11. Proceso de muestreo(Población por distritos de Lima Moderna)

Tabla 12. Participación por género

Tabla 13. Población por rango de edad

Tabla 14. Población por nivel socioeconómico

Tabla 15. Distribución de encuestas por distritos y nivel socioeconómico

Tabla 16. Diseño de instrumento

Tabla 17. ¿Utiliza baños públicos?

Tabla 18. ¿Con que frecuencia que usa los baños públicos?

Tabla 19. ¿Usted cree que el estado de los baños podría afectar su salud?

Tabla 20. ¿Conoce algún producto que le permita evitar el contacto de su piel con el inodoro al usar los baños públicos

Tabla 21. ¿Ha utilizado este tipo de producto?

Tabla 22. Si su respuesta a la pregunta 4 fue indeciso, desconozco o desconozco totalmente, nos gustaría conocer las razones de su respuesta

Tabla 23. ¿Qué marcas de cobertor sanitario para inodoro ha visto en el mercado?

Tabla 24. Que marcas de cobertor para inodoro es la que Ud. Utiliza actualmente

Tabla 25.Regularmente, cuando hace uso de un baño público, en qué lugares utiliza el cobertor sanitario para inodoros

Tabla 26. ¿Si se ofrece un nuevo cobertor sanitario para inodoro que presenta los siguientes atributos, Garantiza el cuidado de su salud, calidad por encima de los productos de la competencia, precios adecuados y que se encuentren en puntos de ventas accesibles?¿Qué tan importante le parecen los atributos del producto? 
Tabla 27. De los atributos mencionados ¿Cuál considera más importante?

Tabla 28. ¿Cuál es la presentación del cobertor sanitario para inodoro que sería de su preferencia? $\quad 75$

Tabla 29. ¿En qué punto de venta le gustaría encontrar el pack del cobertor? $\quad 76$

Tabla 30. ¿En el punto de venta en que área le gustaría encontrar el pack del cobertor sanitario para inodoros?

Tabla 31. Con respecto a la compra ¿Cuál es la frecuencia con la que compra el producto o estaría dispuesto a comprarlo?

Tabla 32. Al momento de realizar de su compra ¿Cuantos paquetes del cobertor sanitario para inodoro compra o compraría?

Tabla 33. ¿Cuánto estaría Usted dispuesto a pagar por un pack de acuerdo a su elección de contenido?

Tabla 34. Luego de la presentación e introducción de los atributos del nuevo cobertor sanitario para inodoros ¿Ud. Estaría dispuesto a comprarlo?

Tabla 35. Si su respuesta fue "Indiferente", "Probablemente No" y definitivamente No, ¿Nos gustaría conocer las razones? En el caso de que el encuestado responda esta pregunta se finaliza su encuesta.

Tabla 36. ¿Qué medio de comunicación considera el más importante para realizar la publicidad del cobertor sanitario para inodoros?

Tabla 37. ¿Mercado potencial - mujeres de Lima moderna del entre 20 a 54 años de edad y de NSE A,B y C

Tabla 38. Mercado disponible

Tabla 39. Mercado efectivo

Tabla 40. Mercado objetivo

Tabla 41. Mercado objetivo proyectado 90

Tabla 42. Frecuencia de compra anual

Tabla 43. Pronostico de ventas

Tabla 44. Cuadro comparativo

Tabla 45. Relación de cercanía

Tabla 46. Ratios - Razón

Tabla 47. Relaciones de actividades

Tabla 48. Diagrama de distribución sin limitaciones de espacio

Tabla 49. Dimensiones de máquinas e instalaciones( en metros )

Tabla 50. Dimensiones de máquinas e instalaciones

Tabla 51. Dimensiones y superficies ajustadas para maquinas e instalaciones 
Tabla 53. Demanda estimada mensual y anual

Tabla 54. Capacidad disponible

Tabla 55.Requerimientos

Tabla 56. Costos de operación

Tabla 57. Factores críticos

Tabla 58. Factores objetivos

Tabla 59. Factores objetivos por distritos

Tabla 60. Cuadro porcentual

Tabla 61 Tabla calificativa

130

Tabla 62. Índices de localización de todos los distritos

Tabla 63. Composición accionaria

Tabla 64. Análisis de la visión

Tabla 65. Visión - Análisis de la Misión

Tabla 66. Sueldos del personal 153

Tabla 67. Estructura de precio 158

Tabla 68. Cuadro de distribución de supermercados

Tabla 69. Programación de mercaderistas: Cadena de supermercados

Tabla 70. Presupuesto de marketing y ventas - Soles

Tabla 71.Constitución de empresas - licencias

Tabla 72. Software

Tabla 73. Inversión intangible

Tabla 74. Acondicionamiento de local

Tabla 75. Artículos de oficina

Tabla 76. Total gastos pre operativos

Tabla 77 Máquinas y equipos

Tabla 78. Mobiliario

Tabla 79. Unidades de distribución y venta

Tabla 80. Consolidado - Total inversión tangible 179

Tabla 81. Activos diferidos

Tabla 82. Compras de insumo

Tabla 83. Sueldos y salarios

Tabla 84. Servicios

Tabla 85. Total gastos pre - operativos 181

Tabla 86. Flujo de efectivo de los primeros 5 meses

Tabla 87. Máximo déficit acumulado 
Tabla 89. Préstamo a solicitar a una entidad financiera 182

Tabla 90. Inversión total en soles 183

Tabla 91. Condiciones financieras 183

Tabla 92. Financiamiento de rubros de inversiones en nuevos S/. 184

Tabla 93. Definición de cuota 185

Tabla 94. Amortización de la deuda en soles $\quad 185$

Tabla 95. Costo de capital promedio ponderado 188

Tabla 96. Presupuestos totales 189

Tabla 97. Presupuestos de ventas 189

Tabla 98. Presupuesto de costos de producción - Soles 190

Tabla 99. Presupuesto de compra - Soles 191

Tabla 100. Presupuesto de costo de ventas - Soles 191

Tabla 101. Presupuesto de gastos administrativos - Soles 192

Tabla 102. Presupuesto de marketing y venta - Soles 193

Tabla 103. Presupuesto de gastos financieros - Soles 193

$\begin{array}{ll}\text { Tabla 104.Estado de ganancias y pérdidas proyectado } & 194\end{array}$

Tabla 105. Balance general proyectado 195

Tabla 106. Flujo de caja proyectado 196

Tabla 107. Evaluación Económica 197

Tabla 108. Evaluación Financiera 198

Tabla 109. Ratios 199

Tabla 110. Análisis punto de equilibrio 200

Tabla 111. Reducción del precio en 5.0\% 200

Tabla 112. Reducción del precio en 10.0\% 201

Tabla 113. Reducción del precio en 13.707\% 201

Tabla 114. Aumento del costo del papel 15\% 201

Tabla 115. Aumento del costo del papel 30\% 202

Tabla 116. Aumento del costo del papel 44.6914\% 202

Tabla 117. Análisis de escenarios 203 


\section{ÍNDICE DE FIGURAS}

Figura 1. Baños públicos $\quad 20$

Figura 2. Crecimiento del mercado 23

Figura 3. Crecimiento del Sector $2009-2017$.

Figura 4. Mercado de Cosméticos: Producción e importación 25

Figura 5.Tendencia anual del mercado al 2019

Figura 6. Tendencia de crecimiento del mercado del sector. 26

Figura 7. Participación del Mercado 2011 al $2014 \quad 27$

Figura 8. Línea termoencogibles 28

Figura 9. Línea Comercial 28

Figura 10. Cobertor Queen. 29

Figura 11. Safet-t-gard. 29

Figura 12. Línea Snacks 30

Figura 13. Línea comidas 30

Figura 14. Línea de higiene 31

Figura 15. PBI de América latina 34

Figura 16. Índice de precios al consumidor $\quad 35$

Figura 17. Tasa de interés de referencia del BCRP $2003-2016$

Figura 18. Tipo de cambio Nominal 36

Figura 19. Índice de confianza del consumidor en Lima y el interior 37

Figura 20. Situación del peruano en relación al total del ingreso familiar 39

Figura 21. Población económicamente activa urbana de 24 a $64 \quad 40$

Figura 22. Estilos de vida $\quad 41$

Figura 23. Virtualización $\quad 44$

Figura 24. Cobertor sanitario $\quad 52$

Figura 25. ¿Utiliza baños públicos $\quad 64$

Figura 26. ¿Con qué frecuencia usa los baños públicos? 65

Figura 27. ¿Usted cree que el estado de los baños podría afectar su salud? 66

Figura 28. ¿Conocimiento de producto para evitar contacto de la piel con el inodoro $\quad 67$

Figura 29. ¿Utilización del producto 68

Figura 30. ¿Razones de su respuesta $\quad 69$

Figura 31. ¿Marcas de cobertor $\quad 70$

Figura 32. ¿Marcas de cobertor que utiliza actualmente 71 
Figura 33. ¿Lugares que usa los baños públicos 72

Figura 34. ¿Importancia de los atributos de un nuevo cobertor 73

Figura 35. ¿Atributos más importante $\quad 74$

Figura 36. ¿preferencia de presentación de packs $\quad 75$

Figura 37. ¿Punto de venta que Ud. le gustaría encontrar los packs de los nuevos cobertores? $\quad 76$

Figura 38. Preferencia de ubicación en puntos de venta 77

Figura 39. Frecuencia de compra del producto 78

Figura 40. Numero de paquetes que compra o compraría 79

Figura 41. Precio que pagaría 80

Figura 42. Disposición de compra del nuevo producto 81

Figura 43. Razones por las que no compraría el producto 82

Figura 44. Medio de comunicación que generaría mayor impacto en la venta de cobertor sanitario. $\quad 83$

Figura 45. Flujograma de los procesos productivos 96

Figura 46. Maquina convertidora automática de protectores sanitarios 97

Figura 47. Dobladora automática Manufacturing \& Processing Machinery 98

Figura 48. Forma de doblado 99

Figura 49. Embolsadora 100

Figura 50. Transpaleta hidráulica 102

Figura 51. Balanza de piso de 2000kg 103

Figura 52. Andamios para producto terminado 103

$\begin{array}{ll}\text { Figura 53. Diagrama relacional de actividades } & 105\end{array}$

Figura 54. Rollo de papel 106

$\begin{array}{ll}\text { Figura 55. Bolsa de polietileno } & 107\end{array}$

Figura 56. Publicidad GS1 - Código de barras 107

$\begin{array}{ll}\text { Figura 57. Cajas de cartón } & 108\end{array}$

Figura 58. Camión de reparto 109

Figura 59. Diagrama relacional de actividades $\quad 112$

Figura 60. Distribución de equipos y maquinarias $\quad 117$

Figura 61. Principios. Elaboración del equipo de investigación 145

Figura 62. Formulación de estrategias del negocio 146

Figura 63. Estructura organizacional. Elaborada por el equipo investigador $\quad 147$

Figura 64. Estrategias de Marketing 155

Figura 65. Propuesta de Valor de producto 155

Figura 66. Cobertor sanitario 156 
Figura 67. Diseño de canal de fuente

Figura 68. Diseño de estrategia comunicacional 160

$\begin{array}{ll}\text { Figura 69. Mercado objetivo } & 161\end{array}$

Figura 70. Medios 162

Figura 71. Sampling. $\quad 163$

Figura 72. Relaciones publicas $\quad 164$

Figura 73. Plan de ventas 165

Figura 74. Cuadro Distribución de Supermercados por coordinador 167

Figura 75. Ubicación de competidor Queen en supermercado. 169

Figura 76. Ubicación recomendada para el nuevo producto 169

$\begin{array}{ll}\text { Figura 77. Jalavistas en góndola } & 170\end{array}$

Figura 78. Diferentes soluciones, planteadas por CHESS 171

Figura 79. Alineación estratégica de las políticas. 173 


\section{INTRODUCCIÓN}

El plan de negocios a desarrollarconsiste en la producción y comercialización de un cobertor sanitario para inodoros. Este producto es una lámina de papel biodegradable que se posiciona encima de la taza evitando el contacto con el cuerpo, teniendo como principal objetivo el prevenir el desarrollo de enfermedades y proteger la salud de las damas al hacer uso de los baños públicos. Por ello, el producto está dirigido al segmento femenino, de 20 a 54 años de edad de los NSE A, B y C de Lima Moderna.

El presente plan de negocios contempla nueve capítulos, los cuales se detallan a continuación.

El primer capítulo, refiere generalidades, evaluación del entorno externo e interno, la oportunidad de negocio, objetivos, alcances y limitaciones.

El segundo capítulo, evalúa el segmento de mercado y aspectos macro y micro del entorno, lo cual termina en el desarrollo de las matrices EFE y el MPC.

El tercer capítulo, presenta el estudio de mercado, desarrollando entrevista de profundidad, focus group y encuesta. Las cuales permiten definir el segmento a atender y las características del producto.

El cuarto capítulo desarrolla la proyección del mercado objetivo finalizando en el pronóstico de ventas.

En el capítulo cinco, se muestra la ingeniería del proyecto, en el cual se determina los equipos y maquinarias, la ubicación de la planta y almacenes y los procesos internos de producción.

En el capítulo seis, se muestra el estudio organizacional que comprende los aspectos de visión, misión, objetivos, cultura y política. Así mismo, se presenta la estructura organizacional y el perfil de los puestos.

En el capítulo siete, se muestra el plan de marketing, analizando la estrategia de posicionamiento, comunicacional, de ventas y distribución. De la misma forma, se evalúa el mix de marketing que se aplica en la estrategia, así como también las políticas de ventas. 
En el capítulo ocho, se efectúa la planificación financiera desde la inversión y presupuestos, hasta el flujo de caja proyectado.

En el capítulo nueve, se realiza el análisis Económico- Financiero que determinarán la viabilidad y rentabilidad del proyecto. 


\section{CAPITULO I: GENERALIDADES}

\subsection{Antecedentes}

En temas de salud, el rol del Estado es importante en la creación de la normatividad y fomento de la cultura preventiva, orientada al desarrollo de ciudadanos conocedores de sus deberes y derechos y por los cuales pueden exigir su cumplimiento, amparados en la justicia que les garantiza el Estado.

En los países desarrollados, en lo referido a normatividad, el Estado ha desarrollado políticas o lineamientos para el cuidado de la salud de las personas, relacionados con el mantenimiento, higiene y limpieza de los baños públicos; con la finalidad de disminuir o reducir la posibilidad de contagiarse de enfermedades en esos establecimientos.

La creación de normativas, junto con otros factores ha generado que la población desarrolle una cultura de prevención, mediante la exigencia del cumplimiento de las normas emitidas por los gobiernos, dando como resultado la mejora en la calidad y atención de los servicios a la población.

Por otro lado, en los países en vías de desarrollo la normatividad que avala la seguridad y cuidado de la población en aspectos de salud es limitado. Y esta situación se agudiza por los escasos recursos cuando el Estado debe realizar las actividades de control y cumplimiento de las normas emitidas. De la misma forma, la poca presencia del Estado sumada a las costumbres y falta de educación de la población incrementa el riesgo de contagio de enfermedades en los baños públicos.

En este contexto, el mercado peruano no ha desarrollado el segmento del producto cobertor sanitario para inodoros, este producto es desconocido en el mercado. Sin embargo existieron algunos esfuerzos de introducir este producto en el mercado.

La empresa PROTISA buscó el ingreso del cobertor sanitario para inodoro en el sector B2B, introduciéndolo como un producto para completar el pack de aseo en hoteles y en empresas. Bertarelli (2016) Jefe de Marketing, División Institucional Productos Tissúe del Perú S.A.- PROTISA, manifestó que el alto precio del producto aunado a la poca cultura del usuario,impidió alcanzar las metas del plan de ventas en el canal (Ver encuesta). 
Por su parte Oliva (2016) ejecutivo de Logística de Compras - Corporación Wong, comenta que el Centro Comercial Plaza Norte ingreso el cobertor sanitario para inodoro como parte del pack de servicios para el uso de los inodoros, sin embargo el desconocimiento del público lo termina definiendo como un papel toalla para limpiarse las manos.

La empresa Termoencogibles del Perú realizó un pedido de cobertores sanitarios para inodoro a China y los empacó con su marca,a la fecha se evidencia que solo mantiene dos caras visibles en góndola en la sección de material de limpieza del hogar del Supermercado Tottus.

Finalmente, se puede concluir que el Cobertor Sanitario para Inodoros es un producto desconocido en el mercado peruano, por lo cual los antecedentes son exiguos y no tiene representatividad.

\subsection{Determinación del problema u oportunidad}

Los inodoros de los baños públicos, usualmente se caracterizan por no estar debidamente limpios ni aseados y está relacionado por la forma de uso, costumbres y educación de las personas, las cuales generan un impacto negativo en la sociedad, ya que atentan contra la salud de las personas.

La falta de confianza de las personas por el uso de los inodoros en los baños públicos, fundamentalmente, por el sector femenino e infantil está relacionado a que podrían tener sus superficies contaminadas con gran cantidad de bacterias, las cuales a simple vista no se pueden observar a pesar de que el inodoro se vea muy limpio, y que podrían producir impactos negativos en el cuerpo como: infecciones urinarias, cálculos en los riñones, cistitis, dolor al orinar, fiebre ocasionada por bacterias, escalofríos, dolor de estómago, calambres entre otros.

Sin embargo, esta debilidad del Estado, en infraestructura y educación de la población ofrece la oportunidad de generar cultura de prevención y cuidado de la salud de las personas, mediante la producción y comercialización de un producto que disminuya el riesgo de contraer enfermedades cuando se hace uso de los inodoros de los baños públicos. 
Por otro lado, el sector femenino transmite las costumbres y hábitos a sus hijos de no sentarse en las tazas de los inodoros de baños públicos. Una publicación de la revista Emedemujer (2016) comenta que hay personas que utilizan plástico sobre la superficie de la taza o la secan con papel, lo cual evitará mojarse, pero no logra eliminar los diferentes microorganismos que ahíse encuentran.

Asimismo, expertos como el Dr. Gerba (2016)bacteriólogo de la Universidad de Colorado comenta que el $50 \%$ de los asientos de baño en los principales hoteles y restaurantes estaban contaminados con la bacteria Coliform.

El Dr. Gerba (2016), también manifiesta "que otro problema frecuente, el cual es desconocido por las mujeres, es que el orinar semi-parada produce incontinencia urinaria. Por ejemplo, en el caso de las mujeres que optan por no sentarse en el servicio higiénico al orinar". La posición adoptada para hacerlo semi-parada es incómoda y no natural, y cuando es muy frecuente, puede traer complicaciones que a la larga causan el estiramiento de los tejidos de la pelvis, y lo que puede causar un descenso de vejiga, lo que podría producir incontinencia urinaria.

\subsection{Justificación del proyecto}

La creación de esta empresa en el Perú se hace con el fin de generar la cultura de prevención de enfermedades en el usode los inodoros de los baños públicos de Lima Moderna, los cuales según estudiosse encuentran infectados porbacterias y microbios como: estafilococos, psedomonas, Coliform, Escherichia coli, el Norovirus, la Salmonella o las Campylobacter.

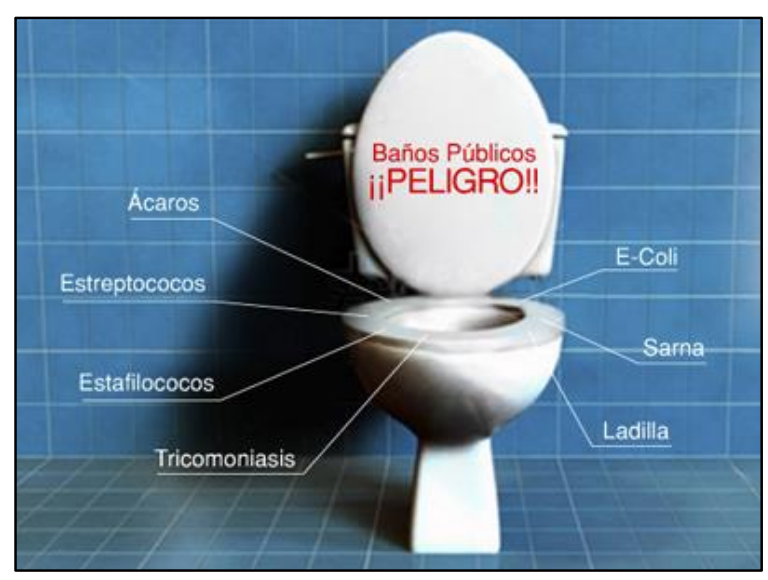

Figura 1. Los diferentes microbios y bacterias que se puede encontrar en un inodoro de baño público. Adaptado deelambienteron.wordpress.com, 2016. 
Como consecuencia, el plan de negocio busca diseñar un proyecto para producir y comercializar un cobertor sanitario para inodoro.

Cabeprecisar que al ingresar a un baño público las condiciones de salubridad y aseo no son de las mejores, por tal motivo esimportante considerar este producto en la categoría de higiene y cuidado personal.

Por otro lado, el desarrollo de este plan de negocios cumple con la normatividad y lineamientos que exige la Escuela de Postgrado alaplicar los conocimientos adquiridos durante la maestría, en los diferentes ámbitos de la administración y llevarlos a un escenario real que admita aprovechar las oportunidades del mercado en el sector propuesto.

\subsection{Objetivos generales y específicos Objetivos Generales}

Determinar la viabilidad de la implementación de una empresa productora y comercializadorade uncobertor sanitario para inodoros en Lima Moderna.

\section{Objetivos Específicos}

Realizar un estudio de mercado que permita conocer el mercado objetivo, características del producto y canales de venta a comercializar.

Diseñar estrategias de marketing que permitan posicionar el producto y su penetración en el mercado.

Evaluartamaño de infraestructura, flujo de operaciones y distribución.

Realizar la evaluación económica y financiera del proyecto para determinar laviabilidad y rentabilidad del negocio.

\subsection{Alcances y limitaciones de la investigación}

Los alcances que se buscan con la investigación son los siguientes:

El proyecto de producción y comercialización del cobertor sanitario para inodoros se desarrollará en el ámbito de Lima Moderna dirigido al sector femenino, y con un horizonte de 5 años.

Las limitaciones de la investigación están relacionadas a lo siguiente:

Escasa información de este tipo de producto en el mercado peruano, por lo tanto se realizan diferentes tipos de investigación, de tipo primario, para la recolección de datos 
e información que sustente la viabilidad y desarrollo del proyecto, tales como: entrevistas de profundidad, focus group y encuestas.

Al ser una investigación en la que se utiliza un muestreo no probabilístico, fue complicado ubicar personas que cumplan con el perfil del cliente y aplicarles la encuesta. 


\section{CAPITULO II: ESTRUCTURA ECONOMICA DEL SECTOR}

\subsection{Descripción del estado actual de la industria}

El cobertor sanitario para inodoro no existe en el mercado peruano; sin embargo, por sus características y como parte de la estrategia del proyecto este producto se debería incluir en la categoría de higiene y cuidado personal.

Por otro lado, según la clasificación del INEI (2010):

Relacionada a la Clasificación Industrial Internacional Uniforme - CIIU 1709, ubica el productoen el sector Industria Manufacturera, de la categoría o división Fabricación papel y productos de papel, grupo Fabricación de papel y productos de papel y finalmente en la clase:Fabricación de productos de papel y guata de celulosa de uso doméstico y para la higiene personal: pañuelitos faciales; pañuelos, toallas, servilletas; papel higiénico; toallas higiénicas y tampones, pañales y forros de pañales para bebés; y vasos, platos y bandeja.

A pesar de la falta de información detallada de la categoría, se ha considerado que la descripción de la industria se desarrolle como punto de partida de manera globalizada considerando el análisis del mercado de cosmética e higiene y cuidado personal.

Para el Gremio Peruano de Cosmética e Higiene (Copecoh, 2015) de la Cámara de Comercio de Lima (CCL), esta industria representa unos US\$434,000 millones a nivel mundial y en la última década ha venido tomando más importancia en el mundo, por lo que se le ha dado mayor relevancia a todo lo que tenga que ver con este sector.

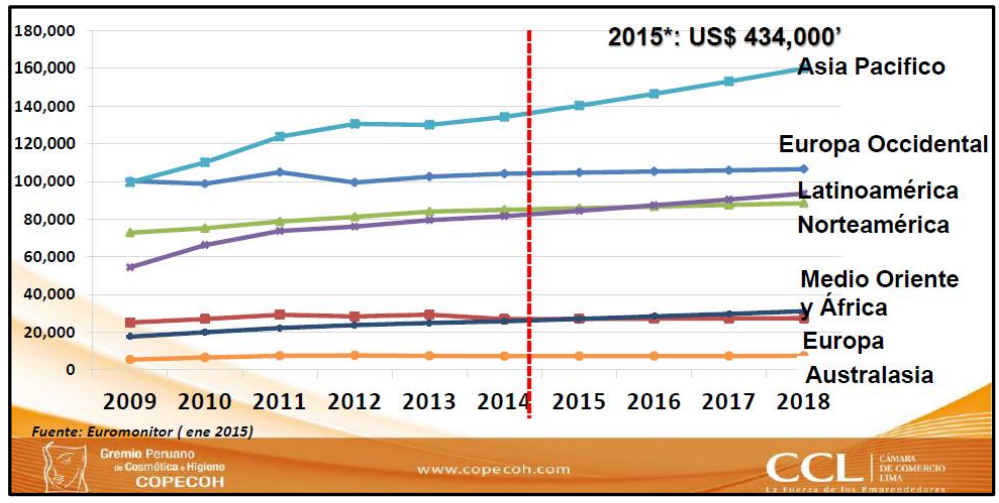

Figura2. Crecimiento del mercado de Cosmética e Higiene. Adaptado de Cámara de comercio de Lima, Copecoh.com, 2015. 
Al respecto, los productos de cosmética e higiene y cuidado personal en el Perú vienen registrando importantes incrementos en ventas, inclusive en el 2012 registró un crecimiento en dólares de $23 \%$ respecto al 2011 , alcanzando los US $\$ 2,307$ millones según estudio de inteligencia de mercado realizado por el Comité Peruano de Cosmética e Higiene (Copecoh, 2013).

El año 2013 tuvo un leve crecimiento del 3\% respecto al 2012 debido a una desaceleración de la economía que afectó a todos los sectores de consumo, este mismo comportamiento desacelerado se observa en el 2014 donde el sectorcosmética e higiene y cuidado personal decreció en $-4 \%$ respecto al 2013, llegando a sumar un mercado de US\$2,277 millones. El año 2015 presentó un decrecimiento del $-4 \%$ respecto del 2014 (US $\$ 2,169$ millones) cuando se había estimado una desaceleración de $-3 \%$ respecto al 2014 (US\$2,201 millones).

Para los años 2015 al 2019 se espera un incremento de las ventas en este sector debido a un incremento de la capacidad adquisitiva de los peruanos, el desarrollo comercial de los centros comerciales, las ofertas diversificadas producto de las importaciones y la inversión privada, entre otros.

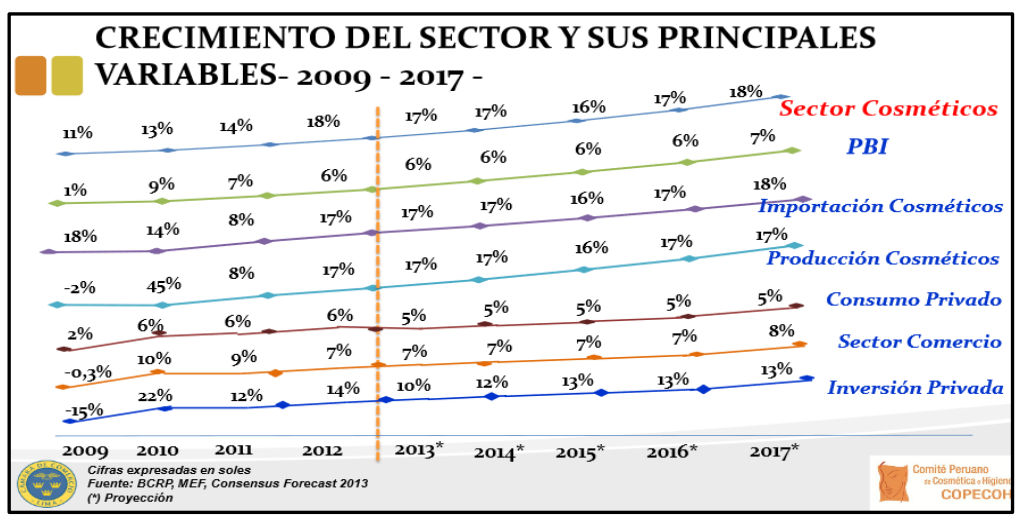

Figura 3. Crecimiento del Sector 2009 - 2017. Se muestra el incremento de ventas en el sector. Adaptado de Cámara de Comercio de Lima, Copecoh.com, 2013.

En cuanto al crecimiento por categorías, Higiene y Cuidado Personal, capilares y tratamiento corporal tuvieron una mayor expansión del $8 \%, 7 \%$ y $1 \%$ respectivamente. En tanto las que mostraron retrocesos fueron: fragancia (-8\%), maquillaje $(-4 \%)$ y tratamiento facial $(-1 \%)$. 


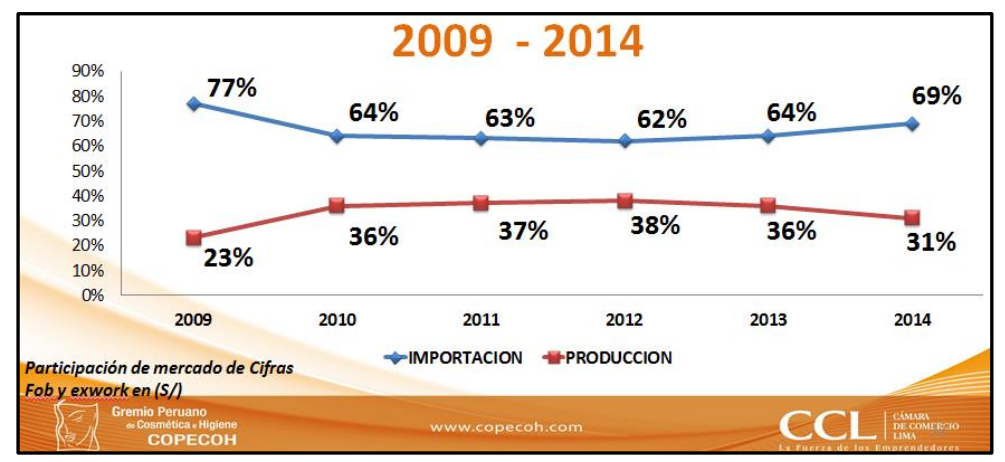

Figura 4. Mercado de Cosméticos: Producción e importación. La importación de productos de cosmética e higiene y cuidado personal alcanzan actualmente el $69 \%$ del mercado total. Adaptado de Cámara de Comercio de Lima, Copecoh.com, 2013.

El ministerio de economía y finanzas (2018), estima que a partir del 2017 hasta el 2019 el sector mantendrá una tasa de crecimiento anual del 6\%, crecimiento que se verá reflejado por la relación existente con las variables macroeconómicas: crecimiento del $\mathrm{PBI}$ con la industria, nivel de importaciones, nivel de la producción, la tasa de consumo y el nivel de inversión.

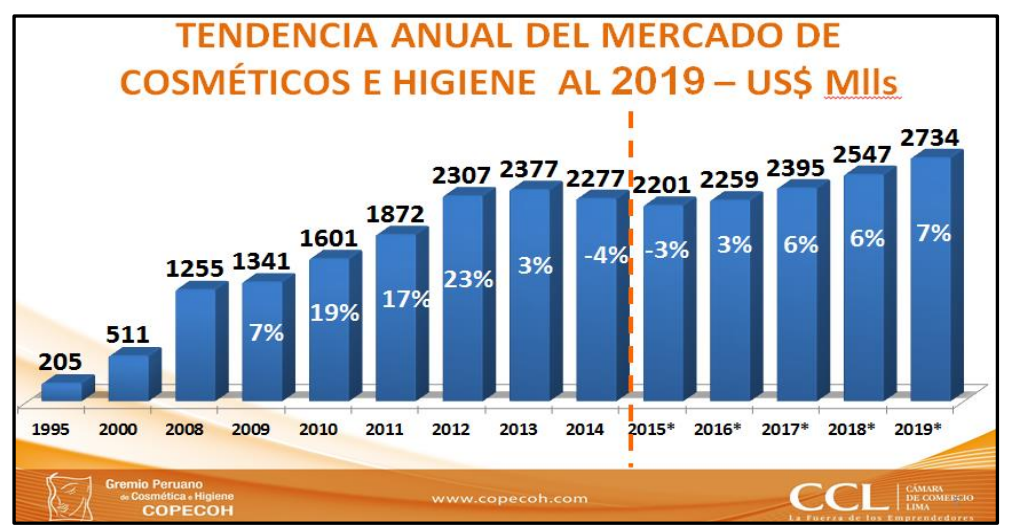

FIGURA 5.TENDENCIA ANUAL DEL MERCADO AL 2019. SE MUESTRA UN INCREMENTO EN LA TASA DE CRECIMIENTO. Adaptado de Cámara de Comercio de Lima, Copecoh.com, 2015.

\subsubsection{Segmentación de la industria.}

Para ubicarnos dentro de la segmentación de la industria se debe considerar que el producto según la clasificación industrial internacional uniforme, le corresponde el CIIU 1709 que incluye: 
"Fabricación de productos de papel y guata de celulosa de uso doméstico y para la higiene personal: pañuelitos faciales; pañuelos, toallas, servilletas; papel higiénico; toallas higiénicas y tampones, pañales y forros de pañales para bebés; y vasos, platos y bandejas". (INEI, 2015)

Según los resultados del Estudio de Inteligencia Comercial de Copecoh (2016), las ventas del sector cosmético e higiene y cuidado personal peruano ascenderían a S/. 6,399 millones en este año 2015, en comparación a los S/. 6,464 millones del 2014.

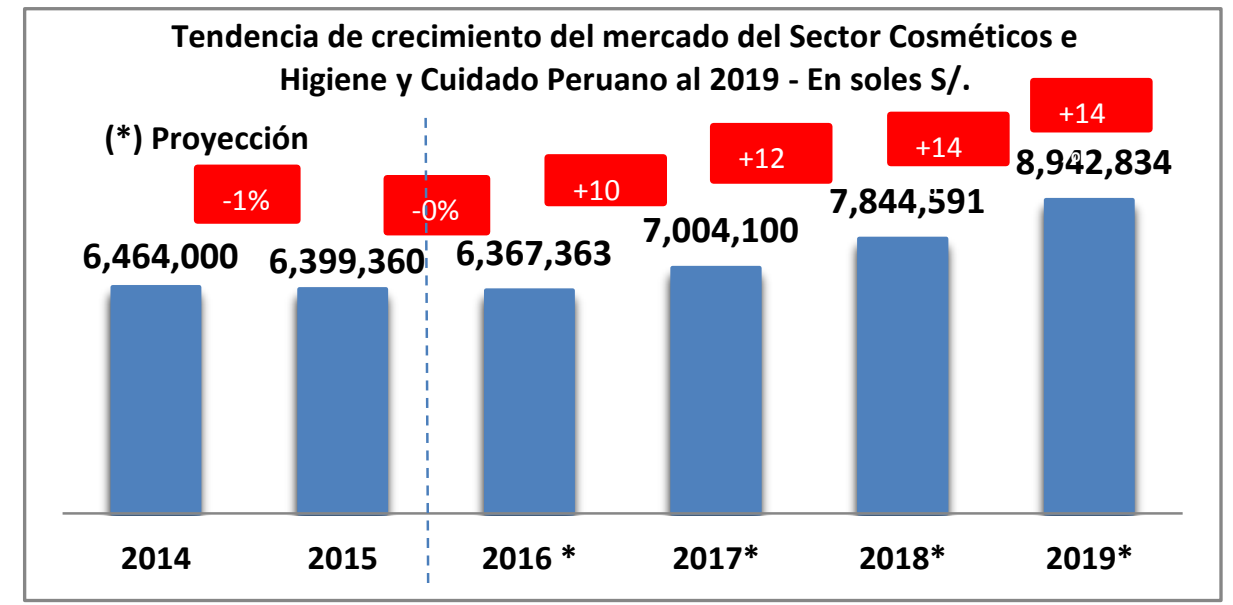

Figura 6. Tendencia de crecimiento del mercado del sector. Se observa que en el año 2016, Copecoh proyectó que el sector cosmético e higiene y cuidado personal no registraría ningún crecimiento $(0 \%)$, mientras que, a partir del 2017, en un escenario optimista, se iniciaría la recuperación con un avance de $10 \%$ ese año, y de $12 \%$ y $14 \%$ en el 2018 y 2019 , respectivamente.Adaptado de Cámara de Comercio de Lima, Copecoh.com, 2015.

Según datos del estudio, el consumo per cápita en el sector cosmética e higiene y cuidado personal entre mujeres de 20 a 40 años en Perú fue de US\$ 603 el 2014 y para el 2015 se proyecta un consumo de US $\$ 518$, una caída de $-14 \%$.

Con respecto al consumo per cápita vemos que todavía existen oportunidades de crecimiento, si se compara con otros países por ejemplo Chile es el que ocupa el primer 
lugar con un consumo per cápita de US\$ 870 el 2014 y US\$ 731 el 2015, seguido por Brasil con US\$1,264 el año pasado y US\$ 595 proyectados para el 2015.

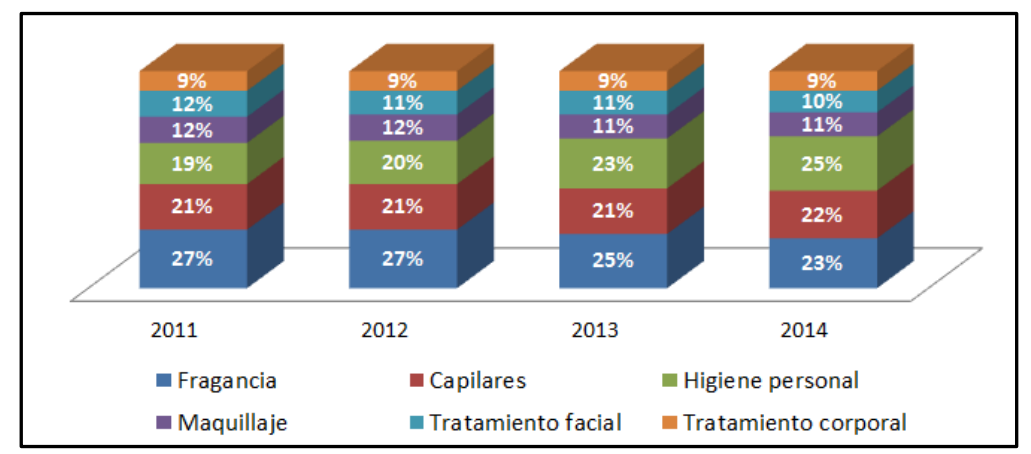

Figura 7 Participación del mercado 2011 al 2014. El equipo de investigación plantea esta figura en donde se puede apreciar que la categoría de higiene y cuidado personal tiene una participación importante dentro del sector, el cual mantiene un crecimiento sostenido.Adaptado de Cámara de Comercio de Lima, Copecoh.com, 2015.

Puesto que se refiere a una ruta de compra con productos complementarios y asociados en su uso diario: toallas higiénicas, tampones, pañitos húmedos, entre otros.Por esta razón, se quiere aprovechar que dicha categoría es la adecuada para este producto innovador.

Asimismo, hemos identificado que en la ruta de consumo de productos de higiene y cuidado personal el cobertor sanitario para inodoro completa el circuito de higiene y cuidado personal en el hábito o costumbre de usos en el sector femenino.

Por lo tanto, el plan de negocio propuesto se presenta como una gran alternativa para seguir desarrollando la categoríacon productos de higiene para la protección de la salud.

\subsubsection{Empresas que la conforman}

\section{$\checkmark$ Termoencogibles del Perú S.A.}

Es una empresa peruana que registra fecha de inicio de actividades desde 01 de diciembre de 1986, tiene domicilio fiscal en Jr. Domingo Casanova $N^{\circ} 357$ en el distrito 
de Lince en Lima y, una fábrica ubicada en Jirón Amauta № 290 en el distrito de Chorrillos en Lima. Registra 335 trabajadores en su nómina al mes de noviembre del 2015 (Sunat, 2015) y su corte de negocio es la fabricación de PVC termoencogible.

Termoencogibles del Perú S.A. comercializa los cobertores sanitarios para inodoro con la marca "Cobertores Sanitarios Queen" de su línea Sanitary Solutions, esta información se encuentra impresa en la caja (Termoencogible, 2015).Sin embargo en su portal de negocio de internet sólo se muestran 2 líneas de negocio:

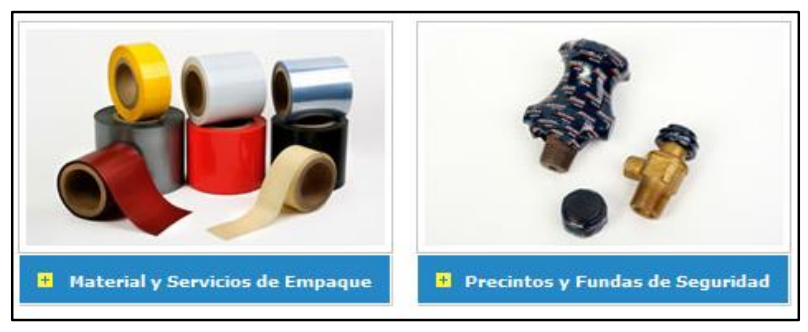

Figura 8. Línea Termoencogibles. Adaptado de Tercoencogibles.com, 2015.

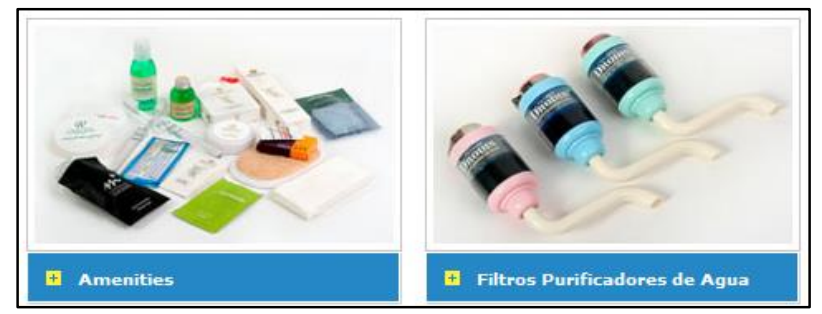

Figura 9. Línea Comercial. Termoencogibles (2015), dentro de su línea comercial fabrica filtros purificadores de agua.Adaptado de Tercoencogibles.com, 2015.

Termoencogibles del Perú S.A. registra una compra de cobertores sanitarios a la China en el mes de enero del 2014 y a la fecha no registra más compras, los cobertores sanitarios son adquiridos en sachets de 2 piezas y colocados en una caja de 6 sachets (12 piezas/caja), el producto es chino y el único valor agregado que le da esta empresa es que les coloca el empaque final y los comercializa en tiendas Tottus en el área de productos de limpieza. 
Tabla 1.

Compra Termoencogibles del Perú S.A.

\begin{tabular}{|c|c|c|c|c|c|c|c|}
\hline ADUANA & $\begin{array}{l}\text { AÑO } \\
\text { DUA }\end{array}$ & CANT. & $\begin{array}{l}\text { UNIDAD } \\
\text { MEDIDA }\end{array}$ & PRODUCTO & ORIGEN & PROCEDENCIA & $\begin{array}{c}\text { VALOR } \\
\text { FOB\$ }\end{array}$ \\
\hline Marítima del Callao & 2013 & 4740 & $U$ & Etiquetas & Ecuador & Ecuador & 0 \\
\hline $\begin{array}{l}\text { Marítima del Callao } \\
\text { Tumbes }\end{array}$ & $\begin{array}{l}2014 \\
2014\end{array}$ & $\begin{array}{c}350000 \\
3000\end{array}$ & Pza. & $\begin{array}{l}\text { Cubierta de } \\
\text { asiento de } \\
\text { baño } \\
\text { Etiquetas }\end{array}$ & $\begin{array}{l}\text { China } \\
\text { Ecuador }\end{array}$ & $\begin{array}{l}\text { China } \\
\text { Ecuador }\end{array}$ & $\begin{array}{r}2450 \\
24\end{array}$ \\
\hline Tumbes & 2014 & 2000 & $U$ & Etiquetas & Ecuador & Ecuador & 12 \\
\hline
\end{tabular}

Nota: Adaptado de "Origen, procedencia yvalor de los cobertores de baño" por Datos Perú, 2016.
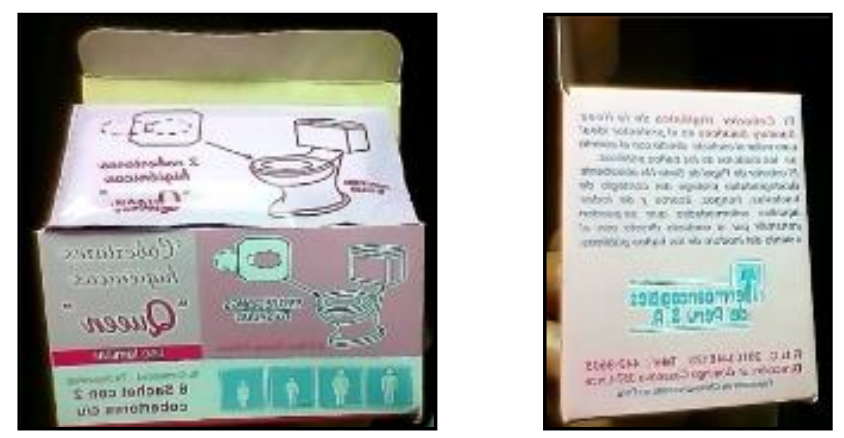

Figura 10. Cobertor Queen. Modelo de cobertor sanitario para inodoro, según marca Termoencogibles del Perú. Adaptado de Termoencogibles.com, 2016.

\section{$\checkmark \quad$ KMC International SAC.}

Es una compañía que cuenta con 17 años de operaciones en el negocio de importación y distribución de diversas categorías de productos de consumo masivo e institucional, comercializa entre uno de sus ítems, el producto cobertores sanitario para inodoros con la marca Safe-t-gard, lo importan desde China.
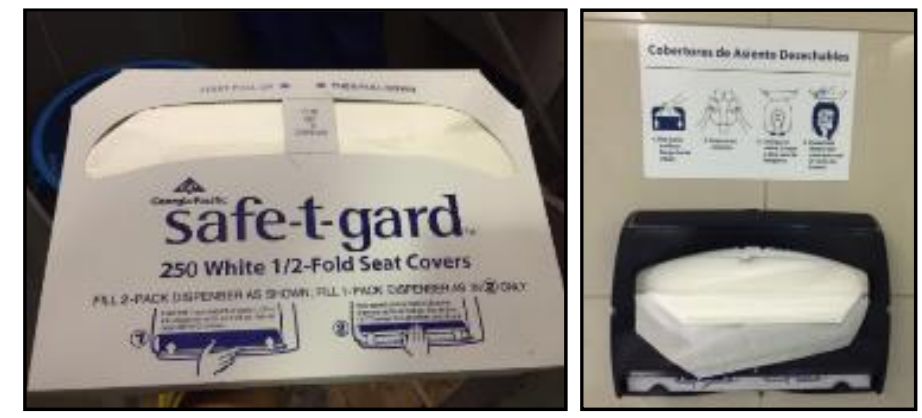

Figura 11. Safet-t-gard. Modelo de dispensador de KMC International SAC. Adaptado de Amazon.es, 2016. 
Su domicilio legal es Av. Nugget 350 en El Agustino y su oficina de ventas en Río Piura 120 - San Luis, al cierre del año 2015 registra 69 trabajadores. En el caso de los cobertores sanitarios solo atiende un solo cliente y es Corporación Wong quien tiene dentro de sus negocios de infraestructura los centros comerciales: Plaza Norte y Mall del Sur.

Entre los principales productos de alta calidad y reconocimiento internacional que representan se encuentran: Conagra Foods, Nissin Foods, Unilever USA, Dial Corporation y Snider's of Hanover.

Su portafolio de productos se divide en 3 líneas:

- Línea Snacks, Marcas principales

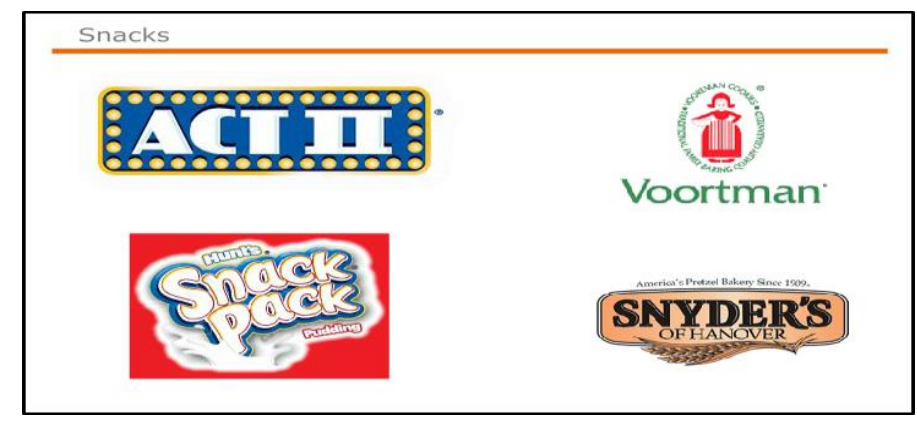

Figura 12. Línea Snacks. Marcas principales de snaks comercializadas por Kmc International S.A.C (2016)

- Línea Comidas, Marcas principales

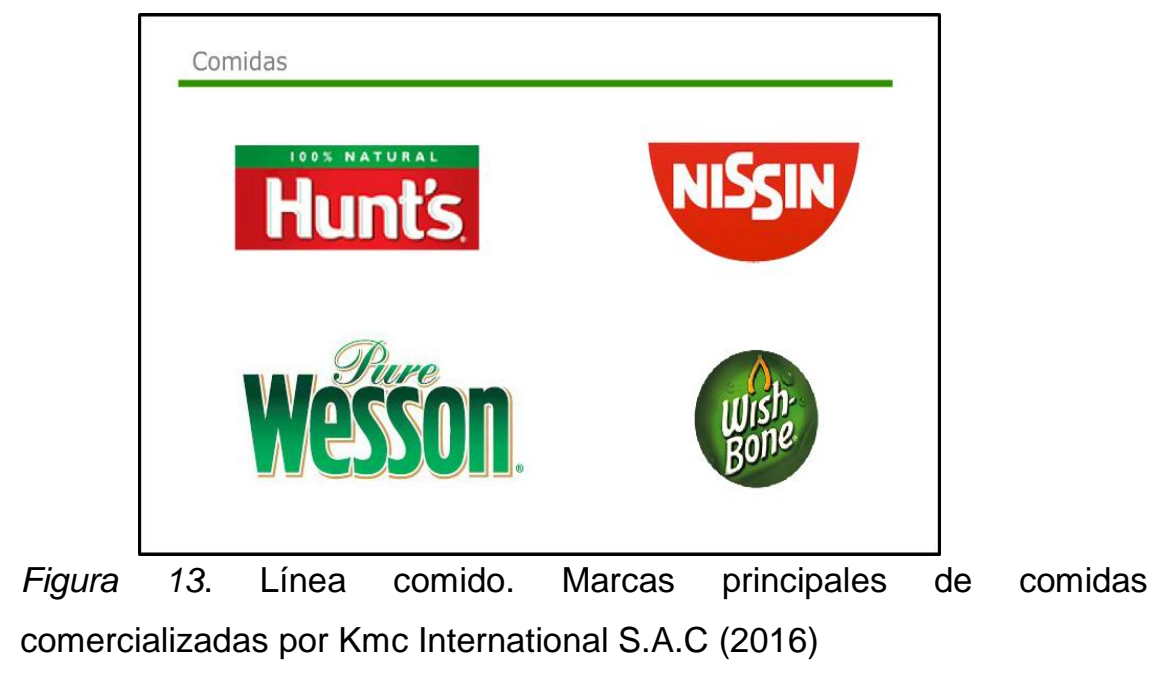


- Línea de Higiene, dentro de los cuales se encuentra la marca

Safe-t-gard, que son los cobertores sanitarios para inodoros que importan desde China.

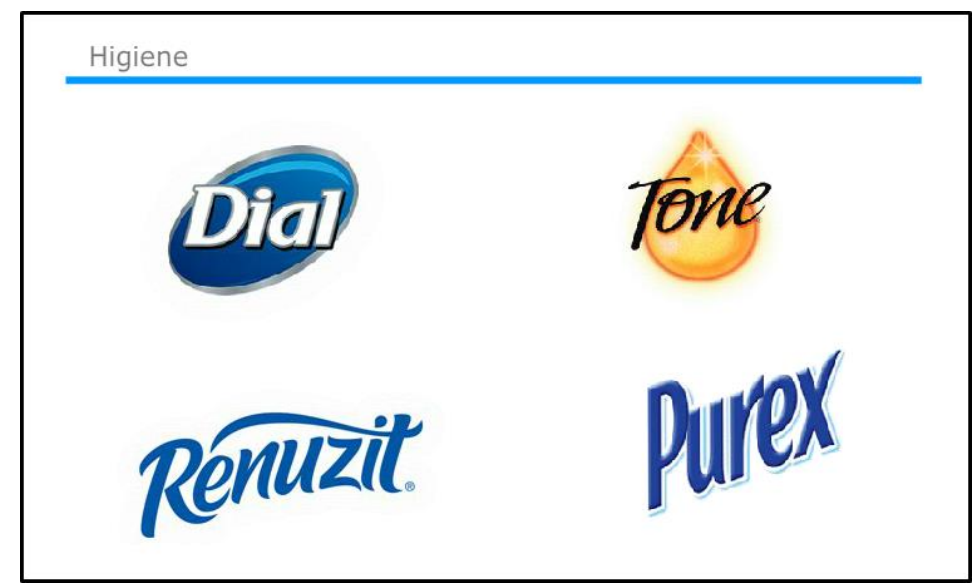

Figura 14. Línea de higiene. Marcas principales de higiene comercializadas por Kmc International S.A.C. Adaptada de kmcint.com, 2016.

La cobertura de distribución de su portafolio abarca las principales ciudades del país, las cuales incluye cadenas de supermercados, mayoristas, distribuidores, bodegas y catering.

Cuentan con 12 distribuidores para Lima Moderna.(Kmc International S.A.C,2016).

\subsection{Análisis de la competencia}

Analizar información sobre la competencia es fundamental para la creación de una estrategia exitosa de negocios. Conocer a la competencia es un atarea difícil, pues el organigrama de las empresas hace que tengan múltiples áreas que compiten en diversos sectores de la industria. Por otro lado, la información sobre la gestión de estas áreas es de carácter privado por ser estratégico para la empresa. Asimismo, la información de marketing y ventas no es pública (David, 2012).

Lo importante es definir ciertos valores o factores que representen el éxito para la gestión de la empresa y con ellos poder compararse con la competencia. De esta forma se puede obtener información el mercado observando: el entorno comercial, la 
publicidad, como es la atención al cliente, los precios, ubicación en puntos de venta, líneas de productos, presentaciones entre otros.

\subsubsection{Empresas que ofrecen el mismo producto o servicio, indicando las} semejanzas y diferencias que tienen con el proyecto de empresa.

Las empresas que ofrecen el mismo producto son:

- Termoencogibles del Perú S.A.; y

- KMC International SAC.

Ambas empresas tienen diferencias con nuestro proyecto:

- Importan y comercializan varias marcas que forman parte de su portafolio de productos, de los cuales uno de los ítems son los cobertores sanitarios para inodoros.

- Importan de China el cobertor sanitario, cada empresa competidora atiende a 1 solo cliente con los cobertores, en el caso de Termoencogibles a supermercados Tottus y en el caso de KMC a Corporación Wong.

- En el presente caso, se va a fabricar y comercializar los cobertores sanitarios donde es importante resaltar que es nuestro único producto del portafolio.

\subsection{Análisis del contexto actual y esperado}

\subsubsection{Análisis político - gubernamental - Legal}

El Perú es un país respetuoso de las inversiones, generando los espacios adecuados para que las empresas puedan desarrollar sus negocios sostenibles. Esto se justifica con más de 25 años de gobiernos democráticos que sostienen el camino del crecimiento y la estabilidad política como eje impulsor del crecimiento del país. Actualmente el Perú es gobernado por el Sr. Pedro Pablo Kucynski, quien en segunda vuelta derrotó a la Señora Keiko Fujimori, con un 50.12\% versus el 49.88\% (Fuente ONPE al $100 \%$ de las actas procesadas). Sin embargo, el congreso es mayoritariamente de Fuerza Popular, partido de la Señora Keiko Fujimori, generando equilibrio en las fuerzas políticas del país, y el desarrollo de espacios políticos para la búsqueda de acuerdos que definan la ruta del desarrollo económico del país.

Por otro lado, con respecto al tema político legal relacionado al sector de higiene y cuidado personal, el Perú ha firmado acuerdos con los países miembros de la Comunidad Andina, como la Decisión 706 y la Decisión 516. Ambas decisiones son 
legislaciones que regulan los productos de higiene doméstica, productos absorbentes de higiene personal y productos cosméticos. Con respecto a la decisión 516, esta generó el marco previo para la Decisión 706 pues brindó como resultado el incremento del comercio entre las naciones de la comunidad. Por ello, estas decisiones buscan armonizar las legislaciones de los países miembros de la Comunidad Andina de Naciones. (Comunidad Andina, 2008).

Por otro lado, a través de la Cámara de Comercio de Lima, se ha establecido $\mathrm{COPECOH}$, que es el Comité Peruano de Cosmética e Higiene y Cuidado Personal, este comité es una asociación sin fines de lucro compuesto por empresas del sector privado, fabricantes, importadores, distribuidores, licenciatarios, mayoristas y titulares de la marca de productos cosméticos e higiene y cuidado personal; agrupando al $99 \%$ de empresas relacionados a este sector. $\mathrm{COPECOH}$ busca desarrollar el sector de cosmética e higiene y cuidado personal en el Perú, mediante alianzas con otras insituciones latinoamericanas como el Consejo de Asociaciones de la Industria de Cosméticos de Latinoamérica (CASIC) y al Consejo Empresarial Andino de la Industria Cosmética (CEANIC), en ambos casos se encuentra asociado a ellos. Asimismo, brinda información actualizada del sector y apoya su participación en eventos nacionales e internacionales. (Morales, O’Connor, Rivera, Suárez; 2017).

Con respecto a la información, $\mathrm{COPECOH}$ elabora Estudios de Inteligencia Comercial del sector Cosméticos e higiene y Cuidado Personal, en el caso del estudio del 2016, COPECOH indica que el sector cosméticos e higiene y Cuidado personal crecerá 6\% anual, asimismo las expectativas para el 2017 y 2018 son de un crecimiento mínimo de $6 \%$ de crecimiento anual, con un mercado que superará los S/ 7.000 millones. Esta información del comité es importante pues se evidencia el crecimiento del sector y las oportunidades de negocios a nuevos productos.

El analísis político legal es favorable para el lanzamiento de nuevos productos, pues el marco legal y democrático del país sostiene y garantiza las inversiones. Asimismo, las instituciones asociadas al sector promueven los nuevos productos, y brindan la información y asesorías para su comercialización en el país.

\subsubsection{Análisis económico}

La economía del Perú se encuentra estable, con más de 15 años de crecimiento constante. El año 2015, según información del INEI, el Perú cerro con un crecimiento 
anual del 3.3\%. A pesar de las crisis en los mercados internacionales, el robusto mercado interno genera la fuerza necesaria para que la economía permanezca estable

y en crecimiento. Lo cual es un factor potente, pues la demanda del consumidor interno no se ha retraído, se ha mantenido e incrementado año a año. Este constante crecimiento muestra que el país es atractivo para el desarrollo de inversiones, lo cual mejora las expectativas de crecimiento anual. Con respecto a los siguientes años la expectativa de crecimiento se mantiene en $4 \%$ anual (según lo proyectado por el FMI). Asimismo, la economía peruana es la que ha generado una mayor expansión en Latinoamérica, durante los últimos años, y en las proyecciones también se observa su liderazgo en las economías de la región. Este es un factor más que evidencia lo atractivo que es el país para los inversionistas.

\begin{tabular}{|l|c|c|c|}
\hline América Latinay el Caribe & -0.7 & 1.2 & 2.1 \\
\hline América del Sur & -2.3 & 0.8 & 1.8 \\
\hline $\begin{array}{l}\text { América del Sur sin } \\
\text { economías en } \\
\text { contracción* }\end{array}$ & 2.4 & 2.9 & 3.3 \\
\hline $\begin{array}{l}\text { América Latina } \\
\text { II Perú }\end{array}$ & & & \\
\hline Colombia & 4.0 & 4.3 & 3.5 \\
\hline Argentina & 1.9 & 2.6 & 3.5 \\
\hline Chile & -2.4 & 2.2 & 2.8 \\
\hline II México & 1.6 & 2.1 & 2.7 \\
\hline Brasil & $\mathbf{2 . 2}$ & $\mathbf{1 . 7}$ & $\mathbf{3 . 0}$ \\
\hline Venezuela & -3.5 & $\mathbf{0 . 2}$ & $\mathbf{1 . 5}$ \\
\hline & $-\mathbf{1 2 . 0}$ & -6.0 & -3.0 \\
\hline
\end{tabular}

Figura 15. PBI de América latina. PBI de diferentes países de América Latina y el Caribe de los años 2016, 2017 y 2018. Fondo Monetario Internacional (2018). Adaptado de peru21.pe/economia/peru-lideraracrecimiento-economico-2017-62887, 2017.

Por otro lado, existen otros indicadores que orientan para analizar el desenvolvimiento de la economía del país: 


\section{- Índice de precios al consumidor}

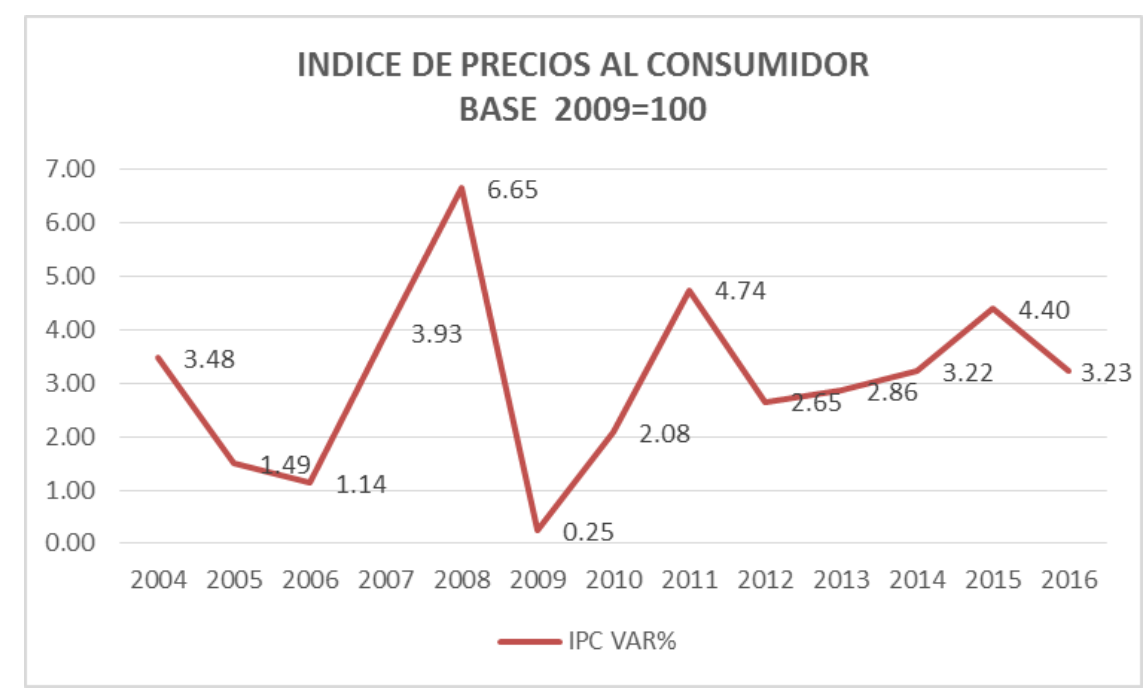

Figura 16. Índice de precios al consumidor. El cual evidencia en su mezcla de 12 variables que durante el 2016 alcanzó el 3.23\% de variación. Factor que mejoro con respecto al año anterior, lo cual evidencia que la pérdida del valor del dinero en el mercado se está revirtiendo. Información obtenida deINEI (2017).Adaptada de inei.gob.pe, 2017.

\section{- Tasa de Interés}

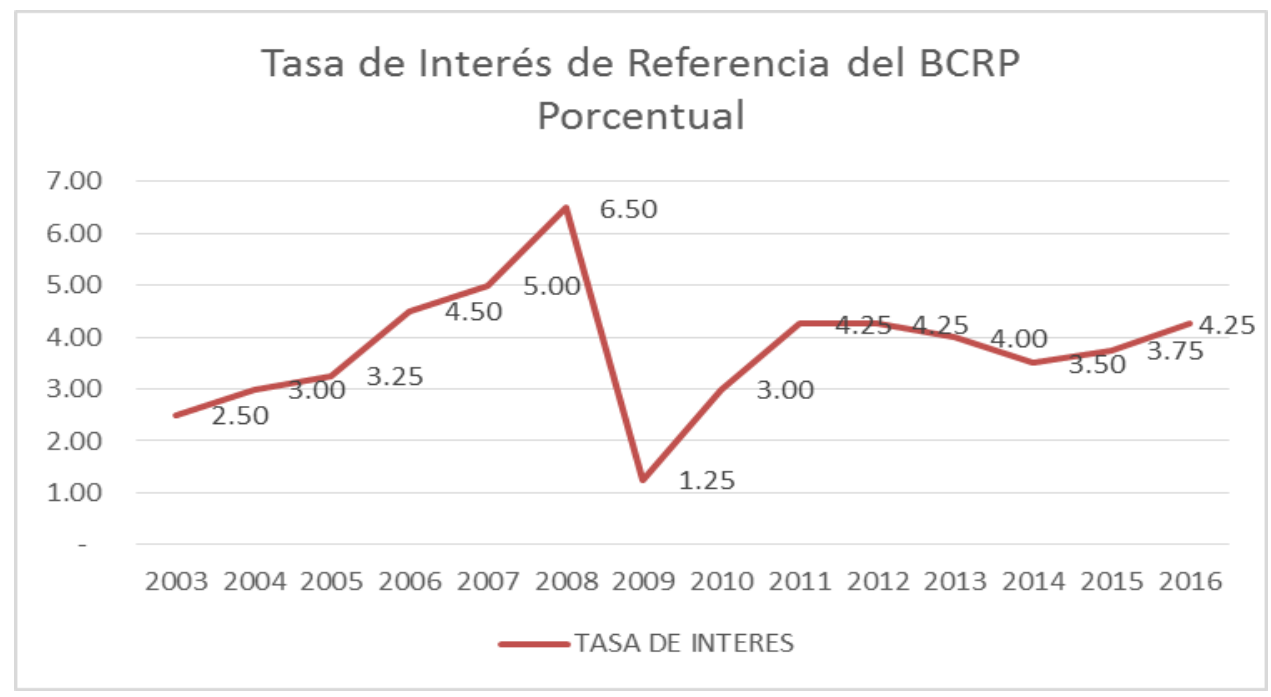

Figura 17. Tasa de interés de referencia del BCRP 2003 - 2016 a diciembre de cada año. A pesar de un ligero incremento de la tasa de interés con respecto al año anterior, se evidencia una sostenibilidad en el tiempo entre 3\% a $4 \%$ anual, según planteó el Banco Central de Reserva del Perú (2016). Adaptada de bcrp.gob.pe, 2016. 
- Tipo de Cambio, en el mercado peruano existen el tipo de cambio real y el tipo de cambio nominal. El primero se conoce por la capacidad de intercambiar bienes y servicios de un país a otro.

El tipo de cambio nominal, es la capacidad de cambio de la moneda nacional por la de otro país.

Este último es el tipo de cambio más usado y es el que puede permitir conocer la capacidad adquisitiva de una moneda en otro país.

En el siguiente cuadro se puede apreciar que el tipo de cambio nominal se ha mantenido estable en el país, durante un período largo de tiempo, lo que nos indica que la moneda peruana se ha mantenido estable y esto se refleja en el poder adquisitivo de las personas.

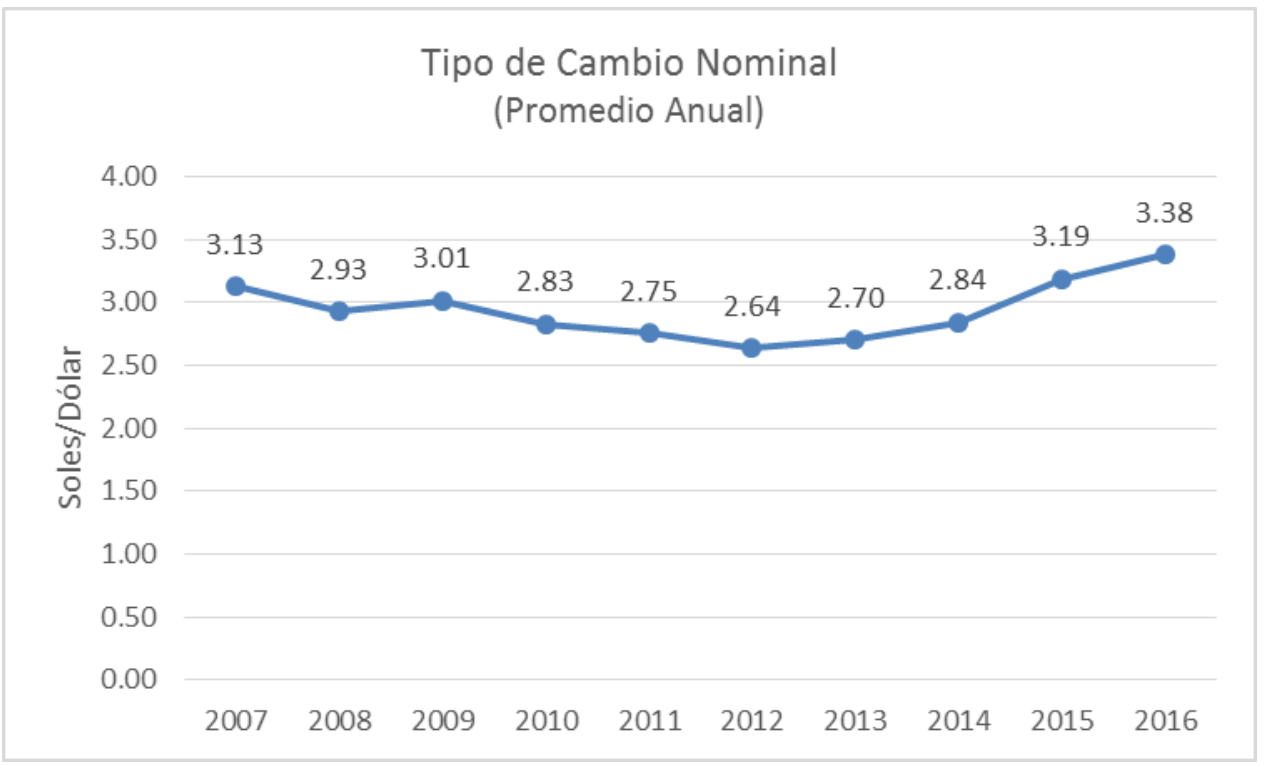

Figura 18. Tipo de cambio Nominal. Al cierre del año 2016 el dólar mostró una recuperación cerrando con 3.38 soles por dólar. La variación porcentual positiva con respecto al año 2015 fue de 5.95\% según el Banco Central de Reserva del Perú (2016). Adaptada de bcrp.gob.pe, 2016.

- El nivel de confianza del consumidor, es un indicador que refleja el optimismo de los consumidores relacionado a la estabilidad financiera y la estabilidad de la economía del país. La seguridad por la economía define las actividades de consumo en 
el mercado local. Si el consumidor se siente seguro y cómodo con su entorno económico y financiero, este se representará en la seguridad económica de sus acciones impulsando la expansión de la economía. Por otro lado, si la confianza disminuye la conducta es de ahorro evitando el consumo en la economía, provocando contracciones económicas.

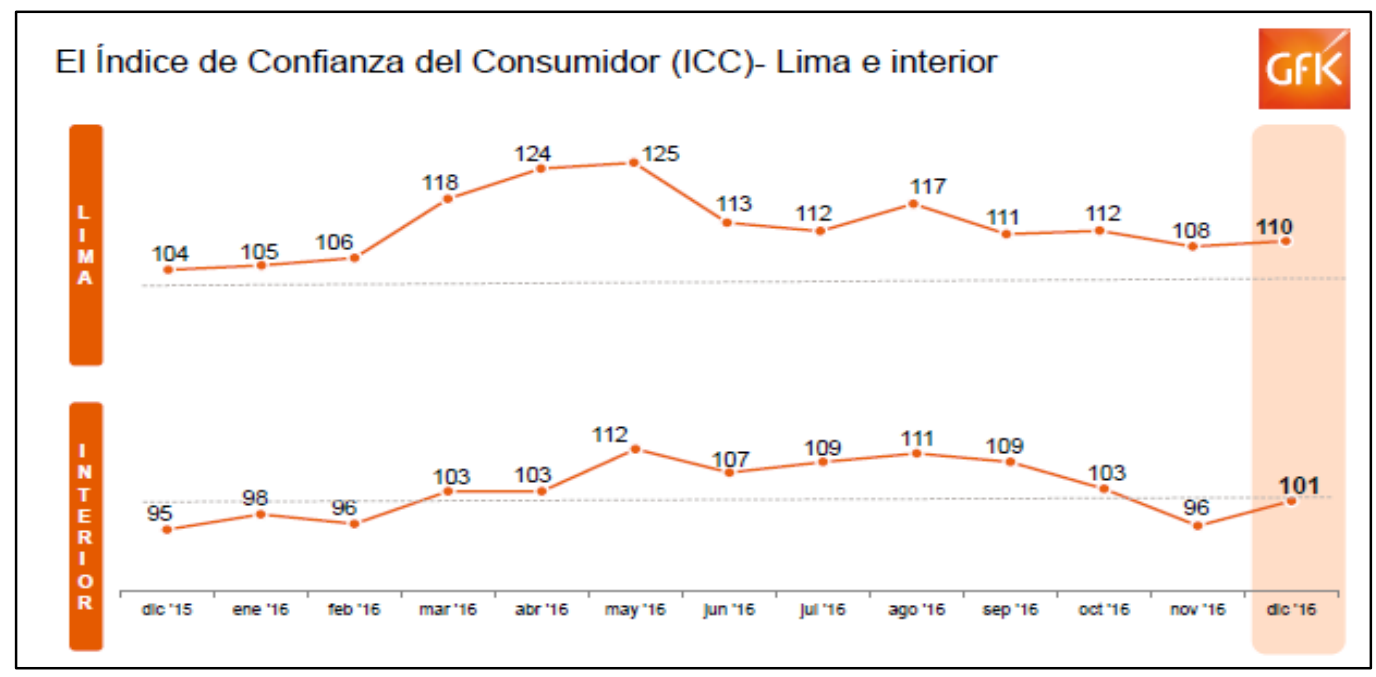

Figura 19. Índice de confianza del consumidor en Lima y el interior. La figura evidencia la disminución de la confianza del consumidor durante varios meses, lo que representa una contracción de la economía peruana. (GfK, 2016). Adaptada de archivo.gestion.pe/economia/gfk-confianza-consumidor-empieza-bordear-zona-peligrosapesimismo-2176501/3, 2016.

Por otro lado, el efecto de China, el poderoso país asiático, puede generar ciertos efectos negativos en nuestra economía y esto debido a que la economía China se ha desacelerado, del crecimiento económico de dos dígitos en los años anteriores ha pasado a crecer el 2015 a su menor tasa (6.9\%) y según la tendencia de años anteriores, se puede observar que esta se mantendrá o sostendrá en el tiempo.

La desaceleración dela economía China afecta a la economía del país debido a que somos exportadores de productos primarios para su transformación, los cuales son comprados por el mercado chino, y al disminuir su capacidad productiva, este efecto podría producir la disminución del crecimiento económico del Perú y también la volatilidad del tipo de cambio. 
Sin embargo, el país ha sabido desarrollar el consumo interno, el cual ha sostenido nuestra economía con un crecimiento constante a pesar de los cambios y efectos en el exterior.

El análisis económico es favorable al desarrollo de inversiones en el país debido a la sostenibilidad del crecimiento económico, y esto debido a la fuerte demanda interna, lo cual favorece los negocios en el país.

\subsubsection{Análisis cultural - social}

En los baños de los establecimientos públicos existen diferencias en el mantenimiento y aprovisionamiento de ellos. Por un lado, existen establecimientos que hacen los esfuerzos por mantener sus baños con todos los productos necesarios para el uso de sus clientes y el debido aseo de sus instalaciones. Y, por otro lado, existen los establecimientos que no cuentan con los productos mínimos necesarios en sus baños y, tampoco con el debido aseo. Esta observación podría fundamentarse en la poca cultura de los peruanos de exigir espacios con las condiciones mínimas para su uso y, también existe el lado de las Instituciones Públicas, encargadas del control y/o supervisión de estos, que no cuentan con los recursos necesarios para cumplir con estas actividades.

Esta falta de cultura con respecto a la higiene y prevención de enfermedades, se convierte en una oportunidad para nuestro plan de negocio. Por lo cual, es necesario conocer los aspectos culturales y sociales que enmarcan el mercado y que esta información, posteriormente, sirva para formular estrategias en la búsqueda de la aceptación de nuestro producto por los consumidores.

- Distribución de ingresos, este indicador muestra que más del $60 \%$ de la población cuenta con los recursos necesarios para poder vivir sin contratiempos, cumpliendo con todas sus necesidades y obligaciones. La población restantetiene dificultades en cumplir con lo necesario para vivir. Sin embargo, el probable segmento al que se dirigirá el producto se encuentra ubicado entre la población que cuenta con recursos para atender sus necesidades. 


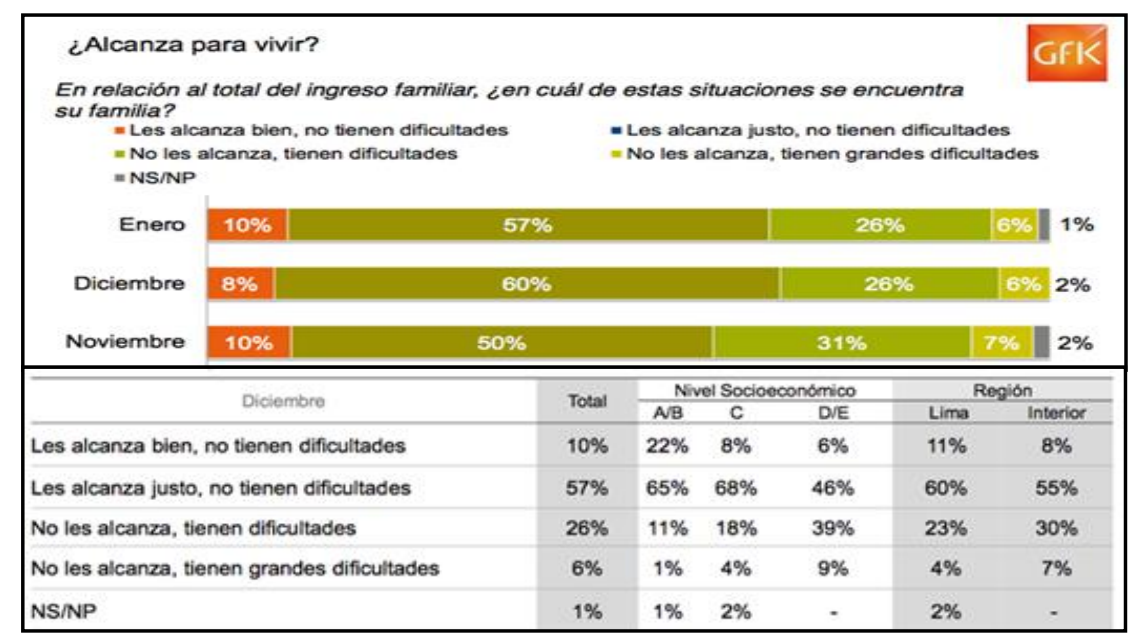

Figura 20. Situación del peruano en relación al total del ingreso familiar. Los datos muestran si el ingreso que perciben por familia es suficiente para vivir sin contratiempos. (GfK, 2015). Adaptada de archivo.gestion.pe/economia/gfk-confianza-consumidor-empieza-bordearzona-peligrosa-pesimismo-2176501/3, 2015.

\section{Tabla 2}

Principales indicadores del país

\begin{tabular}{lcrr}
\hline \multicolumn{1}{c}{ Lima Principales Indicador } & Medida & Año & \multicolumn{1}{c}{ Lima } \\
\hline Población estimada & Personas & 2015 & $9,838,251$ \\
Esperanza de vida & Años de vida & 2015 & 77.9 \\
Crecimiento poblacional & Porcentaje & 2015 & 1.5 \\
Población inmigrante & Porcentaje & 2007 & 55.7 \\
Población emigrante & Porcentaje & 2007 & 5.6 \\
Población con educación superior universitaria & & & 21.4 \\
(15 y más años de edad) & Porcentaje & 2012 & 54.6 \\
Acceso a TV Cable (Hogares) & Porcentaje & 2012 & 52.6 \\
Acceso a Telefonía fija & Porcentaje & 2012 & 87.5 \\
Hogares c/telf. Móvil & Porcentaje & 2012 & 36.8 \\
& \% respecto total & & $1,846,339$ \\
Hogares con internet & de hogares & 2012 & $12,902,187$ \\
Líneas telefónicas fijas en servicio & Unidad & 2010 & 2010 \\
Líneas telefónicas móviles en servicio & Unidad & 2012 & \\
\hline
\end{tabular}

Nota: Adaptado de "Descripción de los principales indicadores de la población de Lima según medida y año, INEI (2016)" por INEI, 2016. 


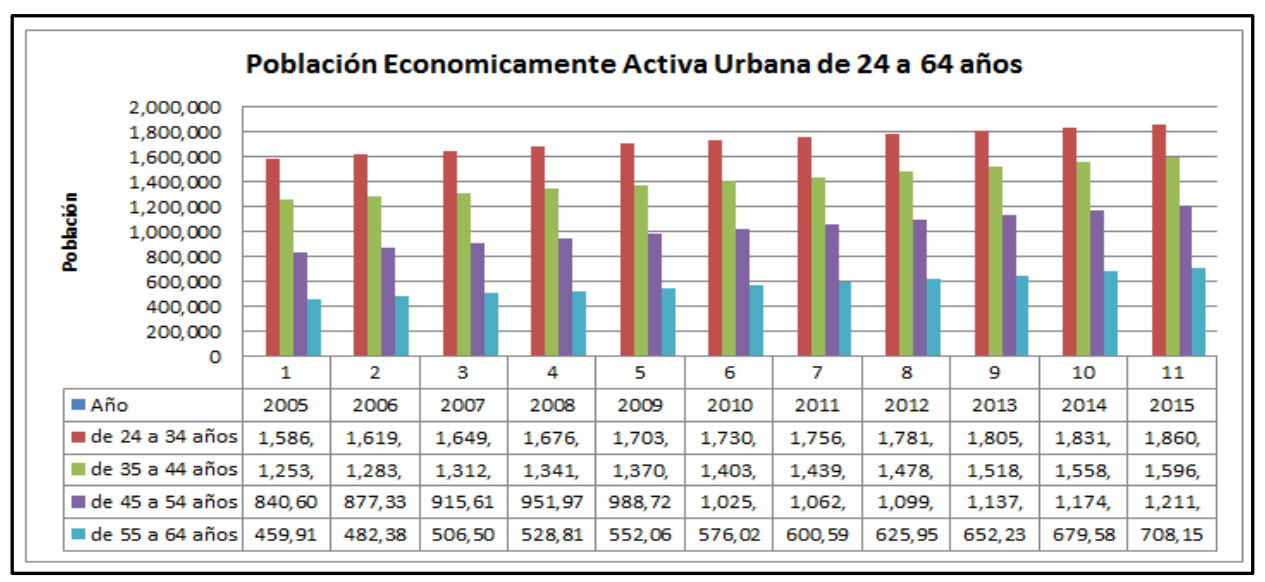

Figura 21. Población económicamente activa urbana de 24 a 64. Planteado por el INEI - Series Nacionales (2015) para los años 2005 al 2014. Adaptada de inei.gob.pe, 2015.

Prado (2010) manifiesta que "los ingresos del segmento femenino han crecido más que los ingresos del segmento masculino, pues aumentaron en $2.9 \%$, mientras que los de los varones un $0.7 \%$, pero siguen siendo menores a los del varón (equivalen al $67 \%$ del ingreso promedio del hombre)".

Este indicador es importante debido a que esta información muestra el comportamiento de sus ingresos y la capacidad de poder adquisitivo y decisión de compra.

Los Estilos de vida, según lo expresado por Arellano, la definición del estilo de vida de las personas, está encasillada en expresiones que definen,la forma en que entienden su forma de vivir; este entendimiento se muestra en todas las facetas de la vida y en su forma de actuar (trabajo, ocio, sexo, alimentación, indumentaria, etc.), principalmente se evidencia en los usos y costumbres de la vida diaria, y también se puede apreciar en su vivienda, los objetos y los bienes que posee.. Por lo cual, es importante conocer el estilo de vida del consumidor para poder desarrollar estrategias adecuadas al segmento que se busca atender. 


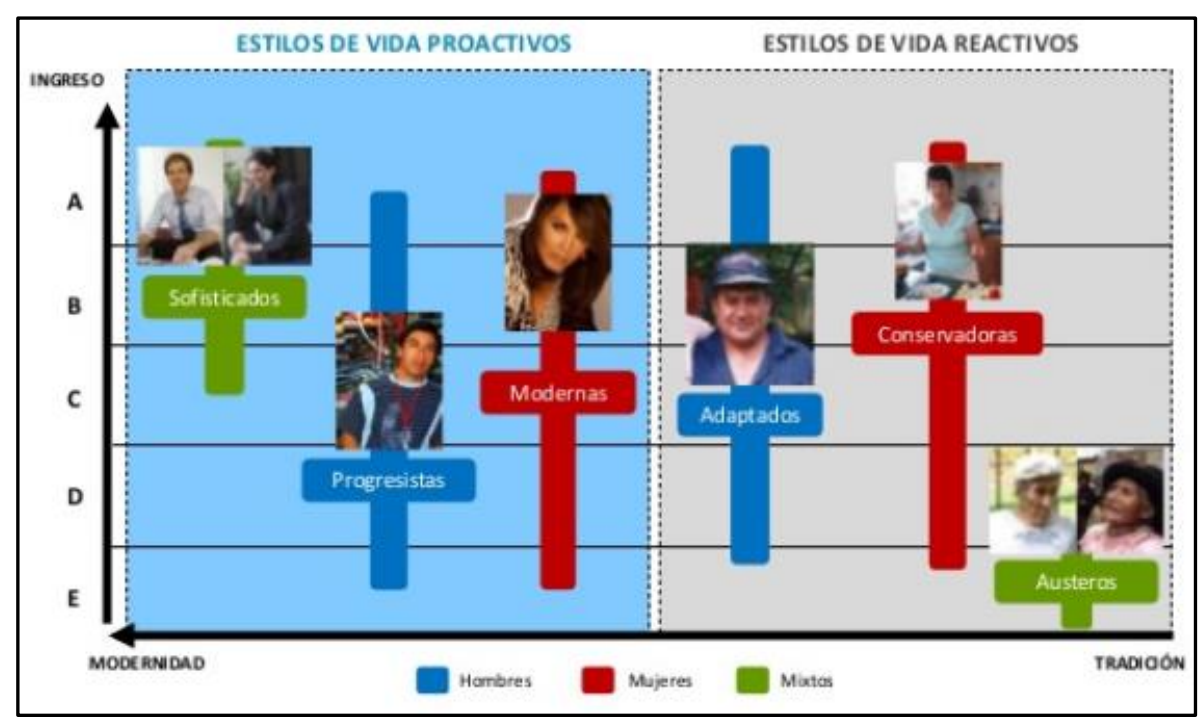

Figura 22. Estilos de vida. Arellano (2017) plantea diferentes estilos de vida, el proactivo y el reactivo, cada uno de ellos con características específicas para cada género. Adaptado de ArellanoMarketing/estilos-de-vida-arellano-marketing, 2017.

Educación, para el desarrollo del país este es un factor clave, pues su desarrollo se relaciona directamente al emprendimiento y la innovación, al cambio de estilo de vida y la movilidad social. Asimismo, es un factor que define lo que el consumidor debe exigir y más aún con productos relacionados a la salud de ellos y sus familias. Por lo cual, la información para educar y entender cómo vivir saludablemente es importante para la población.

- Modas y tendencias, el consumidor peruano siempre está atento a los cambios que se dan en la moda internacional, sin embargo,estos cambios deben ser elegantes ante cualquier situación. Asimismo, la moda podría entenderse como un canal para ingresar al mercado y luego convertirse en un estilo de vida sostenible en el tiempo, debido a que el producto está orientado hacia mejorar la salud de las personas en sus usos y costumbres diarios.

- Calidad de vida, afecta a diferentes aspectos de la sociedad alcanzando a la sociedad misma, la población o comunidad, el aspecto físico y mental, por lo cual su significado es complejo, y se puede evidenciar en las distintas definiciones que se le da dependiendo del punto de vista de la materia que lo define. 
La calidad de vida se puede evaluar en varias dimensiones: Bienestar físico, bienestar material, bienestar social, desarrollo (productividad, contribución, educación) y bienestar emocional.

Un indicador muy usado para medir la calidad de vida es el Índice de Desarrollo Humano (IDH), establecido por las Naciones Unidas para medir el grado de desarrollo de los países a través del Programa de las Naciones Unidas para el Desarrollo (PNUD).

- La población femenina, es importante entender el sector femenino y su población pues servirá para definir el perfil del consumidor y poder desarrollar las estrategias adecuadas para lograr su preferencia de compra.

\section{a. Más de 7 millones de mujeres conforman la fuerza laboral del Perú.}

En el Perú existen 15 millones 887 mil mujeres y de las cuales 7 millones 100 mil 100 son trabajadoras. Ellas representan el 95.4\% de la Población Económicamente Activa (PEA) femenina, de acuerdo al Instituto Nacional de Estadística e Informática (INEI).

\section{b. Mujeres avanzan en el acceso a la educación}

Nivel educativo. El $36.4 \%$ de las mujeres que trabajan han alcanzado nivel de educación secundaria, $30.9 \%$ primaria, $16.7 \%$ superior universitaria y $16.0 \%$ superior no universitaria, de acuerdo a la Encuesta Nacional de Hogares (ENAHO, 2016).

\subsubsection{Análisis tecnológico.}

Este aspecto es muy importante y clave para las diferentes industrias y empresas. La tecnología es una motor que impulsa su desarrolla, logrando la mejora de la calidad y reduciendo los tiempos y maximizando la productividad de las empresas para ofrecer sus productos y servicios. Los factores tecnológicos permiten que las empresas e industrias puedas disminuir las barreras de entrada y producir de forma más eficiente. Pero también el rápido avance de la tecnología es difícil de asimilar por las empresas, pues se generan rápidamente, por otro lado influye en el costo de las tecnologías y la capacidad de contratar personal capacitado para su uso y aprovechamiento óptimo. 
- Explosión de las Redes Sociales, esta nueva plataforma de comunicaciones es necesaria y clave para las empresas hoy en día. Los clientes actuales y los potenciales se encuentran ahí, y las herramientas del marketing tienen la misión de adecuar su comunicación para alcanzar estos sectores de consumidores altamente segmentados establecidos en comunidades y que requieren de un canal adecuado para comunicar nuestro producto

Evidentemente, incluir estrategias para el uso de esta nueva plataforma de comunicación es importante, pues permitirá acercarse a los consumidores de forma directa. Por otro lado, estas acciones y su alcance deben ser evaluados por las áreas de ventas, comerciales, y producción de las empresas.

- Virtualización, es la posibilidad de crear un entorno virtual semejante de algún insumo tecnológico, como por ejemplo virtualizar una plataforma de hardware, un sistema, entre otros.

La virtualización (VMM) permite gestionar los cuatro recursos de un ordenador (CPU, Memoria, Dispositivos Periféricos y Conexiones de Red) y así podrá distribuir dichos recursos entre todos los equipos virtualizados creados en el computador central. Esto permite generar múltiples ordenadores virtuales desde el mismo ordenador físico

La denominación es antigua; data desde 1960, y ha sido utilizado en múltiples aspectos y escenarios de la informática, desde sistemas completos computacionales, hasta componentes individuales.

El desarrollo avanzado de estas nuevas plataformas y tecnologías de virtualización ha hecho que en los últimos años se haya vuelto a prestar atención a este concepto. 


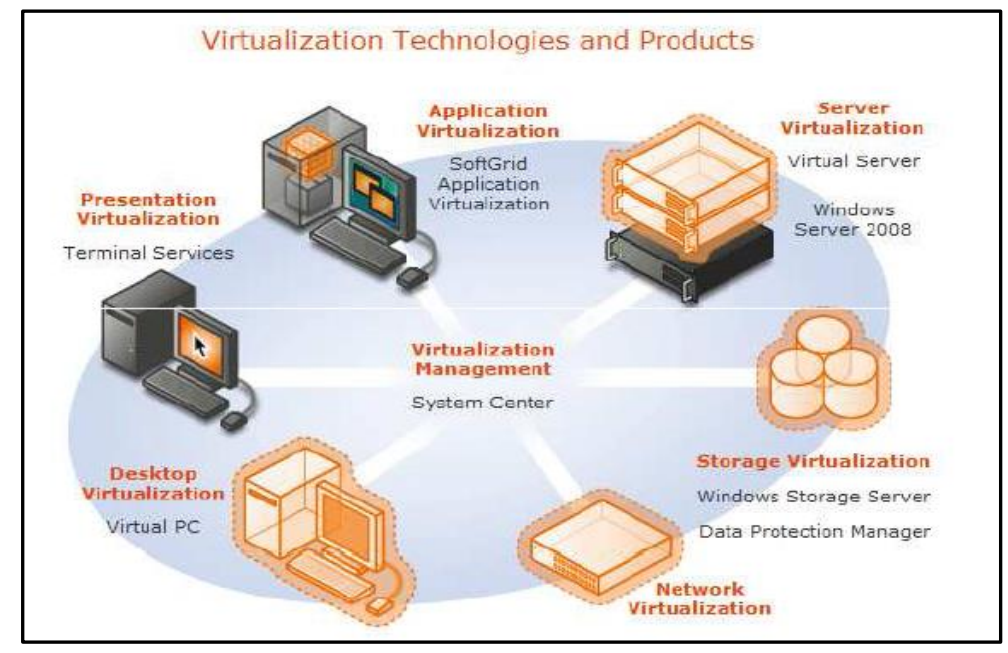

Figura 23. Virtualización. La virtualización es la mezcla de recursos en diferentes ubicaciones físicas, o mediante la simplificación del sistema de control. Adaptado de perulinux.pe, (2016).

- Internet, tiene la capacidad de comunicación veloz con los usuarios, permite dirigir y distribuir información, permitiendo nuevos canales de comunicación y relaciones entre las personas, ofreciendo una gran cantidad de insumos para lograr diversión y entretenimiento, permitiendo una comunicación más simple. Por otro lado, es posible conocer e interactuar con población de todos los lados del mundo. Asimismo, la internet permite obtener información en tiempo real.

Tabla 3.

Hogares con acceso a tecnologías de información ycomunicación - internet.

\begin{tabular}{lcccccc}
\hline \multicolumn{1}{c}{ Ámbito Geográfico } & 2008 & 2009 & 2010 & 2011 & 2012 & 2013 \\
\hline Total & 8.6 & 11 & 13 & 16.4 & 20.2 & 22.1 \\
Lima Metropolitana 1/ & 18.6 & 23.4 & 25.7 & 32.7 & 38.7 & 41.4 \\
Lima y Callao 2/ & 17.3 & 21.7 & 24.1 & 30.7 & 36.5 & 39.4 \\
Lima Provincias 3/ & 4.2 & 4.3 & 8.6 & 11 & 15.7 & 18.2
\end{tabular}

Nota: Adaptado de "El acceso a internet es un servicio TIC asociado al acceso a tecnología digital" por INEI 2014.

1/ Incluye la provincia de Lima y la provincia constitucional del Callao

2/ Comprende el departamento de Lima y la provincia constitucional del Callao

3/ Excluye la provincia de Lima 
- Tecnología móvil, el avance tecnológico acelerado en este sector ha permitido que los Smartphone se desempeñen como computadoraspermitiendo que las comunicaciones y las accione de compra/venta se puedan realizar gracias al internet móvil.

Tabla 4.

Hogares con acceso a tecnologías de información y comunicación.

\begin{tabular}{lllllll}
\hline \multicolumn{1}{c}{ Ámbito Geográfico } & $\mathbf{2 0 0 8}$ & $\mathbf{2 0 0 9}$ & $\mathbf{2 0 1 0}$ & $\mathbf{2 0 1 1}$ & $\mathbf{2 0 1 2}$ & $\mathbf{2 0 1 3}$ \\
\hline Total & 59.7 & 67.0 & 73.1 & 75.2 & 79.7 & 82.0 \\
Lima Metropolitana 1/ & 75.7 & 80.3 & 83.3 & 85.6 & 88.8 & 88.5 \\
Lima y Callao 2/ & 74.2 & 78.9 & 82.2 & 84.3 & 87.4 & 87.7 \\
Lima Provincias 3/ & 60.3 & 65.6 & 71.6 & 71.1 & 74.2 & 79.6
\end{tabular}

Nota:Adaptado de "El acceso a internet es un servicio TIC asociado al acceso a tecnología digital" por INEI 2015.

1/ Incluye la provincia de Lima y la provincia constitucional del Callao

2/ Comprende el departamento de Lima y la provincia constitucional del Callao

3/ Excluye la provincia de Lima

\subsubsection{Análisis Ecológico.}

Dentro del análisis PESTE la Ecología tiene relación directa con el medioambiente que nos rodea, así como con la protección y desarrollo sostenible del planeta.

En lo referente a medioambiente y desarrollo sostenible podemos considerar los comentarios de la III Cumbre Social Andina en el Parlamento Andino: el planeta está cada vez más deteriorado debido a los muchos problemas existentes. Los problemas ambientales se relacionan directamente con los problemas de índole social y financiero, y sí bien los líderes han debatido a cerca de su naturaleza, y de su preservación desde hace mucho tiempo, sólo fue hasta 1987 cuando el entonces presidente del Banco Mundial, Sr. Barber B. Conable (1986), exhortó a todas las naciones a realizar un gran esfuerzo para unirse y cooperar en realizar acciones reales para conservar el entorno natural del orbe. En su discurso realizado en Washington D. C., dijo lo siguiente:

"Tenemos conocimiento de que los recursos básicos de la Tierra, el aire y el agua, sobre los que se sustenta la supervivencia del planeta, están amenazados. Pero el esfuerzo común para resolver los problemas comunes del mundo requiere de ciertogrado de coordinación institucional y una dosis de voluntad política, que el hombre invierte más frecuentemente en destruir que en preservar". 
De lo expuesto se puede entender que la exigencia sobre el mantener y preservar los recursos naturales se basa en entrelazar esfuerzos conjuntos entre todas las naciones, que aseguren el mantenimiento de la naturaleza, y de esta forma se genere un crecimiento económico responsable y que aporte a una globalización comprometida con la naturaleza.

La naturaleza y el desarrollo son dos conceptos que se relacionan entre sí en la economía actual. La naturaleza se relaciona directamente con la economía, y esta última en su crecimiento ha afectado la naturaleza. En los diversos países el desarrollo de la producción tiene relación directa con el medio ambiente. Así como el tipo de modelo económico elegido para su desarrollo, de estos últimos el modelo proteccionista y la globalización han afectado mucho a I naturaleza pos la forma de su implementación y puesta en marcha. También es importante 'precisar que los países andinos tienen una vasta riqueza de recursos naturales, sin embargo, su uso no ha sido el más adecuado y se encuentra cerca de una crisis de recursos naturales. El futuro de las futuras generaciones estará determinado por la forma de aprovechamiento de los recursos naturales existentes y la responsabilidad en su manejo.

Las dificultades del medio ambiente pueden clasificarse de acuerdo a ciertos temas específicos como: Cambio Climático Global, Agotamiento del Ozono Estratosférico, Cambio de la Cubierta de las Tierras y Desertificación, Deforestación, Conservación de la Diversidad Biológica, Contaminación Transfronteriza del Aire, Los Océanos y sus Recursos Vivientes, Comercio/Industria y el Ambiente, Dinámica de la Población (Parlamento Andino, 2017).

Para la protección y sustentabilidad del planeta, son importantes las políticas gubernamentales las cuales deben de tener en cuenta cualquier tipo de empresa que inicia operaciones en el mercado peruano.

- La Importancia del consumo de productos biodegradables, casi todos los elementos que utilizamos a diario, son biodegradables, el problema, es el tiempo que demora en ocurrir ese hecho. Un producto que empleamos en nuestro día a día es el papel y el mismo tarda entre 2 a 5 meses en degradarse. El daño que causa es enorme, y no se tiene en cuenta jamás, de donde proviene el mismo, que sale del proceso de celulosa tomada de los árboles. 
El principal problema de su creación es la cantidad de árboles que se talan para ello, y se debería estar más conscientes en su empleo. El papel se recicla, y el célebre papel higiénico es una muestra de ello, ya que muchos utilizan papel reciclado para su elaboración. Se podría evitar mucha contaminación si se comienza a "reciclar" por la misma sociedad este elemento, y un paso muy sencillo para eso es utilizar ambos lados del papel, algo que casi nunca se hace.

Otro de los elementos biodegradables es el cartón, y es uno de los más utilizados, principalmente el tetra pack (de las cajas de leche), el cual tarda 5 años en degradarse. El nylon también es muy utilizado y la duración de degradación es de 30 a 40 años, siendo también muy nocivo para el medio ambiente.

Existe una gran campaña en la actualidad que intenta disminuir la cantidad de elementos nocivos para el medio ambiente, y para ello se intenta que sean lo más biodegradables posible. Este es el caso de los detergentes, ya que sus componentes también contaminan el ambiente, aunque eso se encuentra fuera del tema actual. (Ferrando, 2008).

Para la protección y sustentabilidad del planeta, son importantes las políticas gubernamentales las cuales deben de tener en cuenta cualquier tipo de empresa que inicia operaciones en el mercado peruano, como parte del Ejecutivo en nuestro país es importante considerar:

Ley General del Ambiente Nro. 28611 - Publicada el 15 de octubre del 2005(Ministerio del ambiente, 2013), la cual establece lineamientos y normas para la conservación y mantenimiento del Medio ambiente, su sostenibilidad en el tiempo y el uso adecuado de los recursos naturales. Así como, su debida reutilización y uso sostenible. Estas normas deben ser aplicadas por las empresas siendo responsables en el uso de sus recursos y como afectan al medio ambiente. Mayor información la podemos encontrar en el anexo del trabajo.

\section{Oportunidades y amenazas - variables externas}

\section{Oportunidades}

- Ligera recuperación de la economía en el Perú, PBI 2015 por encima de expectativa $3.26 \%$, mayores ingresos familiares y se generan mejores expectativas para el año 2016. 
- La tendencia del estilo de vida conduceal consumidor a cuidar y proteger su salud.

- Tendencia al consumo de productos biodegradables

- Incremento del estilo de vida de madres y segmento femenino que laboran fuera del hogar.

- Reducción de la pobreza en nuestro país.

- El incremento de la población económicamente activa de las mujeres, obliga al uso de servicios públicos fuera del hogar.

- Incremento del número de supermercados en Lima Moderna, tendencia al crecimiento.

- Mayor penetración de internet en los hogares, mejora el acceso a la información, comunicación con grupos del segmento femenino adulto.

- $\quad$ No existe una venta masiva de este producto en el mercado peruano.

- Redes sociales en crecimiento y que apoyan a la comercialización del producto.

\section{Amenazas}

- Fortalecimiento del dólar lo que podría afectar el precio de los insumos principales para la fabricación del producto.

- Desaceleración de la demanda interna en nuestro país.

- Contracción del sub sector no primario -1.69\%.

- Falta de una cultura de protección de la salud e higiene en el uso de baños públicos.

- Incertidumbre de los inversionistas por el año de elecciones presidenciales.

- Desaceleración de la economía de China la cual afecta la economía del país, disminuyendo el poder adquisitivo de los consumidores peruanos. 


\subsection{Matriz EFE - Factores Externos}

Tabla 5.

Matriz EFE - Factores Externos

\begin{tabular}{|c|c|c|c|c|}
\hline № & Oportunidades & Peso & Puntaje & $\begin{array}{c}\text { Puntaje } \\
\text { Ponderado }\end{array}$ \\
\hline \multirow{4}{*}{1} & Ligera recuperación de la economía en el Perú. PBI 2015 & & & \\
\hline & por encima de expectativa $3.26 \%$, mayores ingresos & & & \\
\hline & familiares y se generan mejores expectativas para el año & & & \\
\hline & 2016. & 0.07 & 4 & 0.28 \\
\hline \multirow{2}{*}{2} & La tendencia del estilo de vida actual está haciendo que & & & \\
\hline & el consumidor busque cuidar y proteger su salud. & 0.08 & 4 & 0.32 \\
\hline 3 & Tendencia del consumo de productos biodegradables. & 0.06 & 3 & 0.18 \\
\hline \multirow{2}{*}{4} & Incremento del estilo de vida de madres y segmento & & & \\
\hline & femenino que laboran fuera del hogar, & 0.07 & 4 & 0.28 \\
\hline 5 & Reducción de la pobreza en nuestro país. & 0.05 & 3 & 0.15 \\
\hline \multirow{3}{*}{6} & El incremento de la población económicamente activa de & & & \\
\hline & las mujeres, obliga al uso de servicios públicos fuera del & & & \\
\hline & hogar. & 0.06 & 3 & 0.18 \\
\hline \multirow{3}{*}{7} & Incremento del número de supermercados en Lima & & & \\
\hline & Moderna, tendencia al crecimiento de las diferentes & & & \\
\hline & cadenas. & 0.08 & 3 & 0.24 \\
\hline \multirow{4}{*}{8} & Mayor penetración de internet/redes sociales en los & & & \\
\hline & hogares, mejora de acceso a la información, & & & \\
\hline & comunicación con comunidades del segmento en el & & & \\
\hline & mercado peruano. & 0.07 & 4 & 0.28 \\
\hline \multirow{3}{*}{9} & No existe una venta masiva de este producto en el & & & \\
\hline & mercado peruano. & 0.06 & 3 & 0.18 \\
\hline & Sub Total & 0.60 & & 2.09 \\
\hline № & Amenazas & Peso & Puntaje & $\begin{array}{c}\text { Puntaje } \\
\text { Ponderado }\end{array}$ \\
\hline \multirow{2}{*}{1} & Fortalecimiento del dólar, los insumos principales se & & & \\
\hline & importan de otros países. & 0.13 & 2 & 0.26 \\
\hline 2 & Desaceleración de la demanda interna en nuestro país. & 0.04 & 3 & 0.12 \\
\hline \multirow{2}{*}{3} & Falta de una cultura de protección de la salud e higiene & & & \\
\hline & en el uso de baños fuera del hogar. & 0.12 & 2 & 0.24 \\
\hline \multirow{2}{*}{4} & Incertidumbre de los inversionistas por el ingreso de un & & & \\
\hline & nuevo presidente. & 0.07 & 2 & 0.14 \\
\hline \multirow[t]{3}{*}{5} & $\begin{array}{l}\text { Desaceleración de la economía de China, principal } \\
\text { comprador a nivel mundial. }\end{array}$ & 0.04 & 2 & 0.08 \\
\hline & Sub Total & 0.40 & & 0.84 \\
\hline & Total & 1.00 & & 2.93 \\
\hline
\end{tabular}

Nota: 4=La respuesta superior, 3=La respuesta está por encima del promedio, 2=La respuesta es promedio, 1=La respuesta es deficiente.

Elaboración propia 
Para la construcción de la matriz EFE, se ha considerado la entrevista de profundidad realizada al experto en marketing Christian Marky - Jefe de Marketing PROTISA PERU- a quien se le consultó sobre los pesos y puntajes que podríamos asignar a las diferentes variables, como parte del análisis de oportunidades y amenazas de la evaluación externa.

Como conclusión del análisis externo se ha identificado luego del puntaje ponderado tanto oportunidades como amenazas una calificación total de 2.93, el total del ponderado indica que nuestra empresa está por encima del promedio de 2.5 (David, 2013, p. 81), significa que está aprovechando las oportunidades externas, evitando las amenazas a las cuales podría enfrentarse.

\subsection{Matriz de perfil competitivo}

Para la identificación de los factores críticos en el diseño de la matriz de perfil competitivo se tomó como punto de análisis la entrevista de profundidad que se realizó a Christian Marky, Jefe de Marketing PROTISA PERU, su experiencia en la comercialización del producto hace algunos años en nuestro país fue determinante para definir la ponderación y calificación de la matriz.

Entre los factores más importantes para alcanzar el éxito en la industria son la calidad de producto 0.15 y distribución de ventas 0.15 , con respecto a los niveles percibidos, la marca Queen, según indica su puntuación es de 3.08 resulta con la mayor calificación, luego a continuación nuestro producto con el cobertor sanitario para inodoros con una calificación de 3.07, ambas marcas se ubican en la categoría de fortaleza menor y la marca Safe-t-gard con 2.99, ubicándose en la categoría de debilidad menor (David, 2013, p. 138). 
Tabla 6.

Matriz de perfil competitivo

\begin{tabular}{|c|c|c|c|c|c|c|c|c|c|c|}
\hline \multirow{2}{*}{$\begin{array}{l}\mathbf{N} \\
\underline{0}\end{array}$} & \multirow{2}{*}{$\begin{array}{l}\text { Factores Críticos } \\
\text { para el Éxito }\end{array}$} & \multirow{2}{*}{$\begin{array}{l}\text { Pondera } \\
\text { ción }\end{array}$} & \multicolumn{2}{|c|}{ Termoencogibles } & \multicolumn{2}{|c|}{$\begin{array}{c}\text { Kmc Internacional } \\
\text { SAC }\end{array}$} & \multicolumn{2}{|c|}{ Conversit } & \multicolumn{2}{|c|}{ Flushables } \\
\hline & & & $\begin{array}{l}\text { Califica } \\
\text { ción }\end{array}$ & $\begin{array}{l}\text { Puntua } \\
\text { ción }\end{array}$ & $\begin{array}{l}\text { Califica } \\
\text { ción }\end{array}$ & $\begin{array}{l}\text { Puntua } \\
\text { ción }\end{array}$ & $\begin{array}{l}\text { Califica } \\
\text { ción }\end{array}$ & $\begin{array}{l}\text { Puntua } \\
\text { ción }\end{array}$ & $\begin{array}{l}\text { Califica } \\
\text { ción }\end{array}$ & $\begin{array}{l}\text { Puntu } \\
\text { ación }\end{array}$ \\
\hline 1 & $\begin{array}{l}\text { Calidad del } \\
\text { Producto }\end{array}$ & 0.15 & 4 & 0.60 & 4 & 0.60 & 4 & 0.60 & 4 & 0.60 \\
\hline 2 & Posición financiera & 0.08 & 3 & 0.24 & 4 & 0.32 & 3 & 0.24 & 3 & 0.24 \\
\hline 3 & $\begin{array}{l}\text { Estructura de la } \\
\text { organización }\end{array}$ & 0.08 & 4 & 0.32 & 4 & 0.32 & 4 & 0.32 & 3 & 0.24 \\
\hline 4 & $\begin{array}{l}\text { Distribución de } \\
\text { ventas }\end{array}$ & 0.15 & 2 & 0.30 & 1 & 0.15 & 1 & 0.15 & 1 & 0.15 \\
\hline 5 & $\begin{array}{l}\text { Experiencia } \\
\text { General }\end{array}$ & 0.10 & 4 & 0.40 & 4 & 0.40 & 4 & 0.40 & 4 & 0.40 \\
\hline 6 & $\begin{array}{l}\text { Capacidad de } \\
\text { producción }\end{array}$ & 0.12 & 3 & 0.36 & 3 & 0.36 & 3 & 0.36 & 3 & 0.36 \\
\hline 7 & $\begin{array}{l}\text { Dedicación de los } \\
\text { empleados }\end{array}$ & 0.10 & 3 & 0.30 & 4 & 0.40 & 4 & 0.40 & 4 & 0.40 \\
\hline 8 & Precio competitivo & 0.12 & 3 & 0.36 & 2 & 0.24 & 2 & 0.24 & 2 & 0.24 \\
\hline 9 & Publicidad & 0.10 & 2 & 0.20 & 2 & 0.20 & 2 & 0.20 & 2 & 0.20 \\
\hline & Total & 1 & & 3.08 & & 2.99 & & 2.91 & & 2.83 \\
\hline
\end{tabular}

Nota: Las calificaciones están relacionadas a fortalezas y debilidades donde:

4 =fortaleza principal, 3 =fortaleza menor, 2 =debilidad menor, 1 =debilidad principal.

Elaboración propia 


\section{CAPITULO III: ESTUDIO DE MERCADO}

\subsection{Descripción del servicio o producto}

El negocio está enfocado en la fabricación y comercialización de un cobertor sanitario para inodoros. El producto está fabricado con una fibra de papel rectangular, con las esquinas recortadas en diagonal; presenta un orificio en el centro en forma de foco, el cual está pre cortado, en tres lados a excepción de la base, para facilitar una lengüeta que permitirá recoger el cobertor sanitario para inodoro y arrojarlo en el tacho del baño. Además, uno de los lados del producto tiene una textura rugosa para conseguir que se adhiera a la tapa plástica de los inodoros, y el otro lado tiene una superficie lisa con la finalidad de un tacto suave al cuerpo del usuario.

La principal función del cobertor sanitario para inodoros es evitar el contacto de la piel con la superficie de las tapas de inodoros y así evitar el contacto con virus o bacterias, y mediante su uso disminuir el impacto de estos en la salud de las personas.

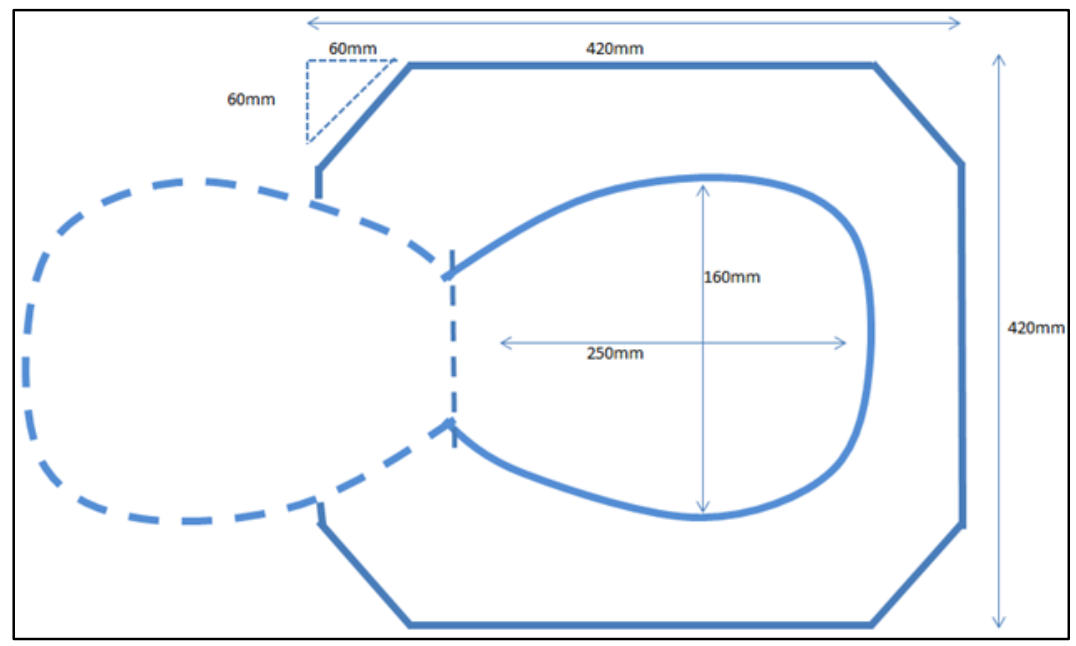

Figura 24. Cobertor sanitario. Elaboración propia.

El cobertor sanitario para inodoros tiene como especificación técnica lo siguiente: es una fibra de papel elaborada por fibras de árboles y plantas, las cuales son procesadas en una molienda, tratadas para blanquearlas, llevadas al área de secado y, finalmente endurecidas. Como resultado de este proceso obtiene la pulpa de celulosa, a la cual se le agregan ciertas sustancias para brindarle la textura requerida por el producto, así como la capacidad de biodegradarse al contacto con el agua. 
Por otro lado, el cobertor sanitario para inodoros tiene como formato una presentación en un pack de diez cobertores, doblados y plegados, dentro de una bolsa de plástico con los logotipos de la marca, forma de uso y toda la información de etiquetado obligatoria por ley.

Finalmente, las principales características del cobertor sanitario para inodoros son las siguientes:

- Fácil de usar, se desenvuelve, se rompe el pre cortado y se coloca encima de la tapa del inodoro.

- Tamaño promedio, el formato es adecuado a cualquier tamaño de inodoro

- Material no tóxico, producido con fibras de papel.

- $\quad$ Presentación de bolsillo, la presentación es adecuada para el bolsillo o cartera.

\subsection{Selección del segmento del mercado}

La investigación de mercado se realizará con el objetivo de conocer el nivel de aceptación que tendría el producto cobertor sanitario para inodoros en el mercado de Lima Moderna, específicamente en el segmento femenino, y de esta forma podremos cuantificar el número de personas interesadas en usar el producto, así como la frecuencia de compra, lugares de compra y poder establecer el plan de ventas para el presente proyecto.

La investigación de mercado aportará datos importantes para una mejor toma de decisiones, pues permite conocer ciertas variables clave que con una correcta estrategia determinarán el éxito del proyecto y disminuirán el riesgo de fracaso durante su ejecución.

Por tanto, es importante conocer al potencial consumidor, y este conocimiento decantado en las variables del marketing mix: precio, plaza, publicidad y promoción; permitirán satisfacer las necesidades de nuestros potenciales clientes.

Para la realización de la definición de este segmento de mercado se han analizado las variables siguientes:

a. Segmentación Geográfica, al ser el cobertor sanitario para inodoros un producto nuevo para el mercado peruano se ha seleccionado como ámbito geográfico para su estudio el espacio denominado Lima Moderna. $Y$ esto debido a que la futura planta de producción y comercialización se instalará en Lima, además que los potenciales consumidores se ubican principalmente en el espacio seleccionado. 
b. Segmentación Demográfica, en lo que se refiere a género se ha determinado que el producto se oriente al sector femenino, y esto debido a que es nuestro potencial usuario debido a la información obtenida en el análisis PESTE sobre el uso incorrecto de los baños públicos. Con respecto a las edades se determinó el rango de 20 a 54 años, puesto que son mujeres que ya trabajan, amas de casa y son las decisoras de compra.

\subsection{Investigación cualitativa}

La investigación cualitativa proporcionará información primaria relacionada a usos y costumbres, presentación del producto y búsqueda de información relacionada a las $4 p$ del marketing mix. Para obtener esta información se realizará un muestreo no Probabilístico, en el cual la muestra es elegida por los investigadores de forma directa, no es aleatoria. Asimismo, la investigación cualitativa utilizará el diseño de investigación exploratoria. Según Naresh K. Malhotra la investigación exploratoria, sirve para analizar el problema, brindando conocimiento y comprensión de la situación. Por lo cual se utilizarán dos tipos de herramientas:

a) Entrevistas de profundidad, se realizarán entrevistas dirigidas a un profesional de salud, un experto en infraestructura, un experto en marketing, un experto en comercialización de productos de higiene y cuidado personal y un experto en operaciones.

b) Focus group, se desarrollarán paneles con personas del segmento femenino de los distritos de Lima Moderna. Para ello se dividirán en tres grupos relacionados por edades con grupo de mujeres entre los 20 a 54 años de edad.

\subsubsection{Proceso de muestreo.}

Para esta etapa se buscará referentes del sector de negocio con la finalidad de realizar las entrevistas de profundidad y potenciales consumidores finales para la realización de los Focus Group. 


\subsubsection{Diseño de instrumento.}

a) Entrevistas de profundidad, para la selección de los expertos a entrevistar se desarrolló un perfil de las personas que debían de ser entrevistadas y que podrían aportar con su experiencia interdisciplinaria en los diferentes aspectos de la producción y comercialización del cobertor sanitario para inodoros. A continuación se presenta la ficha de reclutamiento de los cinco (05) expertos a entrevistar:

Tabla 7.

Perfiles de expertos

\begin{tabular}{|c|c|c|c|c|c|}
\hline $\begin{array}{l}\text { Experto en } \\
\text { Obras }\end{array}$ & $\begin{array}{c}\text { Experto en } \\
\text { Comercialización }\end{array}$ & $\begin{array}{l}\text { Experto en } \\
\text { Marketing }\end{array}$ & Experto en Salud & $\begin{array}{l}\text { Experto en } \\
\text { Operaciones }\end{array}$ & $\begin{array}{c}\text { Experto en } \\
\text { Supermercados }\end{array}$ \\
\hline $\begin{array}{l}\text {-Profesional en } \\
\text { Ingeniería Civil }\end{array}$ & $\begin{array}{c}\text {-Profesional en } \\
\text { Ingeniería } \\
\text { Industrial }\end{array}$ & $\begin{array}{l}\text {-Profesional en } \\
\text { Marketing }\end{array}$ & $\begin{array}{l}\text {-Profesional en } \\
\text { Medicina, } \\
\text { Enfermería y/o } \\
\text { Obstetricia }\end{array}$ & $\begin{array}{l}\text {-Profesional en } \\
\text { Ingeniería }\end{array}$ & $\begin{array}{l}\text {-Profesional en } \\
\text { Administración }\end{array}$ \\
\hline $\begin{array}{l}\text {-Experiencia en } \\
\text { el rubro de } \\
\text { construcción } \\
\text { mayor a } 5 \text { años. }\end{array}$ & $\begin{array}{l}\text {-Experiencia en } \\
\text { logística de } \\
\text { supermercados } \\
\text { en el segmento } \\
\text { de aseo } \\
\text { personal. }\end{array}$ & $\begin{array}{l}\text {-Experiencia en } \\
\text { Marketing de } \\
\text { consumo masivo } \\
\text { mayor a } 5 \text { años }\end{array}$ & $\begin{array}{l}\text {-Experiencia en } \\
\text { el rubro de } \\
\text { construcción } \\
\text { mayor a } 5 \text { años. }\end{array}$ & $\begin{array}{l}\text {-Experiencia en } \\
\text { el sector de } \\
\text { operaciones de } \\
\text { plantas de papel } \\
\text { mayor a } 5 \text { años. }\end{array}$ & $\begin{array}{c}\text {-Experiencia en } \\
\text { el sector } \\
\text { comercial de } \\
\text { consumo masivo }\end{array}$ \\
\hline $\begin{array}{l}\text {-Edad de } 28 \\
\text { años a más. }\end{array}$ & $\begin{array}{l}\text {-Edad de } 28 \\
\text { años a más. }\end{array}$ & $\begin{array}{l}\text {-Edad de } 28 \\
\text { años a más. }\end{array}$ & $\begin{array}{l}\text {-Edad de } 28 \\
\text { años a más. }\end{array}$ & $\begin{array}{l}\text {-Edad de } 28 \\
\text { años a más. }\end{array}$ & $\begin{array}{l}\text {-Edad de } 28 \\
\text { años a más. }\end{array}$ \\
\hline $\begin{array}{l}\text {-Conocimiento } \\
\text { de sistemas de } \\
\text { agua y desagüe. }\end{array}$ & $\begin{array}{c}\text {-Especializado } \\
\text { en el segmento } \\
\text { de higiene } \\
\text { personal. }\end{array}$ & $\begin{array}{l}\text {-Conocimientos } \\
\text { de lanzamientos } \\
\text { de productos e } \\
\text { investigación de } \\
\text { mercado. }\end{array}$ & & & $\begin{array}{c}\text { - Conocimientos } \\
\text { de negociación } \\
\text { comercial }\end{array}$ \\
\hline
\end{tabular}

Nota: Se muestra detalladamente el perfil según el puesto, elaborado por el equipo investigador.

Elaboración Propia. 
Asimismo, esta es la ficha de técnica de la entrevista de profundidad

Tabla 8.

Entrevistas de profundidad.

\begin{tabular}{|c|c|}
\hline $\begin{array}{l}\text { Diseño de } \\
\text { investigación }\end{array}$ & Descripción \\
\hline $\begin{array}{l}\text { Ámbito } \\
\text { geográfico }\end{array}$ & Distritos de Lima Moderna \\
\hline Universo & $\begin{array}{l}\text { Especialistas en las áreas de salud, marketing, infraestructura y producción y } \\
\text { comercialización }\end{array}$ \\
\hline Duración & 50 a 60 minutos \\
\hline Participantes & 01 persona por sesión \\
\hline Metodología & $\begin{array}{l}\text { Entrevista individual, acerca del producto y con el objetivo de conocer a profundidad el } \\
\text { punto de vista o parecer de los entrevistados, relacionado con el campo en el cual se } \\
\text { desarrollan. }\end{array}$ \\
\hline Propósito & $\begin{array}{l}\text { Conocer el nivel de aceptación que tendría el cobertor para sanitarios, por parte de los } \\
\text { especialistas. }\end{array}$ \\
\hline $\begin{array}{l}\text { Hábitos de } \\
\text { consumo }\end{array}$ & $\begin{array}{l}\text { Obtener información de aceptación del producto relacionada con la experiencia de los } \\
\text { especialistas y trasladada a la realidad. }\end{array}$ \\
\hline $\begin{array}{l}\text { Prueba del } \\
\text { producto }\end{array}$ & Testeo del producto y presentación de venta. \\
\hline
\end{tabular}

b) Focus Group, para la realización de esta herramienta de investigación cualitativa se consideró como base para seleccionar a los participantes los criterios definidos en la segmentación. Por lo cual la ficha de reclutamiento muestra tres variables que acotan la segmentación de los posibles entrevistados para los tres focus group realizados. A continuación, se presenta la ficha técnica para la utilización de la herramienta cualitativa: 


\section{Tabla 9.}

\section{Ficha Técnica del Focus Group}

\begin{tabular}{llll}
\hline Técnica Cuantitativa & Variable de Focalización & Variable Primaria & Variable Secundaria \\
\hline Focus Group 01 & Mujeres de Lima & NSE A al C & Edades entre los 20 y 54 \\
& Moderna & & años \\
Focus Group 02 & Mujeres de Lima & NSE A al C & Edades entre los 20 y54 \\
& Moderna & & años \\
Focus Group 03 & Mujeres de Lima & NSE A al C & Edades entre los 20 y 54 \\
& Moderna & & años
\end{tabular}

Nota: Determinación de las variables para la aplicación de focus group.

Elaboración Propia.

Tabla10.

Focus Group

\begin{tabular}{|c|c|}
\hline $\begin{array}{l}\text { Diseño de } \\
\text { investigación }\end{array}$ & Descripción \\
\hline Ámbito geográfico & Distritos de Lima Moderna \\
\hline Universo & Mujeres del NSE A, B y Ccon edades entre los 20 y 54 años. \\
\hline Duración & 50 a 60 minutos \\
\hline Participantes & 8 a 10 personas \\
\hline Metodología & $\begin{array}{l}\text { Entrevista grupal al segmento seleccionado, con el objetivo de analizar sus opiniones y } \\
\text { comentarios acerca del producto y obtener la máxima información posible mediante la } \\
\text { interacción de los integrantes del grupo. }\end{array}$ \\
\hline & Conocer el nivel de aceptación que tendría el cobertor para sanitarios, por parte del Público \\
\hline Propósito & $\begin{array}{l}\text { Objetivo, mediante la realización del estudio cualitativo. El objetivo es conocer los gustos y } \\
\text { preferencias de los consumidores hacia el producto. }\end{array}$ \\
\hline Hábitos de consumo & $\begin{array}{l}\text { Obtener información de aceptación de producto, frecuencia de uso, frecuencia de Compra, } \\
\text { lugares y Ocasión que se realiza el consumo, Motivo de la Compra (envase, sabor, calidad, } \\
\text { precio). }\end{array}$ \\
\hline Prueba del producto & Testeo del producto y presentación de venta. \\
\hline
\end{tabular}

Nota: Descripción de los aspectos a tomar en cuenta para el focus group.

Elaboración propia. 


\subsubsection{Análisis y procesamiento de datos.}

a) Entrevista de Profundidad

Se realizaron entrevistas a cinco (05) especialistas en diferentes disciplinas relacionadas con el producto y la información correspondiente a las conclusiones alcanzadas se puede revisar en el anexo del proyecto. Los entrevistados fueron:

- Entrevista 001 Ingeniero Civil el Sr. Carlos Jiménez

Supervisor de obras - Consultor Independiente

- Entrevista 002 Ingeniero Industrial el Sr. David Oliva Aragón

Ejecutivo de Logística - Corporación Wong - Centro Comercial Plaza Norte

- Entrevista 003 Licenciado en MKT el Sr. Christian Marky Bertarelli Jefe de Marketing PROTISA PERU

- Entrevista 004 Licenciado en Enfermería la Sra. Maritza García

- Entrevista 005 Ingeniero Químico el Sr. Carlos Bullón

Gerente de Operaciones PROTISA Colombia

- Entrevista 006 Ingeniero Industrial Sr. Jorge Sifuentes Canales

Jefe de Compras de Productos de Gran Consumo de Hipermercados Tottus

b) Focus Group

La investigación se realizó a tres grupos de posibles usuarios segmentados por edades, la información alcanzada se puede revisar en el anexo del proyecto

\subsubsection{Conclusiones de la investigación cualitativa}

\section{Conclusiones}

1. Generar el conocimiento y difusión del cobertor sanitario para inodoros como un producto que ayude a disminuir las enfermedades.

2. El cobertor sanitario para inodoros fue aceptado por los entrevistados.

3. El producto disminuiría la posibilidad de contraer enfermedades.

4. La presentación en pack de 10 unidades, pack de bolsillo, fue la preferida.

5. El punto de venta elegido fue el supermercado, en los espacios para cuidado personal e higiene de mujeres.

6. Sobre el precio los entrevistados indicaron que estarían dispuestos a pagar un precio establecido entre los $\mathrm{S} / 2.00$ hasta $\mathrm{S} / 3.00$.

7. La información de uso debía de ser explicada, y sobretodo indicando su desecho en tachos

8. La comunicación a través de redes sociales internet, y algunos medios tradicionales y folletería. 


\subsection{Investigación cuantitativa}

\subsubsection{Proceso de muestreo.}

Para poder definir la muestra se toma en consideración algunos criterios que permitirían determinar el mercado. En este sentido, Se tomará en cuenta la información de CPI, Compañía Peruana de Investigación de Mercado y Opinión de Mercado S.A.C. Market Report 2016.

Para realizar la presente investigación considerará lanzar el producto en los 12 distritos de Lima Moderna

Tabla 11:

Población por distritos de Lima Moderna

\begin{tabular}{lc}
\hline \multicolumn{1}{c}{ Distritos } & Población \\
\hline JESUS MARIA & 73,200 \\
LINCE & 51,300 \\
PUEBLO LIBRE & 77,800 \\
MAGDALENA & 55,800 \\
SAN MIGUEL & 138,300 \\
MIRAFLORES & 84,000 \\
SAN ISIDRO & 55,600 \\
SAN BORJA & 114,400 \\
SURCO & 351,200 \\
LA MOLINA & 175,100 \\
BARRANCO & 30,600 \\
SURQUILLO & 93,200 \\
\hline TOTAL & $1,300,500$ \\
\hline Nota: Adaptado de “Fuente de CPI $2016 ”$, por CPI 2016.
\end{tabular}

\section{Proceso de muestreo}

Con esta población inicial aplicamos los siguientes criterios que permitirán determinar el mercado:

a) Género, esta variable delimitará el segmento orientándolo al sector femenino, el cual representa el $51.19 \%$ de la población proyectada de Lima departamental y la provincia constitucional del Callao. 
Tabla 12.

Participación por género

\begin{tabular}{|c|c|c|c|c|}
\hline & & Total & Hombre & Mujer \\
\hline Población de Lima Moderna & 2016 & $1,300,500$ & 634,777 & 665,723 \\
\hline \multicolumn{2}{|c|}{ \% PARTICIPACION POR GENERO } & $100 \%$ & $48.81 \%$ & $51.19 \%$ \\
\hline
\end{tabular}

Nota: Adaptado de "Fuente CPI 2016", por CPI 2016

b) Edades, en este criterio se ha definido que la investigación se circunscriba a la población femenina $-51.44 \%$ de la población- que se encuentre entre las edades de 20 a 54 años.

Tabla 13.

Población por Rango de edad

\begin{tabular}{ccc}
\hline \multicolumn{4}{c}{ POBLACIÓN FEMENINA DE LIMA MODERNA } & $\mathbf{2 0 1 6}$ \\
\hline \% POR RANGO DE EDAD & $51.44 \%$ & $\mathbf{3 4 2 , 4 4 8}$ \\
\hline
\end{tabular}

Nota: Adaptado de "Fuente CPI 2016", por CPI 2016.

c) Nivel socio económico -NSE, para poder definir la población se tomó como base la investigación de APEIM del 2016 sobre NSE de la población en Lima Moderna y el Perú. En este estudio los niveles socio económicos A, B y C concentran el $69.8 \%$ de la población.

Tabla 14.

Población por Nivel Socioeconómico

\begin{tabular}{ccc}
\hline \multicolumn{3}{c}{ POBLACIÓN FEMENINA DE LIMA MODERNA POR NSE 2016} \\
\hline$\%$ DE LA POBLACION DEL NSE A,B Y C & $92.20 \%$ & $\mathbf{3 1 5 , 7 3 7}$ \\
\hline
\end{tabular}

Nota: Se plasma solamente la información del sexo femenino debido a que es el público objetivo; Nota: Adaptado de “Datos obtenidos de APEIM (2016)”, por Apeim 2016. 
Con la definición de estas variables concluimos que el segmento de mercado está comprendido por una población que asciende a 315,737mujeres, entre las edades de 20 a 54 años de edad y de los niveles socioeconómicos A, B y C, que habitan en los distritos de Lima Moderna. Estas mujeres se caracterizan, según, la segmentación de estilos de vida de Arellano, por ser modernas: amas de casa, estudiantes y profesionales; que siempre están buscando productos nuevos para satisfacer sus necesidades y las de su familia. La investigación cuantitativa tiene por instrumento el desarrollo de encuestas al segmento seleccionado, para el desarrollo de este trabajo de campo es necesario reducir nuestro segmento a una muestra representativa de la población a alcanzar. Para la definición de la muestra es necesaria la aplicación de la fórmula para universo infinito (Pickers, 2015):

Donde:

$$
n=\frac{z^{2} \times P \times Q}{e^{2}}
$$

$$
\begin{aligned}
& N=315,737 \text { Mujeres } \\
& z=1.96(95 \% \text { de confianza }) \\
& e=0.05(5 \% \text { margen de error }) \\
& p=q=0.5: \\
& p+q=10100 \%
\end{aligned}
$$

Al realizar el desarrollo de la fórmula se puede definir la cantidad de encuestas a realizar, para alcanzar la representatividad del segmento a investigar, con lo cual obtuvimos como tamaño de muestra: 384 encuestas.

Con el tamaño de la muestra definida y haciendo uso de las variables área geográfica, género y NSE se desarrolló el siguiente cuadro que indica la cantidad de encuestas que se deben hacer por distrito para poder alcanzar la representatividad deseada para el proyecto. 
Tabla 15.

Distribución de encuestas por Distritos y Nivel Socioeconómico

\begin{tabular}{lcccc}
\hline LIMA MODERNA & $\begin{array}{c}\text { NUMERO DE } \\
\text { ENCUESTAS }\end{array}$ & NSE A & NSE B & NSE C \\
\hline & & $13.70 \%$ & $58.00 \%$ & $22.20 \%$ \\
JESUS MARIA & 22 & $\mathbf{1 4 . 5 9 \%}$ & $\mathbf{6 1 . 7 7 \%}$ & $\mathbf{2 3 . 6 4 \%}$ \\
LINCE & 15 & 3 & 14 & 5 \\
PUEBLO LIBRE & 23 & 2 & 9 & 4 \\
MAGDALENA & 16 & 3 & 14 & 6 \\
SAN MIGUEL & 41 & 2 & 10 & 4 \\
& & 6 & 25 & 10 \\
MIRAFLORES & 25 & $36 \%$ & $43 \%$ & $\mathbf{1 5 . 8 5 \%}$ \\
SAN ISIDRO & 16 & $\mathbf{3 8 . 1 9 \%}$ & $\mathbf{4 5 . 9 6 \%}$ & 5 \\
SAN BORJA & 34 & 9 & 11 & 3 \\
SURCO & 104 & 13 & 7 & 5 \\
LA MOLINA & 52 & 40 & 16 & 8 \\
& & 20 & 48 & $43.30 \%$ \\
BARRANCO & & $4.20 \%$ & 24 & $\mathbf{5 7 . 5 0 \%}$ \\
SURQUILLO & 9 & $\mathbf{5 . 5 8 \%}$ & $\mathbf{2 7 . 8 0 \%}$ & $\mathbf{5}$ \\
\hline TOTAL & 28 & 1 & $36.92 \%$ & 87 \\
\hline
\end{tabular}

Elaboración Propia

\subsubsection{Diseño de instrumento.}

Tabla 16.

Diseño de instrumento

Diseño de
investigación

\begin{tabular}{|c|c|}
\hline Técnica & Encuesta presencial \\
\hline Instrumento & Cuestionario con 20 preguntas, de tipo cerradas y enescala de Likert. \\
\hline Tipo de muestreo & Probabilístico. \\
\hline Universo & Mujeres del NSE A, B, C con edades entre los 20 a 54 años. \\
\hline Población (P) & Proporción de la población que tiene la característica que interesa medir $\mathrm{P}=50.0 \%$ \\
\hline Nivel de confianza $(z)$ & $95 \%$. Para $95 \%, z=1.96$ \\
\hline $\begin{array}{l}\text { Máximo Error muestral } \\
\text { (e) }\end{array}$ & +-0.00025 \\
\hline $\begin{array}{l}\text { Tamaño y Composición } \\
\text { de la muestra }\end{array}$ & $\begin{array}{l}\text { La muestra estuvo compuesta por } 384 \text { mujeres encuestadas, pertenecientes a los NSE A, } \\
\text { B y C }\end{array}$ \\
\hline Trabajo de campo & El levantamiento de información fue realizado del 05 de febrero al 10 de febrero de 2019 \\
\hline
\end{tabular}




\subsubsection{Análisis y procesamiento de datos.}

Las encuestas se realizaron en los distritos de Lima Moderna en los cuales existen supermercados, puesto que al realizar la investigación cualitativa se determinó que los entrevistados definieron como lugar de compra preferido: los supermercados. Luego de definir este segmento la determinación de la muestra arrojo la realización de 384 encuestas, de las cuales mostramos los resultados a continuación: 
Tabla 17.

¿Utiliza baños públicos?

\begin{tabular}{|c|c|c|c|c|c|c|c|c|c|c|c|c|c|c|}
\hline Respuestas & $\begin{array}{l}\text { JESUS } \\
\text { MARIA }\end{array}$ & LINCE & $\begin{array}{c}\text { PUEBLO } \\
\text { LIBRE }\end{array}$ & $\begin{array}{c}\text { MAGDAL } \\
\text { ENA }\end{array}$ & $\begin{array}{c}\text { SAN } \\
\text { MIGUEL }\end{array}$ & $\begin{array}{c}\text { MIRAFLOR } \\
\text { ES }\end{array}$ & $\begin{array}{l}\text { SAN } \\
\text { ISIDRO }\end{array}$ & $\begin{array}{c}\text { SAN } \\
\text { BORJA }\end{array}$ & SURCO & $\begin{array}{c}\text { LA } \\
\text { MOLINA }\end{array}$ & $\begin{array}{c}\text { BARRANC } \\
0 \\
\end{array}$ & $\begin{array}{c}\text { SURQUI } \\
\text { LLO }\end{array}$ & TOTAL & $\%$ \\
\hline $\begin{array}{l}\text { Muy } \\
\text { Frecuentemente }\end{array}$ & 2 & 1 & 3 & 1 & 4 & 2 & 1 & 3 & 13 & 6 & 0 & 3 & 39 & $10.16 \%$ \\
\hline Frecuentemente & 9 & 6 & 8 & 7 & 15 & 10 & 7 & 13 & 38 & 17 & 5 & 9 & 144 & $37.50 \%$ \\
\hline Ocasionalmente & 6 & 5 & 6 & 4 & 10 & 8 & 4 & 9 & 24 & 13 & 2 & 6 & 97 & $25.26 \%$ \\
\hline Raramente & 2 & 3 & 4 & 3 & 8 & 3 & 3 & 5 & 16 & 11 & 1 & 5 & 64 & $16.67 \%$ \\
\hline Nunca & 3 & 0 & 2 & 1 & 4 & 2 & 1 & 4 & 13 & 5 & 1 & 5 & 41 & $10.68 \%$ \\
\hline TOTAL & 22 & 15 & 23 & 16 & 41 & 25 & 16 & 34 & 104 & 52 & 9 & 28 & 384 & $100.00 \%$ \\
\hline
\end{tabular}

Nota: Tabla elaborada con los datos obtenidos de la pregunta 1 del cuestionario.

Elaboración Propia.

Figura 25. ¿Utiliza baños públicos?

Utliza los baños publicos

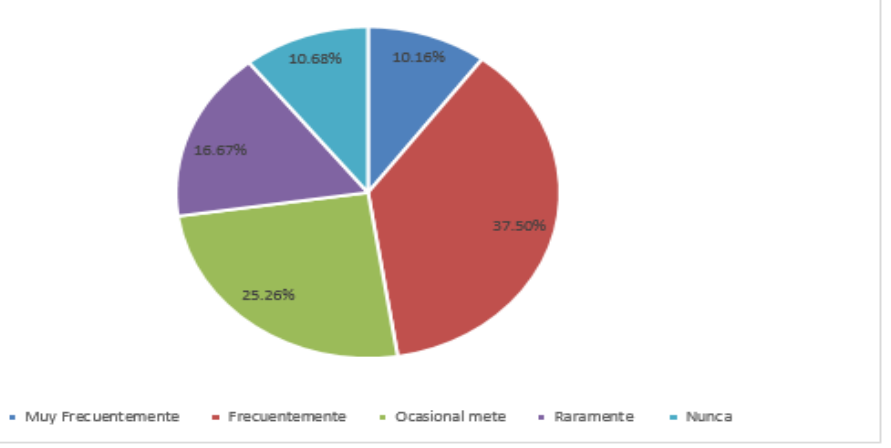

Elaboración propia

Resultado: Del total de encuestadas, el 10.16\% afirmó que si usa baños públicos muy frecuentemente y el 37.50\% frecuentemente por lo cual la probabilidad de contraer enfermedades es muy alta, mientras que el $25.26 \%$ lo utiliza ocasionalmente, el $16.67 \%$ lo utiliza raramente y el $10.68 \%$ no lo utilizanunca. 
Tabla 18.

¿Con qué frecuencia usa los baños públicos?

\begin{tabular}{|c|c|c|c|c|c|c|c|c|c|c|c|c|c|c|}
\hline Respuestas & $\begin{array}{l}\text { JESUS } \\
\text { MARIA }\end{array}$ & LINCE & $\begin{array}{l}\text { PUEBLO } \\
\text { LIBRE }\end{array}$ & MAGDALENA & $\begin{array}{c}\text { SAN } \\
\text { MIGUEL }\end{array}$ & $\begin{array}{c}\text { MIRAFL } \\
\text { ORES }\end{array}$ & $\begin{array}{l}\text { SAN } \\
\text { ISIDRO }\end{array}$ & $\begin{array}{c}\text { SAN } \\
\text { BORJA }\end{array}$ & SURCO & $\begin{array}{c}\text { LA } \\
\text { MOLINA }\end{array}$ & BARRANCO & SURQUILLO & TOTAL & $\%$ \\
\hline 1 vez por semana & 3 & 2 & 3 & 2 & 6 & 4 & 1 & 4 & 18 & 13 & 1 & 3 & 60 & $17.44 \%$ \\
\hline 2 veces por semana & 4 & 3 & 5 & 3 & 9 & 5 & 3 & 5 & 22 & 15 & 1 & 5 & 80 & $23.26 \%$ \\
\hline 3 veces por semana & 5 & 4 & 6 & 4 & 10 & 6 & 5 & 9 & 25 & 9 & 3 & 7 & 93 & $27.03 \%$ \\
\hline 4 veces por semana & 7 & 6 & 7 & 6 & 12 & 8 & 6 & 12 & 26 & 10 & 3 & 8 & 111 & $32.27 \%$ \\
\hline TOTAL & 19 & 15 & 21 & 15 & 37 & 23 & 15 & 30 & 91 & 47 & 8 & 23 & 344 & $100.00 \%$ \\
\hline
\end{tabular}

Nota: Tabla elaborada con los datos obtenidos de la pregunta 2 del cuestionario.

Elaboración Propia.

Figura 26. ¿Con qué frecuencia usa los baños públicos?

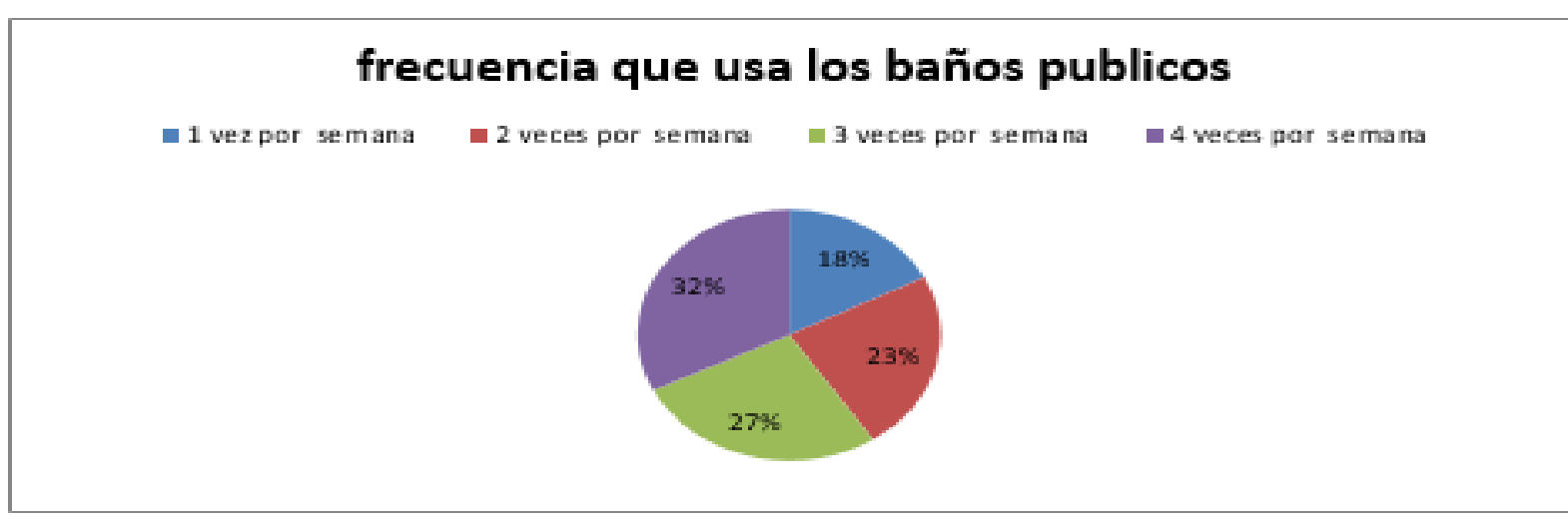

Elaboración propia.

Resultado: Del total de encuestadas, el 32.27\% afirmó que usa baños públicos por lo menos 4 veces por semana, mientras que el $17.44 \%$, el $23.26 \%$, y el $27.03 \%$, lo utilizan una, dos y tres veces por semana respectivamente. 
Tabla 19.

¿Usted cree que el estado de los baños podría afectar su salud?

\begin{tabular}{|c|c|c|c|c|c|c|c|c|c|c|c|c|c|c|}
\hline Respuestas & $\begin{array}{l}\text { JESUS } \\
\text { MARIA }\end{array}$ & LINCE & $\begin{array}{l}\text { PUEBLO } \\
\text { LIBRE }\end{array}$ & MAGDALENA & $\begin{array}{c}\text { SAN } \\
\text { MIGUEL }\end{array}$ & MIRAFLORES & $\begin{array}{c}\text { SAN } \\
\text { ISIDRO }\end{array}$ & SURCO & $\begin{array}{c}\text { SAN } \\
\text { BORJA }\end{array}$ & $\begin{array}{c}\text { LA } \\
\text { MOLINA }\end{array}$ & BARRANCO & SURQUILLO & TOTAL & $\%$ \\
\hline Niños & 7 & 6 & 8 & 6 & 14 & 8 & 1 & 22 & 10 & 19 & 1 & 5 & 107 & $31.10 \%$ \\
\hline Mujeres & 8 & 6 & 10 & 7 & 16 & 9 & 7 & 62 & 13 & 23 & 1 & 11 & 173 & $50.29 \%$ \\
\hline Hombres & 1 & 1 & 0 & 0 & 1 & 2 & 1 & 1 & 1 & 1 & 3 & 0 & 12 & $3.49 \%$ \\
\hline Ancianos & 3 & 2 & 3 & 2 & 6 & 4 & 6 & 6 & 6 & 4 & 3 & 7 & 52 & $15.12 \%$ \\
\hline TOTAL & 19 & 15 & 21 & 15 & 37 & 23 & 15 & 91 & 30 & 47 & 8 & 23 & 344 & $100.00 \%$ \\
\hline
\end{tabular}

Nota: Tabla elaborada con los datos obtenidos de la pregunta 3 del cuestionario.

Elaboración Propia.

Figura 27. ¿Considera que los baños públicos podrían afectar su salud?

Sector de la poblacion que es afecta segun el estado de

los baños publicos

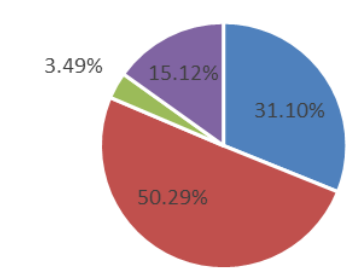

- NIÑOS - HOMBRES - MUJERES - ANCIANOS

Elaboración propia.

Resultado: Según la encuesta realizada, el sector más afectado serían las mujeres con un $50.3 \%$, seguido por los niños con un $31.1 \%$, los ancianos con $15.1 \%$ y los hombres solo con un $3.5 \%$. 
Tabla 20

¿Conoce algún producto que le permita evitar el contacto de su piel con el inodoro al usar los baños públicos?FILTRO 1

\begin{tabular}{|c|c|c|c|c|c|c|c|c|c|c|c|c|c|c|}
\hline Respuestas & $\begin{array}{l}\text { JESUS } \\
\text { MARIA }\end{array}$ & LINCE & $\begin{array}{l}\text { PUEBLO } \\
\text { LIBRE }\end{array}$ & MAGDALENA & $\begin{array}{c}\text { SAN } \\
\text { MIGUEL }\end{array}$ & MIRAFLORES & $\begin{array}{c}\text { SAN } \\
\text { ISIDRO }\end{array}$ & SURCO & $\begin{array}{c}\text { SAN } \\
\text { BORJA }\end{array}$ & $\begin{array}{c}\text { LA } \\
\text { MOLINA }\end{array}$ & BARRANCO & SURQUILLO & TOTAL & $\%$ \\
\hline Conozco totalmente & 4 & 4 & 4 & 2 & 9 & 2 & 1 & 30 & 3 & 12 & 1 & 1 & 73 & $21.22 \%$ \\
\hline Conozco parcialmente & 6 & 3 & 3 & 3 & 9 & 5 & 1 & 20 & 9 & 9 & 1 & 2 & 71 & $20.64 \%$ \\
\hline indeciso & 2 & 3 & 4 & 4 & 7 & 4 & 3 & 5 & 5 & 9 & 1 & 3 & 50 & $14.53 \%$ \\
\hline Desconozco & 4 & 2 & 4 & 2 & 6 & 5 & 3 & 20 & 9 & 9 & 1 & 6 & 71 & $20.64 \%$ \\
\hline Desconozco totalmente & 3 & 3 & 6 & 4 & 6 & 7 & 7 & 16 & 4 & 8 & 4 & 11 & 79 & $22.97 \%$ \\
\hline TOTAL & 19 & 15 & 21 & 15 & 37 & 23 & 15 & 91 & 30 & 47 & 8 & 23 & 344 & $100.00 \%$ \\
\hline
\end{tabular}

Nota: Tabla elaborada con los datos obtenidos de la pregunta 4 del cuestionario.

Elaboración propia.

Figura 28. ¿Conoce algún producto que le permita evitar el contacto de su piel con el inodoro al usar los baños públicos?

\section{Conocimiento de producto para evitar contacto de la piel con el inodoro}

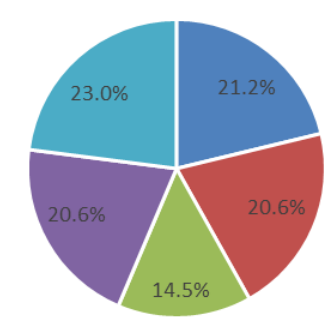

- conozco totalmente

- conozco parcialmente

- DESCONOZCO I- DESCONOZCO TOTALMENTE

Elaboración propia.

Resultado: Del total de encuestadas el $9.6 \%$ manifestó que conoce totalmente el producto y el $16.6 \%$ lo conoce parcialmente, por otro lado el $15.7 \%$ se mostró indeciso en su respuesta y el $23.8 \%$ y el $34.2 \%$ manifiesta que desconoce y desconoce totalmente el producto respectivamente. 
Tabla 21.

¿Ha Utilizado este tipo de productos? FILTRO 2

\begin{tabular}{|c|c|c|c|c|c|c|c|c|c|c|c|c|c|c|}
\hline Respuestas & $\begin{array}{l}\text { JESUS } \\
\text { MARIA }\end{array}$ & LINCE & $\begin{array}{l}\text { PUEBLO } \\
\text { LIBRE }\end{array}$ & MAGDALENA & $\begin{array}{c}\text { SAN } \\
\text { MIGUEL }\end{array}$ & MIRAFLORES & $\begin{array}{l}\text { SAN } \\
\text { ISIDRO }\end{array}$ & SURCO & $\begin{array}{c}\text { SAN } \\
\text { BORJA }\end{array}$ & $\begin{array}{c}\text { LA } \\
\text { MOLINA }\end{array}$ & BARRANCO & $\begin{array}{c}\text { SURQUI } \\
\text { LLO }\end{array}$ & TOTAL & $\%$ \\
\hline Muy Frecuentemente & 2 & 2 & 1 & 1 & 4 & 1 & 1 & 13 & 4 & 7 & 1 & 1 & 38 & $26.39 \%$ \\
\hline Frecuentemente & 2 & 2 & 2 & 1 & 5 & 2 & 1 & 9 & 3 & 5 & 1 & 1 & 34 & $23.61 \%$ \\
\hline Ocasionalmente & 1 & 1 & 1 & 2 & 6 & 1 & 0 & 10 & 1 & 7 & 0 & 0 & 30 & $20.83 \%$ \\
\hline Raramente & 2 & 0 & 1 & 0 & 0 & 1 & 0 & 13 & 1 & 2 & 0 & 0 & 20 & $13.89 \%$ \\
\hline Nunca & 3 & 2 & 2 & 1 & 3 & 2 & 0 & 5 & 3 & 0 & 0 & 1 & 22 & $15.28 \%$ \\
\hline TOTAL & 10 & 7 & 7 & 5 & 18 & 7 & 2 & 50 & 12 & 21 & 2 & 3 & 144 & $\begin{array}{c}100.00 \\
\%\end{array}$ \\
\hline
\end{tabular}

Nota: Tabla elaborada con los datos obtenidos de la pregunta 5 del cuestionario. Elaboración propia.

Figura 29. ¿Ha Utilizado este tipo de productos?

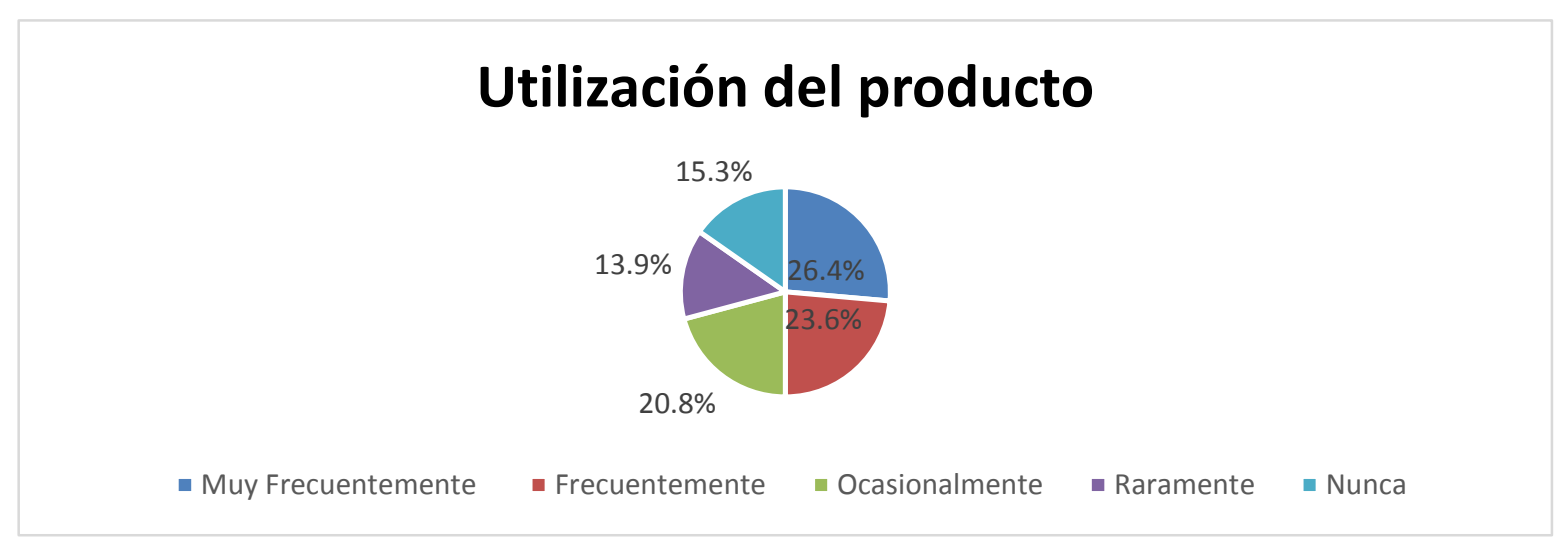

Elaboración propia.

Resultado: Respecto a la utilización del producto se tiene que el $26.4 \%$ manifiesta que muy frecuentemente ha utilizado el producto y el $23.1 \%$ lo ha utiliza frecuentemente, el $20.8 \%$ lo utiliza ocasionalmente, el $13.9 \%$ lo utiliza raramente y el $15.3 \%$ nunca ha utilizado el producto. 
Tabla 22.

Si su respuesta a la pregunta 4 fue Indeciso, Desconozco o Desconozco totalmente, Nos gustaría conocer las razones de su respuesta

\begin{tabular}{|c|c|c|c|c|c|c|c|c|c|c|c|c|c|c|}
\hline Respuestas & $\begin{array}{l}\text { JESUS } \\
\text { MARIA }\end{array}$ & LINCE & $\begin{array}{l}\text { PUEBLO } \\
\text { LIBRE }\end{array}$ & MAGDALENA & $\begin{array}{c}\text { SAN } \\
\text { MIGUEL }\end{array}$ & MIRAFLORES & $\begin{array}{l}\text { SAN } \\
\text { ISIDRO }\end{array}$ & SURCO & $\begin{array}{c}\text { SAN } \\
\text { BORJA }\end{array}$ & $\begin{array}{c}\text { LA } \\
\text { MOLINA }\end{array}$ & BARRANCO & SURQUILLO & TOTAL & $\%$ \\
\hline $\begin{array}{l}\text { Desconocía la } \\
\text { existencia del } \\
\text { producto }\end{array}$ & 1 & 1 & 3 & (6) & 7 & 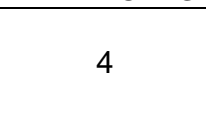 & 3 & 15 & 5 & 6 & 1 & - & 54 & $27.00 \%$ \\
\hline $\begin{array}{l}\text { No lo considero } \\
\text { necesario }\end{array}$ & 5 & 3 & 2 & 2 & 4 & 1 & 2 & 12 & 4 & 4 & 1 & 1 & 41 & $20.50 \%$ \\
\hline $\begin{array}{l}\text { Considero que puede } \\
\text { tener un precio alto }\end{array}$ & 1 & 2 & 2 & 3 & 5 & 3 & 2 & 5 & 2 & 4 & 1 & 5 & 35 & $17.50 \%$ \\
\hline $\begin{array}{l}\text { Desconozco donde lo } \\
\text { venden }\end{array}$ & 1 & 1 & 3 & 2 & 2 & 4 & 3 & 6 & 4 & 5 & 2 & 6 & 39 & $19.50 \%$ \\
\hline Otros & 1 & 1 & 4 & 1 & 1 & 4 & 3 & 3 & 3 & 7 & 1 & 2 & 31 & $15.50 \%$ \\
\hline Total & 9 & 8 & 14 & 10 & 19 & 16 & 13 & 41 & 18 & 26 & 6 & 20 & 200 & $100.00 \%$ \\
\hline
\end{tabular}

Nota: Tabla elaborada con los datos obtenidos de la pregunta 6 del cuestionario. Elaboración propia.

Figura 30.Razones por las que no compra el producto

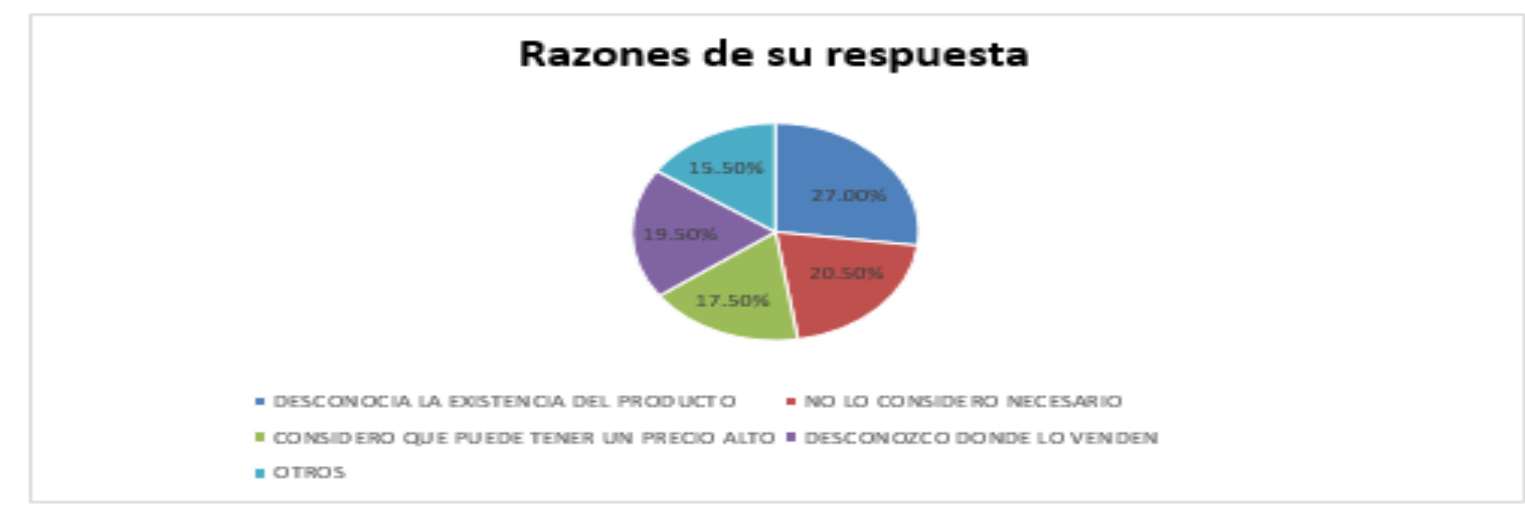

Elaboración propia.

Resultado: Las razones por las cuales no compraban el producto, el 27\% de las encestadas manifestaron que desconocían la existencia del producto, el $20.5 \%$ que no lo consideraban necesario, el 19.5\% desconocía donde lo venden, el 17.5\% consideraban que desconocían donde lo venden y el $15.5 \%$ por otras razones. 
Tabla 23.

Si Ud. conoce el producto ¿Qué marcas de cobertor sanitario para inodoro ha visto en el mercado?

\begin{tabular}{|c|c|c|c|c|c|c|c|c|c|c|c|c|c|c|}
\hline Respuestas & $\begin{array}{l}\text { JESUS } \\
\text { MARIA }\end{array}$ & LINCE & $\begin{array}{c}\text { PUEBLO } \\
\text { LIBRE }\end{array}$ & MAGDALENA & $\begin{array}{c}\text { SAN } \\
\text { MIGUEL }\end{array}$ & MIRAFLORES & $\begin{array}{c}\text { SAN } \\
\text { ISIDRO }\end{array}$ & SURCO & $\begin{array}{c}\text { SAN } \\
\text { BORJA }\end{array}$ & $\begin{array}{c}\text { LA } \\
\text { MOLINA }\end{array}$ & BARRANCO & SURQUILLO & TOTAL & $\%$ \\
\hline Flushables & 2 & 1 & 2 & 1 & 2 & 1 & 1 & 7 & 3 & 5 & 0 & 1 & 26 & $18.06 \%$ \\
\hline WC Protect & 3 & 1 & 1 & 1 & 3 & 2 & 1 & 4 & 2 & 6 & 0 & 1 & 25 & $17.36 \%$ \\
\hline Coversit & 1 & 2 & 1 & 1 & 4 & 1 & 1 & 6 & 4 & 3 & 0 & 1 & 25 & $17.36 \%$ \\
\hline $\begin{array}{l}\text { Protector sanitario } \\
\text { Maxilimpio }\end{array}$ & 2 & 1 & 1 & 0 & 1 & 2 & 0 & 3 & 2 & 4 & 1 & 1 & 18 & $12.50 \%$ \\
\hline producto en plaza norte & 1 & 1 & 1 & 1 & 2 & 3 & 1 & 8 & 2 & 4 & 1 & 1 & 26 & $18.06 \%$ \\
\hline $\begin{array}{l}\text { Producto encontrado en } \\
\text { totus - Queen }\end{array}$ & 1 & 1 & 3 & 1 & 5 & 2 & 1 & 7 & 4 & 6 & 1 & 1 & 33 & $22.92 \%$ \\
\hline total & 10 & 7 & 7 & 5 & 18 & 7 & 2 & 50 & 12 & 21 & 2 & 3 & 144 & $100.00 \%$ \\
\hline
\end{tabular}

Nota: Tabla elaborada con los datos obtenidos de la pregunta 7 del cuestionario. Elaboración propia.

Figura 31. ¿Qué marcas de protectores conoce?

\section{Marcas de cobertor}

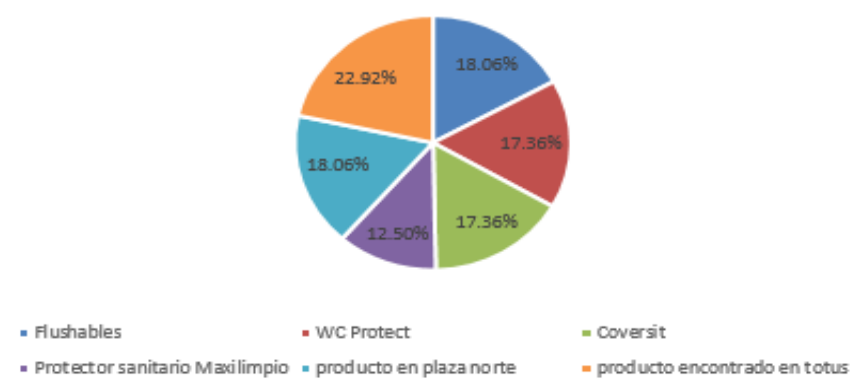

- Protector sanitario Maxilimpio - producto en plaza norte = producto encontrado en totus

Elaboración propia.

Resultado: El 22.92\% manifiesta que conoce la marca encontrada en Tottus-Queen, el17.36\% manifiesta que conoce la marca Coversit, el $18.06 \%$ la marca Flushables, el $12.50 \%$ conoce la marca maxilimpio y solo el $17.36 \%$ la marca Wc Protect, lo cual muestra que la marca más conocida en el mercado es la Coversit. 
Tabla 24.

¿De las marcas mencionadas en la pregunta anterior, Que marca de cobertor sanitario para inodoro es la que Ud. Utiliza actualmente?

\begin{tabular}{|c|c|c|c|c|c|c|c|c|c|c|c|c|c|c|}
\hline Respuestas & $\begin{array}{l}\text { JESUS } \\
\text { MARIA }\end{array}$ & LINCE & $\begin{array}{l}\text { PUEBLO } \\
\text { LIBRE }\end{array}$ & MAGDALENA & $\begin{array}{l}\text { SAN } \\
\text { MIGUEL }\end{array}$ & MIRAFLORES & $\begin{array}{l}\text { SAN } \\
\text { ISIDRO }\end{array}$ & SURCO & $\begin{array}{c}\text { SAN } \\
\text { BORJA }\end{array}$ & $\begin{array}{c}\text { LA } \\
\text { MOLINA }\end{array}$ & BARRANCO & SURQUILLO & TOTAL & $\%$ \\
\hline Flushables & 3 & 3 & 4 & 2 & 5 & 3 & 1 & 8 & 2 & 7 & 1 & 1 & 40 & $27.78 \%$ \\
\hline WC Protect & 2 & 1 & 2 & 2 & 2 & 4 & 1 & 5 & 3 & 5 & 1 & 2 & 30 & $20.83 \%$ \\
\hline $\begin{array}{l}\text { Producto encontrado en } \\
\text { tottus }\end{array}$ & 1 & 2 & 1 & 2 & 4 & 2 & 1 & 13 & 5 & 8 & 1 & 1 & 41 & $28.47 \%$ \\
\hline Coversit & 2 & 1 & 2 & 2 & 6 & 2 & 2 & 5 & 7 & 2 & 0 & 2 & 33 & $22.92 \%$ \\
\hline total & 10 & 7 & 7 & 5 & 18 & 7 & 2 & 50 & 12 & 21 & 2 & 3 & 144 & $100.00 \%$ \\
\hline
\end{tabular}

Nota: Tabla elaborada con los datos obtenidos de la pregunta 8 del cuestionario. Elaboración propia.

Figura 32. ¿Qué marca de cobertor sanitario para inodoro es la que Ud. Utiliza actualmente?

\section{Marcas de cobertor que utiliza actualmente}

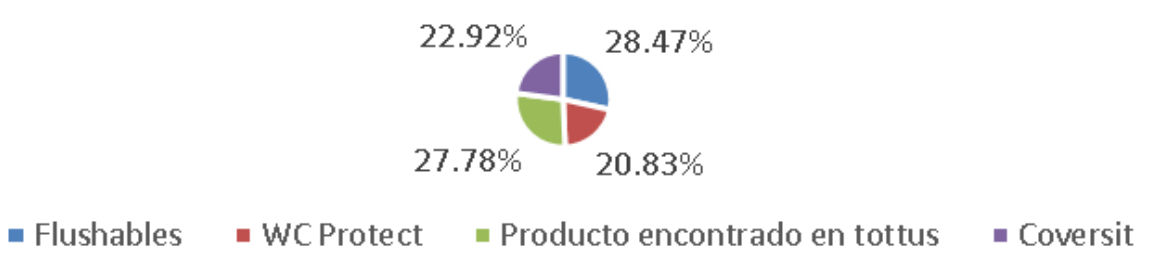

Elaboración propia.

Resultado: Del total de encuestadas tenemos que lamarca que más se utiliza es Producto encontrado en Tottus-Queen con un 28.4\%, seguido de la marca Flushables con $27.78 \%$, Wc protect con $20.83 \%$, y finalmente el protector sanitario Maxilimpio con un $22.9 \%$. 
Tabla 25.

Regularmente, cuando hace uso de un baño público, en qué lugares utiliza el cobertor sanitario para inodoros.

\begin{tabular}{|c|c|c|c|c|c|c|c|c|c|c|c|c|c|c|}
\hline Respuestas & $\begin{array}{l}\text { JESUS } \\
\text { MARIA }\end{array}$ & LINCE & $\begin{array}{l}\text { PUEBLO } \\
\text { LIBRE }\end{array}$ & MAGDALENA & $\begin{array}{c}\text { SAN } \\
\text { MIGUEL }\end{array}$ & MIRAFLORES & $\begin{array}{l}\text { SAN } \\
\text { ISIDRO }\end{array}$ & SURCO & $\begin{array}{l}\text { SAN } \\
\text { BORJA }\end{array}$ & $\begin{array}{c}\text { LA } \\
\text { MOLINA }\end{array}$ & BARRANCO & SURQUILLO & Total & $\%$ \\
\hline En su centro de trabajo & 1 & 1 & 1 & 1 & 2 & 1 & 0 & 3 & 1 & 2 & 0 & 0 & 13 & $9.03 \%$ \\
\hline En Restaurantes & 2 & 1 & 1 & 1 & 2 & 3 & 1 & 5 & 3 & 5 & 1 & 2 & 27 & $18.75 \%$ \\
\hline En Supermercados & 2 & 2 & 2 & 2 & 3 & 3 & 1 & 8 & 5 & 6 & 1 & 1 & 36 & $25.00 \%$ \\
\hline En su centro de estudios & 1 & 1 & 2 & 2 & 2 & 1 & 1 & 5 & 2 & 2 & 0 & 1 & 20 & $13.89 \%$ \\
\hline $\begin{array}{l}\text { En Centros comerciales y } \\
\text { otros }\end{array}$ & 2 & 2 & 3 & 2 & 8 & 3 & 2 & 10 & 6 & 7 & 1 & 2 & 48 & $33.33 \%$ \\
\hline TOTAL & 8 & 7 & 9 & 8 & 17 & 11 & 5 & 31 & 17 & 22 & 3 & 6 & 144 & $100.00 \%$ \\
\hline
\end{tabular}

Nota: Tabla elaborada con los datos obtenidos de la pregunta 9 del cuestionario. Elaboración propia.

Figura 33. ¿Con qué frecuencia compraría usted el cobertor sanitario para inodoro? Frecuencia semanal de compra por el público objetivo.

\section{Lugares que usa los baños publicos}

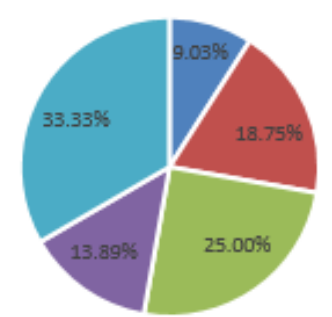

- En su centro de trabajo - En Restaurantes a En Supermercados - En su centro de estudios a En centros comercilas y otros

\section{Elaboración propia.}

Resultado: Del total de encuestadas las personas usan los servicios higiénicos en los centros comerciales con un $33.3 \%$, luego el $25 \%$ en los supermercados, en Restaurantes el $18.75 \%$, En su centro de estudios el $13.89 \%$ yen su centro de trabajo el $9.03 \%$ 
Tabla 26.

Si se ofrece un nuevo cobertor sanitario para inodoro que presenta los siguientes atributos, Garantiza el cuidado de su salud, calidad por encima de los productos de lacompetencia, precios adecuados y que se encuentren en puntos de ventas accesibles;Que tan importante le parecen los atributos del producto?

\begin{tabular}{|c|c|c|c|c|c|c|c|c|c|c|c|c|c|c|}
\hline Respuestas & $\begin{array}{l}\text { JESUS } \\
\text { MARIA }\end{array}$ & LINCE & $\begin{array}{l}\text { PUEBLO } \\
\text { LIBRE }\end{array}$ & MAGDALENA & $\begin{array}{l}\text { SAN } \\
\text { MIGUEL }\end{array}$ & MIRAFLORES & $\begin{array}{l}\text { SAN } \\
\text { ISIDRO }\end{array}$ & $\begin{array}{l}\text { SAN } \\
\text { BORJA }\end{array}$ & SURCO & $\begin{array}{c}\text { LA } \\
\text { MOLINA }\end{array}$ & BARRANCO & SURQUILLO & Total & $\%$ \\
\hline Muy importantes & 1 & 3 & 2 & 2 & 9 & 5 & 2 & 28 & 8 & 10 & 2 & 10 & 82 & $27.06 \%$ \\
\hline importantes & 3 & 4 & 3 & 3 & 6 & 6 & 6 & 25 & 3 & 8 & 2 & 6 & 75 & $24.75 \%$ \\
\hline indeciso & 2 & 2 & 3 & 1 & 6 & 7 & 3 & 12 & 6 & 12 & 1 & 3 & 58 & $19.14 \%$ \\
\hline $\begin{array}{l}\text { no lo considera } \\
\text { importante }\end{array}$ & 5 & 2 & 6 & 2 & 6 & 2 & 1 & 10 & 3 & 6 & 1 & 1 & 45 & $14.85 \%$ \\
\hline $\begin{array}{l}\text { no tiene ningun grado } \\
\text { de Importancia }\end{array}$ & 3 & 1 & 5 & 5 & 6 & 2 & 1 & 4 & 6 & 7 & 1 & 2 & 43 & $14.19 \%$ \\
\hline Total & 14 & 12 & 19 & 13 & 33 & 22 & 13 & 79 & 26 & 43 & 7 & 22 & 303 & $100.00 \%$ \\
\hline
\end{tabular}

Nota: Tabla elaborada con los datos obtenidos de la pregunta 10 del cuestionario. Elaboración propia.

Figura 34. ¿Qué tan importante le parecen los atributos del producto?

\section{Importancia de los atributos de un nuevo} cobertor

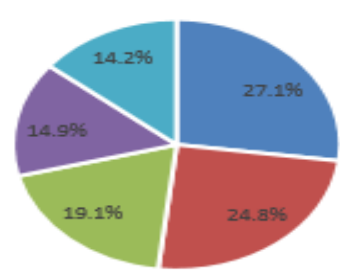

- Muy importante - Importante $A$ indeciso - no lo considera importante - no tieneningun gado de competencia

\section{Elaboración propia.}

Resultado: Del total de encuestadas el $27.1 \%$ considera muy importante los atributos de un nuevo cobertor, el $24.8 \%$

Importante, el $19.1 \%$ indeciso, el $14.9 \%$ no lo considera importante y el $14.2 \%$ no tiene ningún grado de competencia. 
Tabla 27.

De los atributos mencionados ¿Cuál considera más importante?

\begin{tabular}{|c|c|c|c|c|c|c|c|c|c|c|c|c|c|c|}
\hline Respuestas & $\begin{array}{l}\text { JESUS } \\
\text { MARIA }\end{array}$ & LINCE & $\begin{array}{c}\text { PUEBLO } \\
\text { LIBRE }\end{array}$ & MAGDALENA & $\begin{array}{c}\text { SAN } \\
\text { MIGUEL }\end{array}$ & MIRAFLORES & $\begin{array}{c}\text { SAN } \\
\text { ISIDRO }\end{array}$ & $\begin{array}{c}\text { SAN } \\
\text { BORJA }\end{array}$ & SURCO & $\begin{array}{c}\text { LA } \\
\text { MOLINA }\end{array}$ & BARRANCO & SURQUILLO & Total & $\%$ \\
\hline cuidado de la salud & 7 & 5 & 5 & 6 & 12 & 9 & 6 & 39 & 11 & 14 & 3 & 11 & 128 & $42.24 \%$ \\
\hline calidad del producto & 2 & 3 & 3 & 2 & 8 & 8 & 3 & 17 & 6 & 11 & 2 & 6 & 71 & $23.43 \%$ \\
\hline puntos de ventas accesibles & 2 & 2 & 7 & 2 & 6 & 3 & 2 & 10 & 3 & 8 & 1 & 2 & 48 & $15.84 \%$ \\
\hline precio competitivo & 3 & 2 & 4 & 3 & 7 & 2 & 2 & 13 & 6 & 10 & 1 & 3 & 56 & $18.48 \%$ \\
\hline Total & 14 & 12 & 19 & 13 & 33 & 22 & 13 & 79 & 26 & 43 & 7 & 22 & 303 & $100.00 \%$ \\
\hline
\end{tabular}

Nota: Tabla elaborada con los datos obtenidos de la pregunta 11 del cuestionario. Elaboración propia.

Figura 35. De los atributos mencionados ¿Cuál considera más importante?

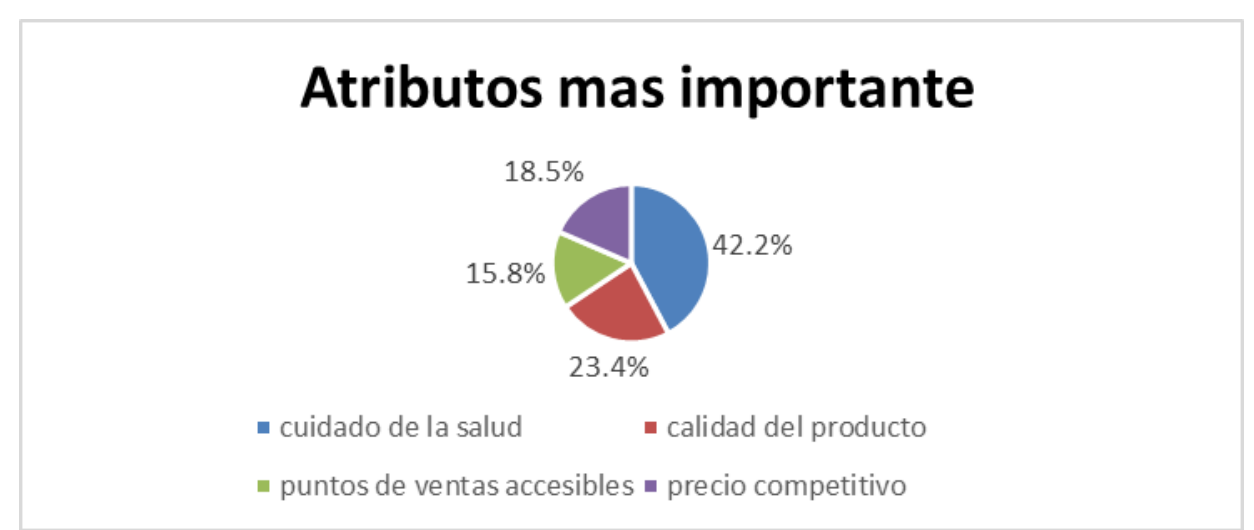

Elaboración propia.

Resultado: El 42.2\% de las encuestadas manifiesta que el atributomás importante es el cuidado de la salud, el $23.4 \%$ manifiesta que es la calidad del producto, el $15.8 \%$ considera importante que tenga puntos de ventas accesibles y el $18.5 \%$ que tenga precios competitivos. 
Tabla 28.

¿Cuál es la presentación del cobertor sanitario para inodoro que sería de su preferencia?

\begin{tabular}{|c|c|c|c|c|c|c|c|c|c|c|c|c|c|c|}
\hline Respuestas & $\begin{array}{l}\text { JESUS } \\
\text { MARIA }\end{array}$ & LINCE & $\begin{array}{l}\text { PUEBLO } \\
\text { LIBRE }\end{array}$ & MAGDALENA & $\begin{array}{c}\text { SAN } \\
\text { MIGUEL }\end{array}$ & MIRAFLORES & $\begin{array}{c}\text { SAN } \\
\text { ISIDRO }\end{array}$ & $\begin{array}{c}\text { SAN } \\
\text { BORJA }\end{array}$ & SURCO & $\begin{array}{c}\text { LA } \\
\text { MOLINA }\end{array}$ & BARRANCO & SURQUILLO & Total & $\%$ \\
\hline Pack con 05 Unidades & 4 & 2 & 3 & 2 & 7 & 3 & 2 & 14 & 6 & 5 & 2 & 5 & 55 & $18.15 \%$ \\
\hline Pack con 10 Unidades & 6 & 7 & 12 & 6 & 15 & 8 & 6 & 35 & 9 & 17 & 3 & 9 & 133 & $43.89 \%$ \\
\hline Pack con 15 Unidades & 4 & 3 & 4 & 5 & 11 & 11 & 5 & 30 & 11 & 21 & 2 & 8 & 115 & $37.95 \%$ \\
\hline Total & 14 & 12 & 19 & 13 & 33 & 22 & 13 & 79 & 26 & 43 & 7 & 22 & 303 & $100.00 \%$ \\
\hline
\end{tabular}

Nota: Tabla elaborada con los datos obtenidos de la pregunta 12 del cuestionario. Elaboración propia.

Figura 36. ¿Cuál es la presentación del cobertor sanitario para inodoro que sería de su preferencia?

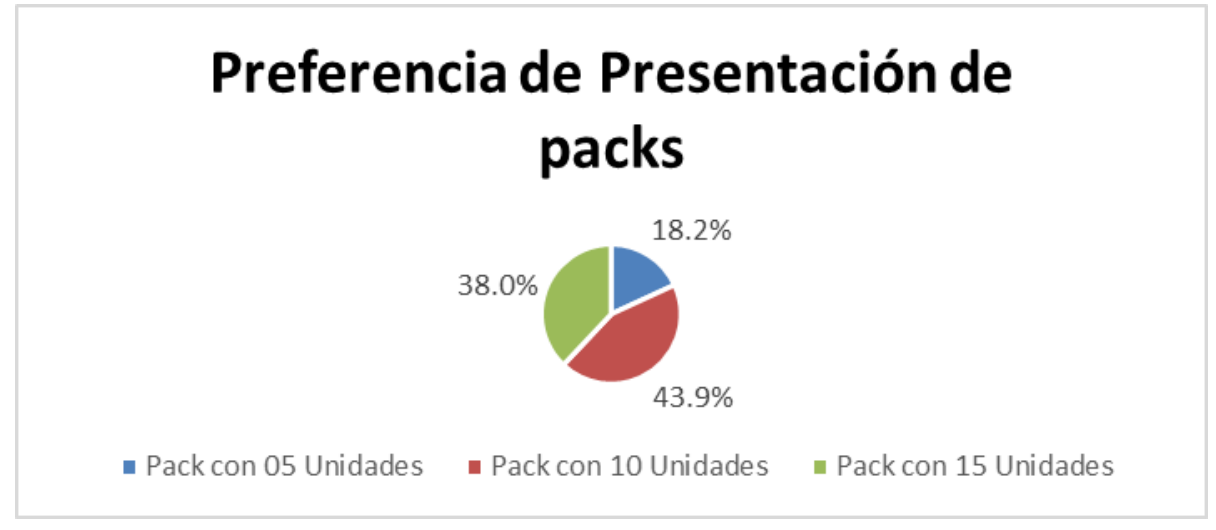

Elaboración propia.

Resultado: Del total de encuestadas que estaría dispuesto a comprar el pack con 10 unidades abarcando el $43.9 \%$, el $18.2 \%$ pack con 05 unidades y el $38 \%$ un pack con 15 unidades. 
Tabla 29.

¿En qué punto de venta le gustaría encontrar el pack del cobertor?

\begin{tabular}{|c|c|c|c|c|c|c|c|c|c|c|c|c|c|c|}
\hline Respuestas & $\begin{array}{l}\text { JESUS } \\
\text { MARIA }\end{array}$ & LINCE & $\begin{array}{c}\text { PUEBLO } \\
\text { LIBRE }\end{array}$ & MAGDALENA & $\begin{array}{c}\text { SAN } \\
\text { MIGUEL }\end{array}$ & MIRAFLORES & $\begin{array}{c}\text { SAN } \\
\text { ISIDRO }\end{array}$ & $\begin{array}{c}\text { SAN } \\
\text { BORJA }\end{array}$ & SURCO & $\begin{array}{c}\text { LA } \\
\text { MOLINA }\end{array}$ & BARRANCO & SURQUILLO & Total & $\%$ \\
\hline Supermercados & 5 & 5 & 6 & 6 & 12 & 9 & 6 & 39 & 11 & 14 & 3 & 11 & 127 & $54.74 \%$ \\
\hline Mercados & 2 & 3 & 2 & 2 & 8 & 8 & 3 & 17 & 6 & 11 & 2 & 6 & 70 & $30.17 \%$ \\
\hline Farmacias & 3 & 3 & 7 & 2 & 6 & 3 & 2 & 10 & 3 & 8 & 1 & 2 & 50 & $21.55 \%$ \\
\hline Tiendas de conveniencia & 4 & 1 & 4 & 3 & 7 & 2 & 2 & 13 & 6 & 10 & 1 & 3 & 56 & $24.14 \%$ \\
\hline Total & 14 & 12 & 19 & 13 & 33 & 22 & 13 & 79 & 26 & 43 & 7 & 22 & 303 & $130.60 \%$ \\
\hline
\end{tabular}

Nota: Tabla elaborada con los datos obtenidos de la pregunta 13 del cuestionario. Elaboración propia.

Figura 37. ¿En qué punto de venta le gustaría encontrar el pack del cobertor?

\section{Punto de venta que Ud le gustaria encontrar} los packs de los nuevos cobertores

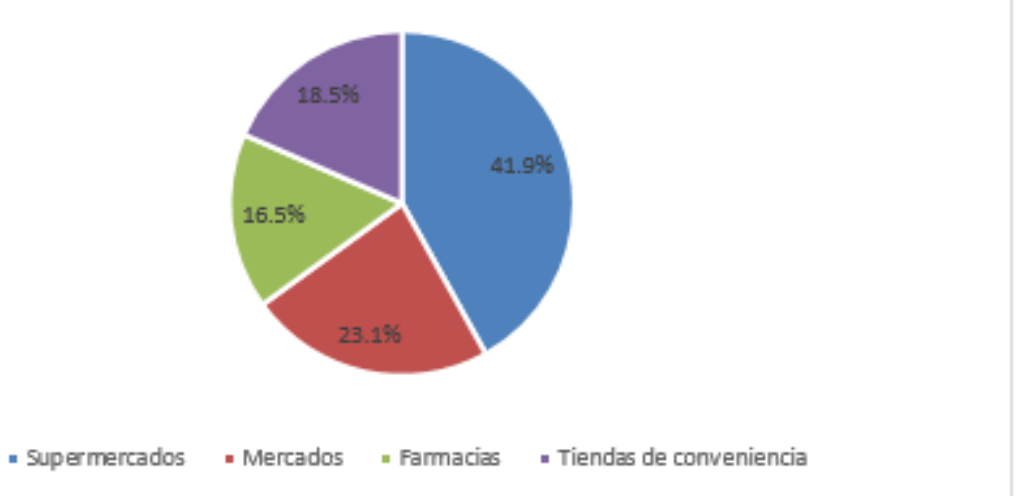

Elaboración propia.

Resultado: El 41.9\% de las encuestadas eligió los supermercados, el23.1\% prefirió el mercado,y el 18.5\% prefirió tiendas de conveniencia mientras que el $16.5 \%$ preferiría encontrarlo en farmacias 
Tabla 30. ¿En el punto de venta en que área le gustaría encontrar el pack del cobertor sanitario para inodoros?

\begin{tabular}{|c|c|c|c|c|c|c|c|c|c|c|c|c|c|c|}
\hline Respuestas & $\begin{array}{l}\text { JESUS } \\
\text { MARIA }\end{array}$ & LINCE & $\begin{array}{c}\text { PUEBLO } \\
\text { LIBRE }\end{array}$ & MAGDALENA & $\begin{array}{c}\text { SAN } \\
\text { MIGUEL }\end{array}$ & MIRAFLORES & $\begin{array}{c}\text { SAN } \\
\text { ISIDRO }\end{array}$ & $\begin{array}{l}\text { SAN } \\
\text { BORJA }\end{array}$ & SURCO & $\begin{array}{c}\text { LA } \\
\text { MOLINA }\end{array}$ & BARRANCO & SURQUILLO & TOTAL & $\%$ \\
\hline Belleza & 4 & 2 & 3 & 2 & 7 & 3 & 2 & 14 & 6 & 5 & 2 & 5 & 55 & $18.15 \%$ \\
\hline Cuidado Personal & 6 & 7 & 12 & 6 & 15 & 8 & 6 & 35 & 9 & 17 & 3 & 9 & 133 & $43.89 \%$ \\
\hline Higiene & 4 & 3 & 4 & 5 & 11 & 11 & 5 & 30 & 11 & 21 & 2 & 8 & 115 & $37.95 \%$ \\
\hline Total & 14 & 12 & 19 & 13 & 33 & 22 & 13 & 79 & 26 & 43 & 7 & 22 & 303 & $100.00 \%$ \\
\hline
\end{tabular}

Nota: Tabla elaborada con los datos obtenidos de la pregunta 14 del cuestionario. Elaboración propia.

Figura 38. ¿En el punto de venta en que área le gustaría encontrar el pack del cobertor sanitario para inodoros?

\section{Preferencia de ubicación en puntos de venta}

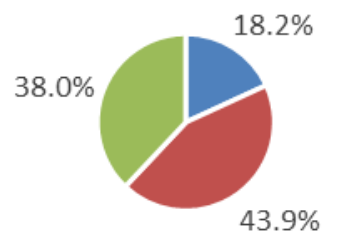

- Belleza - Cuidado Personal = Higiene

\section{Elaboración propia.}

Resultado: El 43.9\% consideró que el producto se debe ubicar en el área de cuidado personal, el 38\% prefirió el área de higiene, mientras que $18.2 \%$ prefirió el área de belleza. 
Tabla 31.

Con respecto a la compra ¿Cuál esla frecuencia con la que compra el producto o estaría dispuesto a comprarlo?

\begin{tabular}{|c|c|c|c|c|c|c|c|c|c|c|c|c|c|c|}
\hline Respuestas & $\begin{array}{l}\text { JESUS } \\
\text { MARIA }\end{array}$ & LINCE & $\begin{array}{c}\text { PUEBLO } \\
\text { LIBRE }\end{array}$ & MAGDALENA & $\begin{array}{c}\text { SAN } \\
\text { MIGUEL }\end{array}$ & MIRAFLORES & $\begin{array}{l}\text { SAN } \\
\text { ISIDRO }\end{array}$ & $\begin{array}{c}\text { SAN } \\
\text { BORJA }\end{array}$ & SURCO & $\begin{array}{c}\text { LA } \\
\text { MOLINA }\end{array}$ & BARRANCO & SURQUILLO & TOTAL & $\%$ \\
\hline 4 Veces por mes & 2 & 3 & 2 & 2 & 8 & 8 & 3 & 17 & 6 & 11 & 2 & 6 & 70 & $30.17 \%$ \\
\hline 3 Veces por mes & 4 & 1 & 4 & 3 & 7 & 2 & 2 & 13 & 6 & 10 & 1 & 3 & 56 & $24.14 \%$ \\
\hline 2 Veces por mes & 5 & 5 & 6 & 6 & 12 & 9 & 6 & 39 & 11 & 14 & 3 & 11 & 127 & $54.74 \%$ \\
\hline $1 \mathrm{vez}$ al mes & 3 & 3 & 7 & 2 & 6 & 3 & 2 & 10 & 3 & 8 & 1 & 2 & 50 & $21.55 \%$ \\
\hline Total & 14 & 12 & 19 & 13 & 33 & 22 & 13 & 79 & 26 & 43 & 7 & 22 & 303 & $130.60 \%$ \\
\hline
\end{tabular}

Nota: Tabla elaborada con los datos obtenidos de la pregunta 15 del cuestionario. Elaboración propia.

Figura 39. ¿Cuál esla frecuencia con la que compra el producto o estaría dispuesto a comprarlo?

\section{Frecuencia de compra del producto}

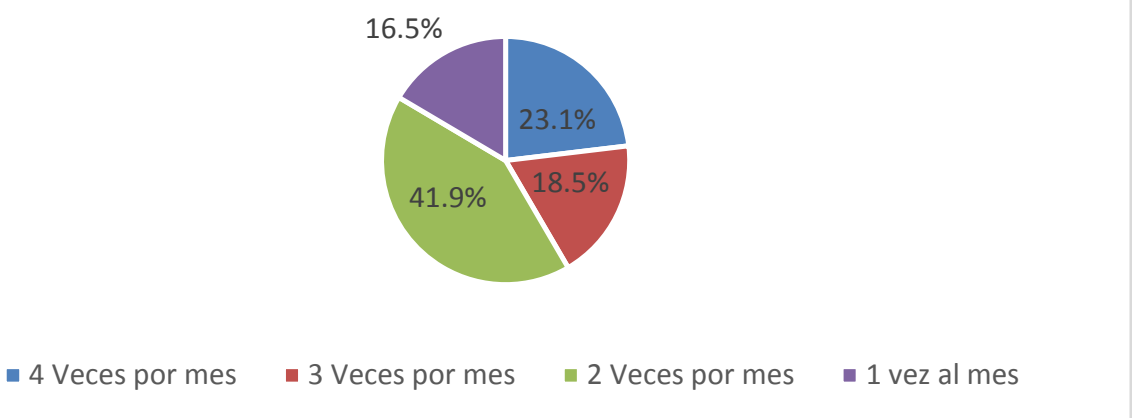

Elaboración propia.

Resultado: El $41.9 \%$ manifestó que compraría el producto 2 veces por mes, el $23.1 \% 4$ veces por mes,el $18.5 \% 3$ veces por mes mientras que el $16.5 \% 1$ vez al mes. 
Tabla 32.

Al momentode realizar de su compra ¿Cuantos paquetes del cobertor sanitario para inodoro compra o compraría?

\begin{tabular}{|c|c|c|c|c|c|c|c|c|c|c|c|c|c|c|}
\hline Respuestas & $\begin{array}{l}\text { JESUS } \\
\text { MARIA }\end{array}$ & LINCE & $\begin{array}{l}\text { PUEBLO } \\
\text { LIBRE }\end{array}$ & MAGDALENA & $\begin{array}{c}\text { SAN } \\
\text { MIGUEL }\end{array}$ & MIRAFLORES & $\begin{array}{c}\text { SAN } \\
\text { ISIDRO }\end{array}$ & $\begin{array}{c}\text { SAN } \\
\text { BORJA }\end{array}$ & SURCO & $\begin{array}{c}\text { LA } \\
\text { MOLINA }\end{array}$ & BARRANCO & SURQUILLO & TOTAL & $\%$ \\
\hline 1 paquete & 2 & 2 & 2 & 1 & 3 & 1 & 1 & 9 & 2 & 6 & 1 & 3 & 33 & $10.89 \%$ \\
\hline 2 paquetes & 5 & 4 & 6 & 4 & 10 & 5 & 3 & 13 & 7 & 7 & 1 & 3 & 68 & $22.44 \%$ \\
\hline 3 paquetes & 2 & 2 & 3 & 2 & 8 & 7 & 3 & 22 & 6 & 17 & 3 & 8 & 83 & $27.39 \%$ \\
\hline Mas de tres paquetes & 5 & 4 & 8 & 6 & 12 & 9 & 6 & 35 & 11 & 13 & 2 & 8 & 119 & $39.27 \%$ \\
\hline Total & 14 & 12 & 19 & 13 & 33 & 22 & 13 & 79 & 26 & 43 & 7 & 22 & 303 & $100.00 \%$ \\
\hline
\end{tabular}

Nota: Tabla elaborada con los datos obtenidos de la pregunta 16 del cuestionario. Elaboración propia.

Figura 40. ¿Cuantos paquetes del cobertor sanitario para inodoro compra o compraría?

\section{Numero de paquetes que \\ compra o compraría}

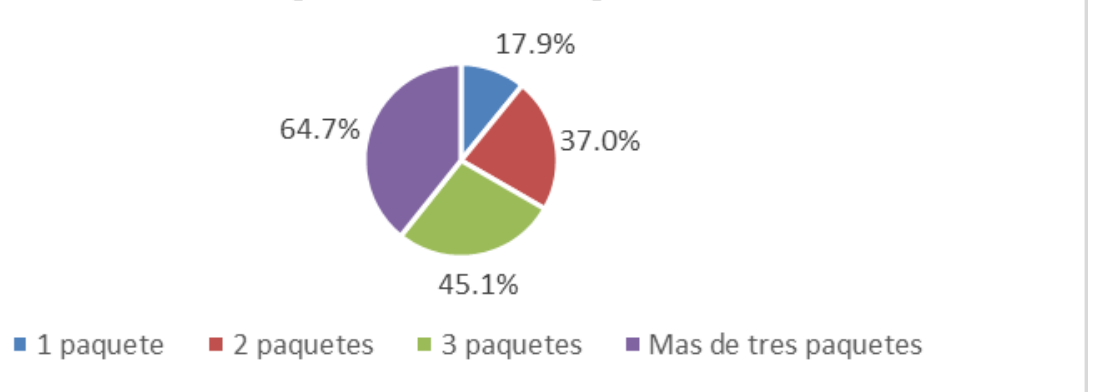

Elaboración propia.

Resultado: El 39.27 \% manifestó que compraría más de tres paquetes, el 27.39\%compraría 3 paquetes,el 22.44\% compraría 2paquetes mientras que el $10.89 \%$ solo compraría un paquete. 
Tabla 33.

¿Cuánto estaría Usted dispuesto a pagar por un pack de acuerdo a su elección de contenido?

\begin{tabular}{|c|c|c|c|c|c|c|c|c|c|c|c|c|c|c|}
\hline Respuestas & $\begin{array}{l}\text { JESUS } \\
\text { MARIA }\end{array}$ & LINCE & $\begin{array}{c}\text { PUEBLO } \\
\text { LIBRE }\end{array}$ & MAGDALENA & $\begin{array}{c}\text { SAN } \\
\text { MIGUEL }\end{array}$ & MIRAFLORES & $\begin{array}{l}\text { SAN } \\
\text { ISIDRO }\end{array}$ & $\begin{array}{c}\text { SAN } \\
\text { BORJA }\end{array}$ & SURCO & $\begin{array}{c}\text { LA } \\
\text { MOLINA }\end{array}$ & BARRANCO & SURQUILLO & TOTAL & $\%$ \\
\hline Entre $S / 1.50$ y $S / 2.00$ & 6 & 7 & 12 & 6 & 15 & 8 & 6 & 35 & 9 & 17 & 3 & 9 & 133 & $43.89 \%$ \\
\hline Entre S/2.01 y S/2.5 & 4 & 3 & 4 & 5 & 11 & 11 & 5 & 30 & 11 & 21 & 2 & 8 & 115 & $37.95 \%$ \\
\hline $\mathrm{De} S / 2.51$ a mas & 4 & 2 & 3 & 2 & 7 & 3 & 2 & 14 & 6 & 5 & 2 & 5 & 55 & $18.15 \%$ \\
\hline Total & 14 & 12 & 19 & 13 & 33 & 22 & 13 & 79 & 26 & 43 & 7 & 22 & 303 & $100.00 \%$ \\
\hline
\end{tabular}

Nota: Tabla elaborada con los datos obtenidos de la pregunta 17 del cuestionario. Elaboración propia.

Figura 41. ¿Cuánto estaría Usted dispuesto a pagar por un pack de acuerdo a su elección de contenido?

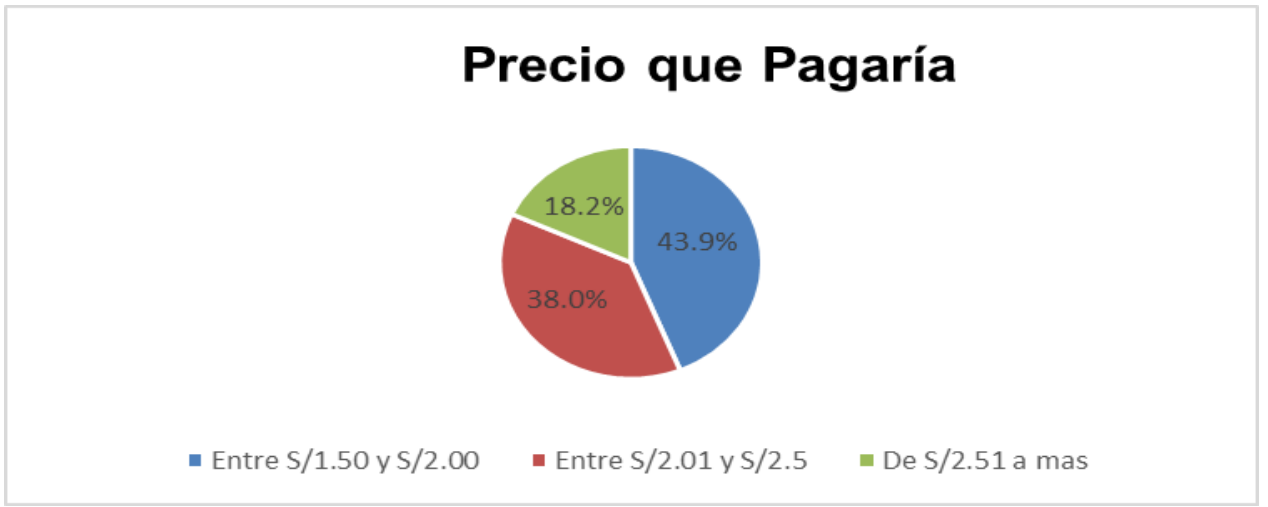

Elaboración propia.

Resultado: El 38\% eligió el precio entre 1.50 a 2.00 soles, el $43.9 \%$ prefirió el precio 2.01 a 2.50 soles, mientras que $18.2 \%$ prefirió el precio de 2.50 soles a más. 
Tabla 34.

Luego de la presentación e introducción de los atributos del nuevo cobertor sanitario para inodoros ¿Ud. Estaría dispuesto a comprarlo?

\begin{tabular}{|c|c|c|c|c|c|c|c|c|c|c|c|c|c|c|}
\hline Respuestas & $\begin{array}{l}\text { JESUS } \\
\text { MARIA }\end{array}$ & LINCE & $\begin{array}{c}\text { PUEBLO } \\
\text { LIBRE }\end{array}$ & MAGDALENA & $\begin{array}{c}\text { SAN } \\
\text { MIGUEL }\end{array}$ & MIRAFLORES & $\begin{array}{l}\text { SAN } \\
\text { ISIDRO }\end{array}$ & $\begin{array}{c}\text { SAN } \\
\text { BORJA }\end{array}$ & SURCO & $\begin{array}{c}\text { LA } \\
\text { MOLINA }\end{array}$ & BARRANCO & SURQUILLO & TOTAL & $\%$ \\
\hline Definitivamente si & 3 & 2 & 5 & 3 & 10 & 2 & 2 & 18 & 6 & 10 & 1 & 3 & 65 & $21.45 \%$ \\
\hline Probablemente Si & 5 & 4 & 7 & 5 & 12 & 10 & 5 & 34 & 11 & 13 & 2 & 8 & 116 & $38.28 \%$ \\
\hline Indiferente & 2 & 2 & 2 & 2 & 2 & 2 & 2 & 6 & 3 & 5 & 1 & 2 & 31 & $10.23 \%$ \\
\hline Probablemente No & 2 & 2 & 3 & 2 & 6 & 7 & 3 & 12 & 6 & 9 & 2 & 6 & 60 & $19.80 \%$ \\
\hline Definitivamente No & 2 & 2 & 2 & 1 & 3 & 1 & 1 & 9 & 0 & 6 & 1 & 3 & 31 & $10.23 \%$ \\
\hline Total & 14 & 12 & 19 & 13 & 33 & 22 & 13 & 79 & 26 & 43 & 7 & 22 & 303 & $100.00 \%$ \\
\hline
\end{tabular}

Nota: Tabla elaborada con los datos obtenidos de la pregunta 18 del cuestionario. Elaboración propia.

Figura 42. ¿Ud. Estaría dispuesto a comprarlo?

\section{Disposición de compra del nuevo producto}

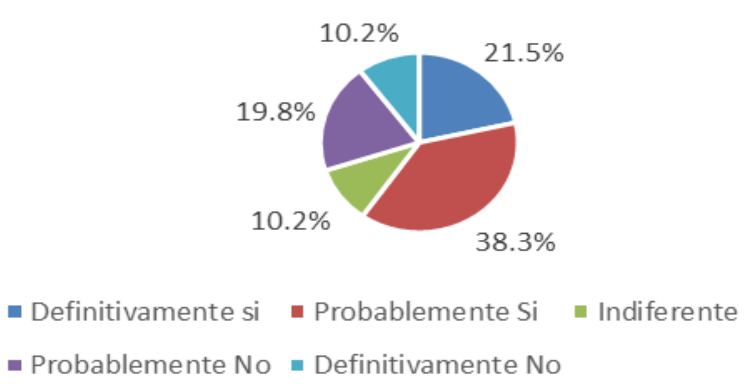

Elaboración propia.

Resultado: El 38.3\% de las encuestadas manifestó que probablemente sí compraría el producto, el 21.5\% definitivamente sí, el 19.8\% manifestó que probablemente no, el 10,2\% era indiferente y el mismo porcentaje manifestó que definitivamente no. 
Tabla 35.

Si su respuesta fue "Indiferente", "Probablemente No" y definitivamente No, ¿Nos gustaría conocer las razones? En el caso de que el encuestado responda esta pregunta se finaliza su encuesta.

\begin{tabular}{|c|c|c|c|c|c|c|c|c|c|c|c|c|c|c|}
\hline Respuestas & $\begin{array}{l}\text { JESUS } \\
\text { MARIA }\end{array}$ & LINCE & $\begin{array}{l}\text { PUEBLO } \\
\text { LIBRE }\end{array}$ & MAGDALENA & $\begin{array}{c}\text { SAN } \\
\text { MIGUEL }\end{array}$ & MIRAFLORES & $\begin{array}{l}\text { SAN } \\
\text { ISIDRO }\end{array}$ & $\begin{array}{l}\text { SAN } \\
\text { BORJA }\end{array}$ & SURCO & $\begin{array}{c}\text { LA } \\
\text { MOLINA }\end{array}$ & BARRANCO & SURQUILLO & TOTAL & $\%$ \\
\hline Uso complicado del producto & 0 & 1 & 1 & 0 & 2 & 3 & 2 & 7 & 2 & 5 & 1 & 1 & 25 & $22.32 \%$ \\
\hline $\begin{array}{l}\text { No me parece atractiva la } \\
\text { presentacion }\end{array}$ & 1 & 2 & 0 & 0 & 3 & 2 & 0 & 4 & 1 & 3 & 0 & 1 & 17 & $15.18 \%$ \\
\hline $\begin{array}{l}\text { Uso los baños publicos } \\
\text { esporadicamente }\end{array}$ & 1 & 0 & 2 & 1 & 2 & 1 & 2 & 6 & 2 & 2 & 0 & 2 & 21 & $18.75 \%$ \\
\hline $\begin{array}{l}\text { No considero que } \\
\text { necesariamente cuide la salud }\end{array}$ & 1 & 1 & 5 & 3 & 7 & 4 & 1 & 10 & 4 & 7 & 2 & 4 & 49 & $43.75 \%$ \\
\hline Total & 3 & 4 & 8 & 4 & 14 & 10 & 5 & 27 & 9 & 17 & 3 & 8 & 112 & $100.00 \%$ \\
\hline
\end{tabular}

Nota: Tabla elaborada con los datos obtenidos de la pregunta 19 del cuestionario. Elaboración propia

Figura 43. Razones por las que no compraría el producto

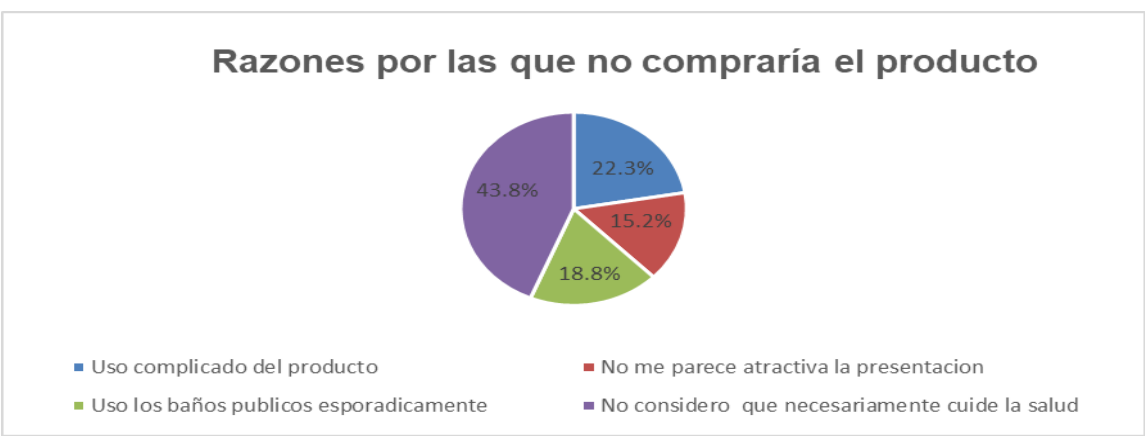

Elaboración propia.

Resultado: El 44.2\% de las encuestadas manifestó que no comprará el producto porque no considera que necesariamente cuide la salud, eligió, el $22.1 \%$ considera que uso es complicado, el $18.8 \%$ manifestó que usa baños públicos esporádicamente y el $15.2 \%$ que no le parece atractiva la presentación. 
Tabla 36.

¿Qué medio de comunicación considera el más importante para realizar la publicidad del cobertor sanitario para inodoros?

\begin{tabular}{|c|c|c|c|c|c|c|c|c|c|c|c|c|c|c|}
\hline Respuestas & $\begin{array}{l}\text { JESUS } \\
\text { MARIA }\end{array}$ & LINCE & $\begin{array}{c}\text { PUEBLO } \\
\text { LIBRE }\end{array}$ & MAGDALENA & $\begin{array}{c}\text { SAN } \\
\text { MIGUEL }\end{array}$ & MIRAFLORES & $\begin{array}{c}\text { SAN } \\
\text { ISIDRO }\end{array}$ & $\begin{array}{c}\text { SAN } \\
\text { BORJA }\end{array}$ & SURCO & $\begin{array}{c}\text { LA } \\
\text { MOLINA }\end{array}$ & BARRANCO & SURQUILLO & TOTAL & $\%$ \\
\hline TV & 1 & 1 & 1 & 1 & 3 & 1 & 1 & 3 & 2 & 2 & 0 & 2 & 18 & $5.94 \%$ \\
\hline Radio & 1 & 1 & 2 & 1 & 2 & 2 & 1 & 5 & 2 & 2 & 0 & 2 & 21 & $6.93 \%$ \\
\hline Revistas & 1 & 1 & 1 & 1 & 2 & 2 & 1 & 4 & 2 & 3 & 0 & 2 & 20 & $6.60 \%$ \\
\hline Redes Sociales & 3 & 2 & 3 & 3 & 6 & 4 & 3 & 20 & 6 & 8 & 2 & 3 & 63 & $20.79 \%$ \\
\hline Paginas Web & 2 & 1 & 1 & 2 & 2 & 1 & 1 & 9 & 4 & 4 & 1 & 2 & 30 & $9.90 \%$ \\
\hline Vallas & 0 & 0 & 1 & 0 & 1 & 1 & 0 & 2 & 1 & 1 & 0 & 0 & 7 & $2.31 \%$ \\
\hline Total & 8 & 6 & 9 & 8 & 16 & 11 & 7 & 43 & 17 & 20 & 3 & 11 & 159 & $52.48 \%$ \\
\hline
\end{tabular}

Nota: Tabla elaborada con los datos obtenidos de la pregunta 20 del cuestionario. Elaboración propia.

Figura 44. ¿Qué medio de comunicación considera el más viable para realizar la publicidad del cobertor sanitario para inodoros?34

Medio de comunicacion que generaria mayor

impacto en la venta de cobertor sanitario

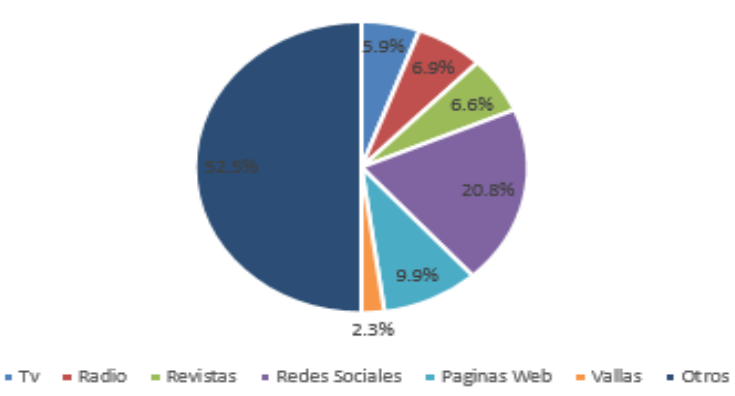

Elaboración propia.

Resultado: El 20.8\% de las encuestadas consideró que las redes sociales son el medio más adecuado para dar a conocer el producto, el $5.9 \%$ la televisión, el $6.9 \%$ la radio, el $6.6 \%$ las revistas, el $9.9 \%$ las páginas web y solo el 2.3 las vallas publicitarias. 
Luego de haber realizado el análisis de la investigación cuantitativa, a través de la realización de 384 encuestas, se obtuvo las siguientes conclusiones:

a. En lo referente a la utilización de baños públicos el $10.16 \%$ afirmó que si usa baños públicos muy frecuentemente y el $37.50 \%$ frecuentemente por lo cual la probabilidad de contraer enfermedades es muy alta, mientras que el $25.26 \%$ lo utiliza ocasionalmente, el $16.67 \%$ lo utiliza raramente y el $10.68 \%$ no lo utiliza nunca.

b. Respecto a la frecuencia de uso el $32.27 \%$ afirmó que usa baños públicos por lo menos 4 veces por semana, mientras que el $17.44 \%$, el $23.26 \%$, y el $27.03 \%$, lo utilizan una, dos y tres veces por semana respectivamente.

c. El sector más afectado serían las mujeres con un $50.3 \%$, seguido por los niños con un $31.1 \%$, los ancianos con $15.1 \%$ y los hombres solo con un $3.5 \%$.

d. En Cuanto al conocimiento del producto, el 9.6\% manifestó que conoce totalmente el producto y el $16.6 \%$ lo conoce parcialmente, por otro lado el $15.7 \%$ se mostró indeciso en su respuesta y el $23.8 \%$ y el $34.2 \%$ manifiesta que desconoce y desconoce totalmente el producto respectivamente.

e. Respecto a la utilización del producto se tiene que el $26.4 \%$ manifiesta que muy frecuentemente ha utilizado el producto y el $23.1 \%$ lo ha utiliza frecuentemente, el $20.8 \%$ lo utiliza ocasionalmente, el $13.9 \%$ lo utiliza raramente y el $15.3 \%$ nunca ha utilizado el producto.

f. En cuanto a las razones por las cuales no compraban el producto, el $27 \%$ de las encestadas manifestaron que desconocían la existencia del producto, el $20.5 \%$ que no lo consideraban necesario, el $19.5 \%$ desconocía donde lo venden, el $17.5 \%$ consideraban que desconocían donde lo venden y el $15.5 \%$ por otras razones.

g. Respecto al conocimiento de marcas el $17.36 \%$ manifiesta que conoce la marca Conversit, el $18.06 \%$ la marca Flushables, el $12.50 \%$ conoce la marca maxilimpio y solo el $17.36 \%$ la marca Wc Protect, lo cual muestra que la marca más conocida en el mercado es la Coversit.

h. La marca que más se utiliza Coversit con un $28.4 \%$, seguido de la marca Flushables con $27.78 \%$, Wc protect con $20.83 \%$, y finalmente el protector sanitario Maxilimpio con un $22.9 \%$.

i. Del total de encuestadas las personas usan los servicios higiénicos en los centros comerciales son un $33.3 \%$, luego el $25 \%$ en los supermercados, en Restaurantes el $18.75 \%$, En su centro de estudios el $13.89 \%$ y en su centro de trabajo el $9.03 \%$ 
j. En cuanto a los atributos del cobertor, el $27.1 \%$ considera muy importante los atributos de un nuevo cobertor, el $24.8 \%$ Importante, el $19.1 \%$ indeciso , el $14.9 \%$ no lo considera importante y el $14.2 \%$ no tiene ningún grado de competencia.

k. El $42.2 \%$ de las encuestadas manifiesta que el atributomás importante es el cuidado de la salud, el $23.4 \%$ manifiesta que es la calidad del producto, el $15.8 \%$ considera importante que tenga puntos de ventas accesibles y el $18.5 \%$ que tenga precios competitivos.

I. Respecto a la presentación por contenido las encuestadas manifestaron que estaría dispuesto a comprar el pack con 10 unidades abarcando el $43.9 \%$, el $18.2 \%$ pack con 05 unidades y el $38 \%$ un pack con 15 unidades

m. En cuanto a la preferencia de lugar de compra del producto, el $41.9 \%$ de las encuestadas eligió los supermercados, el $23.1 \%$ prefirió el mercado, y el 18.5\% prefirió tiendas de conveniencia mientras que el 16.5\% preferiría encontrarlo en farmacias.

n. El $43.9 \%$ consideró que el producto se debe ubicar en el área de cuidado personal, el $38 \%$ prefirió el área de higiene, mientras que $18.2 \%$ prefirió el área de belleza

o. El $41.9 \%$ manifestó que compraría el producto 2 veces por mes, el $23.1 \% 4$ veces por mes, el $18.5 \% 3$ veces por mes mientras que el $16.5 \% 1$ vez al mes.

p. El $64.7 \%$ manifestó que compraría más de tres paquetes, el $45.1 \% 3$ paquetes, el $37.04 \%$ compraría 2 paquetes mientras que el $17.9 \%$ solo compraría un paquete.

q. El 38\% eligió el precio entre 1.50 a 2.00 soles, el $43.9 \%$ prefirió el precio 2.01 a 2.50 soles, mientras que $18.2 \%$ prefirió el precio de 2.50 soles a más.

r. El $38.3 \%$ de las encuestadas manifestó que probablemente sí compraría el producto, el $21.5 \%$ definitivamente sí, el 19.8\% manifestó que probablemente no, el $10,2 \%$ era indiferente y el mismo porcentaje manifestó que definitivamente no.

s. El $44.2 \%$ de las encuestadas manifestó que no comprará el producto porque no considera que necesariamente cuide la salud, eligió, el $22.1 \%$ considera que uso es complicado, el 18.8\% manifestó que usa baños públicos esporádicamente y el $15.2 \%$ que no le parece atractiva la presentación.

t. El $20.8 \%$ de las encuestadas consideró que las redes sociales son el medio más adecuado para dar a conocer el producto, el 5.9\% la televisión, el 6.9\% la 
radio, el $6.6 \%$ las revistas, el 9.9\% las páginas web y solo el 2.3 las vallas publicitarias.

\subsection{Perfil del consumidor tipo y sus variantes}

El consumidor o usuario del cobertor sanitario para inodoros, está conformado por mujeres trabajadoras o amas de casa, que se caracterizan por tener ingresos o decisión de compra en los productos del hogar. Son mujeres entre las edades de 20 a54 años de los distritos de Lima Moderna. Estas mujeres siempre están buscando nuevos productos que hagan más fácil su vida diaria y también, que mejoren su salud y la de su familia. 


\section{CAPITULO IV: PROYECCION DEL MERCADO OBJETIVO}

\subsection{El ámbito de la proyección}

El ámbito de proyección está definido por el segmento de mercado objetivo al cual se quiere atender. Este segmento de mercado es afectado por ciertas variables que permitirán pronosticar las ventas anuales.

\subsection{Selección del método de proyección}

A continuación se detallaran los mercados potencial, disponible, efectivo y objetivo.

\subsubsection{Mercado potencial.}

Son las personas que reúnen las características solicitadas como clientes que pueden demandar el producto. Para poder definir la cantidad de población con estas características se ha utilizado la siguiente fórmula:

Mercado Potencial $=$ (Población Proyectada en distritos con
supermercados $) *($ Segmentación N.S.E. en \%) $*$ (Segmentación
Demográfica Sexo en \%) * (Segmentación Demográfica Rango de Edad en
$\%)$

Tabla 37.

Mercado Potencial-Mujeres de Lima Moderna del entre 20 a 54 años de edad y de NSE $A, B$ y $C$

\begin{tabular}{lcccc}
\hline & Total población & $\begin{array}{c}\text { Participación } \\
\text { por Género } \\
\text { ( Mujeres) }\end{array}$ & $\begin{array}{c}\text { Participación } \\
\text { por Rango de } \\
\text { edad } \\
\text { (20-54 años ) }\end{array}$ & $\begin{array}{c}\text { Participación } \\
\text { por NSE } \\
\text { ( A,B y C) }\end{array}$ \\
\cline { 3 - 5 } & & $\mathbf{5 1 . 1 9 \%}$ & $\mathbf{5 1 . 4 4 \%}$ & $\mathbf{9 2 . 2 0 \%}$ \\
\hline POBLACIÓN LIMA MODERNA 2016 & $1,300,500$ & 665,726 & 342,449 & 315,738 \\
\hline
\end{tabular}

Nota: Adaptada por "Fuente: INEI; CPI Y APEIM", por INEI, CPI y APEIM. 


\subsubsection{Mercado Disponible}

Está constituido por consumidores que estarían dispuestos o interesados en comprar el producto investigado. Para el cálculo del mercado disponible usamos la siguiente fórmula:

$$
\begin{gathered}
\text { Mercado Disponible }=(\text { Mercado Potencial }){ }^{*} \text { Porcentaje de } \\
\text { Encuestados que Conocen el producto * Porcentaje de Encuestados } \\
\text { que consumen el producto }
\end{gathered}
$$

Para definir el mercado disponible se toma en cuenta la pregunta 4 (Filtro 1) y la pregunta 5 de la encuesta (Filtro 2) cuyos resultados se manifiestan en las tablas 20 y 21 de presente trabajo en donde se tiene lo siguiente

- El $41.86 \%$ manifestó que conocía total y parcialmente el producto

- El 84.7\% manifestó había utilizado el producto Muy frecuentemente,

Frecuentemente, Ocasionalmente y Raramente

En base a esta información se determina que el mercado disponible está

\section{Tabla 38.}

\begin{tabular}{|c|c|c|c|c|}
\hline & $\begin{array}{l}\text { Mercado } \\
\text { Potencial }\end{array}$ & $\begin{array}{c}\text { Conocen el } \\
\text { producto }\end{array}$ & $\begin{array}{c}\text { Participación } \\
\text { por Rango de } \\
\text { edad } \\
\text { (20-54 años) }\end{array}$ & $\begin{array}{c}\text { Total mercado } \\
\text { Disponible }\end{array}$ \\
\hline & & $41.83 \%$ & $84.7 \%$ & \\
\hline Mercado Disponible2016 = & 315,738 & 665,726 & 342,449 & 119,976 \\
\hline
\end{tabular}

Mercado Disponible

Nota: Tabla elaborada con los datos obtenidos de la pregunta 4 y 5 del cuestionario.

Elaboración propia.

\subsubsection{Mercado Efectivo}

Está constituido por consumidores que están dispuestos a realizar la compra del producto. Para el cálculo del mercado disponible usamos la siguiente fórmula:

Mercado Efectivo $=($ Mercado Disponible $){ }^{*}$ Población
que tiene disposición de consumir el nuevo producto


Para definir el mercado efectivo se toma en cuenta la pregunta 18 del cuestionario (Filtro 3), en la cual se consulta si consumirían el nuevo cobertor ofrecido, en donde el $59.7 \%$ manifestó que Definitivamente si y probablemente sí quedando entonces el mercado efectivo de la siguiente manera:

Tabla 39.

Mercado Efectivo: Personas que tienen disposición de compra del nuevo producto

$\begin{array}{ccc}\text { Mercado } & \begin{array}{c}\text { Comprarían el } \\ \text { producto }\end{array} & \text { Mercado Efectivo } \\ \text { Disponible } & \text { a }\end{array}$

Mercado Efectivo $2016=$

119,976

$59.7 \%$

66,890

Nota: Tabla elaborada con los datos obtenidos de la pregunta 18 del cuestionario. Elaboración propia.

En base a este resultado obtenemos que el 59. 7. \% de los consumidores del producto compraría el nuevo producto, obteniéndose con ello el mercado efectivo.

\subsubsection{Mercado Objetivo}

Este mercado está comprendido por el conjunto de la población del mercado efectivo a la cual aspiramos a alcanzar en cada uno de los años de la puesta en marcha del proyecto.

Para la presente investigación el mercado objetivo coincide con el mercado efectivo, ya que la capacidad productiva del proyecto, está muy por encima de la demanda del mercado efectivo

Mercado Objetivo $=($ Mercado Efectivo $)$

Tabla 40.

Mercado Objetivo 
En base a la determinación del mercado Objetivopara el año 2016, se hace un proyección del mercado objetivo, tomando como criterio de proyección la tasa de crecimiento población ya que no existen estadísticas del consumo del producto, por ello se considera un crecimiento conservador como es la tasa de crecimiento poblacional que es del $1.55 \%$.

Tabla 41.

Mercado Objetivo Proyectado

\begin{tabular}{cccc}
\hline $\begin{array}{c}\text { MERCADO OBETIVO } \\
\text { PROYECTADO }\end{array}$ & AÑOS & $\begin{array}{c}\text { TASA DE } \\
\text { CRECIMIENTO PROM } \\
\text { ULTIMOS 5 AÑOS }\end{array}$ & $\begin{array}{c}\text { MERCADO OBJETIVO } \\
\text { PROYECTADO }\end{array}$ \\
\hline POBLACIÓN QUE SE & $\mathbf{2 0 1 7}$ & $1.55 \%$ & 67,927 \\
$\begin{array}{c}\text { PRETENDE ATENDER } \\
\text { CON EL PRESENTE }\end{array}$ & $\mathbf{2 0 1 8}$ & $1.55 \%$ & 68,980 \\
PROYECTO & $\mathbf{2 0 1 9}$ & $1.55 \%$ & 70,049 \\
& $\mathbf{2 0 2 0}$ & $1.55 \%$ & 71,135 \\
\hline
\end{tabular}

Elaboración propia.

\subsection{Pronóstico de ventas}

El pronóstico de ventas está constituido por el consumo de los clientes comprendidos en el mercado objetivo, estimando una tasa de crecimiento de los clientes del $1.55 \%$ considerando implementar un crecimientode la inversión en Marketing del 5\% anualmente. Para poder definir el pronóstico se debe que definir la frecuencia de uso del producto. Con esta información podremos definir la cantidad a producir y cuantificar las ventas a alcanzar anualmente.

Las variables a utilizar se definen a continuación:

a. Mercado objetivo, se obtuvo como resultado de la participación que se quiere obtener durante cada uno de los años del proyecto.

b. Frecuencia de uso, con respecto a esta variable, la información se pudo obtener en la investigación cuantitativa a través de la encuesta.

c. Número de productos que compra por vez, con respecto a esta variable, la información se pudo obtener en la investigación cuantitativa mediante la encuesta, 
Tabla 42.

Frecuencia de Compra anual

\begin{tabular}{lccc}
\hline Frecuencia de compra & $\%$ & Unidades por Compra & Ponderado \\
\hline 4 Veces por mes & $23.10 \%$ & 1 & 0.23 \\
3 Veces por mes & $18.48 \%$ & 2 & 0.37 \\
2 Veces por mes & $41.91 \%$ & 3 & 1.26 \\
1 vez al mes & $16.50 \%$ & 4 & 0.66 \\
\hline Total Frecuencia de compra mensual & & 2.52 \\
\hline Total Frecuencia de compra Anual & & 30.22
\end{tabular}

Tabla 43.

Pronóstico de Ventas

\begin{tabular}{cccc}
\hline AÑOS & MERCADO OBJETIVO & $\begin{array}{c}\text { FRECUENCIA DE } \\
\text { COMPRA ANUAL }\end{array}$ & $\begin{array}{c}\text { DEMANDA TOTAL } \\
\text { ANUAL EN PACKS }\end{array}$ \\
\hline $\mathbf{2 0 1 7}$ & 67,927 & 30.22 & $2,052,607$ \\
$\mathbf{2 0 1 8}$ & 68,980 & 30.22 & $2,084,423$ \\
$\mathbf{2 0 1 9}$ & 70,049 & 30.22 & $2,116,731$ \\
$\mathbf{2 0 2 0}$ & 71,135 & 30.22 & $2,149,541$ \\
& 72,237 & 30.22 & $2,182,858$ \\
\hline
\end{tabular}

Nota: Pronóstico de ventas planteado en base al mercado Objetivo y la frecuencia de consumo anual. Elaboración propia.

\subsection{Aspectos críticos que impactan el pronóstico de ventas}

Los aspectos críticos que pueden afectar el pronóstico de ventas son de naturaleza interna y externa. Por lo cual, se debe estar preparados para poder alcanzar la cuota de mercado planteada como objetivo de participación anual. Estos aspectos críticos pueden ser:

Variación de las visitas de los consumidores al canal moderno.

Variación de los precios de los insumos.

Lanzamiento de un nuevo producto competidor en el mercado.

Estrategia de comunicación publicitaria inadecuada. 


\section{CAPITULO V: INGENIERIA DEL PROYECTO}

\subsection{Estudio de Ingeniería}

"El modelamiento de los procesos productivos es una de las principales tareas que deben tenerse en cuenta ya que afectan el proceso de conversión y los costos de operación.

Existen 2 componentes en el modelamiento de los procesos productivos: el diseño modular y la estandarización". (Everett; 1991, p. 143).

El diseño modular es la creación de productos a partir de alguna combinación de subsistemas básicos preexistentes. El concepto de diseño modular se basa en la configuración que se le puede dar a un producto final para satisfacer diferentes necesidades a los clientes con los diferentes subsistemas preexistentes. Este componente adicionalmente permite al diseñador del flujo de los procesos optimizar sus operaciones y buscar eficiencias en producción, permite entre otras cosas al planificador de inventarios simplificar sus requerimientos ya que contará en los almacenes con productos semi terminado que armará cuando el mercado lo solicite.

La estandarización de los productos ofrece beneficios tanto a los consumidores como productores. Los consumidores cuentan en el mercado con un único producto que facilita la sencillez de la compra y mejora en conveniencia las compras de insumos para los productores, mejorando la productividad en el proceso de ventas. El lado riesgoso de este componente es que se genera un estancamiento de la innovación dando posibilidad a que la competencia se aproveche de esta desventaja.

"Por otro lado, existen 5 tipos genéricos de flujos de procesos de producción: de proyectos, el trabajo de taller, por lote, procesos en línea y el flujo continuo". (Everett; 1991, p. 144).

Para los cobertores sanitarios al ser un único producto estandarizado y se producen en modelos definidos ocupa una posición productiva dentro de los procesos en línea, adjuntamos un cuadro comparativo con los procesos de flujo continuo: 
Tabla 44.

Cuadro comparativo.

\begin{tabular}{lll}
\hline Características & en Línea & Flujo continuo \\
\hline Tamaño común de las instalaciones & A menudo grande & Grande \\
Flujo del proceso & Un patrón de flujo rígido & Claro e inflexible \\
Velocidad del proceso & Rápido & Muy rápido \\
Tamaño de corrida & Larga & Muy larga \\
Tasa de cambio en la tecnología del proceso & De moderada a alta & Demasiado alta \\
Contenido de mano de obra & Baja & Muy baja \\
Nivel de habilidad del trabajador & Bajo & Varía \\
Requerimientos de capacitación del trabajador & Bajos & Varían \\
Requerimientos de materiales & Predecibles & Muy predecibles \\
Requerimientos de información sobre & Moderados & \\
producción & Proceso diseñado alrededor & Bajos \\
Programación & De un programa fijo & Dictada por la tecnología \\
Secuencia & Mejoramiento de la & productividad, ajuste de los \\
niveles de personal de apoyo, & Evitando tiempos muertos, \\
Retos cuando es necesario & rebalanceo. & tiempo, reducción de costos.
\end{tabular}

Nota: Adaptado de "Hayes \& Wheelwright. (1984)", por Hayes \& Wheelwright.

\subsubsection{Modelamiento y selección de procesos productivos}

Una de las principales consideraciones en el proceso productivo de los cobertores sanitarios radica en la aplicación de las buenas prácticas de manufacturación de los productos derivados del papel, para esto se aplica el Reglamento Técnico Andino relativo a los Requisitos y Guía de Inspección para el funcionamiento de establecimientos que fabrican Productos de Higiene Doméstica y Productos Absorbentes de Higiene Personal (Decisión 721), la misma que nace del artículo 51 de la Decisión 706 sobre Armonización de Legislaciones en Materia de Productos de Higiene Doméstica y Productos Absorbentes de Higiene Personal donde se establecen los requisitos para el funcionamiento de establecimientos dedicados a la fabricación de productos de higiene doméstica y productos absorbentes de higiene personal, teniendo en cuenta los principios de control y vigilancia que tienen por misión proteger la salud de la población controlando la seguridad y calidad de los productos, a través de prácticas certificadas para su producción. Información adicional la podemos apreciar en el anexo adjunto.. 
Se detalla las principales actividades para determinar el flujo operativo la misma que servirá más adelante pare el desarrollo del layout.

Manejo de la Materia Prima: Un operario de almacén será el encargado de recepcionar la materia prima y almacenarlo, también será el responsable del traslado del jumbo de papel hacia la máquina convertidora y de la bolsa para el empacado, para realizar esta operación deberá hacer uso de una transpaleta manual para su acarreo. Se encargará de digitar en el sistema el peso físico de cada jumbo de papel y de las bobinas de bolsa y el sistema deberá calcularle el rendimiento teórico de las piezas a producirse. En cada recepción de materiales enviará una muestra del papel a laboratorio para verificar las características del papel recibido, acompañará a esta muestra el certificado de calidad proporcionado por el proveedor.

Para el caso de la principal materia prima (jumbo de papel) se debe considerar las características siguientes:

Papel seda: $\quad 20 \mathrm{~g} / \mathrm{m} 2$

Ancho de jumbo: $420 \mathrm{~mm}$

Peso del jumbo: 500 kilogramos aproximadamente

Las dimensiones del protector sanitario son de $420 \mathrm{~mm} \times 420 \mathrm{~mm}$, podemos afirmar que el peso de una pieza de protector sanitario pesa 3.528 gramos,

Peso teórico por unidad $=420 \mathrm{~mm} \times 420 \mathrm{~mm} \times 20 \mathrm{~g} / \mathrm{m} 2=3.528 \mathrm{~g}$

\# Unidades $=500 \mathrm{~kg} / 3.528 \mathrm{~g}=141,723$ unidades aprox.

(Ver figura 24).

Setup de máquina Convertidora automática: un operario de producción será el responsable de controlar el proceso productivo de la máquina convertidora automática que se encargará de cortar el rollo en longitudes de $420 \mathrm{~mm}$ dejándola en el formato rectangular de $420 \mathrm{~mm} \times 420 \mathrm{~mm}$, posteriormente la máquina se encargará de cortar los cuatro vértices del rectángulo en ángulo interior de $45^{\circ}$ con lados de $60 \mathrm{~mm} \times 60 \mathrm{~mm}$.

La máquina convertidora automática se encargará de hacer el corte de la parte interior del protector sanitario en forma de elipse con un diámetro mayor de $250 \mathrm{~mm}$ y un diámetro menor de $160 \mathrm{~mm}$ dejando 3 extremos pre-cortados para su fácil desprendimiento. 
a. Retiro de excedentes y merma: Los 4 extremos cortados en forma de triángulo serán retirados por el operario de producción y acopiados en un lugar lejos de la máquina convertidora sin ser retirados del área de producción.

b. Inspección del producto terminado: Se procede a inspeccionar la calidad del corte y retirar los cobertores que no cumplan con las especificaciones técnicas. Esta actividad estará a cargo del operario de producción.

c. Doblado de Cobertores: El operario de producción debe procurar que la máquina dobladora automática tenga el suministro suficiente para evitar contratiempos. La máquina dejará el cobertor sanitario en dimensiones de 60mm x 100mm.

d. Embolsado de cobertores en empaques plásticos: después de tener los cobertores doblados, la máquina embolsadora se encargará de colocarles el empaque plástico para garantizar su calidad. El embolsado contendrá 10 cobertores sanitarios, esta actividad de control y supervisión estará a cargo de un segundo operario.

e. Pesaje de cobertores sanitarios (producto terminado): Ingresará al sistema el peso de la producción por turno, el cual le calculará un número teórico de piezas a entregar al responsable de almacén de producto terminado. Esta actividad está a cargo del segundo operario de producción.

f. Empacado en caja de cartón y sellado: A continuación, se empacarán en cajas de cartón el cual contendrá 50 bolsas de 10 cobertores sanitarios cada uno. Esto le dará una mejor presentación al producto, ayudará a su apilamiento y custodia en almacén y se garantizará su calidad en los respectivos transportes y manipuleo que se tengan que realizar. Esta actividad estará a cargo del segundo operario de producción.

g. Recepción y custodia de producto terminado: el producto en caja se almacenará, se registrará la producción al sistema, validará la información del pesaje teórico de los cobertores sanitarios y custodiará el producto terminado hasta su retiro, estará a cargo del responsable de almacén.

h. Pesaje de excedentes, merma y producto no conforme: se procederá al pesaje del excedente, producto no conforme y merma por separado y se registrará en el sistema para determinar indicadores de producción posteriormente. A cargo del encargado de almacén y segundo operario de producción al término del turno. 


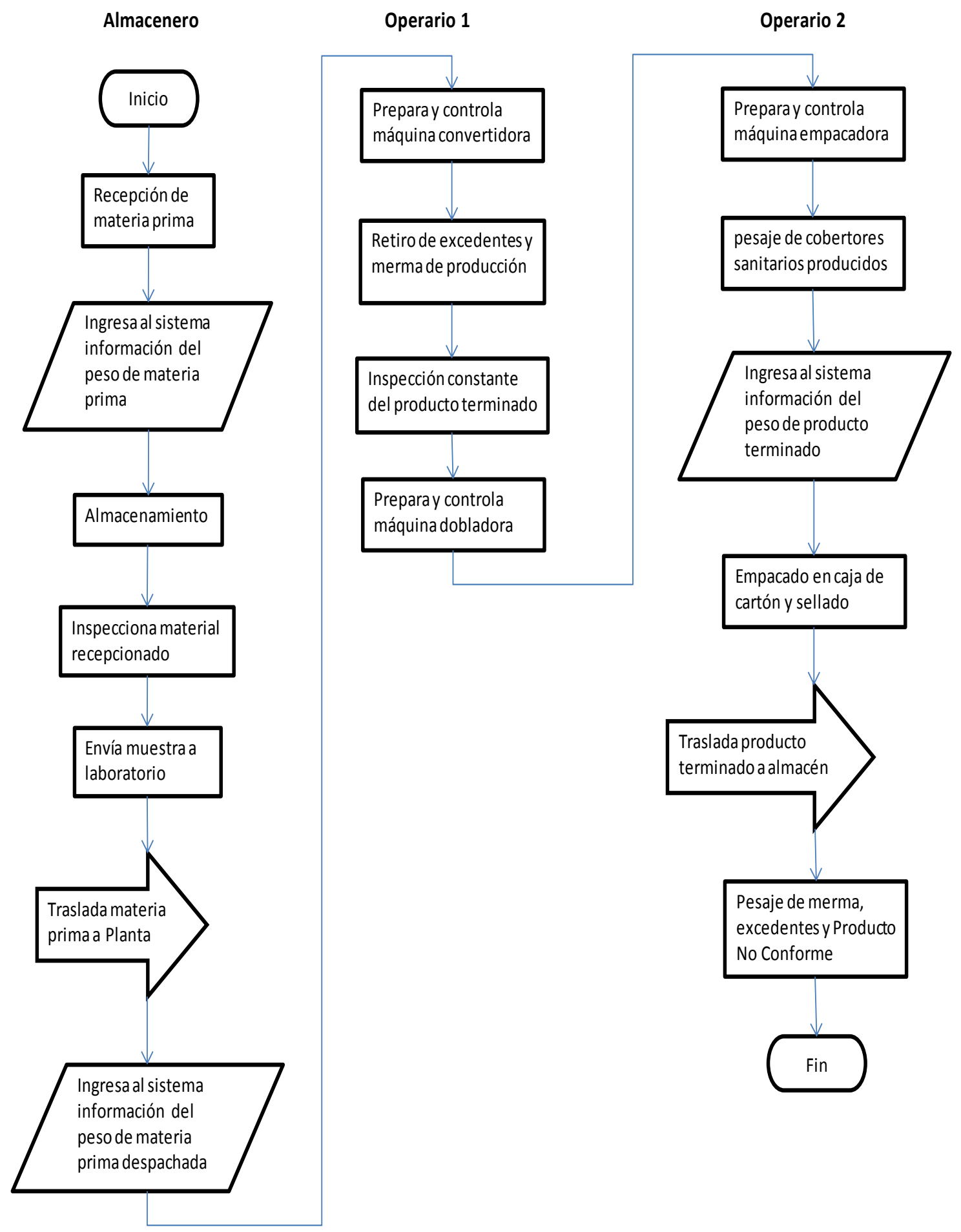

Figura 45. Flujograma de los procesos productivos. Actividades realizadas por almacenero y operarios. Elaboración propia. 


\section{Selección del equipamiento.}

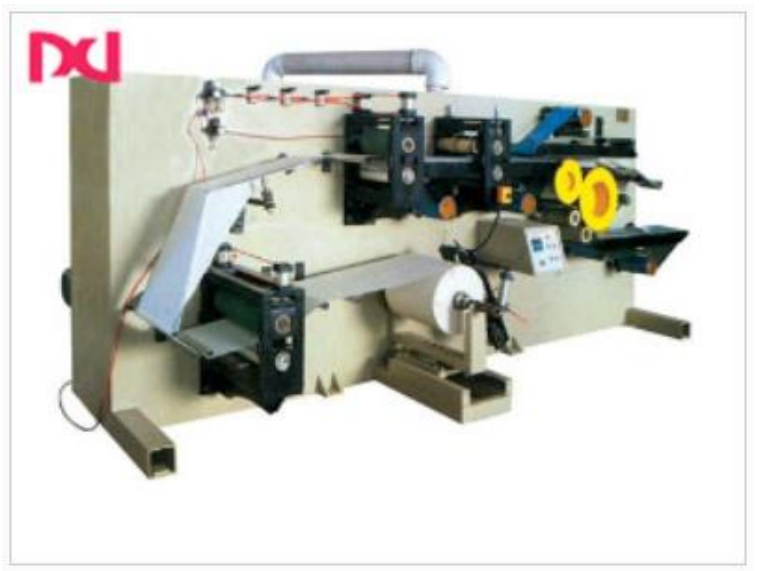

Figura 46. Máquina Convertidora automática de protectores sanitarios CIL-AQ-291 de Cailun Machine (2015). Referenciado de Alibaba.com, 2015

Convertidora automática de protectores sanitarios CIL-AQ-291

Price:

US $\$ 20000.0 /$

Trade Terms:

FOB, CFR, CIF

Payment Terms: $\quad L / C, T / T$, Western Union

Price Valid Time: From Dec 31, 2014 To Dec 31, 2015

\begin{tabular}{|l|l|}
\hline Raw material: & $18-25 \mathrm{~g} / \mathrm{m} 2$ \\
\hline $\begin{array}{l}\text { Raw material } \\
\text { size: }\end{array}$ & $1000 \times 380 \mathrm{~mm}$. \\
\hline Especifications: & idem \\
\hline $\begin{array}{l}\text { Production } \\
\text { capacity: }\end{array}$ & $55 \mathrm{pcs} / \mathrm{min}$ \\
\hline \begin{tabular}{l} 
Machine power: \\
\hline $\begin{array}{l}\text { Overall } \\
\text { dimensions: }\end{array}$
\end{tabular} & $7,85 \mathrm{kw}$ \\
\hline
\end{tabular}




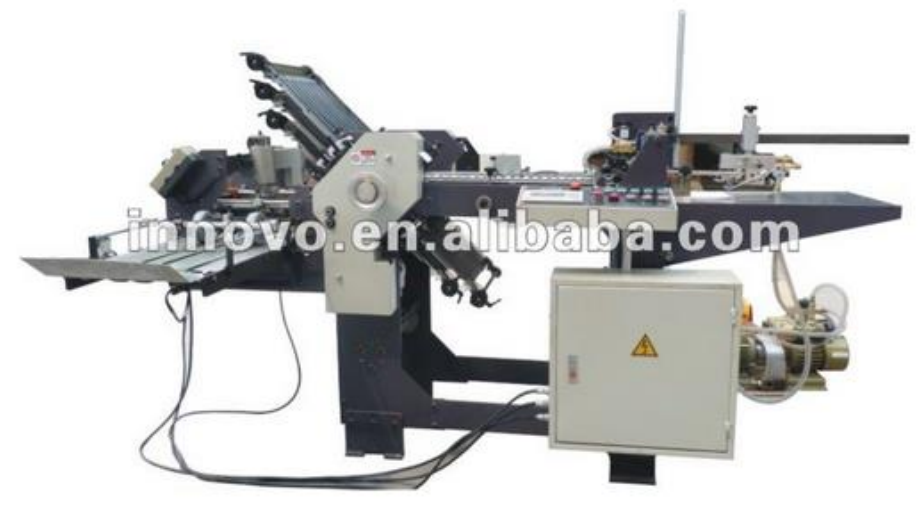

Figura 47. Dobladora automática de Manufacturing \& Processing Machinery (2016)

Referenciado de Alibaba.com, 2016

\section{Combined-Type Paper Folder Machine}

\section{(ZX360-6+1)}

Price:

$\$ 1.0-\$ 10000.0 /$ Piece - Get Latest Price

Trade Terms:

Payment Terms:

Price Valid Time:

FOB, CFR, CIF EXW

UC, T/T, Money Gram, Western Union

From Sep 14, 2015 To Dec 31, 2016

Parameters:

\begin{tabular}{|l|l|}
\hline Model: & $2 \times 360-6+1$ \\
\hline Sheet range: & $10-300 \mathrm{~g} / \mathrm{m}^{2}$ \\
\hline $\begin{array}{l}\text { Finished product } \\
\text { specifications }\end{array}$ & Min. $20^{*} 30 \mathrm{~mm}$ \\
\hline $\begin{array}{l}\text { Overall } \\
\text { dimensions: }\end{array}$ & $2400^{*} 940^{*} 1420 \mathrm{~mm}$ \\
\hline Machine weight: & $440 \mathrm{~kg}$ \\
\hline Machine power: & $3.0 \mathrm{kw}$ \\
\hline Working voltage: & $380 \mathrm{~N}$ \\
\hline Max. sheet size: & $360^{*} 760 \mathrm{~m}$ \\
\hline Min. sheet size: & $30^{*} 80 \mathrm{~mm}$ \\
\hline speed: & $60 \mathrm{~m} / \mathrm{min}$ \\
\hline
\end{tabular}

Product Details

Basic Info.

Model NO: ZX360-6+1

Folding Mechanism: Folding Buckle Structure: Folding

Warranty: One Year

Machine Weight: $440 \mathrm{~kg}$

Brand: Innovo

Machine Power: $3.0 \mathrm{kw}$

Folding display 

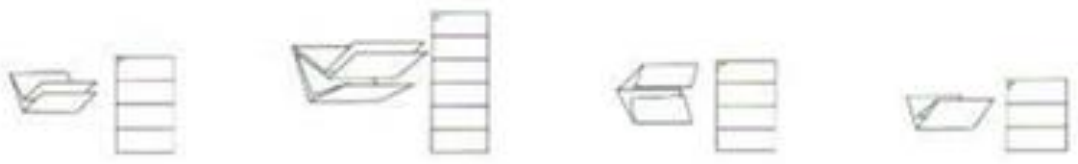

Fodentat tootmes

Fold in half ther smes

Teos solscueng low

Foid in has the trmes.
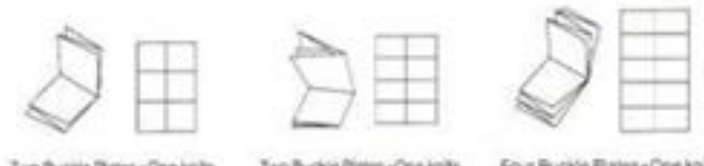

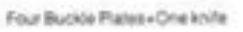
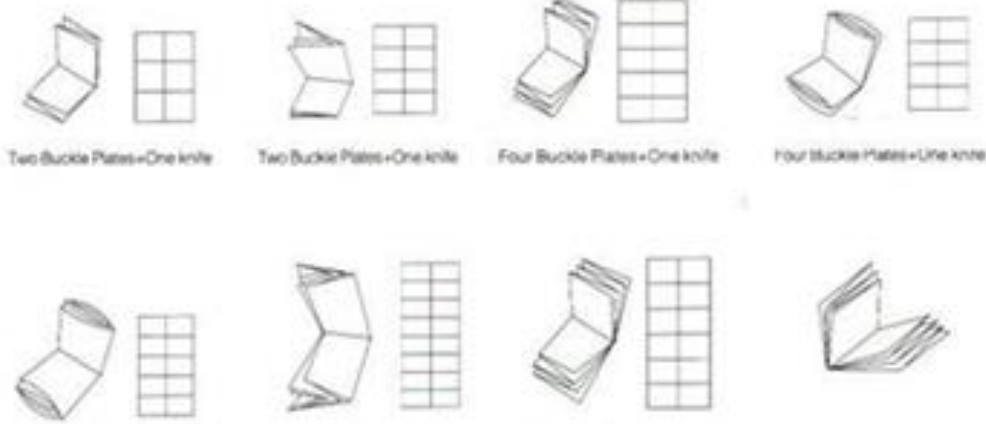

fou Bow numitione inte

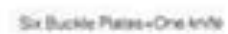

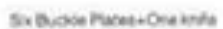

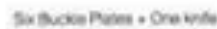
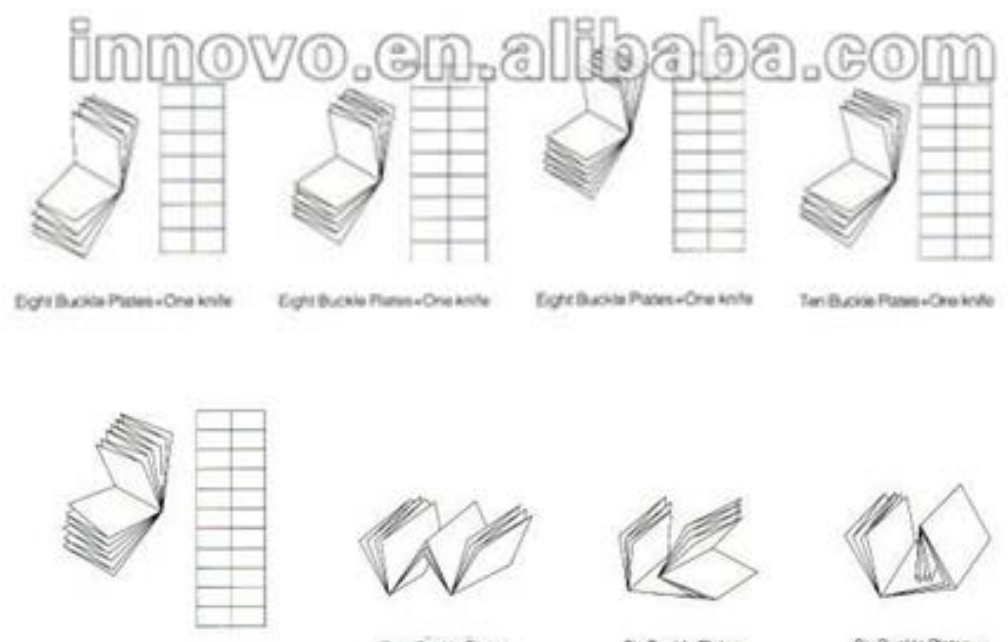

Ten Buckie Pistest One knte

Far Budide Preses

Sx Budile Plves

Sor Buckse Pasis + Four Bucke Pases

Figura 48. Formas de doblado. Adaptado de Alibaba.com (2016) 


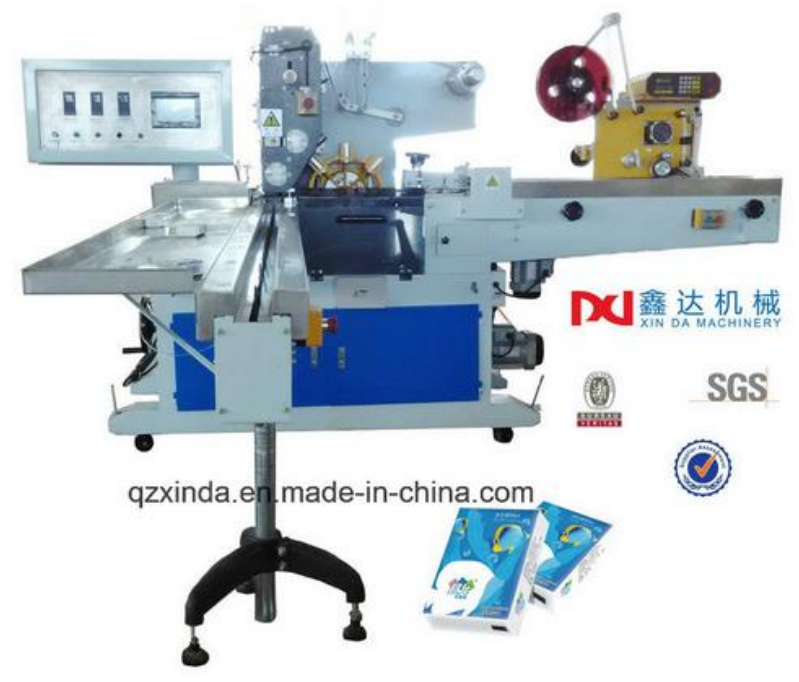

Figura 49. Embolsadora. Qzxinda (2015). Referenciado de Alibaba.com, 2015.

\section{One Bag Standard Handkerchief Tissue \\ Paper Packing Machine}

$\begin{array}{ll}\text { Price: } & \text { US } \$ 10000.0 / \text { set } ~ \\ \text { Trade Terms: } & \text { FOB Let CFR, CIF } \\ \text { Payment Terms: } & \text { LC, T/T, Western Union, negotiation } \\ \text { Price Valid Time: } & \text { From Dec 31, 2014 To Aug 29, 2015 }\end{array}$

Product Details

\section{Basic Info.}

Model NO: ClL-AS-201

Application: Handkerchief Paper

Forming Species: Bag Moulding

Driven Type: Electric

Packaging Type: Bag

Speed: $25-90 \mathrm{bags} / \mathrm{Min}$

Material of Packing: Used Plastic Film

Air Pressure: $\quad 0.3-0.4 \mathrm{MPa}$

Packing Size of Mini: $72 \times 53 \times 26 \mathrm{~mm}$

Power of Motor: $1.1 \mathrm{kw}$

istomatic Grade: Automatic

Type: Filling and Sealing Machine

Forming Function: Filling

Material Type: Film

Packaging Material: Plastic

Used: High-Production Machine to Handkerchief Paper

Control Console: Big Window Touch Screen

Packing Size of Standard: $106 \times 53 \times 26 \mathrm{~mm}$

Function: Touch Screen

Control: by PLC

Export Markets: Global 
Capacidad de producción por máquina

\begin{tabular}{|c|c|c|c|c|c|c|c|c|c|c|c|}
\hline Tipo de Máquina & $\begin{array}{l}\text { Velocidad } \\
\text { Nominal }\end{array}$ & $\begin{array}{l}\text { Velocidad } \\
\text { Promedio } \\
\text { de } \\
\text { Producción }\end{array}$ & $\begin{array}{c}\text { Total } \\
\text { Minutos } \\
\text { por } \\
\text { Turno }\end{array}$ & ineficiencia & $\begin{array}{c}\text { Minutos } \\
\text { Disponibles } \\
\text { por Turno }\end{array}$ & Turnos/día & $\begin{array}{l}\text { Disponibilidad } \\
\text { de días/mes }\end{array}$ & $\begin{array}{c}\text { Protectores } \\
\text { Producidos } \\
\text { por Turno }\end{array}$ & $\begin{array}{l}\text { Packs Por } \\
\text { Turno }\end{array}$ & $\begin{array}{c}\text { Producción } \\
\text { Mensual }\end{array}$ & $\begin{array}{c}\text { Producción } \\
\text { Anual }\end{array}$ \\
\hline \multirow{2}{*}{ CONVERTIDORA } & 500 PZAS X & & & & & & & & & & \\
\hline & MINUTO & 500 & 480 & 144 & 336 & 1 & 26 & 168,000 & 16,800 & 436,800 & $5,241,600$ \\
\hline \multirow{2}{*}{ DOBLADORA } & 428 PIEZAS $X$ & & & & & & & & & & \\
\hline & MINUTO & 428 & 480 & 144 & 336 & 1 & 26 & 143,808 & 14,381 & 373,901 & $4,486,810$ \\
\hline \multirow{2}{*}{ EMBOLSADORA } & 25 A 90 PIEZAS & & & & & & & & & & \\
\hline & X MINUTO & 50 & 480 & 144 & 336 & 1 & 26 & 16,800 & 16,800 & 436,800 & $5,241,600$ \\
\hline
\end{tabular}

Nota: Se ha determinado la producción de convertidora, dobladora y embolsadora, teniendo en cuenta algunos factores. Elaboración propia. 


\section{Especificaciones}

\begin{tabular}{|c|c|}
\hline CIL-AS.201 Automatic Hand & acking machine \\
\hline 1.Spend(bags/min) & 50 \\
\hline 2.Packing size(mm) & Standard type : $106 \mathrm{~mm} \times 53 \mathrm{~mm} \times 26 \mathrm{~mm} \quad 10$ sheets \\
\hline & Mini tye $72 \mathrm{~mm} 53 \mathrm{~mm} \times 26 \mathrm{~mm} \quad 10$ shents \\
\hline 30utine Dimension(mm) & $2840 \times 2650 \times 1720$ \\
\hline 4 Machines Weight(kg) & 1500 \\
\hline 5.Power & $380 \mathrm{~V} 50 \mathrm{~Hz}$ \\
\hline 6.Used Shrink Film & CPP,PE, BOPP औC \\
\hline 7.Compressed presssurẹt & 20.5 \\
\hline
\end{tabular}

\section{0kg Hydraulic Jumbo Roll Paper Lifter}

FOB Price:

US \$650 - 800 / Unit I Get Latest Price

Min.Order Quantity.

1 Unit/Units

Supply Ability:

900 Unit/Units per Month

Port:

Xiamen Port, Fujian

Payment Terms:

$\mathrm{T} / \mathrm{T}$

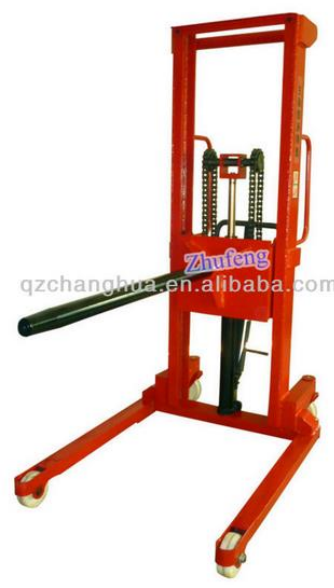

Figura 50. Transpaleta hidráulica. Referenciado de Alibaba.com (2015) 


\section{Proveedor Verificado}

Ningjin County Zhongxin Electronic

Weighing Scale Co., Ltd.

[Shandong, China (Continental) ] $\Theta$

Precio FOB: US $\$ 300-600$

Puerto: Qingdao or Tianjin

Cantidad de pedido mínima: 1

Unidad/es

Condiciones de pago: L/C,T/T

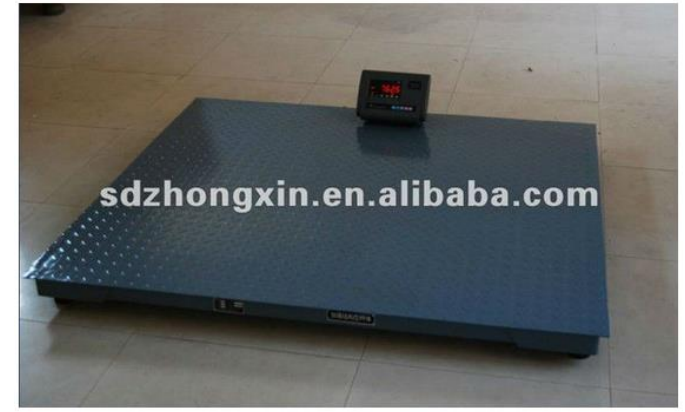

Figura 51. Balanza de Piso de 2000 kg c. Referenciado de Alibaba.com, 2015.

Alibaba China cnc de mecanizado de almacén bastidores de almacenamiento bastidor de hierro

\begin{tabular}{|c|c|}
\hline Precio FOB: & US S 2-20 / Set | Precio-Regateo \\
\hline Puerto: & Guangzhou, Shenzhen, Foshan or as requested \\
\hline Cantidad de pedido mínima & $10 \mathrm{Set} / \mathrm{s}$ MOQ para la fabricación de metal de hoja no es necesario. \\
\hline Capacidad de suministro: & $\begin{array}{l}10000 \text { Set/s por Mes Depende del cliente productos de metal de encargo y } \\
\text { cantidad. }\end{array}$ \\
\hline Plazo de entrega: & 25-30 días después del pago inicial se transfiere. \\
\hline Condiciones de pago: & L/C,D/A,D/P,T/T,Western Union,MoneyGram,Paypal, Cash \\
\hline
\end{tabular}

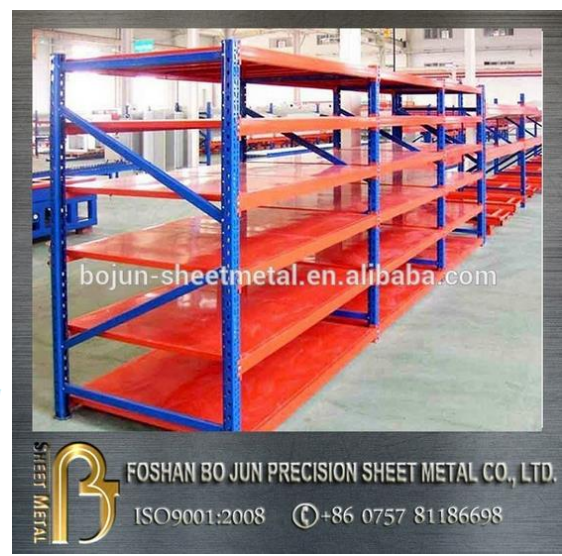

Figura 52. Andamios para producto terminado. Referenciado de Alibaba.com, 2015.

Datos del producto

Datos Básicos

Lugar del origen:

Profundidad:

Anchura:

Material:

tipo de fabricación:

de corte por láser de precisión:

China (Continental) Capacidad de peso:

$5 \mathrm{~mm}$

Número de Modelo:

$600 \mathrm{~mm}$

Característica:

Acero Certificación:

$30 \mathrm{~kg} \quad$ Marca:

de almacenamiento en ... Altura

Conveniente para al air... Tipo:

Iso9001:2008 Uso:

hoja de metal de fabric... de fabricación de materiales:

$\pm 0.05-0.1 \mathrm{~mm} \quad$ la longitud de flexión:

De acero inoxida

la costumbre de tratamiento de superficie: La capa del polvo, de se... el control de calidad:

$3000 \mathrm{~mm}$ max

. 15 a $20 \mathrm{~mm}$

la fabricación de acero característica:

De alta precisión, perso.

Is09001:2008

el tipo de soldadura: Mig, de soldadura tig, y ...

/oem y odm servicio: disponible para person... 


\begin{tabular}{|c|c|c|c|c|c|}
\hline Concepto & Cantidad & $\begin{array}{c}\text { Precio } \\
\text { Unitario } \\
\text { S/. }\end{array}$ & $\begin{array}{c}\text { Total Neto } \\
\text { S/IGV } \\
\text { S/. }\end{array}$ & $\begin{array}{l}\text { IGV } \\
\text { S/. }\end{array}$ & $\begin{array}{c}\text { Precio Total } \\
\text { S/. }\end{array}$ \\
\hline Máquina Convertidora & 1 & 66,000 & 55,932 & 10,068 & 66,000 \\
\hline Máquina Dobladora & 1 & 26,400 & 22,373 & 4,027 & 26,400 \\
\hline Máquina Embolsadora & 1 & 26,400 & 22,373 & 4,027 & 26,400 \\
\hline Carretilla hidráulica & 1 & 2,640 & 2,237 & 403 & 2,640 \\
\hline Andamios & 10 & 66 & 559 & 101 & 660 \\
\hline Herramientas & 1 & 3,000 & 2,542 & 458 & 3,000 \\
\hline Paletas / Parihuelas & 20 & 50 & 847 & 153 & 1,000 \\
\hline Balanza electrónica & 1 & 1,980 & 1,678 & 302 & 1,980 \\
\hline Total Equipos & & & 108,542 & 19,538 & 128,080 \\
\hline
\end{tabular}

\subsubsection{Lay out.}

Usaremos la técnica llamada Planificación Sistemática de la Distribución (SLP), concebida para el diseño de todo tipo de distribuciones en planta independientemente de su naturaleza. Fue desarrollada por Richard Muther en 1961 como un procedimiento sistemático multicriterio, igualmente aplicable a distribuciones completamente nuevas como a distribuciones de plantas ya existentes. El método (resumido en la Figura adjunta) reúne las ventajas de las aproximaciones metodológicas precedentes e incorpora el flujo de materiales en el estudio de distribución, organizando el proceso de planificación total de manera racional y estableciendo una serie de fases y técnicas que permiten identificar, valorar y visualizar todos los elementos involucrados en la implantación y las relaciones existentes entre ellos.

Además en todo momento se tiene en cuenta las especificaciones planteadas en el Reglamento Técnico Andino relativo a los Requisitos y Guía de Inspección para el funcionamiento de establecimientos que fabrican Productos de Higiene Doméstica y Productos Absorbentes de Higiene Personal. DECISION 721 (ver anexo) 


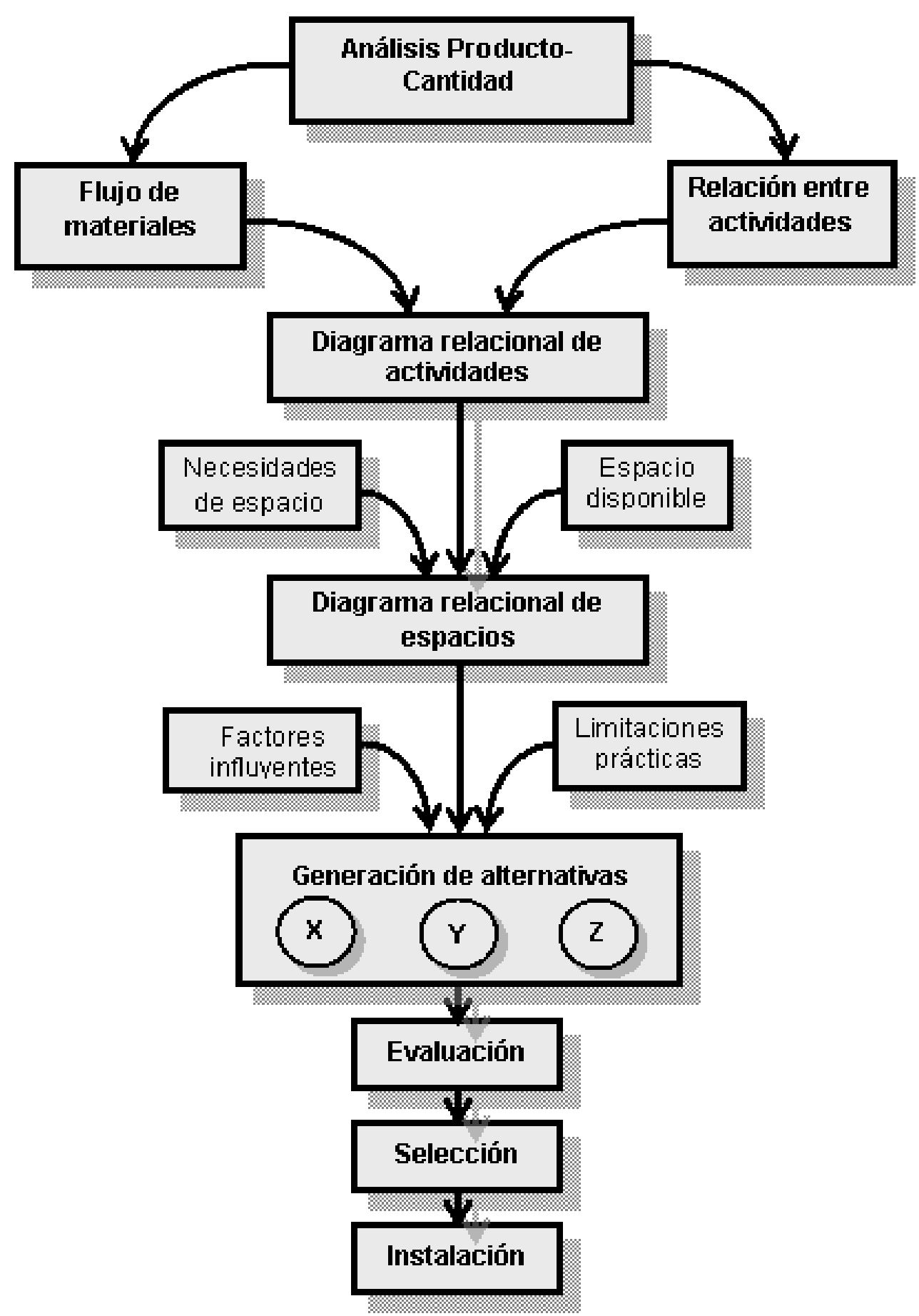

Figura 53. Diagrama relacional de actividades. Elaborado por Pérez (2008).

Referenciado de Monnografías.com, 2008.

\section{a. Análisis de productos-cantidades:}

\section{Rollo de papel Tissue:}

El Protector Sanitario se elabora con un papel llamado tissue que tiene una característica especial, ya que en una de sus caras tiene acabado semisulfurizado que le brinda al papel una impermeabilidad mínima, con el fin de que la humedad que pueda tener el inodoro al 
momento de usar el dispositivo no humedezca el protector y en la otra cara tiene cualidades de absorción y suavidad buscando que el uso del dispositivo sea cómodo y no llegue a irritar la piel del usuario; para la elaboración del protector Sanitario se requiere un corte de $420 \mathrm{~mm}$ de largo por 420mm de ancho. (Sánchez, Moreno y Sánchez; 2012)

El Protector Sanitario tiene una lengüeta con forma de elipse con un diámetro mayor de $250 \mathrm{~mm}$ y un diámetro menor de $160 \mathrm{~mm}$ dejando 3 extremos pre-cortados para su fácil desprendimiento, la cual sirve para facilitar la evacuación del producto, ya que esta lengüeta al momento del uso cae dentro del inodoro y con el simple hecho de descargar el agua, el protector sanitario se deshace y lo absorbe el sanitario.

El rollo de papel tissue se adquiere en bobinas de $500 \mathrm{~kg}$ y su precio es de USD 1000 CIF por rollo.

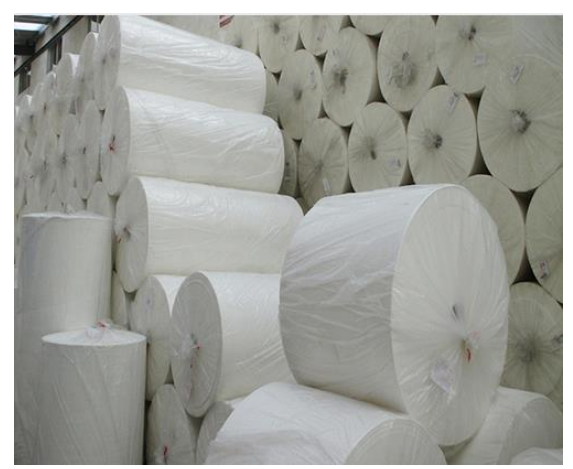

Figura 54. Rollo de papel tissue. Landin (2013).

Referenciado de pelandintecno.blogspot.com, 2013.

\begin{tabular}{cccccc}
\hline Materia Primas & Unidades & $\begin{array}{c}\text { Consumo } \\
\text { Unitario }\end{array}$ & Merma \% & $\begin{array}{c}\text { Merma } \\
\text { Unidades }\end{array}$ & Necesidad \\
\hline Papel (pack $\times 10$ unidades) & gramos & 35.28 & $5.00 \%$ & 1.76 & 37.04 \\
\hline
\end{tabular}

\section{Bolsa de Polietileno:}

Se adquiere en bobinas de $500 \mathrm{~m}$ de longitud con un ancho de $60 \mathrm{~mm}$, este protector de polietileno biodegradable con impresión flexográfica del código de barras del producto y de la forma de uso que permite el traslado del protector sanitario en empaque de 10 unidades, protegiéndolo de la humedad y de gérmenes que lo puedan contaminar. Cada rollo de $500 \mathrm{~m}$ de longitud tiene un rendimiento de 50,000 paquetes de 10 unidades y su costo es de USD 4.92 FOB por rollo. 


\begin{tabular}{|c|c|c|c|c|c|}
\hline Insumos & Unidades & $\begin{array}{c}\text { Consumo } \\
\text { Unitario }\end{array}$ & Merma \% & $\begin{array}{c}\text { Merma } \\
\text { Unidades }\end{array}$ & Necesidad \\
\hline Empaque (bolsa serigrafiada) & unidades & 1.000 & & & 1.00 \\
\hline
\end{tabular}
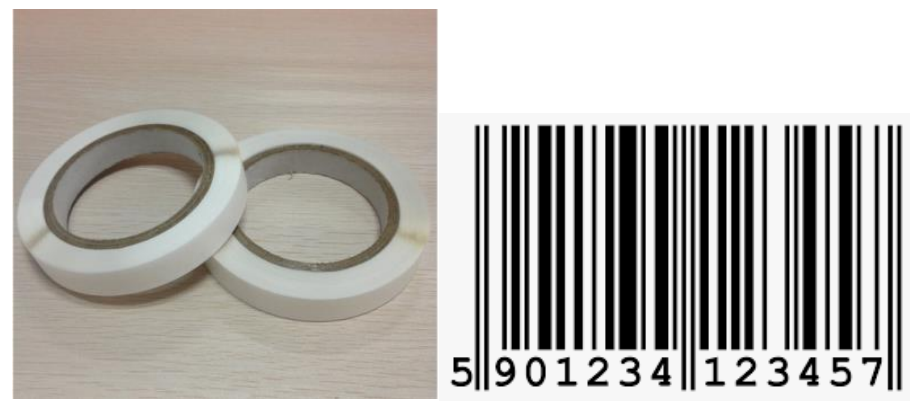

Figura 55. Bolsa de Polietileno. Plasticosguma (2016).

Referenciado de pelandintecno.blogspot.com, 2016.

Al contar con un código de barras único para nuestro producto, se hizo el trámite ante GS1 (http://gs1 pe.org/content/necesita-un-codigo-de-barras-gtin-global-trade-identificationnumber), el costo del código de barras asignado fue de USD 49 (pago único), con este trámite se puede usar internacionalmente este código de barras.

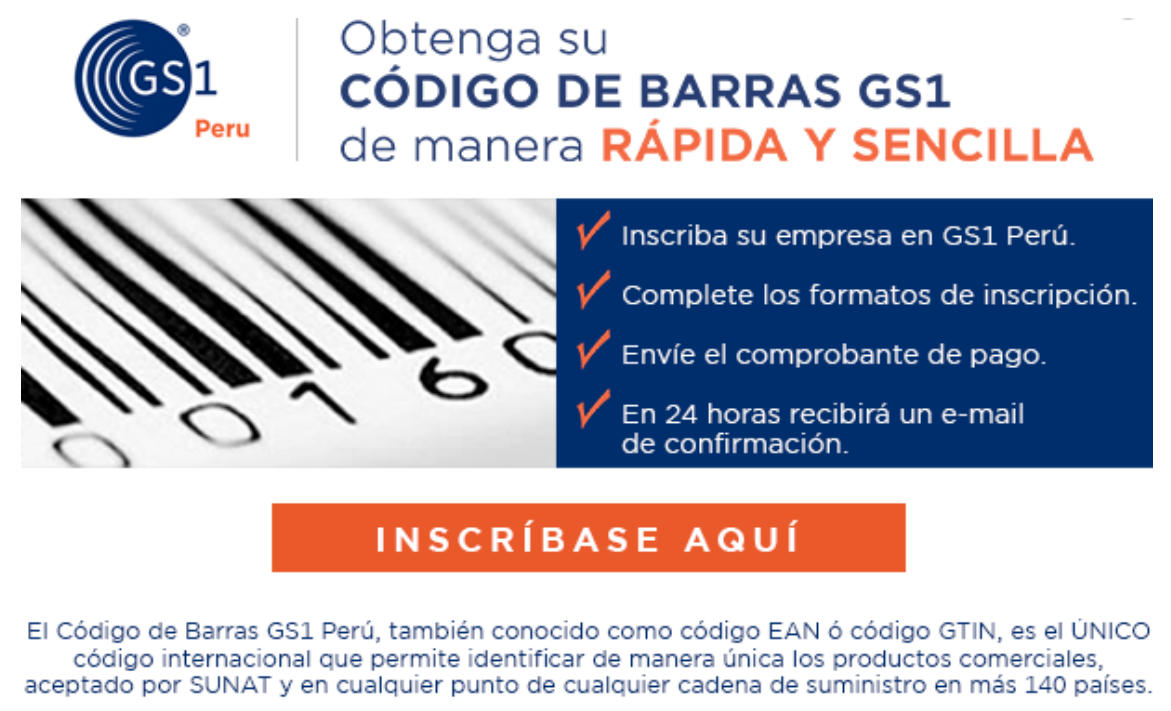

Figura 56. Publicidad GS1. Referenciado por gsl.pe.org, 2018.

\section{Cajas de cartón}

Sirven para el traslado del producto terminado, ayudan a mejorar el control del stock, el proceso de distribución y el manipuleo, En una caja entran 50 paquetes de 10 unidades, cada paquete es de $60 \times 100 \mathrm{~mm} \times 10 \mathrm{~mm}$ (ancho $\times$ largo $\times$ alto), la dimensión de las cajas es de $300 \mathrm{~mm} \times 200 \mathrm{~mm} \times 50 \mathrm{~mm}$ (ancho $\times$ largo $x$ alto) y su precio es de USD 0.20 FOB por caja. 


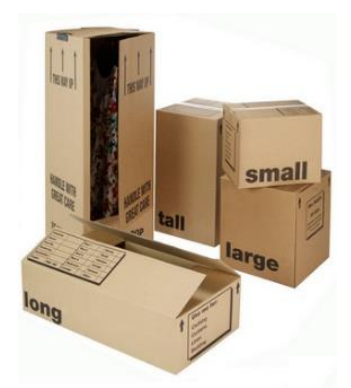

Figura 57. Cajas de cartón. Retif (2016).

\begin{tabular}{cccccc}
\hline Insumos & Unidades & $\begin{array}{c}\text { Consumo } \\
\text { Unitario }\end{array}$ & Merma \% & $\begin{array}{c}\text { Merma } \\
\text { Unidades }\end{array}$ & $\begin{array}{c}\text { Necesida } \\
\text { d }\end{array}$ \\
\hline Cajas de Embalaje & unidades & & & & 1.00 \\
\hline
\end{tabular}

\begin{tabular}{lc}
\hline \multicolumn{1}{c}{ Concepto } & $\begin{array}{c}\text { Costo Unitario } \\
\text { (Soles) }\end{array}$ \\
\hline Papel (pack x 10 unidades) 37.5 grms & 0.48000000 \\
Bolsa serigrafiada & 0.00069431 \\
Caja de cartón (50 packs /caja) & 0.02200000 \\
\hline
\end{tabular}

\section{b. Definición de Unidad de reparto (camión)}

Teniendo la información de los pesos y dimensiones de nuestro producto en cajas de 50 unidades se procede a efectuar el cálculo del tipo de camión más adecuado para el proceso de distribución:

\begin{tabular}{|c|c|c|c|c|c|}
\hline Pesos y Dimesiones & Ancho (m) & Largo (m) & Alto $(\mathrm{m})$ & $\begin{array}{l}\text { Cubicación } \\
\text { (m3) }\end{array}$ & Peso (Kg) \\
\hline Papel & - & - & - & - & 0.037 \\
\hline Caja & 0.300 & 0.200 & 0.050 & 0.003 & 0.100 \\
\hline $\begin{array}{l}\text { Caja conteniendo } 50 \text { packs de } 10 \\
\text { und }\end{array}$ & 0.300 & 0.200 & 0.050 & 0.003 & 1.952 \\
\hline $\begin{array}{l}\text { Capacidad de camión para } \\
\text { distribución (nominal) }\end{array}$ & 2.000 & 3.000 & 2.000 & 12.000 & $2,000.000$ \\
\hline $\begin{array}{l}\text { Número de Cajas posibles de } \\
\text { carga (nominal) }\end{array}$ & & & & $4,000.000$ & $1,024.590$ \\
\hline Venta Packs Mensual Promedio & & & & & $171,051.000$ \\
\hline Ventas mensuales en cajas & & & & & $3,421.020$ \\
\hline Número de Viajes & & & & & 4.00 \\
\hline
\end{tabular}




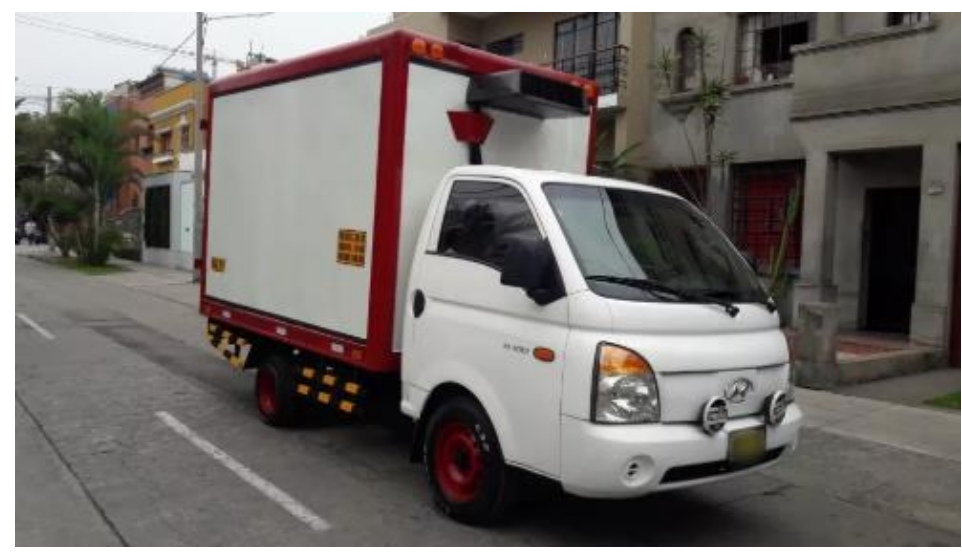

Figura 58. Camión de reparto. Adaptado de Hyundaicamiones,pe, 2017.

Con esta unidad de reparto se podrá iniciar operaciones de entrega la misma que como mínimo es exigida por las empresa que deseamos iniciar operaciones, su costo aproximado es de USD 8000.

\section{c. Definición del Proceso Productivo (Diagrama de Proceso)}

En el punto 5.1.1. de este mismo capítulo se definieron mediante un diagrama de flujo de procesos las actividades a realizar y que también forman parte del análisis de la Planificación Sistemática de la Distribución en la definición del layout. 


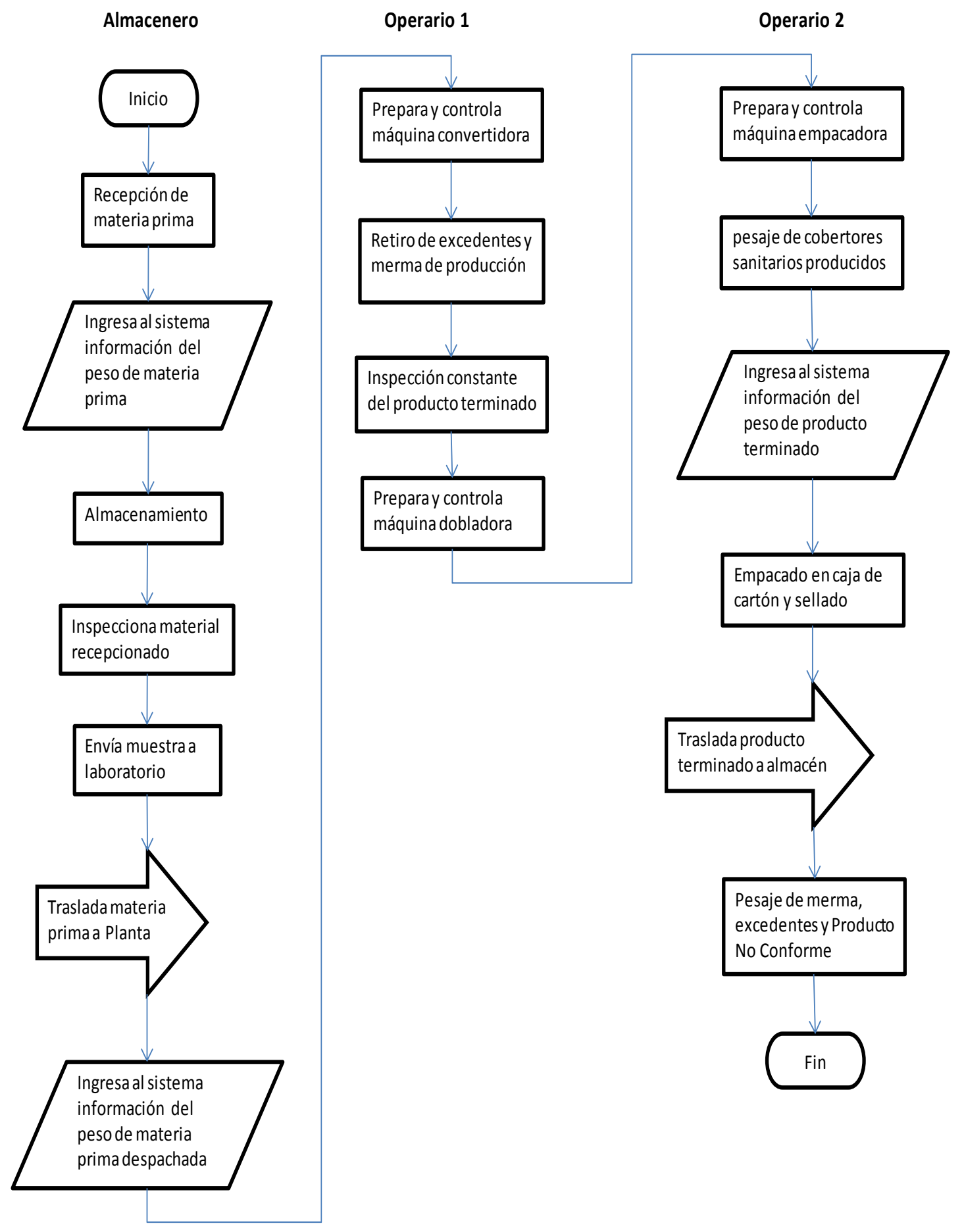

\section{d. Tabla de relaciones de actividades}

Una vez efectuado el análisis producto cantidades y hallado el total de metros cuadrados a usar en las instalaciones. Antes de proceder al desarrollo de los planos de distribución, primero se debe establecer las relaciones de cercanía entre todas las áreas y luego determinaremos el total de metros cuadrados necesarios considerando los pasadizos, para 
esto usaremos la matriz relacional donde declararemos todas las áreas, en ella buscaremos relacionar las áreas con factores de comunicación, seguridad, higiene, personal común, razón cliente-proveedor, etc. Para esto usaremos las siguientes tablas:

Tabla 45.

Relación de cercanía

\begin{tabular}{ccc}
\hline Valor & Cercanía & Código de Lima \\
\hline A & Absolutamente necesario & 4 líneas \\
E & Especialmente importante & 3 Líneas \\
I & Importante & 2 Líneas \\
O & Ordinario & 1 Línea \\
U & Sin importancia & Ninguna Línea \\
X & Indeseable & 1 Línea zigzag \\
XX & Muy indeseable & 2 Líneas zigzag \\
\hline
\end{tabular}

Elaboración propia.

Tabla 46.

Ratios - Razón.

\begin{tabular}{cl}
\hline Ratio & Razón \\
\hline 1 & Por control \\
2 & Por higiene \\
3 & Personal en común \\
4 & Por conveniencia \\
5 & Cliente - proveedor \\
6 & Comunicación \\
\hline
\end{tabular}

Elaboración propia. 
Tabla 47.

Relaciones de Actividades

\begin{tabular}{|c|c|c|c|c|c|c|c|c|c|c|c|}
\hline \multirow{2}{*}{ De } & \multicolumn{11}{|c|}{$\bar{A}$} \\
\hline & 1 & 2 & 3 & 4 & 5 & 6 & 7 & 8 & 9 & 10 & 11 \\
\hline \multirow{2}{*}{ 1.- Oficinas Administrativas } & & A & A & 1 & $\mathrm{U}$ & $\mathrm{U}$ & $\mathrm{U}$ & $x$ & 0 & $U$ & $\mathrm{U}$ \\
\hline & & 1,6 & 1,6 & 1 & 0 & 0 & 0 & 2 & 4 & 0 & 0 \\
\hline \multirow{2}{*}{ 2.- Oficinas de Producción } & & & $A$ & 1 & $A$ & $\mathrm{I}$ & 1 & $x$ & 0 & U & $\mathrm{U}$ \\
\hline & & & 4,6 & 5 & 4,6 & 4 & 5 & 2 & 4 & 0 & 0 \\
\hline \multirow{2}{*}{ 3.- Oficinas de Ventas } & & & & $\mathrm{I}$ & $x$ & 0 & $x$ & $x$ & 0 & $U$ & $\mathrm{U}$ \\
\hline & & & & 5 & 1 & 0 & 1 & 2 & 4 & 0 & 0 \\
\hline \multirow{2}{*}{ 4.- Almacenes } & & & & & A & 0 & 0 & $x$ & 0 & $U$ & $\mathrm{I}$ \\
\hline & & & & & 5 & 0 & 4 & 2 & 4 & 0 & 1 \\
\hline \multirow{2}{*}{ 5.- Producción } & & & & & & A & $E$ & 1 & 0 & $U$ & $\mathrm{U}$ \\
\hline & & & & & & 4 & 5 & 2 & 4 & 0 & 0 \\
\hline \multirow{2}{*}{ 6.- Areas verdes } & & & & & & & $u$ & $x$ & $U$ & $U$ & $u$ \\
\hline & & & & & & & 0 & 2 & 4 & 0 & 0 \\
\hline \multirow{2}{*}{ 7.- Mantenimiento } & & & & & & & & 1 & 0 & $U$ & $u$ \\
\hline & & & & & & & & 2 & 4 & 0 & 0 \\
\hline \multirow{2}{*}{ 8.- SSHH de producción } & & & & & & & & & $x x$ & $U$ & U \\
\hline & & & & & & & & & 2 & 0 & 0 \\
\hline \multirow{2}{*}{ 9.- Comedor } & & & & & & & & & & $U$ & $\mathrm{U}$ \\
\hline & & & & & & & & & & 0 & 0 \\
\hline \multirow{2}{*}{ 10.- Estacionamiento } & & & & & & & & & & & $\mathrm{E}$ \\
\hline & & & & & & & & & & & 1 \\
\hline \multirow[t]{2}{*}{ 11.- Vigilancia } & & & & & & & & & & & \\
\hline & & & & & & & & & & & \\
\hline
\end{tabular}

Nota: Se obtiene una representación gráfica que va aproximando a la distribución en planta. Lo más aconsejable es representar un diagrama al menos con los valores A, E, I. Elaboración propia.

\section{e. Diagrama Relacional de Actividades}

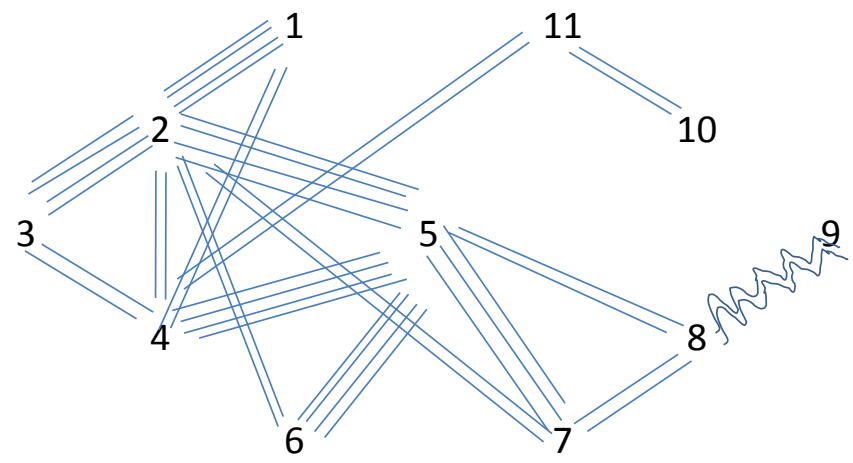

Figura 59. Diagrama relacional de Actividades. Este es un diagrama de la relación inicial basados en la tabla anterior, elaborado por el equipo de investigación.

Luego procedemos a efectuar una distribución inicial basada en el diagrama de relaciones (sin considerar las limitaciones de espacio). 
Tabla 48.

Diagrama de Distribución sin limitaciones de Espacio.

Primer Piso

Segundo piso

11

$10 \quad 5 \quad 3$

$2 \quad 5 \quad 9$

7.8

6

0

Nota: Distribución en primer y segundo piso. Elaboración propia.

\section{f. Necesidades de espacio - cálculo de superficies, definición de máquinas e instalaciones.}

Para efectuar el cálculo del área de las instalaciones consideraremos todos los equipos, máquinas y periféricos que se usarán en el proceso de producción, consideraremos adicionalmente la implementación de oficinas y áreas comunes para una operación adecuada y ordenada.

Tabla 49.

Dimensiones de Máquinas e instalaciones.

\begin{tabular}{|c|c|c|c|c|c|}
\hline Descripción & Cantidad & Unidad & Largo $(m)$ & Ancho (m) & Altura mínima (m) \\
\hline Convertidora & 1 & Und & 13.00 & 4.50 & 0.70 \\
\hline Dobladora & 1 & Und & 2.40 & 1.42 & 0.94 \\
\hline Embolsadora & 1 & Und & 2.84 & 4.65 & 1.72 \\
\hline Transpaleta & 1 & Und & 1.50 & 0.80 & 1.90 \\
\hline Balanza & 1 & Und & 1.00 & 1.00 & 0.30 \\
\hline Andamios & 10 & Juegos & 2.50 & 0.60 & 2.00 \\
\hline Jumbo de papel & 2 & M & 2.20 & 2.20 & 0.42 \\
\hline Bolsas de PVC & 120 & Rollo & 0.50 & 0.50 & 0.10 \\
\hline Cajas de cartón & 465 & Und & 0.30 & 0.12 & 0.10 \\
\hline Materiales auxiliares & 1 & Global & 1.00 & 1.00 & 2.40 \\
\hline Of. Producción & 1 & Und & 3.50 & 2.35 & 2.40 \\
\hline Áreas verdes & 1 & Und & 27.18 & 6.00 & 2.40 \\
\hline Mantenimiento & 1 & Und & 3.00 & 2.00 & 2.40 \\
\hline SS.HH. Producción & 1 & Und & 3.50 & 2.00 & 2.40 \\
\hline Estacionamiento & 3 & Und & 5.00 & 2.60 & 2.40 \\
\hline Vigilancia & 1 & Und & 1.00 & 1.00 & 2.40 \\
\hline
\end{tabular}

Nota: Dimensiones en metros de las instalaciones y de cada maquinaria. Elaboración propia. 
Áreas como Oficina de Ventas, Oficina de Administración y Comedor son diseñados en el segundo piso por lo que no intervienen en el cálculo de la superficie del terreno.

Existen diversos métodos para determinar la superficie del terreno, sin embargo para nuestro caso usaremos la siguiente regla de trabajo:

- Largo x ancho del área o equipo a evaluar.

- Adicionaremos $50 \mathrm{~cm}$. más tanto para la longitud como para el ancho como retiro de pared para asegurar limpieza y orden.

- Adicionaremos $60 \mathrm{~cm}$. más tanto para la longitud como para el ancho considerando los pasadizos por donde podría circular personal.

Tabla 50.

Dimensiones de Máquinas e instalaciones.

\begin{tabular}{|c|c|c|c|c|c|c|}
\hline Descripción & Cantidad & Unidad & Largo $(\mathrm{m})$ & Ancho (m) & Altura mínima (m) & Superficie (m) \\
\hline Convertidora & 1 & Und & 14.10 & 5.60 & 0.70 & 78.96 \\
\hline Dobladora & 1 & Und & 3.50 & 2.52 & 0.94 & 8.82 \\
\hline Embolsadora & 1 & Und & 3.94 & 5.75 & 1.72 & 22.66 \\
\hline Transpaleta & 1 & Und & 2.10 & 1.40 & 1.90 & 2.94 \\
\hline Balanza & 1 & Und & 2.10 & 2.10 & 0.30 & 4.41 \\
\hline Andamios & 10 & juegos & 12.00 & 5.10 & 2.00 & 61.20 \\
\hline Jumbo de papel & 2 & $\mathrm{~m}$ & 6.60 & 3.30 & 0.42 & 21.78 \\
\hline Bolsas de PVC & 120 & rollo & 9.60 & 1.60 & 2.00 & 15.36 \\
\hline Cajas de cartón & 465 & Und & 6.51 & 12.20 & 1.00 & 79.42 \\
\hline Materiales auxiliares & 1 & Global & 2.10 & 2.10 & 2.40 & 4.41 \\
\hline Of. Producción & 1 & Und & 1.01 & 3.10 & 2.40 & 12.71 \\
\hline Áreas verdes & 1 & Und & 27.18 & 6.00 & 2.40 & 163.08 \\
\hline Mantenimiento & 1 & Und & 4.10 & 3.10 & 2.40 & 12.71 \\
\hline SS.HH. Producción & 1 & Und & 4.10 & 2.60 & 2.40 & 10.66 \\
\hline Estacionamiento & 3 & Und & 5.00 & 7.80 & 2.40 & 39.00 \\
\hline Vigilancia & 1 & Und & 1.60 & 1.60 & 2.40 & 2.56 \\
\hline Total & & & & & & 540.68 \\
\hline
\end{tabular}

Nota: La superficie plantea el espacio físico que ocuparía cada maquinaria o instalación.

Elaboración propia.

El área resultante de adicionar pasadizos y retiros de pared es de $540 \mathrm{~m}^{2}$ la cual servirá para poder determinar conjuntamente con el flujo de actividades la distribución de la planta. 


\section{g. Diagrama Relacional de Superficies y generación de Diseños Alternativos.}

Evaluada las dimensiones y necesidad de pasadizos y retiros de pared, se efectúan alternativas de diseño de planta relacionadas al punto d) y e) de la fase anterior, obteniendo una aproximación real al diseño definitivo.

Sustituiremos en el diseño de planos los símbolos de cada área por la superficie que hemos calculado. Resulta práctico redefinir las superficies utilizando programas de diseño como el Visio o Autocad con el fin de obtener superficies proporcionales que encajan entre ellas más fácilmente.

Tabla 51.

Dimensiones y superficies ajustadas para Máquinas e instalaciones.

\begin{tabular}{|c|c|c|c|c|c|c|}
\hline Descripción & Cantidad & Unidad & Largo (m) & Ancho (m) & Altura mínima (m) & Superficie (m) \\
\hline Convertidora & 1 & Und & 14.10 & 8.60 & 0.70 & 121.26 \\
\hline Dobladora & 1 & Und & 3.94 & 2.85 & 0.94 & 11.23 \\
\hline Embolsadora & 1 & Und & 3.94 & 5.75 & 1.72 & 22.66 \\
\hline Transpaleta & 1 & Und & & & & \\
\hline Balanza & 1 & Und & & & & \\
\hline Andamios & 10 & Juegos & & & & \\
\hline Jumbo de papel & 2 & $M$ & 27.16 & 5.70 & 2.40 & 154.81 \\
\hline Bolsas de PVC & 120 & Rollo & & & & \\
\hline Cajas de cartón & 465 & Und & & & & \\
\hline Materiales auxiliares & 1 & Global & & & & \\
\hline Of. Producción & 1 & Und & 4.10 & 3.00 & 2.40 & 12.30 \\
\hline Áreas verdes & 1 & Und & 27.30 & 6.00 & 2.40 & 163.80 \\
\hline Mantenimiento & 1 & Und & 4.10 & 3.08 & 2.40 & 12.42 \\
\hline SS.HH. Producción & 1 & Und & 4.10 & 2.60 & 2.40 & 10.66 \\
\hline Estacionamiento & 3 & Und & 5.00 & 8.60 & 2.40 & 43.00 \\
\hline Vigilancia & 1 & Und & 1.60 & 1.60 & 2.40 & 2.56 \\
\hline Total & & & & & & 554.70 \\
\hline
\end{tabular}

Nota: Tomando como referencia el cuadro hallado en el punto e) anteriormente, el equipo de investigación procede a efectuar los ajustes necesarios hasta hallar el terreno perfecto.

Elaboración propia.

Considerando que pudieran existir las siguientes limitaciones o factores que influyan en la distribución de la planta:

- Materiales (materias primas, productos en curso, productos terminados). Incluyendo variedad, cantidad, operaciones necesarias, secuencias, etc. 
- Maquinaria.

- Trabajadores.

- Movimientos de personas y materiales.

- Espera (almacenes temporales, permanentes, salas de espera).

- Servicios (mantenimiento, inspección, control, programación, etc.

- Edificio (elementos y particularidades interiores y exteriores del mismo, instalaciones existentes, etc.).

- Versatilidad, flexibilidad, expansión.

- Disponibilidad de terrenos

- Precio de local

Teniendo en cuenta todos los factores y limitaciones técnicas se plantean uno o varios diseños alternativos entre los que se elegirá el más idóneo para nuestras necesidades.

Con el diseño elegido se readaptará las superficies realmente disponibles reajustando el diseño donde menos perjuicio se cause al proceso productivo.

Para esto, el área apropiada para las instalaciones debe tener como mínimo las siguientes dimensiones:

$\begin{array}{lll}\text { Ancho } & : & 21.00 \mathrm{~m} \\ \text { Longitud } & : & 30.00 \mathrm{~m} \\ \text { Superficie del terreno : } & 630.00 \mathrm{~m} 2\end{array}$

Se recomienda buscar un terreno que tenga las siguientes dimensiones $21 \mathrm{~m} \times 30 \mathrm{~m}$ que son dimensiones más comerciales de encontrar. 


\subsubsection{Distribución de equipos y maquinarias}
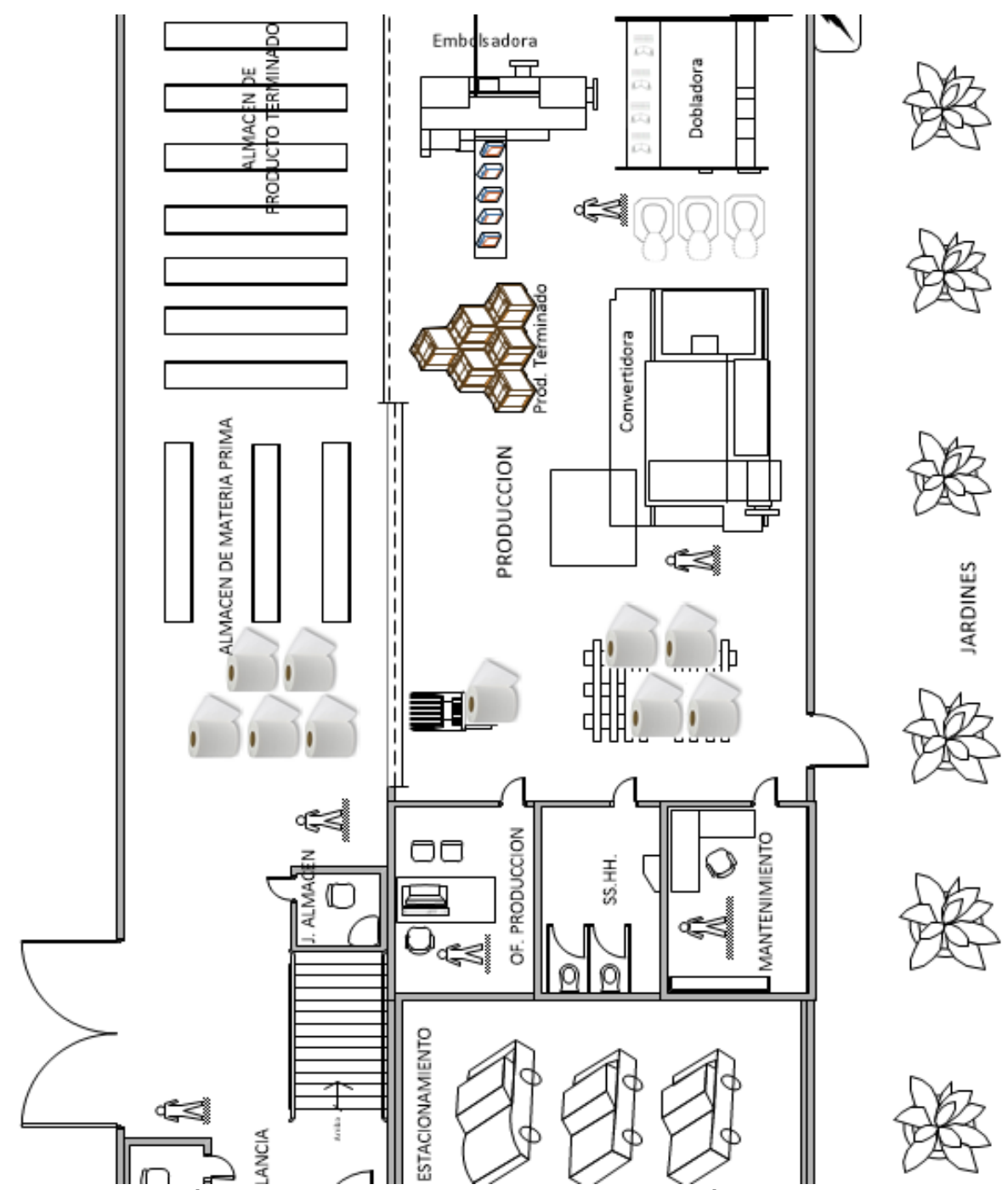

Figura 60. Distribución de equipos y maquinarias. Elaboración propia.

\subsection{Determinación del tamaño}

Para que la empresa pueda ser competitiva en el mercado, no puede basarse por siempre en el estudio de mercado inicial, toda vez que las necesidades de los consumidores van cambiando con el tiempo, por lo que se debe verificar constantemente si la empresa cumple con las necesidades de sus clientes actuales y anticiparse a lo que los clientes necesitarán en el futuro próximo, por medio de la investigación de mercados y el desarrollo o mejoramiento del producto existente o la creación de uno nuevo que pueda suplir las necesidades del consumidor.

Teniendo en cuenta lo anterior, la empresa debe implementar una política de investigación y desarrollo el cual se basa en el estudio de maduración del producto, análisis 
de las necesidades del mercado y la adaptación a los cambios que el cliente requiere. (Sánchez, Moreno y Sánchez, 2012).

En el proceso de investigación, la empresa realizará un pequeño estudio de mercado que permita observar las necesidades actuales y futuras de clientes y proveedores, con el fin de identificar las posibles modificaciones a realizar al producto o si es necesario diseñar uno nuevo y las mejoras que se pueden implementar en el proceso comercial que permita beneficiar tanto a la empresa como a los clientes.

Ahora bien, como con el proceso de investigación seguramente se encontrarán nuevas ideas y necesidades de mercado, con el proceso de desarrollo se busca demostrar o no la factibilidad de hacer esos cambios y se ayuda a convertir esas ideas en realidad.

Por último, en la parte del diseño se elabora la documentación técnica que permite modificar el producto, según las nuevas condiciones y necesidades de mercado encontradas en el proceso de investigación.(Sánchez et al, 2012)

\subsubsection{Proyección de crecimiento}

Se realizará un cálculo de las capacidades de producción de cada una de las máquinas que intervienen en el proceso productivo las cuales servirán como proyección de crecimiento.

a. Máquina convertidora: En cuadro siguiente se muestra información del fabricante respecto a la velocidad de corte de esta máquina reducida en un $10 \%$ respecto a la velocidad nominal a fin de considerar paradas no programadas $u$ otros inconvenientes de la producción, es decir, 49.5 cortes/min. Adicionalmente hemos considerado que los turnos son de 8 horas y se ha establecido que dentro del horario estará la hora de refrigerio, tiempo ocioso, ineficiencias de operario, etc., es decir $336 \mathrm{~min} / \mathrm{turno}$, el trabajo mensual es de lunes a sábado, 26 días y la máquina efectúa cortes simultáneos de 10 cobertores a la vez. Puede apreciarse que aparte de contar con disponibilidad los días domingos, hasta el cuarto año tendremos espacios disponibles de tiempo para efectuar mantenimiento preventivo a las cuchillas y ajustes de ser necesarios.

b. Máquina dobladora: Para el caso de la máquina dobladora de los cobertores sanitarios también hemos considerado información del fabricante sobre su velocidad nominal de doblado de 142 unidades/min, sin embargo, hemos castigado la velocidad 
nominal con un $10 \%$ para obtener una capacidad más o menos real de producción. Para el caso de la dobladora igualmente se ha considerado que el turno sigue siendo de 8 horas con paradas para refrigerio y paradas de personal no programadas (336min/turno), el trabajo será mensual de lunes a sábado, 26 días, esta máquina puede configurarse para que haga doblados simultáneos por lo que se configurará a un máximo de 10 cobertores a la vez. Al no tener todos los turnos ocupados también un margen para efectuar mantenimientos de ser necesario.

c. Máquina embolsadora: al igual que en las otras máquinas, se adjunta información del fabricante donde hemos considerado la velocidad de 50 paquetes/min y se ha castigado con $10 \%$ de velocidad nominal, adicionalmente se ha considerado turnos de 8 horas, 26 días de trabajo al mes y embolsados simultáneos de 10 cobertores que será el contenido de nuestro producto terminado.

Esta máquina embolsa de acuerdo a necesidad, puede ser configurada para que el embolsado sea de 1 pieza hasta 20 piezas, para nuestro plan de negocio, el producto final que ofreceremos al mercado es de 10 unidades por paquete por lo que se ha de realizar el embolsado con esta restricción. 
Tabla 52.

Capacidad de producción por máquina

\begin{tabular}{|c|c|c|c|c|c|c|c|c|c|c|c|}
\hline Tipo de Máquina & $\begin{array}{l}\text { Velocidad } \\
\text { Nominal }\end{array}$ & $\begin{array}{c}\text { Velocidad } \\
\text { Promedio } \\
\text { de } \\
\text { Producción }\end{array}$ & $\begin{array}{c}\text { Total } \\
\text { Minutos } \\
\text { por } \\
\text { Turno }\end{array}$ & ineficiencia & $\begin{array}{c}\text { Minutos } \\
\text { Disponibles } \\
\text { por Turno }\end{array}$ & Turnos/día & $\begin{array}{l}\text { Disponibilidad } \\
\text { de días/mes }\end{array}$ & $\begin{array}{c}\text { Protectores } \\
\text { Producidos } \\
\text { por Turno }\end{array}$ & $\begin{array}{c}\text { Packs Por } \\
\text { Turno }\end{array}$ & $\begin{array}{c}\text { Producción } \\
\text { Mensual }\end{array}$ & $\begin{array}{c}\text { Producción } \\
\text { Anual }\end{array}$ \\
\hline \multirow{2}{*}{ CONVERTIDORA } & 500 PZAS X & & & & & & & & & & \\
\hline & MINUTO & 500 & 480 & 144 & 336 & 1 & 26 & 168,000 & 16,800 & 436,800 & $5,241,600$ \\
\hline \multirow{2}{*}{ DOBLADORA } & 428 PIEZAS $X$ & & & & & & & & & & \\
\hline & MINUTO & 428 & 480 & 144 & 336 & 1 & 26 & 143,808 & 14,381 & 373,901 & $4,486,810$ \\
\hline \multirow{2}{*}{ EMBOLSADORA } & 25 A 90 PIEZAS & & & & & & & & & & \\
\hline & X MINUTO & 50 & 480 & 144 & 336 & 1 & 26 & 16,800 & 16,800 & 436,800 & $5,241,600$ \\
\hline
\end{tabular}

Nota: Se ha determinado la producción de convertidora, dobladora y embolsadora, teniendo en cuenta algunos factores.

Elaboración propia. 
Como puede observarse, la dobladora es la máquina que delimitará la cantidad a producirse anualmente y la que marcará el porcentaje de público objetivo a atender, por lo que la máxima capacidad de producción por turno es de 4486,800 packs por año.

La demanda para los próximos 5 años, tomando en cuenta la proyección sería la siguiente:

Tabla 53.

Demanda Estimada Mensual y Anual

\begin{tabular}{ccc}
\hline Años & $\begin{array}{c}\text { Demanda } \\
\text { Mensual de Packs }\end{array}$ & Demanda Anual de Packs \\
\hline 2017 & 171,051 & $2,052,607$ \\
2018 & 173,702 & $2,084,423$ \\
2019 & 176,394 & $2,116,731$ \\
2020 & 179,128 & $2,149,541$ \\
2021 & 181,905 & $2,182,858$ \\
\hline
\end{tabular}

Elaboración propia.

Esta información de la demanda estimada por los próximos 5 años es conservadora para un escenario donde el mercado aún no conoce el producto, ya que se considera para la proyección de la misma la tasa de crecimiento poblacional de $1.55 \%$, para ello el presupuesto de marketing se irá incrementando en $5 \%$, sin embargo, estas cifras deben ser evaluadas por el área comercial que está en constante contacto con el mercado y conoce el crecimiento real del mismo, por otro lado este cuadro permitirá determinar si contamos con todos los elementos productivos necesarios para atender el mercado objetivo ya que serán comparados con el estudio de mercado.

\subsubsection{Recursos.}

Los principales recursos para la producción son:

a. Materiales, asociado a la necesidad de incrementar los procesos productivos la adquisición de materiales como son: Papel, Polietileno, Cartón, materiales auxiliares, herramientas, equipos, maquinarias, instalaciones toma una vital importancia ya que todos estos materiales tangibles se vuelven en algunos casos escasos y en algunos otros casos obsoletos.

Es importante que el área de Ventas desarrolle estrategias para ofrecer nuevas alternativas en el mercado con la finalidad que el área de logística cumpla con su función de adquirir materiales de menor costo, asociados a un mejor rendimiento y de alta tecnología. 
Por otro lado, el área de Producción deberá mejorar sus procesos productivos y mantener sus equipos y maquinarias en buen estado con la finalidad de darle una vida útil mayor a la proyectada.

b. Humanos, son trascendentales para la existencia de cualquier grupo social; son un factor primordial en la carga de una empresa, de este recurso depende el manejo y funcionamiento de los demás recursos de una empresa. Debe mantenerse siempre la motivación cultural y económica en los trabajadores ya que su frustración recae siempre en la productividad, debe haber siempre un buen clima organizacional asociado al buen trato y la comunicación transversal, la transferencia de conocimiento es básico para el buen desenvolvimiento y la solución de problemas en equipo, la capacitación motiva el desarrollo profesional de los trabajadores.

El área de Recursos Humanos en coordinación con los jefes de área debe hacer un diagnóstico situacional para comprender como es el proceso de toma de decisiones y si todos entienden el rumbo que deben seguir. Deberá realizar un reordenamiento de las áreas de producción, revisando los perfiles y procesos y redefiniendo roles y funciones, unificando criterios y formalizándolos. Deberá hacerse seguimiento de las propuestas y garantizar su continuidad y finalmente reforzar la mejora con incentivos. Esto mejorará la productividad, el trabajo en equipo, la motivación y la pertenencia del trabajador por su área de trabajo.

c. Financieros, asociados al carácter económico y que requiere una empresa para el desarrollo de las actividades, es de vital importancia que el área de Finanzas proporcione los recursos económicos necesarios en caso hubiera la necesidad de un incremento en los recursos antes mencionados.

\subsubsection{Tecnología.}

En cuanto a la tecnología de las máquinas se optaron por la adquisición de unas máquinas de origen chino por ser un poco más económicas y son fáciles de encontrar repuestos alternativos en el mercado peruano, parte de la estrategia es hacer una inversión preoperativa mínima con la finalidad de generar una recuperación de la inversión en un tiempo más corto. Por otro lado, existe en el mercado otras máquinas convertidoras de cobertor sanitario de origen europeo que podrían ser una oportunidad de adquisición cuando la empresa en encuentre consolidada. 


\subsubsection{Flexibilidad}

Hay ciertos factores que se han de considerar para evaluar la flexibilidad de nuestra planta de producción, una de ellas es la capacidad utilizada versus la capacidad instalada total y el otro es el tamaño de las instalaciones.

\section{a. Capacidad utilizada versus la capacidad instalada total}

Considerando que año tras año podría haber una especialización en el uso de las máquinas y estas se encuentran asentadas apropiadamente, se podría considera ahora un incremento de $2.5 \%$ años tras año en la velocidad de las máquinas. El personal de operaciones optimiza sus tiempos de proceso y ésta mejora en $5 \%$ al año. Adicionalmente se los turnos se llevan a su máxima atención con una producción continua de 30 días al mes. Con esta tabla se puede determinar la capacidad instalada total para los próximos 5 años:

Haciendo un comparativo entre la capacidad utilizada y la capacidad instalada total restringida por la máquina de menor capacidad, se adjunta año tras año la capacidad ociosa de planta que podría ser una oportunidad de crecimiento en caso hubiera la necesidad de atender una demanda vertiginosa del mercado, considerando que solo se trabajará un solo turno.

Tabla 54.

Capacidad disponible

\begin{tabular}{cccc}
\hline Años & Capacidad Utilizada & $\begin{array}{c}\text { Capacidad } \\
\text { Instalada }\end{array}$ & Capacidad Disponible \\
\hline 2017 & $2,052,607$ & $4,486,810$ & $54.25 \%$ \\
2018 & $2,084,423$ & $4,486,810$ & $53.54 \%$ \\
2019 & $2,116,731$ & $4,486,810$ & $52.82 \%$ \\
2020 & $2,149,541$ & $4,486,810$ & $52.09 \%$ \\
2021 & $2,182,858$ & $4,486,810$ & $51.35 \%$ \\
\hline
\end{tabular}

Nota: Determinación de la capacidad disponible a través de capacidad utilizada y capacidad instalada para los años 2018, 2019, 2020, 2021 Y 2022.

Elaboración propia.

b. Tamaño de las instalaciones, cuando se evaluó el punto 5.1 .3 y 5.1 .4 de este mismo capítulo se consideró un área de jardines que podrían servir como un área pulmón para el crecimiento de las áreas de producción. En dicho capítulo se calculó un área de $154.81 \mathrm{~m} 2$ para el área de producción y los jardines tienen un área de $163.80 \mathrm{~m} 2$ que podrían duplicar nuestra capacidad productiva., Se calcula una capacidad utilizada bastante moderada, pues se ha estimada un crecimiento de los clientes bastante conservador. 


\subsection{Estudio de localización}

El local donde estará ubicada la planta de elaboración de los protectores sanitarios de papel es en la ciudad de Lima. La razón fundamental radica en que el mercado al cual se va a ingresar son los supermercados de la misma ciudad por lo que el determinar el distrito será el punto de evaluación.

Lima cuenta con más de 155 establecimientos de los denominados hipermercados o supermercados, pertenecientes a las diferentes cadenas comerciales, tales como Plaza Vea, Vivanda, Tiendas Wong, Metro, Tottus, que constituyen lugares donde suele concurrir el cliente objetivo y que constituyen el medio a través del cual se comercializará el producto.

\subsubsection{Definición de factores locacionales.}

Con la finalidad de obtener la ubicación más adecuada se ha elaborado una matriz con distintos factores, a los que se les ha asignado un peso determinado, de acuerdo a su importancia.

Al respecto, se ha considerado tres distritos de Lima Metropolitana, a los cuales para cada factor evaluado se le ha otorgado una calificación entre 1 y 10, siendo 1 para menos adecuado y 10 para más adecuado, usando la siguiente escala:

$\begin{array}{ll}\text { Excelente - Muy Abundante } & 9-10 \\ \text { Muy Buena - Abundante } & 7-8 \\ \text { Buena - Buena Cantidad } & 5-6 \\ \text { Regular - Regular } & 3-4 \\ \text { Mala - Escasa } & 1-2\end{array}$

Los factores para definir la localización han sido los siguientes:

- Proximidad a la Materia Prima alternativa: permite hasta cierto punto considerar la alternativa de comprar materiales locales de mayor costo pero de corto periodo de entrega en caso hubiera problemas en la importación de insumos.

- Proximidad al Mercado: Se trataría de contar con vías rápidas de fácil acceso, a efectos de tener una pronta distribución hacia los puntos donde se vendería el producto, pero como los supermercados se encuentran en todo Lima metropolitana, este factor no es tan crítico. 
- Disponibilidad de Mano de Obra: la empresa requiere contar con personal medianamente calificado que tengan conocimiento en el uso de maquinaria y su mantenimiento, aunque el mayor porcentaje deberá estar constituido por obreros. Por lo tanto se considerarán a los distritos de Lima, Comas e Independencia, en donde existe aproximadamente la misma oferta de trabajo por parte de los obreros y personal medianamente calificado. En cuanto al personal calificado no habrá preocupación puesto que los centros de educación superior se encuentran en diversos distritos de Lima.

- Disponibilidad de Energía Eléctrica limpia: La energía eléctrica representa un suministro básico para el funcionamiento de la planta. La potencia de energía debe ser constante, razón por la cual se requerirá una zona donde la estabilidad de la corriente no deteriore las maquinarias, podría evaluarse la instalación de un banco de condensadores a fin de evitar sobrecargas de energía, que, eventualmente, podrían dañar las maquinarias y equipos.

- Disponibilidad de Transporte y Flete: Este servicio podría ser cubierto por unidades de transporte propio o tercerizado, a fin de poder garantizar el oportuno abastecimiento de las materias primas, así como la adecuada distribución del producto terminado a los supermercados o hipermercados, distribuidos en la gran mayoría de los distritos de Lima Metropolitana.

- Disponibilidad de Terreno: Dada las características del proceso productivo que no afecta al medio ambiente y tampoco se utilizan productos químicos contaminantes 0 similares, no constituye una exigencia localizar la fábrica en una zona industrial pero sí alejado de productos inflamables.

Hay que considerar que las maquinarias y equipos requeridos por la empresa no son muy sofisticados, pero si requieren de montaje técnico especial por lo que el terreno debe contar con techo y un piso apropiado.

El local debe contar con un área de aproximadamente $630.00 \mathrm{~m} 2$ y que esté ubicado en una zona cercana a vías de comunicación fluidas permitiría satisfacer las necesidades para recibir las materias primas sin ningún contratiempo, y poder despachar los productos terminados hacia los diversos supermercados o hipermercados de la capital. 
- Clima: El clima húmedo representa un factor crítico debido a que el producto a comercializar tiene la propiedad de absorber humedad y podría deteriorarse, una vez concluida la producción éste puede almacenarse a temperatura ambiente entre 15 y $30^{\circ} \mathrm{C}$, nivel considerado adecuado para mantener las propiedades y características del producto.

- Eliminación de Desechos: La eliminación de los desperdicios generados en la elaboración del protector sanitario no involucra tener que adoptar planificaciones o previsiones especiales, dado que los desechos generados no son contaminantes. Para el efecto, resultará suficiente utilizar bolsas de plástico de color o cilindros abiertos.

- Reglamentación Fiscal y Legal: Para implementar la empresa se debe constituir legalmente y cumplir con las exigencias fiscales y legales que permitan su operatividad. En la ejecución de estos trámites, se debe tener presente la rapidez y facilidad de las mismas, lo cual dependerá del distrito donde se decida localizar la fábrica.

- Servicios de Construcción, Montaje y Mantenimiento: En la implementación de la fábrica (oficinas, mobiliario, maquinarias y equipos) no debe requerir mayores construcciones, ni montaje de equipos o mantenimiento especial que obligue a contratar a empresas calificadas. En general, se podría considerar que el proyecto involucra obras de menor envergadura tales como levantamiento de tabiquerías e instalación de fajas transportadoras.

\subsubsection{Determinación de la localización óptima}

Existen diversos métodos para evaluar la mejor ubicación de una instalación (modelo de la mediana simple, programación lineal, transporte y costos). Para determinar la mejor localización de la planta usaremos el método de evaluación sinérgico de localización de plantas (Brown y Gibson) basándose en 3 tipos de factores: críticos, objetivos y subjetivos.

Contamos con la siguiente información previa: 
Tabla 55.

Requerimientos

\begin{tabular}{cc}
\hline Requerimientos & Unidades \\
\hline Personal necesario & 5.00 \\
Energía requerida (Kw/mes) & $3,317.60$ \\
Transporte a 10 km (USD) & 150.00 \\
Transporte a 20 km (USD) & 250.00 \\
Transporte a 30 km (USD) & 300.00
\end{tabular}

Elaboración propia.

Ahora, calculemos los costos de operación:

Tabla 56.

Costos de operación

\begin{tabular}{crrr}
\hline Costo de Construcción & \multicolumn{1}{c}{ Ate } & Lima Industrial & \multicolumn{1}{c}{ Chorrillos } \\
\hline Salario anual 05 trabajadores & $30,000.00$ & $24,960.00$ & $30,000.00$ \\
Costo de energía anual & $2,321.21$ & $2,399.73$ & $2,321.21$ \\
Costo de Transporte & $2,940.00$ & $2,520.00$ & $3,120.00$ \\
Transporte a 10 km & 360.00 & 810.00 & 360.00 \\
Transporte a $20 \mathrm{~km}$ & $1,500.00$ & $1,350.00$ & 600.00 \\
Transporte a 30 km & $1,080.00$ & 360.00 & $2,160.00$ \\
Costo de Alquiler dólares $/ \mathrm{m} 2$ & 5.00 & 5.00 & 5.00
\end{tabular}

Nota: Los costos de operación fueron expresados en dólares. Elaboración propia.

a. Factores críticos: se han considerado claves aquellos que afectan directamente al desenvolvimiento de las operaciones, su calificación es binaria ( 1 y 0 ) y se calcula con la factorización de todos los elementos.

$\mathrm{FC}=$ Energía * Clima * Terrenos

En cuadro adjunto se consideran los siguientes factores críticos y su calificación respectiva:

Tabla 57.

Factores críticos

\begin{tabular}{ccccc}
\cline { 2 - 4 } & \multicolumn{3}{c}{ Factor Crítico } & \\
\hline Distrito & Energía & Clima & Terrenos & Factor Crítico \\
\hline Ate & 1.00 & 1.00 & 1.00 & 1.00 \\
Lima Industrial & 1.00 & 1.00 & 1.00 & 1.00 \\
Chorrillos & 1.00 & 1.00 & 1.00 & 1.00 \\
\hline
\end{tabular}

Elaboración propia. 
b. Factores Objetivos: son los costos mensuales o anuales más importantes al establecerse una empresa o mantenerla operativa, como la materia prima será importada, el costo será siempre el mismo para todos los locales por lo que no se considerará en el cuadro adjunto. Su valor relativo se calcula mediante la siguiente fórmula:

$$
F O i=\frac{\frac{1}{C t_{i}}}{\sum_{i=1}^{n} \frac{1}{C t_{i}}}
$$

Hemos considerado como factores objetivos los siguientes:

Tabla 58.

Factores objetivos

Factores Objetivos

\begin{tabular}{cccccccr} 
Distrito & Mano de Obra & Flete & Flete y transporte & Energía & Acondicionamiento & Total \\
\hline Ate & USD 30,000.00 & USD 4,410.00 & USD 2,940.00 & USD 2,321.00 & USD 4,300.00 & USD 43,971.00 \\
Lima Industrial & USD 24,960.00 & USD 3,780.00 & USD 2,520.00 & USD 2,400.00 & USD 4,000.00 & USD 37,660.00 \\
Chorrillos & USD 30,000.00 & USD 4,410.00 & USD 3,120.00 & USD 2,321.00 & USD 4,450.00 & USD 44,301.00 \\
\hline
\end{tabular}

Elaboración propia. 
Para determinar el factor objetivo de los distritos en revisión se tiene lo siguiente:

$$
\begin{gathered}
\text { FOAte } \frac{1}{43971\left(\frac{1}{43971}+\frac{1}{37660}+\frac{1}{44301}\right)}=0.3164 \\
\text { FOLima } \frac{1}{37660\left(\frac{1}{43971}+\frac{1}{37660}+\frac{1}{44301}\right)}=0.3695 \\
\text { FOChorrillos } \frac{1}{44301\left(\frac{1}{48971}+\frac{1}{37660}+\frac{1}{44301}\right)}=0.3141
\end{gathered}
$$

\begin{tabular}{|c|c|c|c|c|c|c|c|}
\hline \multirow{2}{*}{ Distrito } & \multicolumn{5}{|c|}{ Factores Objetivos } & & \multirow{2}{*}{ Total } \\
\hline & Mano de Obra & Flete & Flete y transporte & Energía & Acondicionamiento & & \\
\hline Ate & USD $30,000.00$ & USD $4,410.00$ & USD 2,940.00 & USD $2,321.00$ & USD 4300.00 & USD $43,971.00$ & 0.3183 \\
\hline Lima Industrial & USD $24,960.00$ & USD $3,780.00$ & USD $2,520.00$ & USD $2,400.00$ & USD $4,000.00$ & USD $37,660.00$ & 0.3654 \\
\hline Chorrillos & USD $30,000.00$ & USD $4,410.00$ & USD $3,120.00$ & USD $2,321.00$ & USD $4,450.00$ & USD $44,301.00$ & 0.3162 \\
\hline
\end{tabular}

Tabla 59. Factores objetivos por distritos

c. Factores subjetivos: son los factores de tipo cualitativo pero que afectan el funcionamiento de la planta su calificación es porcentual (\%) y pueden ser de impacto ambiental, clima social, aceptación de la comunidad, facilidad fiscal y municipal, accesos, etc.)

Hemos considerado el siguiente cuadro porcentual con una calificación de Deficiente, buen o excelente y que afecta directamente con el desenvolvimiento de la empresa: 
Tabla 60.

Cuadro porcentual.

\begin{tabular}{lcccc}
\hline \multicolumn{1}{c}{ Factores subjetivos } & Ponderación & Deficiente & Buena & Eficiente \\
\hline Disponibilidad de mano de obra & $27 \%$ & $0 \%$ & $15 \%$ & $30 \%$ \\
Disponibilidad de accesos & $30 \%$ & $0 \%$ & $15 \%$ & $35 \%$ \\
Eliminación de desechos & $19 \%$ & $0 \%$ & $10 \%$ & $20 \%$ \\
Reglamentación fiscal y legal & $24 \%$ & $0 \%$ & $10 \%$ & $30 \%$ \\
\hline Total & \multicolumn{2}{c}{$\mathbf{1 0 0} \%$} & &
\end{tabular}

Elaboración propia.

Esta misma tabla calificativa se aplica para los distritos en evaluación y se obtiene el siguiente cuadro:

Tabla 61.

Tabla calificativa

\begin{tabular}{lcccc}
\hline \multicolumn{1}{c}{ Factores subjetivos } & Ponderación & Deficiente & Buena & Eficiente \\
\hline Disponibilidad de mano de obra & $27 \%$ & $15 \%$ & $15 \%$ & $30 \%$ \\
Disponibilidad de accesos & $30 \%$ & $15 \%$ & $15 \%$ & $35 \%$ \\
Eliminación de desechos & $18 \%$ & $10 \%$ & $10 \%$ & $20 \%$ \\
Reglamentación fiscal y legal & $24 \%$ & $10 \%$ & $10 \%$ & $30 \%$ \\
\hline Total & $100 \%$ & $50 \%$ & $50 \%$ & $115 \%$ \\
\hline
\end{tabular}

Elaboración propia.

Ahora calcularemos el índice de localización y corresponde a la combinación de los factores críticos, objetivos y subjetivos mediante la siguiente fórmula:

$$
I L_{i}=F C_{i}\left\{\left(F O_{i} * \alpha\right)+\left[(1-\alpha)\left(F S_{i}\right)\right]\right\}
$$

Donde Alfa equivale al nivel de confiabilidad de la evaluación y para nuestro caso usaremos un alfa $=80 \%$ o 0.80

El índice de localización para los distritos de Ate, Lima y Chorrillos es:

$$
\begin{gathered}
I L_{\text {Ate }}=1\{(0.3164 * 0.8)+[(1-0.8)(0.50)]\}=0.3532 \\
I L_{\text {Lima }}=1\{(0.3695 * 0.8)+[(1-0.8)(1.15)]\}=0.5256 \\
I L_{\text {Chorrillos }}=1\{(0.3141 * 0.8)+[(1-0.8)(0.50)]\}=0.3518
\end{gathered}
$$


El siguiente tabulado muestra los índices de localización de todos los distritos, podemos observar que el distrito de Lima tiene un índice de localización equivalente a 0,5256 siendo el distrito que tiene el mayor índice de localización y sería la mejor opción.

Tabla 62. Índices de localización de todos los distritos

\begin{tabular}{cc}
\hline Distrito & Índice de Localización \\
\hline Ate & 0.3532 \\
Lima Industrial & 0.5256 \\
Chorrillos & 0.3518
\end{tabular}

Elaboración propia.

Para efectos del proyecto se escoge el distrito de Lima Metropolitana y un local de $630 \mathrm{~m} 2$ con un costo de alquiler de $\mathbf{5 . 0 0}$ dólares $/ \mathrm{m} 2$.

\subsection{Consideraciones legales}

El presente estudio busca delimitar todos los aspectos legales para la viabilidad del proyecto, de acuerdo a las normas de ordenamiento jurídico vigentes en el país. Así mismo, la legislación laboral y su impacto a nivel de sistemas de contratación, prestaciones sociales y demás obligaciones laborales.

La empresa, ingresará al mercado como una persona jurídica en la modalidad de Sociedad Anónima Cerrada (SAC).

La Sociedad Anónima Cerrada - S.A.C., se encuentra regulada por la Ley General de Sociedades - Ley № 26887, 05-12-1997 fue promulgada ysu publicación se realizó el 0912-1997.

La justificación que sustenta elegir este tipo de personería es la siguiente:

- Figura más dinámica y recomendable para una empresa de envergadura pequeña o mediana, pues permite a los accionistas socios participar en forma activa y directa en la administración, gestión y representación social.

- La Sociedad Anónima Cerrada se constituye por la Junta General de Accionistas, Directorio Facultativo y Gerencia General.

- La SAC no tiene acciones inscritas en el Registro Público del Mercado de Valores. Es posible que en su estatuto se establezca un Directorio facultativo, es decir que cuente o no con uno; y pueda contar con una auditoría externa anual si así lo pactase el estatuto o los accionistas. 
- Protección del patrimonio personal de los accionistas frente al patrimonio del negocio y sus riesgos. En un negocio siempre hay un nivel de riesgo donde las cosas pueden ir mal, al constituir una persona jurídica se puede delimitar claramente cuál es el patrimonio que está sujeto a esos riesgos, patrimonio que sus acreedores podrían ejecutar, pero sin tocar el patrimonio personal.

- Mayor credibilidad y presencia en el mercado. Las personas esperan hacer negocios con empresas constituidas como personas jurídicas y las prefieren frente a las personas naturales dado que hay una percepción de permanencia en el tiempo que va más allá de los percances que pueda tener una persona natural y proyecta de esta manera la imagen de ser una organización estable y no improvisada.

- Mejor acceso a las entidades bancarias y de crédito. Los bancos y financieras siempre esperan que las empresas estén constituidas en forma de personas jurídicas y por ello hay más facilidad para acceder a sus productos crediticios.

- Existencia de ventajas tributarias. Si bien como persona natural y sin constituir ninguna persona jurídica se puede tener acceso a todas las ventajas tributarias de la ley, el tener una persona jurídica permite acreditar con mayor facilidad el derecho a gozar de las mismas al tener el patrimonio personal separado claramente del negocio.

- En el Perú, si bien la información de las personas que son socios de una persona jurídica es una información que se puede obtener, lo cierto es que se tiene un relativo anonimato que hoy en día, por temas de seguridad personal y familiar, puede ser muy importante.

- Si no se constituye una S.A.C., persona jurídica, los socios deben regular todos los aspectos de su relación. En cambio, al tener una persona jurídica ya existe una regulación general dada por la ley que le facilita regular la relación entre los socios.

- Mayor estabilidad del negocio. Cualquier incapacidad o incluso muerte de los socios no la afecta, pues la sociedad tiene existencia más allá de la situación personal de los socios.

- Mayor control sobre las decisiones que se tomen en el negocio. Al tener constituida una sociedad se evita el riesgo que alguno de los socios tome decisiones unilaterales que afecten el negocio, dado que en los estatutos de constitución de la sociedad usted regulará quienes son los autorizados a tomar las decisiones a nombre de la empresa.

- Fácil transferencia de la propiedad, pues se transfieren acciones que son los documentos que acreditan las participaciones en la sociedad. 


\subsubsection{Identificación del marco legal.}

\section{a. Forma societaria}

La razón social de la empresa será "Masterkey S.A.C." En el caso de "S.A. Masterkey

S.A.C.", el accionariado estará estructurado en partes iguales y de la forma siguiente:

Tabla 63.

Composición Accionaria

\begin{tabular}{cc}
\hline Accionista & Porcentaje \\
\hline A & $37.04 \%$ \\
B & $26.84 \%$ \\
C & $36.12 \%$ \\
\hline Total & $100.00 \%$
\end{tabular}

Elaboración propia.

Los accionistas constituyen la Junta General de Accionistas (J.G.A.) y son los responsables de aprobar y desaprobar las decisiones e inversiones importantes que la plana gerencial decida implementar.

Para la creación de la empresa se deben realizar los siguientes trámites:

- Definir el nombre de la empresa y realizar la consulta de éste en el Registro Mercantil de la Superintendencia Nacional de los Registros Públicos (SUNARP) con la finalidad de que ninguna empresa tenga dicho nombre y luego de validarlo realizar la reserva del nombre. El nombre elegido es "Masterkey S.A.C".

- La Minuta de Constitución es el documento que formaliza la creación de la empresa, dicho documento debe ser suscrito por los fundadores de la sociedad.

- El Notario Público, redacta la Escritura Pública y la registra ante la Superintendencia Nacional de los Registros Públicos, de no existir observaciones se emitirá el Testimonio de Sociedad o Constitución Social, que legaliza la minuta y es firmada por un notario.

- Con el número de RUC - Registro Único del Contribuyente registrado en la Superintendencia Nacional de Administración Tributaria (SUNAT), la empresa ya puede realizar el pago de sus impuestos.

- La empresa constituida debe elegir cual es el régimen tributario al cual se va a inscribir. 
- Para el funcionamiento de la empresa es necesario tramitar la Licencia Municipal de Funcionamiento ante la Municipalidad del distrito donde se ubique la empresa, en este caso en la Municipalidad de Lima.

- Los Libros Contables a utilizar, dependiendo del régimen elegido, deber ser legalizados ante un Notario Público.

- Se debe tramitar la habilitación del Libro de Planillas, este trámite se realiza ante el Ministerio de Trabajo y Promoción del Empleo (MTPE). Asimismo, las hojas de este libro deben ser legalizadas.

- Los libros a utilizar en la Sociedad "Libros Societarios", deben ser legalizados ante Notario Público, según corresponda (Libro de Actas de Junta General de Accionistas, Matrícula de Acciones, Libro de Actas de Acuerdos del Directorio, etc.).

\section{b. Registro de Marcas y Patentes}

Luego de la constitución de la empresa, es necesario registrar la marca de los productos o servicios a comercializar. Dicho registro se realiza en la Oficina de Signos Distintivos del INDECOPI, la cual es la institución encargada del registro de marcas, nombres y lemas comerciales.

\section{c. Licencias y Autorizaciones}

La Municipalidad de Lima permite obtener la licencia de funcionamiento de dos formas.

La primera es solicitando una licencia temporal. Para ello se debe presentar el Certificado de Zonificación expedido por la misma Municipalidad y cuyo plazo de entrega máximo es 15 días. La duración de la licencia temporal es 12 meses. El costo de la licencia temporal es el $50 \%$ de la licencia indeterminada, es decir S/. 592.50. Luego de cumplido este plazo y salvado todos los requisitos, se obtiene la licencia de funcionamiento indeterminada.

La segunda forma, es realizar una solicitud de licencia a plazo indeterminado ante la Municipalidad de Lima, dicho trámite se encuentra establecido en la Ley № 28976 (Ley Marco de Licencia de Funcionamiento).

\section{d. INDECI}

Para laobtención de Certificado de Defensa Civil, durante el proceso de otorgamiento de Licencia de Funcionamiento, la Municipalidad de Lima solicita Declaración Jurada o Inspección, esta inspección variará dependiendo de la cantidad de metros cuadrados del local, de acuerdo a: 
- Licencia de Funcionamiento realizada por la Municipalidad, todos aquellos de $1 \mathrm{~m}^{2}$ a $100 \mathrm{~m}^{2}$. mediante la evaluación Técnica de Seguridad en Defensa Civil Básica EX POST.

- Licencia de Funcionamiento realizada por la Municipalidad todos aquellos de $101 \mathrm{~m}^{2} \mathrm{a}$ $500 \mathrm{~m}^{2}$. mediante la evaluación Técnica de Seguridad en Defensa Civil Básica EX ANTE.

- Para establecimientos mayores de $501 \mathrm{~m}^{2}$, se gestiona el certificado de Inspección Técnica de Seguridad de Defensa Civil de detalle o multidisciplinaria (INDECI).

En el presente caso se alquilará un local menor a $500 \mathrm{~m}^{2}$ por lo que se aplicaría una Inspección Técnica de Seguridad EX ANTE, que consiste en la verificación de forma ocular del cumplimiento de la Declaración Jurada de Observancia de Condiciones de Seguridad de las Normas de Seguridad en Defensa Civil y la evaluación de la documentación previamente presentada para el inicio del procedimiento y que es solicitada de manera conjunta con el trámite de la Licencia de Funcionamiento.

La inspección es realizada por el Inspector Técnico de Seguridad en Defensa Civil que es convocado por las Oficinas de Defensa Civil de la municipalidad donde se encuentre el local o establecimiento.

\subsubsection{Ordenamiento jurídico de la empresa}

\section{a. Legislación Laboral}

De acuerdo a lo indicado en el Régimen Laboral General de la Actividad Privada, contemplado en el Decreto Legislativo № 728 (Texto Único Ordenado, aprobado por Decreto Supremo № 003-97-TR), la empresa Masterkey S.A.C. se localizará dentro del régimen laboral general.

Las características más representativas son siguientes:

- Remuneración mínima vital de S/. 937.50 para aquellos trabajadores que laboren más de 4 horas diarias.

- Compensación por Tiempo de Servicios (CTS): 1 remuneración mensual + 1/6 de las gratificaciones legales por cada año de servicios, depositada en dos armadas semestrales: 15 de mayo y 15 de noviembre.

- 1 remuneración por Gratificación de Fiestas Patrias y Navidad.

- Jornada laboral máxima de 8 horas diarias o 48 horas a la semana.

- Sistema Pensionario: ONP 13\% o AFP 10\% más comisiones - lo aporta en su integridad el trabajador.

- Seguro Social de Salud: ESSALUD 9\% - lo aporta en su integridad el empleador. 
- Asignación familiar para personas con hijos: 10\% de la RMV - Ley № 25129.

- Licencia Pre y Post natal para maternidad: 45 días naturales de descanso pre natal y 45 días de descanso post natal. Tratándose de nacimiento múltiple el descanso post natal se extiende por 30 días adicionales - Decreto Supremo $\mathrm{N}^{\circ}$ 005-2011-TR.

- Licencia para Paternidad: Licencia remunerada por 4 días hábiles consecutivos, en caso de alumbramiento del cónyuge o conviviente - Ley № 29409.

\section{b. Legislación Tributaria}

La Sociedad Anónima Cerrada está afecta al Impuesto de Tercera Categoría. El pago del Impuesto a la Renta se efectúa al final del ejercicio anual y se calcula sobre las utilidades.

Se puede hacer un pago proyectado y luego realizar el pago correcto para evitar las multas. Los impuestos por ventas se pagan todos los meses de acuerdo al calendario de pago de SUNAT que se rige con el último número del RUC. Otros pagos que se efectúan son arbitrios municipales, licencia municipal los cuales son determinados por cada municipalidad.

\section{Tributos Internos}

En el caso de Masterkey S.A.C., los impuestos que corresponden pagar son los siguientes:

\section{Impuesto a la Renta (IR):}

Aplicada a las utilidades que genere la empresa. El proyecto se verá afecto de una tasa del 29.5\%, que corresponde a personas jurídicas de 3ra categoría. Se debe identificar el régimen al cual pertenece la empresa, según los montos de los ingresos y las características del negocio.

\section{Impuesto General a las Ventas (IGV):}

Es un impuesto aplicado al precio de todo servicio ofertado. A la fecha, la tasa es del 18\%. La emisión del comprobante de pago inicia la obligación tributaria.

El pago del IGV al estado corresponde a la diferencia entre el IGV facturado y el IGV pagado en la adquisición de bienes y servicios. Si el IGV facturado es mayor al IGV pagado será debito fiscal y Si el IGV facturado es menor al IGV pagado será crédito fiscal. 


\section{Impuesto a las Transacciones Financieras (ITF):}

Es el impuesto creado por la Ley $\mathrm{N}^{\circ} 28194$, que grava las operaciones en moneda nacional o extranjera por cualquier ingreso o salida de dinero en las cuentas abiertas en empresas del sistema financiero, y las operaciones que trasmitan pagos de dinero cualquiera que sea el medio que se utilice, excepto las operaciones exoneradas señaladas en el apéndice de la citada ley.

La alícuota del impuesto es cero coma cero cinco por ciento (0,005\%) vigente desde el 01 de abril de 2011, conforme lo establece la ley 29667 publicada el 20 de febrero del mismo año.

\section{c. Requisitos del Registro Sanitario}

- Documento dirigido al Director Ejecutivo de Higiene Alimentaria Zoonosis con carácter de Declaratoria Jurada, el cual debe incluir el número de RUC y firma del representante legal.

- Resultados de los análisis físicos-químicos y microbiológicos del producto analizado, confirmando su calidad e Apto de acuerdo a lo establecido en la normativa sanitaria vigente..

- Rotulado de los productos etiquetados.

- Los alimentos y bebidas de regímenes especiales, deberán señalar sus propiedades nutricionales, acompañando el correspondiente análisis bromatológico practicado por el laboratorio acreditado por INDECOPI.

- Realización del pago correspondiente por el derecho de trámite, el cual asciende a S/. 395.00 soles $(10 \%$ UIT).

- Formulario y anexo (previo presentación de análisis físico - químico y microbiológico, con carácter declaración jurada, suscrito por el representante legal, consignando la información siguiente:

- Razón social, domicilio y № de R. U.C.

- Nombre comercial y marca del producto o grupo de productos

- Relación de ingredientes y composición cuantitativa de los aditivos.

- Condiciones de conservación y almacenamiento como temperatura ambiente y congelado.

- Datos sobre envase utilizado, considerando tipo y material

- Periodo de vida útil del producto en condiciones normales de conservación y almacenamiento.

- Sistema de identificación del lote de producción

- Resultados de los análisis físico - químicos y microbiológicos del producto terminado (para esto se enviaron tres muestras de 500 gramos), realizado por el laboratorio de control de calidad del laboratorio acreditado en el Perú. 
- $\quad$ Luego de la revisión y V.B. se debe de efectuar el depósito en la cuenta del Banco de la Nación.

- $\quad$ Adjuntar el proyecto de etiqueta del producto

\section{d. Rotulados de Productos Industriales Manufacturados}

\section{Ley № 28405 (Ley de Rotulados de Productos Industriales Manufacturados)}

El objeto de la presente ley es establecer de manera obligatoria el rotulado para los productos industriales manufacturados para uso o consumo final que sean comercializados en el territorio nacional, debiendo inscribirse o adherirse en el producto, envase o empaque dependiendo de la naturaleza del producto.

La información exigida en la presente Ley, tiene por objeto proteger la salud humana, la seguridad de la población, el medio ambiente y salvaguardar el derecho a la información de los consumidores y usuarios.

\section{Información del Rotulado}

- Nombre o denominación del producto

- País de fabricación.

- Si el producto es perecible: se necesita fecha de elaboración, condiciones de conservación y observaciones.

- Contenido neto del producto, expresado en unidades de masa o volumen según corresponda.

- En caso de que el producto tenga algún insumo o materia prima que represente algún riesgo para el consumidor o usuario debe ser declarado.

- Nombre y domicilio legal en el Perú del fabricante, importador, envasador o distribuidor responsable según corresponda así como su № de R.U.C.

- Advertencia del riesgo o peligro que pudiera derivarse de la naturaleza del producto así como de su empleo.

- El tratamiento de urgencia en caso de daño a la salud del usuario cuando sea aplicable.

\section{e. Licencia Sanitaria}

Para obtener este documento se remite una solicitud al Ministerio de Salud, para la realización de la inspección que evaluará las condiciones higiénicas y de seguridad requeridas para la fabricación del producto, evaluando que los colaboradores e insumos se encuentren en buenas condiciones. 


\section{f. Seguridad y Salud en el Trabajo}

\section{Ley № 29783 (Ley de Seguridad de Salud en el Trabajo) y su D.S. 005-2012-TR}

- Si se cuenta con más de 20 trabajadores la empresa debe tener un Comité de Seguridad y Salud en el Trabajo, si tuviera menos de 20 trabajadores es necesaria la designación de un Supervisor de Seguridad y Salud en el Trabajo, ambos cumplen las mismas funciones, que indica la ley.

- El empleador tiene la responsabilidad de realizar 4 capacitaciones al año, como mínimo, en temas relacionados a seguridad y salud en el trabajo.

- La empresa es responsable de la entrega de los implementos de seguridad, de acuerdo a la necesidad que requiere el puesto de trabajo.

- Los miembros del Comité de SST y/o Supervisor de SST, tienen derecho a 30 días de licencia con goce de haber para el desempeño de sus funciones en sus respectivas áreas de trabajo.

- El empleador es responsable de la salud de sus trabajadores, para ellos se deben de realizar exámenes ocupacionales.

\section{g. Régimen de Contratación}

Todos los trabajadores de nuestra empresa estarán en planilla y se les abonará los beneficios sociales que le corresponde por ley, de acuerdo a:

- Decreto Supremo № 007-2002-TR (04/07/2002) - T.U.O. de la Ley de jornada de trabajo, horario y trabajos en sobretiempos.

- Decreto Legislativo № 713 con su Decreto Supremo 012-92-TR (03/12/1992) Descansos remunerados de los trabajadores sujetos a régimen laboral de la actividad privada.

- Decreto Supremo № 011-2010-TR (11/11/200) - Incremento de la remuneración mínima vital.

- Ley № 27735 (28/05/2002) con su Decreto Supremo № 005-2002-TR (04/07/2002) - Ley que regula el otorgamiento de las gratificaciones para los trabajadores del régimen laboral de la actividad privada en Fiestas Patrias y Navidad.

- Decreto Legislativo № 688 (05/11/1991) - Seguro de vida. 
- Decreto Supremo № 001-97-TR (01/03/1997) - T.U.O. de la Ley de compensación por tiempo de servicios.

- $\quad$ Ley № 25129 (06/12/1989) - Asignación familiar. 


\section{CAPITULO VI: ASPECTOS ORGANIZACIONALES}

\subsection{Caracterización de la cultura organizacional deseada}

\subsubsection{Visión.}

Al 2021, Posicionar el productocomo una línea de alta calidad en higiene personal que contribuya a proteger y mejorar la calidad de vida de las mujeres, alcanzando el liderazgo en el mercado Nacional y una mayor cuota del mercado.

La visión indica el objetivo a futuro que se quiere alcanzar, el cual analizamos a continuación:

Tabla 64.

Análisis de la Visión

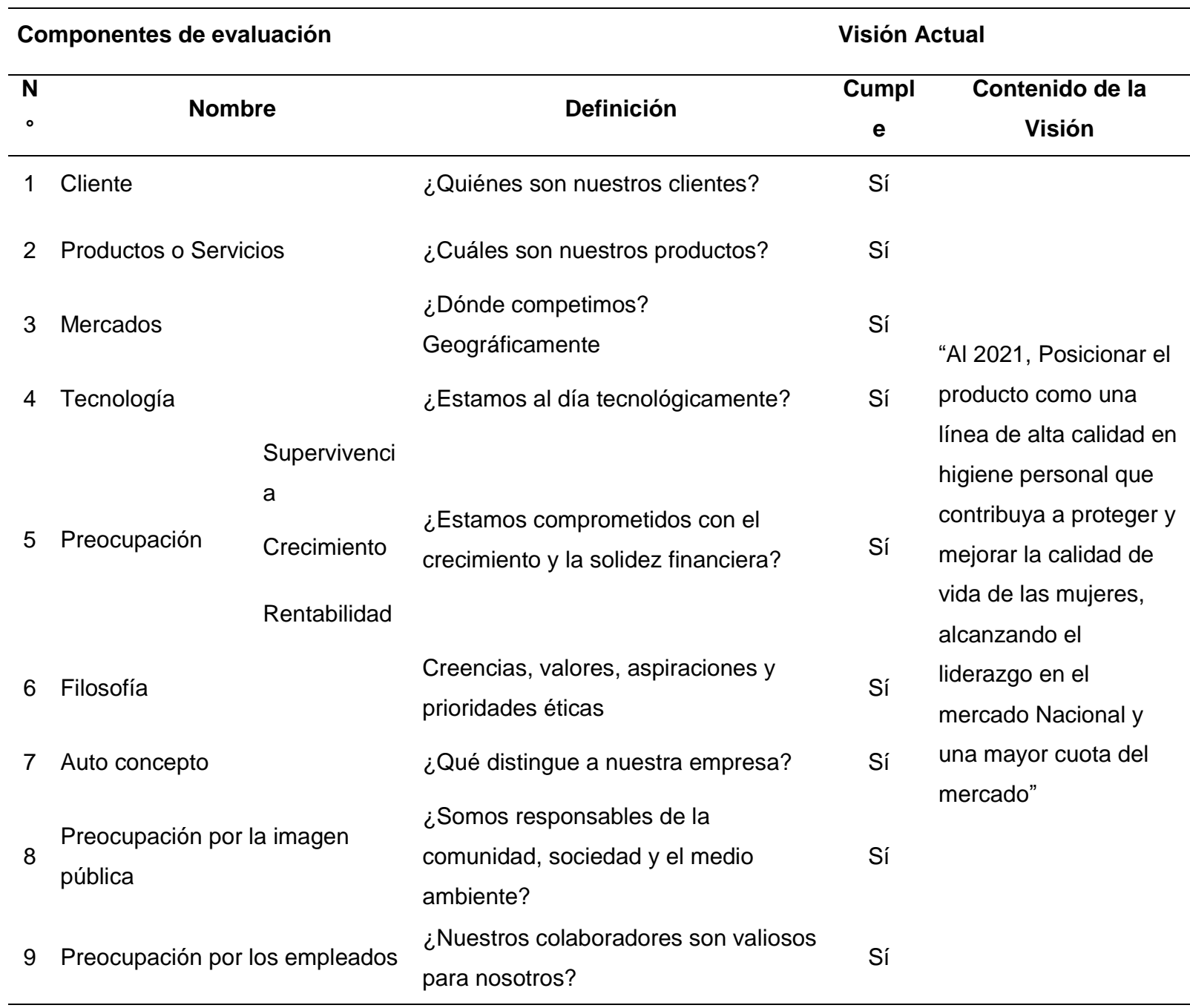

Elaboración propia. 
Desarrollando el análisis de cada una de las variables estas se justifican a continuación:

- Clientes, la visión es clara indicando que nuestros clientes están conformados por mujeres.

- $\quad$ Productos o servicios, la visión indica que nuestro producto es un producto de alta calidad.

- $\quad$ Mercados, la visión refiere que nuestro mercado es el Perú.

- Tecnología, la visión se transmite a través de la palabra "alta calidad" que justifica el hecho de fabricar un producto que genera calidad de vida a sus usuarias, justificada en las exigencias productivas y de selección de insumos.

- Preocupación, la visión a diferencia de la misión evidencia un horizonte de crecimiento del negocio en el largo plazo.

- Filosofía, la visión como la misión tienen que alinearse a las costumbres y usos del grupo objetivo para generar un canal de comunicación semejante entre ellos.

- $\quad$ Auto concepto, la visión nuevamente se refiere a "alta calidad", reflejando la importancia de serlo y como generador de ventajas diferenciales.

- $\quad$ Preocupación por la imagen pública, la visión lo indica a través del desarrollo de un producto de alta calidad y que contribuye a la salud de las personas.

- $\quad$ Preocupación por los empleados, la visión lo indica a través de la palabra "alta calidad", la que se entiende como colaboradores profesionales y técnicos que nos llevan hacia el éxito y el alcance de los objetivos de la empresa. 


\subsubsection{Misión.}

Fabricar y comercializar un cobertor sanitario para inodoros de alta calidad dirigido a las mujeres de Lima Moderna, que contribuya a proteger y mejorar su calidad de vida, sea amigable con el medio ambiente y genere beneficios para la empresa.

La misión indica el quehacer de la empresa, el cual analizamos a continuación:

\section{Tabla 65.}

Visión-Análisis de la Misión.

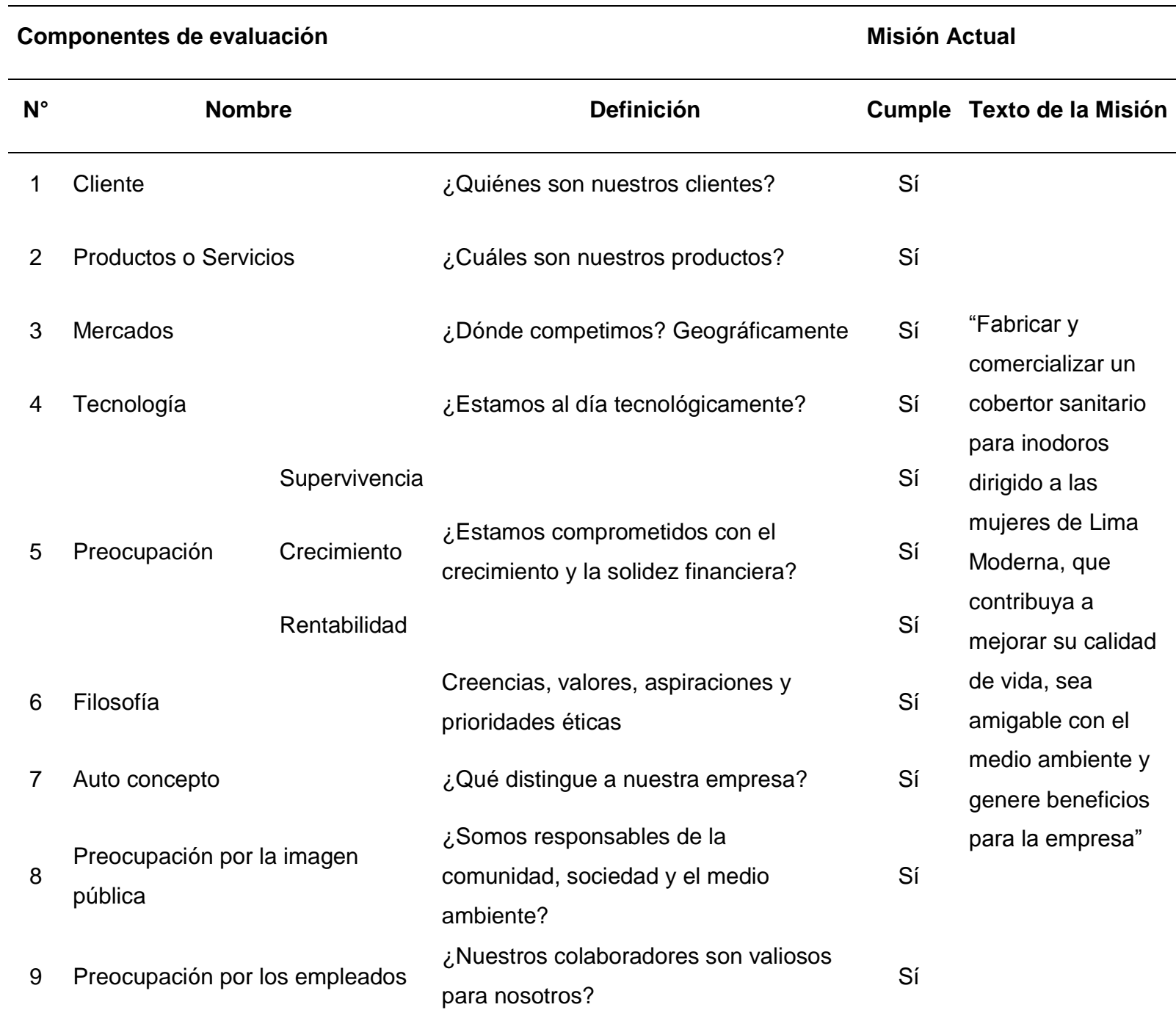

Elaboración propia.

Siguiendo con el análisis, punto por punto la misión se sustenta en lo siguiente:

- Cliente, la misión determina que el segmento de mercado el cual se quiere alcanzar está conformado por el sector femenino. 
- Productos o servicios, la misión es clara al definir que nuestro producto es un cobertor sanitario para inodoros.

- Mercados, la misión indica claramente que nuestro mercado está conformado por las mujeres de Lima Moderna.

- Tecnología, la misión mediante el producto cobertor sanitario para inodoro nos indica el uso de un producto innovador para una necesidad del sector.

- Preocupación, la misión en la palabra "beneficios" nos refiere al hecho de que nuestra empresa busca generar beneficios para la empresa.

- Auto concepto, la misión lo indica a través de la palabra cobertor sanitario para inodoro que se refiere a un producto innovador inexistente en el mercado peruano.

- Filosofía, la misión lo refiere en la búsqueda de mejor calidad de vida y mejor medio ambiente. Buscando ser responsable con nuestras acciones y nuestros productos

- Preocupación por la imagen pública, relacionado con nuestra filosofía de productos responsables con nuestros stakeholders.

- Preocupación por los empleados, relacionado a los beneficios de la empresa. Pues en ella están incluidos los colaboradores.

\subsubsection{Principios}

Los principios de nuestra empresa buscan orientar a nuestros colaboradores en su forma de actuar y también buscan alcanzar la identificación con la empresa. Los principios son los siguientes:

- Compromiso, ofrecemos productos innovadores para nuestros consumidores.

- Responsabilidad, todo lo hacemos a tiempo y en el momento oportuno.

- Innovación, aceptamos los cambios y los adaptamos para la mejora de nuestro producto.

- Trabajo en equipo, lo que hacemos forma parte de un gran objetivo y de lo que ofrecemos a nuestros consumidores. 


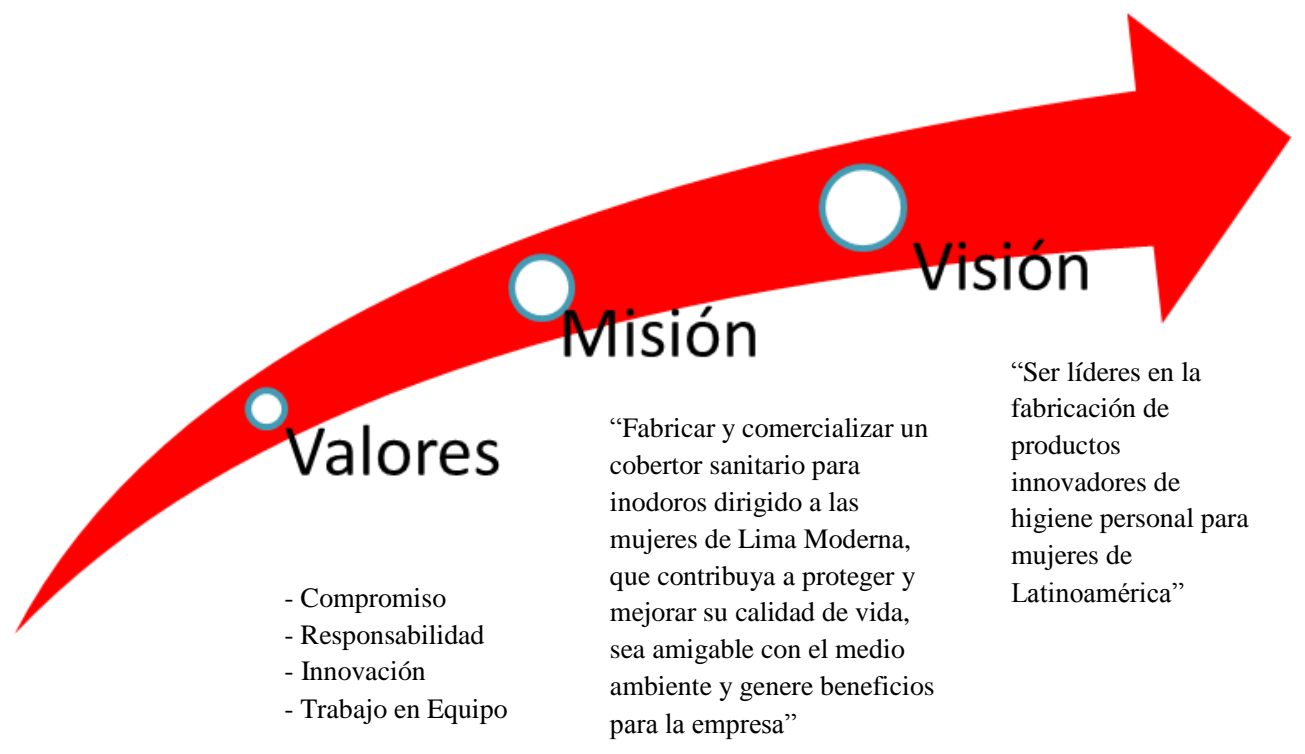

Figura 61. Principios. Elaboración del equipo de investigación.

\subsection{Formulación de estrategias del negocio}

Nuestro proyecto se basa en la Estrategia de Enfoque, estrategias genéricas definidas por Michael Porter.

En lo que concierne a la estrategia de Enfoque, el target se encuentra en los niveles socioeconómicos A, B y $\mathrm{C}$ de las mujeres de 20 a 54 años localizadas en los distritos de Lima Moderna en los cuales existen supermercados de las cadenas de Cencosud, Tottus y Supesa.

En esta estrategia se enfatizará el hecho de contar con un producto relativamente novedoso, buscando posicionar la marca y los beneficios del uso del producto en el mercado objetivo en la prevención de enfermedades al hacer uso de los baños públicos cuando salen fuera del hogar. 


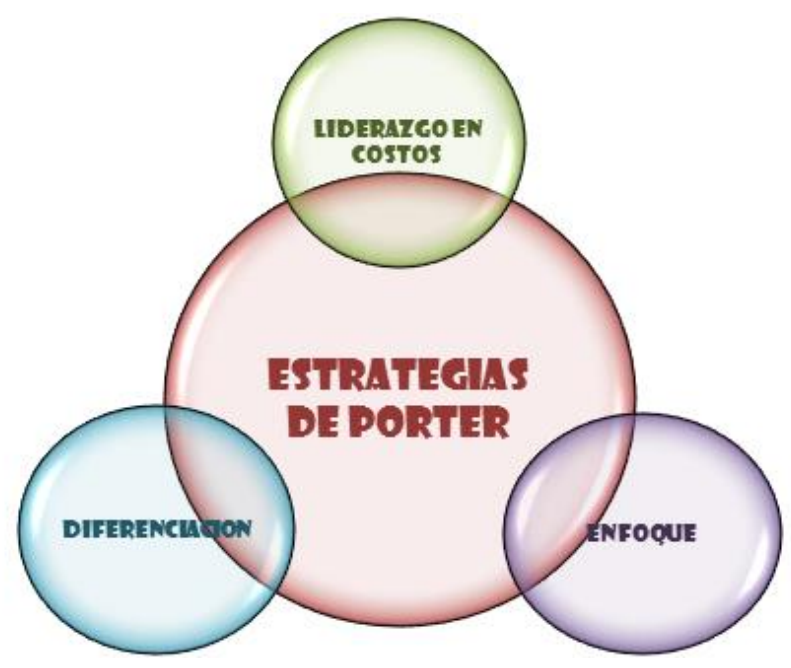

Figura 62. Formulación de estrategias del negocio. Elaborado por Cassamassina, Vivas y Ojeda (2016).

Las estrategias a tener en cuenta para el proyecto van a ser las siguientes:

\subsubsection{Penetración de mercado.}

La estrategia de penetración de mercado, incluye una inversión de marketing, la cual va a estar direccionada para que el producto se posicione día a día en el mercado, ya que a través de la estrategia se pretende introducirlo a través del canal supermercados, que comprende las 3 principales cadenas del mercado de Lima Moderna, considerando como base de análisis los resultados de los estudios de mercado del proyecto en la parte concerniente, a ¿Dónde le gustaría comprar el producto al target group?, donde supermercados representa un $73.08 \%$, lo cual es una muestra del interés de las consumidoras en conseguir el producto en dicho canal de venta.

Nos enfocaremos en capturar el mayor número de consumidoras, las cuales forman parte del target group seleccionado, a través de una estrategia de publicidad digital, la cual nos permitirá desarrollar el valor de la marca.

\subsubsection{Estrategia para el lanzamiento de producto.}

Despertaremos el interés y crear la necesidad del target, a través de una campaña inicialmente orientada a comunicar lo referente a los peligros que se exponen las mujeres cuando utilizan los inodoros públicos cuando salen fuera de casa, los cuales están diseñados en el plan de comunicación digital por la agencia. 
Viene acompañada de un plan de sampling con mercaderistas programadas en las diferentes tiendas de las cadenas, con el objetivo de dar a conocer el producto y sus beneficios.

\subsection{Diseño de la estructura organizacional deseada}

La estructura organizacional de la empresa está desarrollada pensando en la unidad de negocio que generará los ingresos a la empresa y debidamente alineada a la misión, visión y objetivos estratégicos de ésta. Por lo cual es importante definir los aspectos clave que nos indicaran la creación de un área o departamento específico. Asimismo, la interrelación entre dichas unidades y los procesos que se desarrollan entre ellas con la finalidad de generar sinergias y alcanzar los objetivos y metas propuestas. En este sentido el organigrama propuesto para nuestra empresa es el siguiente:

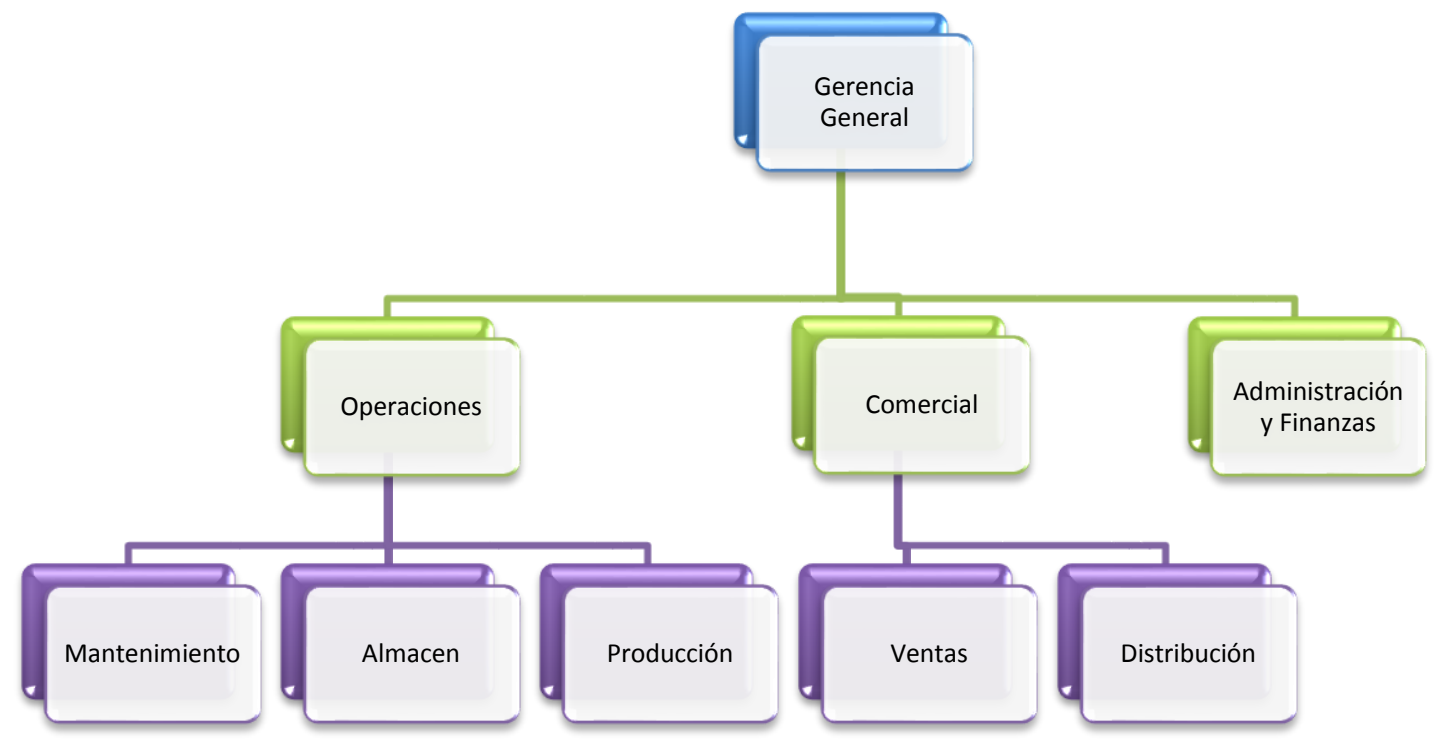

Figura 63. Estructura Organizacional, elaborada por el equipo investigador.

- Gerencia General

- Operaciones

- Marketing y Ventas

- Finanzas y Administración

La estructura organizacional horizontal, permitirá tener líneas de mando y de comunicaciones directa generando así un mejor control de cada uno de los procesos directos e indirectos de la fabricación y comercialización del producto. 
a) Gerencia General, el área que define los objetivos estratégicos de la empresa, así como las estrategias a seguir para el alcance de ellos.

b) Departamento de Operaciones: la principal función es definir los procesos necesarios para el desarrollo de la producción, así como definir la infraestructura tecnológica que soportará dicho flujo y las funciones específicas de cada área. Dentro de este departamento se tienen las siguientes áreas:

- Área de almacén, encargada de la recepción de insumos (entradas), remisión de producto terminados (salidas) y control del movimiento del almacén.

- Área de procesos, encargados de todo el proceso de fabricación de los productos que comercializa la empresa

- Área de Mantenimiento, encargada del control y afinamiento de la maquinaria usada en el proceso productivo.

c) Departamento Comercial, su principal función es generar los ingresos para la empresa y los planes de comunicación hacia los consumidores. El objetivo del área radica en alcanzar los objetivos de venta planificados y generar la rentabilidad de la empresa y la fidelización de los clientes y anunciantes. Por ello esta área definirá dos áreas:

- Área de ventas: Sus funciones están relacionadas al desarrollo de convenios y colocación del producto en los puntos de venta. Con la finalidad de alcanzar los ingresos para la empresa y transmitir la información que pueden captar del mercado externo.

- Área de Marketing: la principal función de esta área es desarrollar los mecanismos de cómo alcanzar la fidelización y preferencia del consumidor, desarrollo de campañas de fidelización y eventos con los clientes.

d) Departamento de Administración y Finanzas, su principal función está relacionada a los procesos administrativos de la empresa y que tiene como objetivo buscar el sostenimiento del negocio en el tiempo, para ello realiza lo siguiente:

- Gestión Financiera: La gestión del dinero y las oportunidades de mejorar la rentabilidad o ahorros en las decisiones financieras. Así como seguimiento en la ejecución de los presupuestos.

- Gestión Contable: Relacionada con el pago de los diferentes compromisos de la empresa: proveedores, impuestos, sueldos, entre otros. Con respecto al movimiento de los libros contables, balance y estados financieros estas labores serán tercerizadas. 
- Gestión de Recursos humanos: Relacionado con la gestión de planillas, asistencias y bienestar del personal. Con respecto al reclutamiento y selección estas labores serán tercerizadas.

- Gestión de logística: Relacionada con la verificación y gestión de los pedidos, supervisión de los servicios de vigilancia y limpieza, y cualquier otro requerimiento o necesidad que tuviera la empresa.

\subsection{Diseño de los perfiles de puestos clave}

A continuación, se presenta la lista de colaboradores con los que debe contar la empresa, de acuerdo al Organigrama, y una breve reseña de las principales funciones. Para mayor detalle del perfil y demás funciones se pueden revisar en el anexo. Son los siguientes:

\section{Gerente General}

\section{Funciones y Responsabilidades}

$\checkmark$ Administrar y organizar las estrategias de la empresa, velar por la correcta aplicación de los presupuestos y generar rentabilidad a los accionistas.

$\checkmark$ Supervisar y controlar el buen funcionamiento de todas las áreas, delegando adecuadamente funciones y límites de autonomía pre-establecida por la cadena de mando.

$\checkmark$ Velar por el óptimo cumplimiento de todo lo que estipula la ley referente a la operación.

\section{Jefe de Departamento de Operaciones}

Funciones y Responsabilidades

$\checkmark$ Administrar, ejecutar y monitorear el proceso productivo.

$\checkmark$ Generar y aprobar la compra de materia prima.

$\checkmark$ Negociar con los proveedores el cronograma de entregas de materia prima y cronogramas de pagos de las órdenes de compra.

\section{Mantenimiento}

\section{Funciones y Responsabilidades}

$\checkmark$ Realizar el mantenimiento preventivo de la maquinaria de la planta.

$\checkmark$ Calibración de la maquinaria industrial.

$\checkmark$ Evaluación de mejoras en el desempeño y eficiencias de la maquinaria. 


\begin{tabular}{l} 
Almacén \\
Funciones y Responsabilidades \\
\hline$\checkmark$ Administrar y llevar el registro de los ingresos y salidas de las materias primas y \\
productos terminados. \\
$\checkmark$ Realizar el control de inventarios en forma semanal, dar las alertas sobre los faltantes \\
de productos a los responsables para su compra oportuna con la finalidad de no tener \\
quiebre de stock. \\
$\checkmark$ Coordinar con los Representantes de Venta la salida de producto para su distribución. \\
\hline
\end{tabular}

\section{Procesos}

\section{Funciones y Responsabilidades}

$\checkmark$ Responsable de la operación de las máquinas

$\checkmark$ Cumplir con las programaciones diarias de producción.

\footnotetext{
Jefe de Departamento Comercial

Funciones y Responsabilidades

$\checkmark$ Realizar el análisis de la proyección de ventas en coordinación con el Jefe de operaciones.

$\checkmark$ Analizar los resultados de las ventas tomando en cuenta la proyección y, realizar acciones en caso estas hayan sido menores a las proyectadas.

$\checkmark$ Realizar el calendario de activaciones de marca, según estaciones y/o necesidades del mercado.
}

\footnotetext{
Coordinador de Canal Supermercado Funciones y Responsabilidades

$\checkmark$ Elaborar un cronograma de visitas y entrega de producto según su cartera de clientes.

$\checkmark$ Administrar el material promocional que se produzca como parte de las campañas de activación que se realicen en el año

$\checkmark$ Brindar permanente apoyo en los eventos realizados por el jefe de Marketing como parte del cronograma de activaciones.
} 


\section{Chofer}

\section{Funciones y Responsabilidades}

$\checkmark$ Excelente capacidad de comunicación con todo tipo de cliente

$\checkmark$ Levantamiento de información de la observación en el punto de venta.

\section{Jefe de Administración y Finanzas}

Funciones y Responsabilidades

$\checkmark$ Llevar un control del presupuesto de gastos de todas las áreas, así como velar por el correcto uso de los mismo

$\checkmark$ Encargado de la evaluación de rentabilidades y manejo del presupuesto anual.

$\checkmark$ Manejo de indicadores de gestión y elaboración de reportes ejecutivos con planes de acción para tomar las medidas correctivas.

\section{Secretaria Recepcionista}

Funciones y Responsabilidades

$\checkmark$ Recepción de llamadas telefónicas.

$\checkmark$ Atención al público interno y externo.

$\checkmark$ Archivo de documentación de las áreas.

$\checkmark$ Apoyo a la Gerencia General

\section{Cadena de Mando y Tramo de Control}

La toma de decisiones tiene la siguiente jerarquía:

Gerente General: Dirección de las 3 jefaturas en línea directa

Jefe de Operaciones: Hacia los operarios de mantenimiento, producción y al encargado de almacén. Estos puestos reportarán directamente al Jefe de Operaciones; este último deberá coordinar, asignar, aprobar entre otros cualquier requerimiento y/o necesidad de manera directa con cada uno de sus subordinados.

Jefe de Marketing y Ventas: Hacia los coordinadores de canal supermercado y chofer; estos deberán reportar directamente a esta jefatura y cualquier coordinación, cambio, requerimiento deberá hacerse en línea directa.

Jefe de Finanzas y Administración: Hacia los asistentes administrativos y la secretaría recepcionista. Todos los puestos reportan al Jefe de administración y finanzas. 


\subsection{Remuneraciones, compensaciones e incentivos}

El nivel de remuneración que se asigna a cada puesto de trabajo se determinó de acuerdo a los sueldos ofrecidos por puestos similares en el mercado, relacionados con sus funciones y responsabilidades. Por otro lado, a partir del tercer año y en los años siguientes del proyecto, y con el consiguiente aumento de los flujos de efectivo, se realiza un incremento anual del $10 \%$ a los sueldos de todo el personal. Asimismo, se ha considerado el costo relacionado a las contribuciones por: ESSALUD, CTS y las dos gratificaciones anuales. 
Tabla 66.

Sueldos del Personal

\begin{tabular}{|c|c|c|c|c|c|c|c|c|c|c|c|c|}
\hline \multirow{2}{*}{$\begin{array}{c}\text { PERIODO } \\
\text { Tipo }\end{array}$} & \multirow{2}{*}{$\begin{array}{r}\text { AÑO } 0 \\
\text { SALARIO }\end{array}$} & \multicolumn{3}{|c|}{ AÑO 1} & \multicolumn{2}{|c|}{ AÑO 2} & \multicolumn{2}{|c|}{ AÑO 3} & \multicolumn{2}{|c|}{ AÑO 4} & \multicolumn{2}{|c|}{ AÑO 5} \\
\hline & & CANT & SALARIO & CANT & SALARIO & CANT & SALARIO & CANT & SALARIO & CANT & SALARIO & CANT \\
\hline \multicolumn{13}{|c|}{ ADMINISTRACIÓN Y FINANZAS } \\
\hline Gerente General & 4,000 & 1 & 3,750 & 1 & 3,872 & 1 & 3,998 & 1 & 4,129 & 1 & 4,263 & 1 \\
\hline Jefe de Administración & 2,800 & 1 & 2,800 & 1 & 2,891 & 1 & 2,986 & 1 & 3,083 & 1 & 3,183 & 1 \\
\hline Secretaria & 1,350 & 1 & 1,350 & 1 & 1,394 & 1 & 1,439 & 1 & 1,486 & 1 & 1,535 & 1 \\
\hline \multicolumn{13}{|c|}{ MARKETING Y VENTAS } \\
\hline Jefe Comercial & - & - & 2,800 & 1 & 2,891 & 1 & 2,986 & 1 & 3,083 & 1 & 3,183 & 1 \\
\hline Coordinador 1 Autoservicios 1 & - & - & 1,500 & 1 & 1,549 & 1 & 1,599 & 1 & 1,652 & 1 & 1,705 & 1 \\
\hline Coordinador 2 Autoservicios 2 & - & - & 1,500 & 1 & 1,549 & 1 & 1,599 & 1 & 1,652 & 1 & 1,705 & 1 \\
\hline Coordinador 3 Autoservicios 3 & - & - & 1,500 & 1 & 1,549 & 1 & 1,599 & 1 & 1,652 & 1 & 1,705 & 1 \\
\hline Chofer distribución & - & - & 1,350 & 1 & 1,394 & 1 & 1,439 & 2 & 1,486 & 3 & 1,535 & 3 \\
\hline Auxiliar de reparto & - & - & 1,000 & 1 & 1,033 & 1 & 1,066 & 2 & 1,101 & 3 & 1,137 & 3 \\
\hline \multicolumn{13}{|l|}{ OPERACIONES } \\
\hline Jefe de Operaciones & - & - & 2,000 & 1 & 2,065 & 1 & 2,133 & 1 & 2,202 & 1 & 2,274 & 1 \\
\hline Almacenero / Logística & - & - & 1,000 & 1 & 1,033 & 1 & 1,066 & 1 & 1,101 & 1 & 1,137 & 1 \\
\hline Mantenimiento & - & - & 1,000 & 1 & 1,033 & 1 & 1,066 & 1 & 1,101 & 2 & 1,137 & 2 \\
\hline Operario 1 & - & - & 1,000 & 1 & 1,033 & 2 & 1,066 & 2 & 1,101 & 2 & 1,137 & 2 \\
\hline Operario 2 & - & - & 1,000 & 1 & 1,033 & 2 & 1,066 & 2 & 1,101 & 2 & 1,137 & 2 \\
\hline
\end{tabular}

Elaboración propia. 


\subsection{Política de recursos humanos}

a. Responsabilidad compartida, entiéndase por este concepto la necesidad de que los colaboradores conozcan que sus acciones generan resultados que pueden afectar a otros colaboradores.

b. Desarrollo de los colaboradores, esta política busca mejorar el perfil de los colaboradores y aumentar su talento dentro de la organización. El objetivo es mejorar la calidad de sus capacidades e incrementar su potencial.

c. Seguridad y salud de los colaboradores, estamos comprometidos con nuestros colaboradores porque creemos que son el recurso más importante de la organización. El asegurar su seguridad y salud los motiva y podemos lograr lo mejor de ellos en sus actividades y funciones.

d. Respeto al desarrollo de la vida profesional y personal, buscamos que los colaboradores alcancen el equilibrio entre estas dos áreas, con la finalidad de potenciar su capacidad profesional y alcanzar así su satisfacción personal.

e. Relaciones personales profesionales, enfocado en el desarrollo de diversos valores que formaran la personalidad de la organización:

- Respeto y confianza, dos pilares que sientan las bases de buenas relaciones entre los colaboradores.

- Transparencia y honestidad, estos valores buscan promover un correcto desarrollo del diálogo interno, y por lo tanto alcanzar comunicación eficaz entre los grupos y colaboradores. 


\section{CAPITULO VII: PLAN DE MARKETING}

\subsection{Estrategias de marketing}

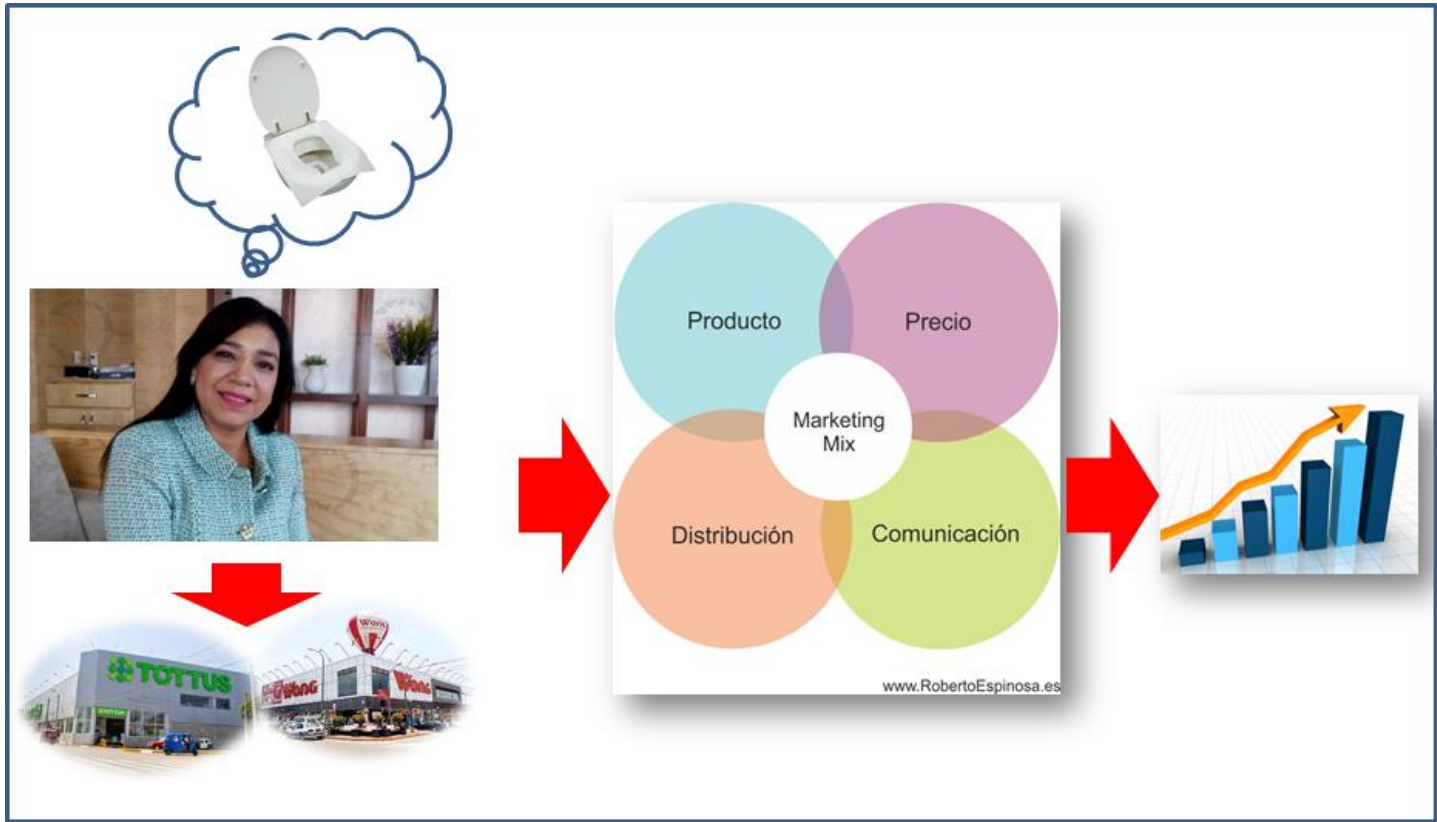

Figura 64. Estrategias de marketing. Elaboración propia.

\subsubsection{Estrategia de producto.}

El cobertor sanitario para inodoro tiene como objetivo principal la protección de la salud de las personas, mediante el uso de los mismos en los baños públicos. El cobertor permite evitar el contacto de la piel con el inodoro y de esta forma disminuir la posibilidad de contraer alguna enfermedad en estas instalaciones. Por lo tanto, la calidad del producto es un factor importante a tener en cuenta en el proceso productivo y así evitar alguna contaminación durante este proceso. A continuación podemos ver como parte de la estrategia de producto, la propuesta de valor para el target:

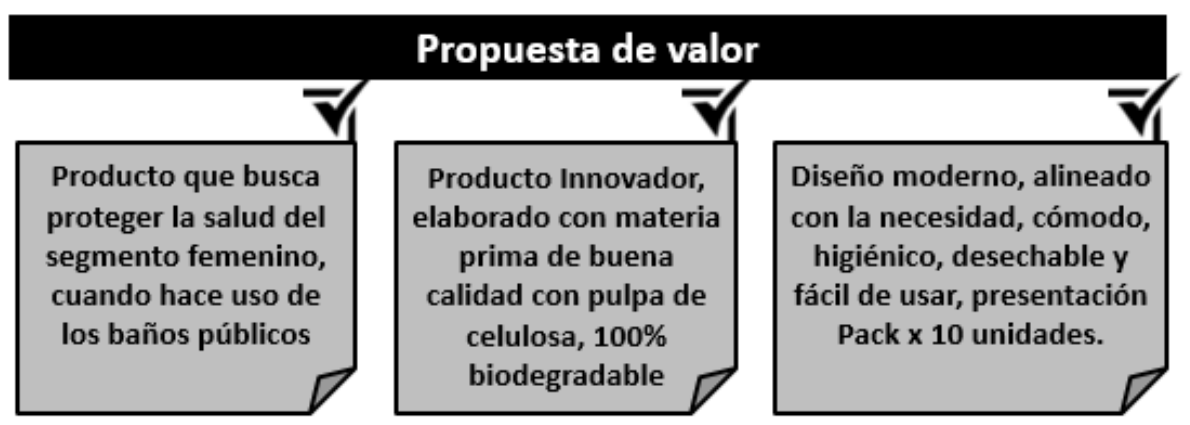

Figura 65. Propuesta de valor de producto.Elaboración propia. 
- Producto que busca proteger la salud de los consumidores

Con el lanzamiento al mercado del cobertor sanitario pretendemos contribuir con la sociedad en la higiene y salud de las personas. Mediante la utilización del producto en los inodoros de los baños públicos, el usuario se protege del contagio de gérmenes e infecciones que pueda contraer al evitar el contacto directo de la piel con el inodoro que se encuentre utilizando.

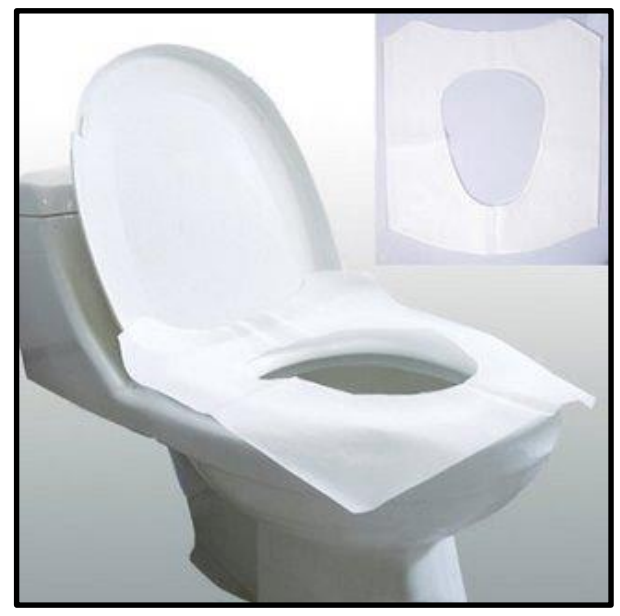

Figura 66. Cobertor sanitario. Elaboración Propia

- Producto Innovador,

Un producto es innovador cuando revoluciona la forma de entender una necesidad, una determinada actividad o servicio que posibilite, por ejemplo, una mejora en la calidad de vida de los consumidores. Tomando como referencia esta definición pretendemos ingresar al mercado con un producto fabricado con materia prima de buena calidad, $100 \%$ degradable, y de esta manera ser pioneros en la categoría con un producto desconocido por el consumidor del mercado de Lima Moderna.

\section{- Diseño moderno alineado con la necesidad,}

El cobertor sanitario para inodoros está fabricado con un tipo de papel que tiene como características un lado suave que permite que la piel del usuario no se irrite y a su vez sea cómodo y placentero en el uso. Y otro lado, áspero para el contacto con el inodoro y que evita el paso de humedad por sus características impermeables. Por otro lado, las dimensiones del producto son adecuadas para evitar la posibilidad de contacto de la piel con el inodoro, por ello la medida del cobertor es más amplia, 
alcanzando una medida de $42 \times 42 \mathrm{~cm}$. Además, posee una lengüeta troquelada, según diagrama, para evitar tocar el inodoro y retirar el papel y poder desecharlo en el tacho del baño. Estas características permiten cubrir en su totalidad los diferentes tipos de inodoros que utilizamos en Lima Moderna ante una necesidad de uso de baño público cuando las mujeres salen fuera de casa. (Ver figura 24).

\section{- Diseño funcional,}

El cobertor sanitario para inodoros está diseñado para garantizar las necesidades requeridas de los clientes, como son: la comodidad, higiénico, desechable y fácil de usar en los baños públicos.

\section{- Presentación,}

\begin{tabular}{|l|l|}
\hline Marca & Brisa \\
\hline Empaque & Paquete $\times 10$ unidades \\
\hline Embalaje & Caja $\times 50$ paquetes $\times 10$ unidades \\
\hline
\end{tabular}

\subsubsection{Estrategia de precio}

Para determinar la estrategia de precio del cobertor sanitario para inodoros, hemos tenido en cuenta las siguientes variables analizadas:

a) Estudio de mercado, se consideró el mayor resultado de la encuesta en la pregunta relacionada al rango de precios: S/. 2.01 a S/ 3.00 el pack.

b) Establecimiento de precio a través de la Asignación de costos y gastos incurridos en el negocio

c) Penetración de mercado, partiendo de la parte conceptual esta estrategia nos permite empezar con un precio por debajo de los competidores, conforme se vaya posicionando la marca, se va incrementando precio, con respecto a la marca Queen estamos $-38 \%$ por debajo del precio. 
Tabla 67.

Estructura de Precio

\begin{tabular}{lc}
\hline \multicolumn{1}{c}{ DETALLE } & VALOR \\
\hline Costo de materia Prima - Pack x 10 unid. & S/. 0.50 \\
Costos Indirectos & 0.11 \\
Mano de obra directa & 0.02 \\
Gastos Administrativo & 0.09 \\
Gastos de Marketing y Ventas & 0.37 \\
Gastos Financieros & 0.09 \\
\hline Costo total & 1.18 \\
\hline Margen de la empresa & 0.45 \\
Valor Venta & 1.63 \\
IGV & 0.29 \\
\hline Precio de Venta a la Cadena & S/. 1.93 \\
\hline Margen Comercial de la cadena & S/. 0.49 \\
IGV & S/. 0.09 \\
\hline Precio de Venta al Público & S/. 2.50 \\
\hline
\end{tabular}

Elaboración propia.

El margen comercial de $30 \%$ del precio de venta para el intermediario incluye los márgenes que son parte de la estrategia de precio de las cadenas, los cuales incluyen lo siguiente:

- $5 \%$ ya que se va a realizar la entrega en el Centro de Distribución y luego se encargan de la entrega en las tiendas ubicadas en los distritos de Lima Moderna.

- $\quad 0.5 \%$ para ser parte del B2B de las cadenas, lo cual permite ser parte de la red de sistemas a través de un software donde se pueden visualizar los pedidos y los stocks en cada una de las tiendas.

- $1.5 \%$ por mercaderismo, esto lo asumen todos los proveedores.

En base a las variables analizadas, concluimos que el precio a establecerse para las consumidoras es acorde con el precio que la mayoría estaría dispuesta a pagar. 


\subsubsection{Estrategia de distribución.}

La estrategia de distribución del cobertor sanitario para inodoros será diferenciada, ya que se introducirá el producto al mercado logrando una mejor cobertura, penetración y acercar el producto al consumidor final: mercado objetivo compuesto por el segmento femenino de 20 a 54 años de los NSE A, B, y C. La estrategia empleada consiste en ir posicionando el producto en Supermercados a lo largo de los 5 años del proyecto.

\section{Canal a través del intermediario- Supermercados}

Para el inicio de operaciones alineada con la formulación de la estrategia, se distribuirá el cobertor sanitario para inodoros a través de un canal indirecto corto, pero es importante tener en cuenta el concepto.

Torre afirma (2018):

"Un canal de distribución suele ser indirecto, porque existen intermediariosentre el proveedor y el usuario o consumidor final. "El tamaño de los canales de distribución se mide por el número de intermediarios (niveles) que forman el camino que recorre el producto. Dentro de los canales indirectos se puede distinguir entre canal corto y canal largo. Un canal corto sólo tiene dos escalones, es decir, un único intermediario entre fabricante y usuario final. Este canal es habitual en la comercialización de automóviles, electrodomésticos, productos de consumo, en que los minoristas o detallistas tienen la exclusividad de venta para una zona o se comprometen a un mínimo de compras. Otro ejemplo típico sería la compra a través de supermercados.

Como parte de la estrategia se alcanzará al consumidor final con el cobertor sanitario para inodoros a través de intermediarios que en este caso son las 3 cadenas de supermercados: Cencosud, Tottus y Supesa ubicados en Lima Moderna, los cuales serán atendidos por el área de logística de distribución, quienes se encargarán de la atención de los pedidos en los centros de distribución de las diferentes cadenas.

Las negociaciones estarán direccionadas,para estar presente con el cobertor sanitario para inodoros en todas las cadenas de supermercados de Lima Moderna, aprovechando la interrelación del Jefe Comercial con los Jefes de compras de las diferentes categorías y con los Gerentes de tiendas de las diferentes cadenas. 


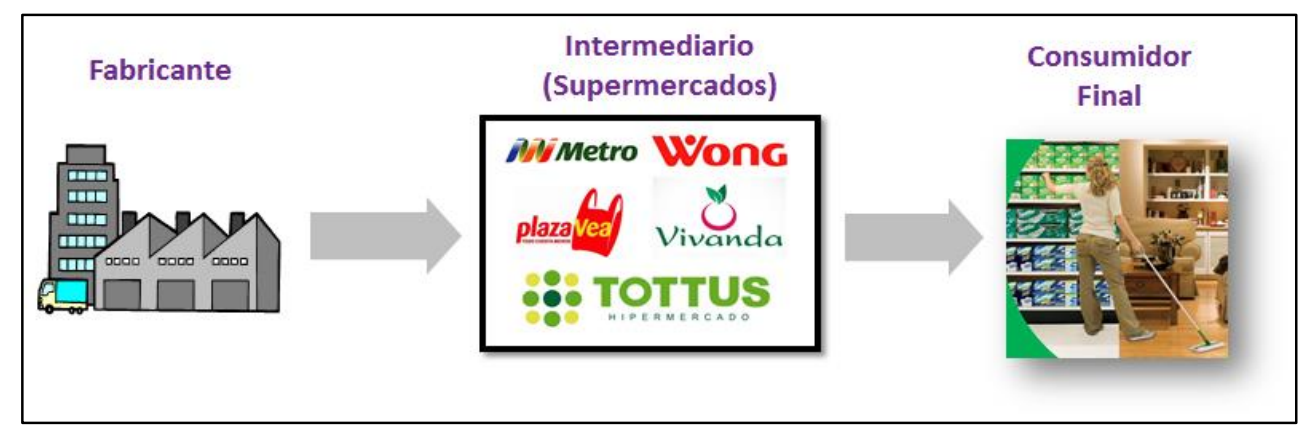

Figura 67. Diseño de canal Fuente, elaborado por el equipo de investigación

\subsubsection{Estrategia de promoción y publicidad.}
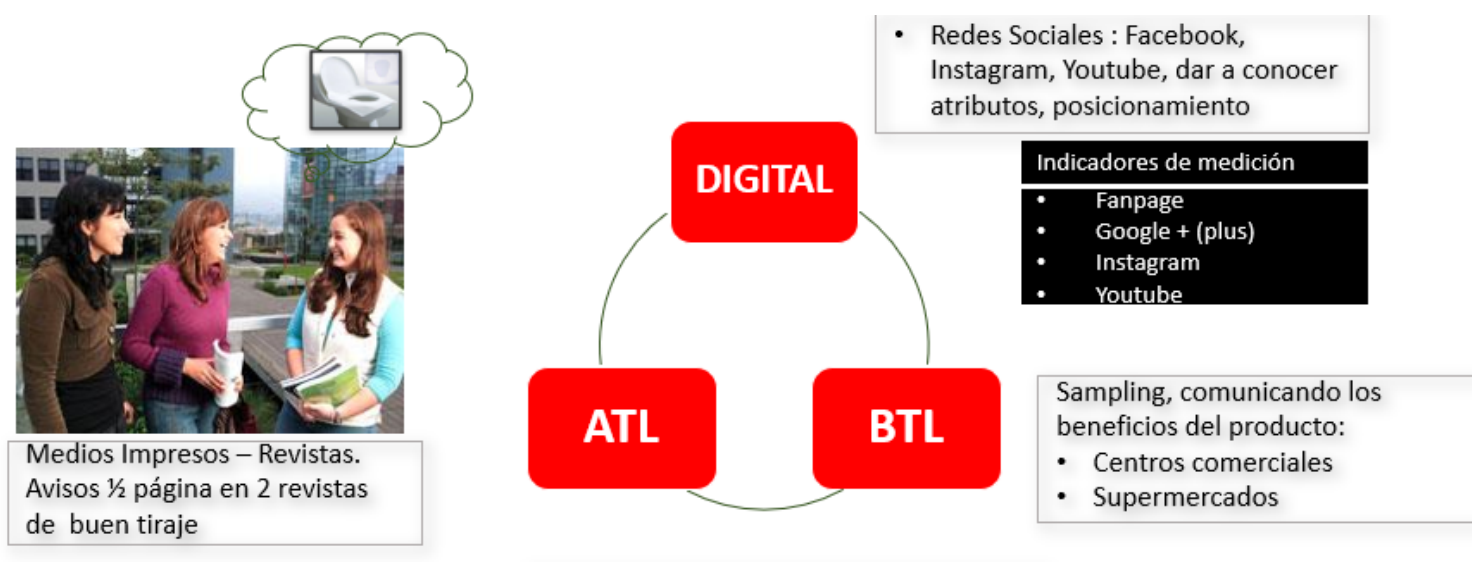

Convenios Institucionales:

Colegio Médico del Perú

Minsa

Essalud, participación en charlas y

seminarios

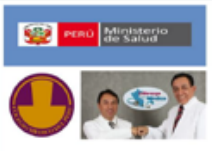

Figura 68. Diseño estrategia comunicacional. Elaboración propia.

Los resultados de los estudios de mercado han sido bastante favorables con respecto a las necesidades identificadas en nuestro target group: proteger su salud cuando tienen la necesidad de utilizar los baños públicos al salir fuera del hogar.

El cobertor sanitario para inodoros no es conocido en nuestro país, por lo tanto, en la etapa de introducción o lanzamiento, será importante generar la cultura, hábito y costumbres de uso del producto. Por lo cual, será fundamental la estrategia de comunicación con el mercado objetivo. La variable de comunicación deberá lograr el equilibrio en la mezcla de los diferentes canales de comunicación: publicidad, promoción de ventas, relaciones públicas y ventas personales. 


\section{Publicidad}

Se contará con un presupuesto de marketing, para informar, crear la necesidad, posicionar y comunicar a las consumidoras del target group, los atributos de nuestro producto.

\section{Objetivo}

Posicionar al cobertor sanitario para inodoros, en una primera etapa, en el mercado de Lima Moderna, buscando ser reconocida por la innovación y la calidad del producto y que tiene la capacidad de proteger la salud de las mujeres.

\section{Mercado objetivo,}

Mujeres de 20 a 54 años de edad, NSE A, B, y C de Lima Moderna.

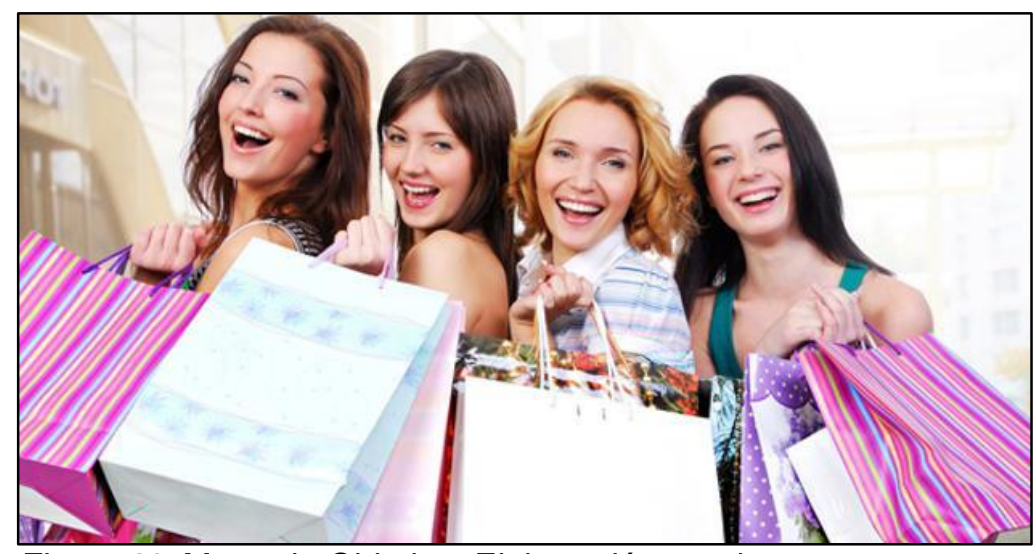

Figura 69. Mercado Objetivo. Elaboración propia.

\section{Eslogan,}

"Soluciones de higiene que protege la salud de las personas".

\section{Medios - Agencia de publicidad digital,}

Hasta hace algunos años los planes de comunicación masiva que involucran: TV, radio, aviso de prensa, paneles, etc., eran la única alternativa para posicionar y comunicar al target los atributos de un producto, así como garantizar los volúmenes de ventas e ingresos, alineados con los objetivos estratégicos y comerciales de las empresas.

Según Median Interactive Group (2013) "Muchas de las empresas han descubierto en el Internet y en la Publicidad Online (digital) una plataforma accesible para alcanzar sus objetivos, dejando atrás, o al menos en un segundo plano, lo que hasta ahora hemos conocido como publicidad tradicional, esto se hace más evidente en empresas 
pequeñas que no pueden hacerse visibles con inversiones de miles de dólares al inicio de sus operaciones".

Teniendo en cuenta el presupuesto de inversión de marketing se contratará una agencia de marketing digital que desarrollará las estrategias orientadas a la comunicación y desarrollo de la marca en redes sociales e internet. Estas estrategias están alineadas a las necesidades de nuestro target group. La agencia digital recibirá un brief en el cual se le presentará el plan integral del negocio.

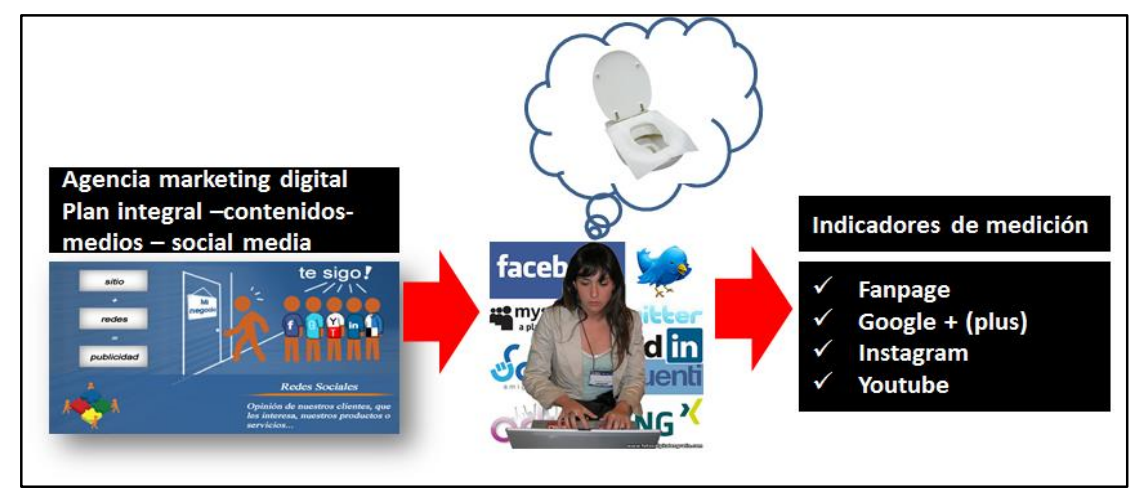

Figura 70. Medios. Elaboración propia.

\section{Página web}

Se creará un portal web con el objetivo de dar a conocer los atributos del cobertor sanitario para inodoros y otros temas importantes relacionados con el cuidado y protección de la salud.

\section{Medios Impresos - Revistas}

Adicionalmente se contará con avisos de media página en 2 revistas Vanidades y Cosmopolitan las cuales obtuvieron el más alto porcentaje de aceptación en el estudio cuantitativo, las cuales son de preferencia del target group.

\section{Promoción de ventas}

Se realizarán promociones de venta para dar a conocer rápidamente el cobertor sanitario para inodoros, por lo cual el presupuesto de promoción de ventas será una herramienta importante para estimular a todos los integrantes de la cadena: mercado objetivo e intermediario. 


\section{Sampling}

Dentro de las estrategias de promoción de ventas es importante tener en cuenta las tendencias del consumidor;es por ello, que se ha considera el "El sampling", ya que es la tendencia de moda en marketing directo. Para Ramírez (2017) el Sampling va a permitir que un consumidor potencial conozca las cualidades del producto sin que nadie más le cuente. Si le gusta, es muy probable que decida comprarlo.

Con el objetivo de introducir al mercado y dar a conocer el cobertor sanitario para inodoros, se contratará una empresa que presta servicios de Trade marketing y ejecución en el retail el plan de distribución de muestras. El cual estará direccionado en las cadenas de supermercados y en los centros comerciales, de tal manera que se beneficie el alto tráfico de consumidores en estos puntos de venta.

Adicionalmente, en coordinación con el Colegio Médico del Perú y algunas Clínicas y Hospitales, se repartirán las muestras gratis a los médicos especialistas. Con la finalidad de que recomienden el cobertor sanitario para inodoros como un producto que ayuda a proteger la salud.

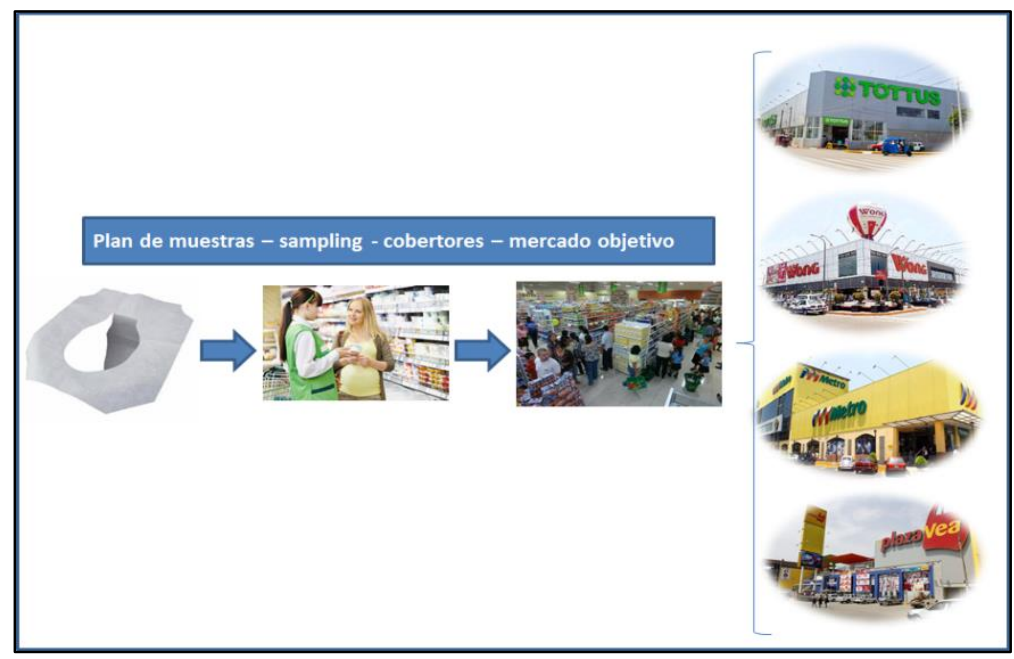

Figura 71. Sampling. Elaboración propia.

\section{Publicidad gráfica}

Afiches y folletos, comunicación estructurada diseñada con la finalidad de atender dos aspectos: crear la necesidad del uso de los cobertores sanitarios para inodoros 
dando a conocer todos los problemas de contraer bacterias, contagios, infecciones, etc. a las cuales se enfrentan las damas cuando hacen uso de los baños públicos, y presentar el producto mostrando todos los atributos relacionados con la protección de la salud.

\section{Relaciones Públicas}

Como parte del plan se buscará establecer convenios con diferentes instituciones: Minsa, Essalud, Colegio Médico del Perú, para participar en charlas, seminarios y simposios, con el objetivo de dar a conocer el cobertor sanitario para inodoros, comunicar sus atributos y buscar generar una cultura que sea beneficiosa para la población, previniendo las infecciones por bacterias que pueden estar inmersas en los baños de un ambiente público.

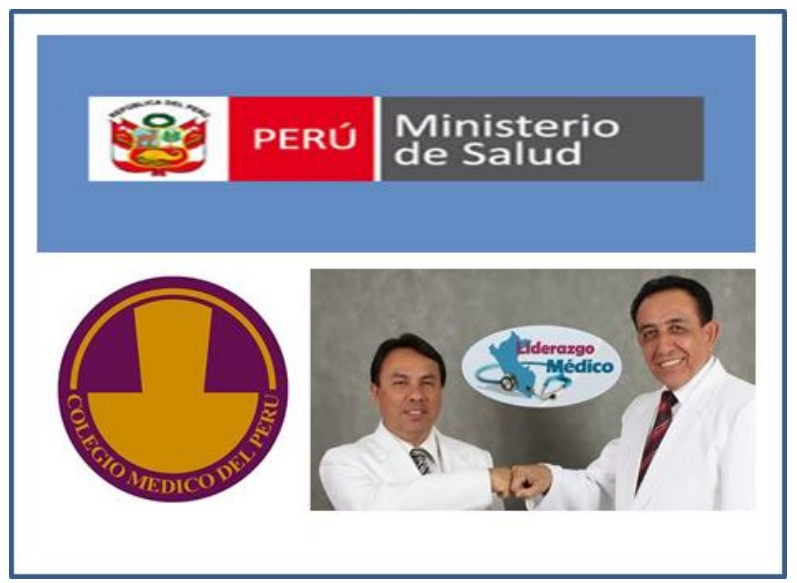

Figura 72. Relaciones públicas. Elaboración propia.

\section{Ventas personales}

Kotler y Armstrong, citados por Thompson (2014) "definen las ventas personales como la presentación personal que realiza la fuerza de ventas de la empresa con el fin de efectuar una venta y cultivar relaciones con los clientes".

En función a la estrategia desarrollaremos los procesos de venta con fuerza de ventas propia. 


\subsection{Estrategia de ventas}

\subsubsection{Plan de ventas.}

\section{Estrategia de Ventas - Desarrollo de Canales de Ventas - Horizonte 5 años}

\section{Supermercados}

$\rightarrow$ Cencosud, Tottus, Supesa $\rightarrow$ FF.VV. 3 coordinadores de Vtas.

Figura 73. Plan de ventas. Elaboración propia.

\subsubsection{Canal Supermercados}

Para comercializar el producto se utilizarán las 3 cadenas de supermercados de Lima Moderna, ya queel público encuestado manifestó que le gustaría encontrar el producto en dichos lugares, para contactar con los supermercados se pretende contratar coordinadores de ventas, quienes se van a encargar de la venta, seguimiento a la ejecución y cumplimiento de los objetivos comerciales.

Con respecto a la atención, servicio y venta, los coordinadores van a estructurar sus carteras de clientes por cadenas para las coordinaciones con los Jefes de compras, de la categoría correspondiente, de las diferentes tiendas.

Los coordinadores de ventas, están divididos por cadenas y reportan al Jefe Comercial quien tiene la responsabilidad de las funciones de marketing y ventas. Como universo en el mercado de Lima Moderna se tiene 60 supermercados. 
Tabla 68

Distribución de supermercados.

\begin{tabular}{llcccc}
\hline \multicolumn{1}{c}{ Lima Moderna } & \multicolumn{1}{c}{ TOTTUS } & METRO & PLAZA VEA & WONG & TOTAL \\
\hline 1 San Miguel & 1 & 2 & 2 & 1 & 6 \\
2 Jesús María & 0 & 3 & 2 & 0 & 5 \\
3 Magdalena & 0 & 0 & 2 & 0 & 2 \\
4 Lince & 0 & 1 & 1 & 0 & 2 \\
5 San Isidro & 1 & 0 & 3 & 1 & 5 \\
6 Miraflores & 1 & 2 & 1 & 5 & 9 \\
7 Surquillo & 1 & 1 & 0 & 0 & 2 \\
8 San Borja & 0 & 1 & 3 & 1 & 5 \\
9 Barranco & 0 & 2 & 1 & 0 & 3 \\
10 Santiago de Surco & 3 & 0 & 7 & 3 & 13 \\
11 La Molina & 1 & 1 & 2 & 3 & 7 \\
12 Pueblo Libre & 0 & 1 & 0 & 0 & 1 \\
\hline \multicolumn{1}{l}{ TOTAL } & $\mathbf{8}$ & $\mathbf{1 4}$ & $\mathbf{2 4}$ & $\mathbf{1 4}$ & $\mathbf{6 0}$
\end{tabular}

Nota: Adaptada de "Distribución de los supermercados existentes en los distritos de Lima Moderna", por Páginas Web de Tottus, Plaza Vea, Metro y Wong (2015)

Coordinador de ventas 1, Cadena Cencosud, que comprende las tiendas de Wong y Metro, siendo un total de 28 tiendas.

Coordinador de ventas 2, que comprende la cadena de Supermercados Peruanos - Plaza Vea con un total de 24 tiendas,

Coordinador de ventas 3, que comprende la cadena de Supermercados Tottus que posee un total de 8 tiendas, por lo que se negociará lanzar el producto en las 8 tiendas de los distritos de Lima Moderna.

Tabla 69.

Cuadro Distribución de Supermercados por coordinador

\begin{tabular}{ccc}
\hline Coordinador & Cadena de Supermercados & TOTAL \\
\hline Coordinador 1 & Cencosud (Wong y Metro) & 28 \\
Coordinador 2 & Supermercados Peruanos (Plaza Vea, Vivanda y Mass) & 24 \\
Coordinador 3 & Supermercados Tottus & 8 \\
\hline
\end{tabular}

Elaboración propia. 


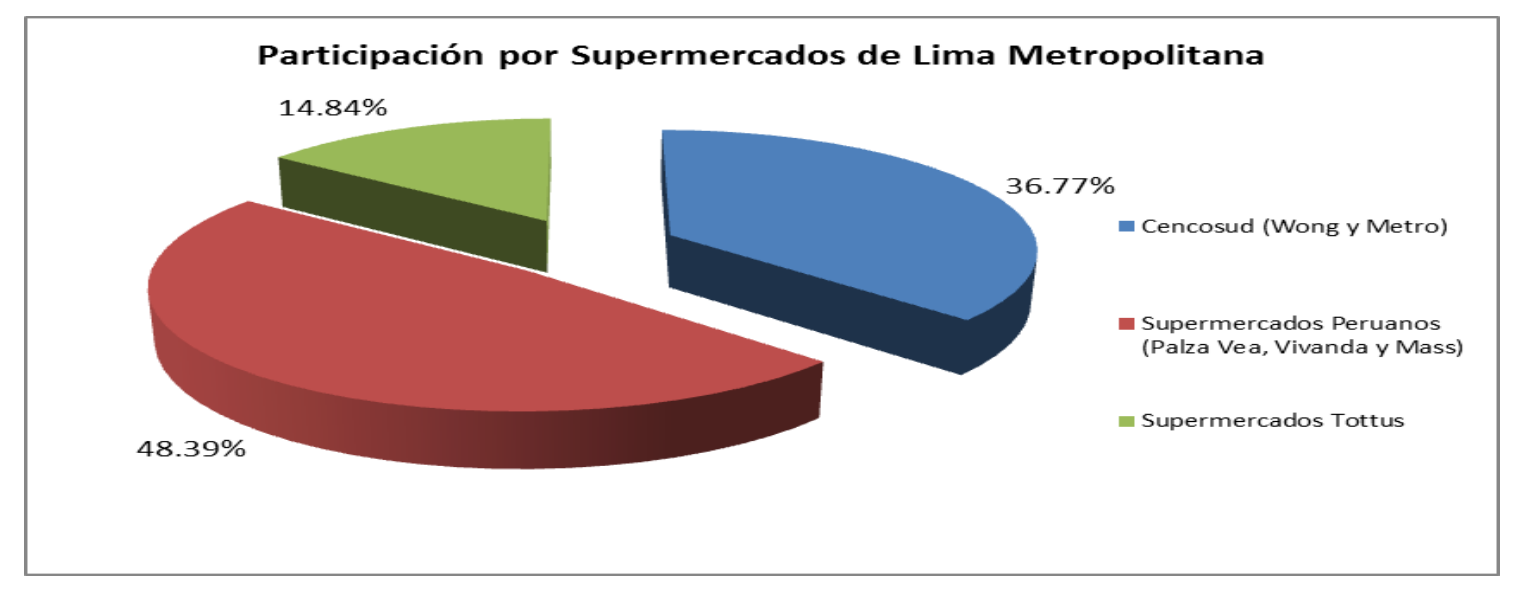

Figura 74.Cuadro Distribución de Supermercados por coordinador. Elaboración propia.

\section{Remuneración del área comercial alineada con el cumplimiento de Objetivos}

La remuneración del Jefe comercial y los coordinadores de ventas estará definida por un sueldo fijo. Este sueldo fijo, de acuerdo a las políticas indicadas por recursos humanos y por el incremento del flujo de efectivo, se incrementará a razón de 1\% anual a partir del tercer año y así hasta el quinto año del proyecto.

\section{Concursos para los Coordinadores de Ventas}

Como parte del plan de ventas se realizará concursos de ventas, relacionados con el cumplimiento de metas, exhibición y seguimiento a productos fuera de stocks en góndolas (out of stocks). 


\section{Segmentación de clientes}

Para efectos de una mejor administración comercial del total de las 60 tiendas de las cadenas, se dividirán las tiendas en función a sus volúmenes de compras, con el objetivo de poder direccionar y destinar de una mejor manera los recursos en función a los ingresos por tienda. Esto nos va permitirá hacer una distribución racional segmentada de los recursos, estrategias y asignación de figuras comerciales del plan de ventas.

Para la segmentación estructurada, como primer paso se elaborará el ranking de las compras de clientes y luego se categorizarán en 3 categorías: Top, Gold y Silver.

\section{Sistema de distribución a las tiendas}

Para la distribución se contará con un programa de reparto, en función a los pedidos del día,el cual se ejecutará con una programación de carga y las entregas se realizarán con camiones propios tipo furgón de 4 toneladas.

Lo favorable para los procesos logísticos y distribución, es que los pedidos de las diferentes cadenas solo se atenderán a través de sus centros de distribución. Cada cadena de supermercados tiene un centro de distribución ubicados en direcciones estratégicamente en Lima Moderna.

$\begin{array}{lll}\text { Cencosud } & \rightarrow & \text { Ate Vitarte. } \\ \text { Tottus } & \rightarrow & \text { Villa El Salvador. } \\ \text { Supesa } & \rightarrow & \text { Lurín. }\end{array}$

\section{Merchandising y exhibición de nuestro producto en góndola de las tiendas.}

Dentro de las coordinaciones con los Gerentes de tiendas de las cadenas se negociará el CATMAN-Planograma (ubicación de los productos en góndola por categoría según contribución) para ubicar el cobertor sanitario para inodoros en la góndola de la categoría de cuidado personal del segmento femenino, con la finalidad de ubicarlos al lado de las toallas sanitarias, protectores diarios, jabones de uso íntimo, pañitos húmedos, aprovechando la ruta de consumo de higiene y cuidado femenino.

Es importante considerar que en el caso del competidor Termoencogibles con su marca Queen en Tottus, su producto está ubicado en el pasillo de accesorios de limpieza y lavavajillas, al respecto consideramos que el producto está situado en una ubicación inadecuada. 


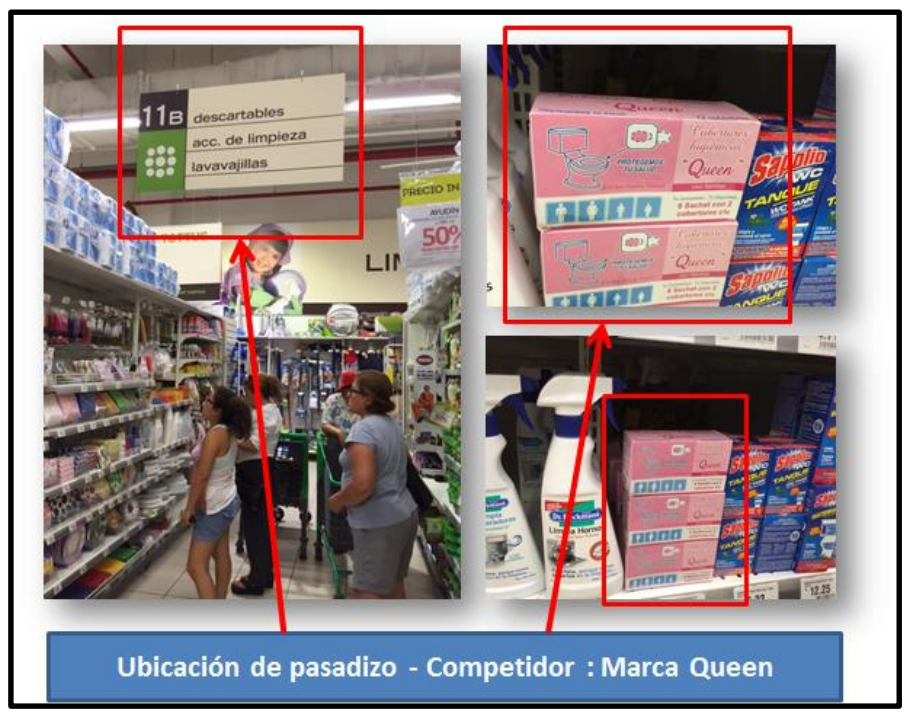

Figura 75. Ubicación de competidor Queen en supermercado. Elaboración propia.

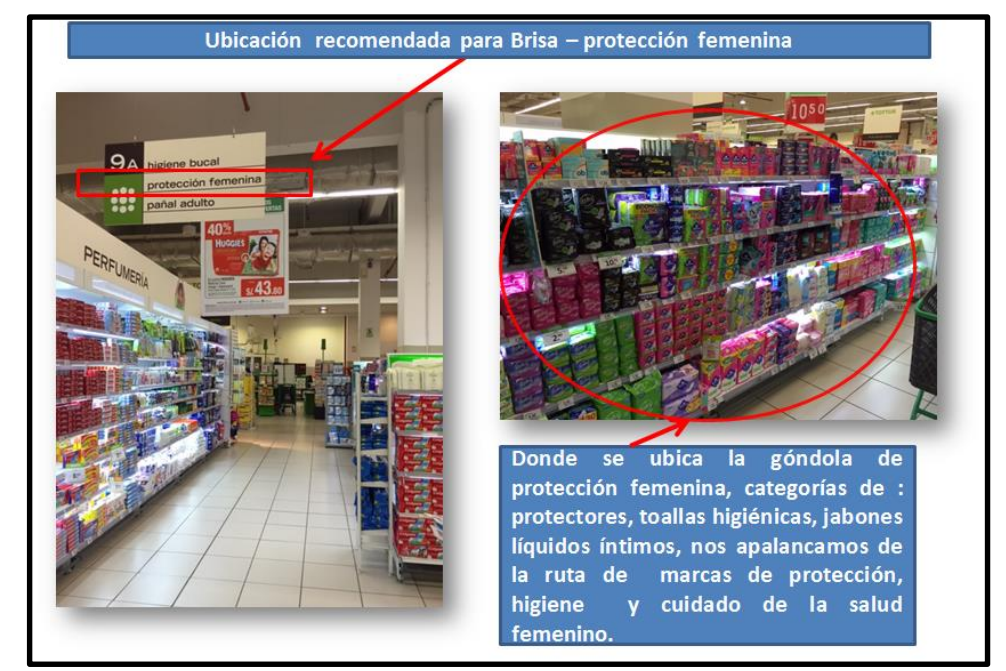

Figura 76. Ubicación recomendada para el nuevo producto. Elaboración Propia.

\section{Jalavistas en góndola}

Este producto sirve para jalar la vista del target en el pasillo de la categoría, donde podemos comunicar el modo de uso de los cobertores. 


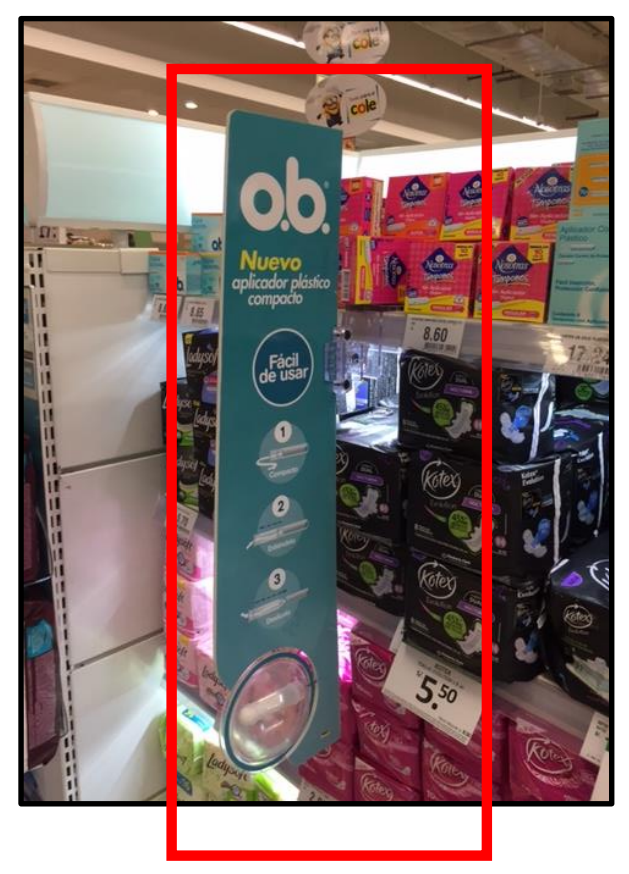

Figura 77. Jalavistas en góndola

Elaboración propia.

\section{Mercaderistas/Impulsadoras de ventas y entrega de muestras gratuitas}

Como parte del plan, en esta etapa de lanzamiento e introducción del producto, estas actividades las se va a tercerizar a través de una empresa que brinda servicios de trade marketing y ejecución en el punto de venta. Esta empresa cuenta con personal con experiencia y conocimientos en el rubro lo que nos garantizará un buen desarrollo de esta etapa.

Las impulsadoras repartirán muestras y folletos, para brindar toda la información y venta conceptual de los problemas que ocasiona el uso de baños públicos fuera del hogar sin el cuidado y protección necesaria de la salud.

Las muestras gratuitas serán distribuidas en supermercados, centros comerciales, universidades, discotecas, en resumen, en aquellos puntos de alto tráfico de consumidoras del target group. El número de impulsadoras está en función al plan y segmentación de las tiendas. Asimismo, la supervisión y control estará a cargo de los coordinadores de ventas. 
Las programaciones, horarios y descansos del personal serán coordinados con la agencia de Trade Marketing.

\section{Seguimiento y control}

Para el seguimiento y control al cumplimiento de los objetivos del negocio y la gestión del día a día de las tiendas, la empresa contará con un software de seguimiento, el cual se convertirá en una poderosa herramienta de gestión e información, para los diferentes niveles de la pirámide estructural de la organización.

Después de algunas evaluaciones y alternativas, se ha determinado que el Software que se alinea con el modelo de negocio es el software CHESS.

Podemos ver las diferentes soluciones que brindan como empresa:

DISTRIBUIR incluye un avanzado desarrollo en todas las operatorias específicas
de manejo de una distribuidora de productos de consumo masivo, sumadas a
las funciones habituales de cualquier sistema administrativo - contable o ERP.

Figura 78. Diferentes soluciones de software, planteadas por CHESS (2016) Referenciado por Chess.com, 2016.

\subsubsection{Políticas de servicios y garantías.}

Las directrices relacionadas a las políticas son todas aquellas directrices a las que la empresa decide acogerse, de tal forma que dichas directivas e ideas sean las que 
motiven las normas generales de actuación de la empresa, determinando así los valores que posee la misma.

De este modo, las políticas de toda compañía suelen estar recogidas por escrito, de tal forma que sean accesibles a todos aquellos colectivos a los que van dirigidas, generalmente clientes, proveedores, accionistas y trabajadores.

Establecer estas políticas ayudará a conocer qué dirección tomar en caso de que exista cualquier tipo de conflicto con alguno de los agentes, lo que permitirá ser justos en la aplicación de decisiones.

Fabre (2017) considera que las políticas empresariales "permitirán crear una imagen de marca, gracias a la cual todos podrán conocer cuáles son los valores y forma de actuar de la empresa. Estas políticas podrán generar un "boca a boca" que puede ser muy positivo o negativo, según la impresión que la empresa haya generado". Por ejemplo, podría ser que la empresa brinda una buena atención al cliente pero mala en la calidad de nuestros productos, y al revés con nuestra competencia.

A continuación, alguna de las políticas del área de Marketing y publicidad, que están alineadas con las estrategias y objetivos de la empresa:

- Todos los integrantes de la empresa deben mantener un comportamiento ético y moral.

- Nuestros productos cumplen con todos los estándares de calidad.

- Las ventas al crédito se realizarán con un máximo de factura a 60 días.

- Las mermas/robos de productos originadas en las tiendas son asumidas por el cliente.

- Compromiso con un servicio de calidad.

\section{Alineación estratégica de las políticas:}

Las políticas como parte del marco estratégico van a ser muy importantes para que se encuentren alineadas la visión y misión, con los valores y la cultura organizacional de la empresa para el cumplimiento de los objetivos estratégicos. 

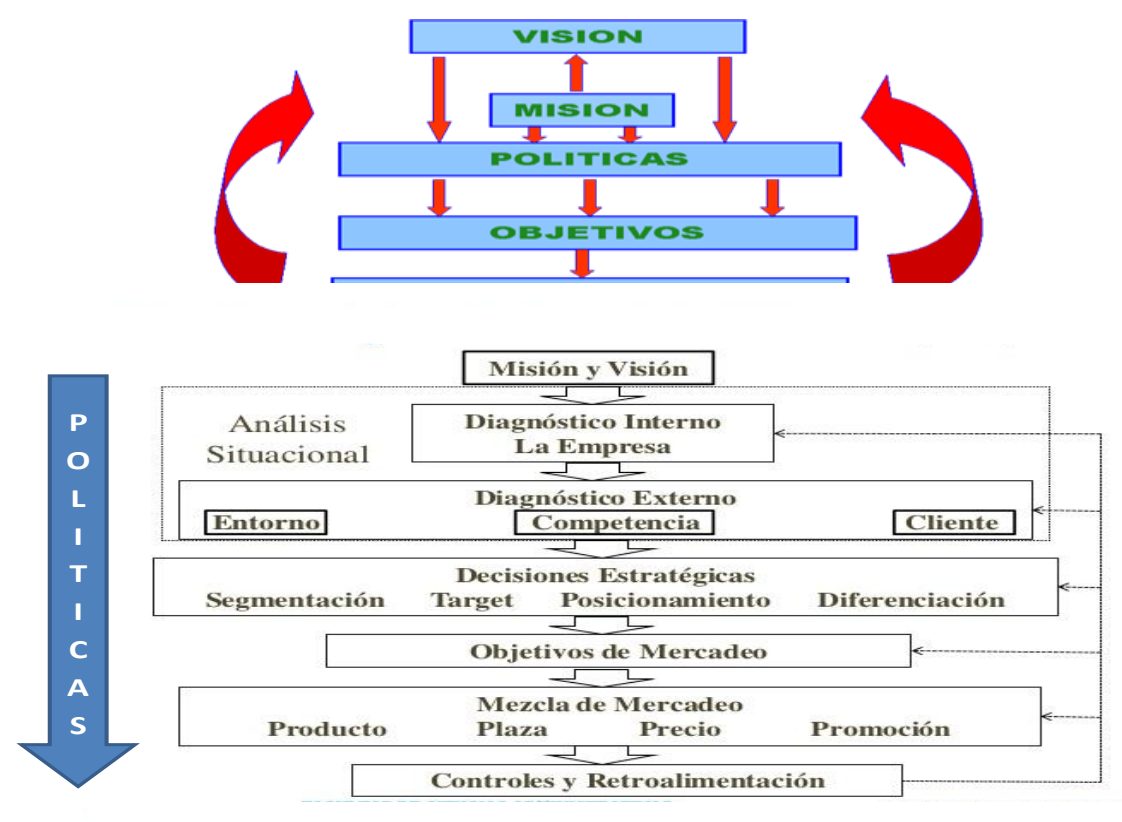

Figura 77. Alineación estratégica de las políticas. Elaboración propia.

\subsubsection{Presupuesto de marketing con un horizonte a 5 años del plan de negocio.}

Tabla 70.

Presupuesto de Marketing y Ventas - Soles

\begin{tabular}{|c|c|c|c|c|c|c|}
\hline Concepto & AÑO 0 & AÑO 1 & AÑO 2 & AÑO 3 & AÑO 4 & AÑO 5 \\
\hline Sueldos & - & 158,662 & 163,834 & 210,374 & 259,773 & 268,242 \\
\hline Servicios & - & 20,327 & 20,446 & 21,125 & 15,651 & 16,889 \\
\hline Depreciación & - & 8,949 & 8,949 & 8,949 & 8,949 & 8,949 \\
\hline Sampling & 13,886 & 41,658 & - & - & - & - \\
\hline $\begin{array}{l}\text { Gastos logísticos } \\
\text { Derecho de ingreso a } \\
\text { Supermercados }\end{array}$ & - & 30,000 & 30,0000 & 6,615 & 30,000 & 30,000 \\
\hline Agencia publicidad digital & - & 170,000 & 180,000 & 190,500 & 201,525 & 213,101 \\
\hline $\begin{array}{l}\text { Revistas aviso } 1 / 2 \text { página - } 12 \\
\text { avisos } \\
\text { Folletos A-4 - 200,000 x S/. } \\
0.20 \mathrm{c} / \mathrm{u}\end{array}$ & - & 40,000 & 40,006 & 42,007 & 44,107 & 46,312 \\
\hline Afiches $2,000 \times \mathrm{S} / .2 .50 \mathrm{c} / \mathrm{u}$ & - & 2,500 & 2,506 & 2,632 & 2,763 & 2,901 \\
\hline Jalavistas - 500 x S/. $10.00 \mathrm{c} / \mathrm{u}$ & - & 2,500 & 2,506 & 2,632 & 2,763 & 2,901 \\
\hline $\begin{array}{l}\text { Agencia impulsadoras-50 x S/. } \\
2,198.008 \text { Año 1) }\end{array}$ & - & 109,900 & 115,395 & 121,165 & 127,223 & 133,584 \\
\hline $\begin{array}{l}\text { Total Presupuesto de Gastos } \\
\text { de Marketing y Ventas }\end{array}$ & 13,886 & 763,470 & 620,344 & 688,917 & 755,266 & 788,518 \\
\hline
\end{tabular}

Elaboración propia. 


\section{CAPITULO VIII: PLANIFICACION FINANCIERA}

\subsection{La inversión}

La fabricación y comercialización del cobertor sanitario para inodoros, necesitará de inversión para la puesta en marcha de la empresa. Como el principal insumo es adquirido en dólares americanos se ha considerado como tipo de cambio, para el horizonte de evaluación de cinco años, el correspondiente al año 2016 indicado en el Marco Macroeconómico Multianual 2015 al 2018, emitido por el Banco Central de Reserva del Perú, el cual asciende a S/ 3.30 soles.

\subsubsection{Inversión Pre-operativa}

La inversión está distribuida de la siguiente manera por la Inversión preoperativa que está conformada por desembolsos realizados en Acondicionamiento del local, equipos de protección y seguridad, artículos de aseo y oficina; Inversión Intangible, conformada por los gastos de constitución ylos software; Inversión Tangible, conformada por equipos, mobiliarios y vehículos; Inversión en Activos Diferidos conformada por los adelantes de alquiler y Gastos Pre-operativos conformados por las Compras, Sueldos y Salarios, Servicios/Gastos Fijos y Gastos de Marketing. A continuación se detallan la distribución de la inversión.

a. La inversión Intangible, constituida por los gastos relacionados con la constitución de la empresa y compras de software que asciende a S/ 18,595. 
Tabla 71.

Constitución de Empresa - Licencias

\begin{tabular}{|c|c|c|c|}
\hline Concepto & Total Neto & IGV & Total en S/. \\
\hline Consulta de nombre & 3.39 & 0.61 & 4.00 \\
\hline Solicitud de Reserva de Razón Social & 15.25 & 2.75 & 18.00 \\
\hline \multicolumn{4}{|l|}{ Indecopi } \\
\hline Búsqueda de Marca & 26.26 & 4.73 & 30.99 \\
\hline Publicación & 292.39 & 52.63 & 345.02 \\
\hline Registro de Marca & 465.95 & 83.87 & 549.82 \\
\hline \multicolumn{4}{|l|}{ Publicación } \\
\hline De Aviso en El Peruano & 211.86 & 38.14 & 250.00 \\
\hline \multicolumn{4}{|l|}{ Minuta de Constitución: } \\
\hline Minuta aprobada por el Abogado & 423.73 & 76.27 & 500.00 \\
\hline Inscripción ante Notario Público: Escritura & 423.73 & 76.27 & 500.00 \\
\hline \multicolumn{4}{|l|}{ Inscripción en Registros Públicos: } \\
\hline Ingreso a Registros & 14.41 & 2.59 & 17.00 \\
\hline Derecho de Inscripción & 508.47 & 91.53 & 600.00 \\
\hline \multicolumn{4}{|l|}{ Licencia Municipal } \\
\hline Certificado de Zonificación & 211.86 & 38.14 & 250.00 \\
\hline Licencia de Funcionamiento Definitiva & 463.82 & 83.49 & 547.31 \\
\hline \multicolumn{4}{|l|}{ INDECI } \\
\hline Certificado de defensa civil & 254.24 & 45.76 & 300.00 \\
\hline \multicolumn{4}{|l|}{ Sunat } \\
\hline Comprobantes de Pagos y Libros & 423.73 & 76.27 & 500.00 \\
\hline \multicolumn{4}{|l|}{ Libro de Planillas: } \\
\hline Costo del libro de planillas & 25.42 & 4.58 & 30.00 \\
\hline Costo de Legalización por 100 páginas & 26.27 & 4.73 & 31.00 \\
\hline \multicolumn{4}{|l|}{ Libros Contables } \\
\hline Costo de los Libros & 152.54 & 27.46 & 180.00 \\
\hline Costo de Legalización por 7 libros & 127.12 & 22.88 & 150.00 \\
\hline Defensa Civil & 381.36 & 68.64 & 450.00 \\
\hline Registro Sanitario & 322.03 & 57.97 & 380.00 \\
\hline \multicolumn{4}{|l|}{ Derecho de código de barras } \\
\hline Código de Barras & 137.03 & 24.67 & 161.7 \\
\hline $\begin{array}{l}\text { Total Constitución de Empresa - } \\
\text { Licencias }\end{array}$ & 4,911 & 884 & $5,795.00$ \\
\hline
\end{tabular}


Tabla 72.

Software

\begin{tabular}{cccc}
\hline Concepto & Total Neto s/IGV & IGV & Total en S/. \\
\hline Página Web & 508.47 & 91.53 & 600.00 \\
Software integral (Microsoft Office) & 5084.75 & 915.25 & $6,000.00$ \\
Software Integrado & 4237.29 & 762.71 & $5,000.00$ \\
Antivirus & $1,016.95$ & 183.05 & $1,200.00$ \\
\hline Total Sistemas & $\mathbf{1 0 , 8 7 4}$ & $\mathbf{1 9 5 3}$ & $\mathbf{1 2 , 8 0 0}$
\end{tabular}

Elaboración propia.

Tabla 73

Inversión Intangible

\begin{tabular}{lccc}
\hline \multicolumn{1}{c}{ Concepto } & Total Neto & IGV & Precio Total \\
\hline Total Constitución de empresa - licencias & 4,911 & 884 & 5,795 \\
Total Software & 10,874 & 1953 & 12,800 \\
Total Inversión Intangible (S/.) & 15,758 & 2,837 & 18,595
\end{tabular}

Elaboración propia.

b. Inversión pre-operativa que está conformada por desembolsos realizados en Acondicionamiento del local, equipos de protección y seguridad, artículos de aseo y oficina, la cual asciende a S/. 26,016.

Tabla 74.

Acondicionamiento de Local

\begin{tabular}{lccccc}
\hline \multicolumn{1}{c}{ Concepto } & Cantidad & $\begin{array}{c}\text { Precio } \\
\text { Unitario }\end{array}$ & Total Neto & IGV & Precio Total \\
\hline Acondicionamiento de local & 40 & 330 & 10,824 & 2,376 & 13,200 \\
\hline $\begin{array}{l}\text { Total Acondicionamiento de } \\
\text { Local }\end{array}$ & & & $\mathbf{1 0 , 8 2 4}$ & $\mathbf{2 , 3 7 6}$ & $\mathbf{1 3 , 2 0 0}$ \\
\hline
\end{tabular}

Elaboración propia. 
Tabla 75.

Artículos de oficina

\begin{tabular}{|c|c|c|c|c|c|}
\hline Concepto & Cantidad & $\begin{array}{l}\text { Precio } \\
\text { Unitario }\end{array}$ & Total Neto & IGV & Precio Total \\
\hline Útiles de oficina & 12 & 300 & 3,051 & 549 & 3,600 \\
\hline EPP & 30 & 40 & 1,017 & 183 & 1,200 \\
\hline Uniformes & 24 & 40 & 814 & 146 & 960 \\
\hline $\begin{array}{l}\text { Artículos de Limpieza (paños, } \\
\text { esponjas, ácido muriático...) }\end{array}$ & 12 & 500 & 5,085 & 915 & 6,000 \\
\hline Artículos de Oficina & & & 9,966 & 1,794 & 11,760 \\
\hline
\end{tabular}

Elaboración propia.

Tabla 76 .

Total Gastos Preoperativos

\begin{tabular}{lccc}
\hline \multicolumn{1}{c}{ Concepto } & Total Neto & IGV & Precio Total \\
\hline Habilitación del local & 10,824 & 2,376 & 13,200 \\
Artículos de Aseo y Oficina & 9,966 & 1,794 & 11,760 \\
Equipos de Protección y Seguridad & 895 & 161 & 1,056 \\
\hline Total Gastos Pre operativos & $\mathbf{2 1 , 6 8 5}$ & $\mathbf{4 , 3 3 1}$ & $\mathbf{2 6 , 0 1 6}$ \\
\hline
\end{tabular}

Elaboración propia.

c. La inversión Tangible, constituida por la compra de activos para la operación del proyecto: maquinarias, mobiliario, unidades de distribución que asciende a $\mathrm{S} / 211,642$. 
Tabla 77.

Máquinas y Equipos.

\begin{tabular}{lccccc}
\hline Concepto & Cantidad & $\begin{array}{l}\text { Precio } \\
\text { Unitario }\end{array}$ & Total Neto & IGV & Precio Total \\
\hline Máquina Convertidora & 1 & 6,000 & 55,932 & 10,068 & 66,000 \\
Máquina Dobladora & 1 & 26,400 & 22,373 & 4,027 & 26,400 \\
Máquina Embolsadora & 1 & 26,400 & 22,373 & 4,027 & 26,400 \\
Carretilla hidráulica & 1 & 2,640 & 2,237 & 403 & 2,640 \\
Andamios & 10 & 66 & 559 & 101 & 660 \\
Herramientas & 1 & 3,000 & 2,542 & 458 & 3,000 \\
Paletas / Parihuelas & 20 & 50 & 847 & 153 & 1,000 \\
Balanza electrónica & 1 & 1,980 & 1,678 & 302 & 1,980 \\
\hline Total Máquinas y equipos & & & $\mathbf{1 0 8 , 5 4 2}$ & $\mathbf{1 9 , 5 3 8}$ & $\mathbf{1 2 8 , 0 8 0}$ \\
\hline
\end{tabular}

Elaboración propia.

Tabla 78.

Mobiliario.

\begin{tabular}{lccccc}
\hline Concepto & Cantidad & $\begin{array}{c}\text { Precio } \\
\text { Unitario }\end{array}$ & Total Neto & IGV & Precio Total \\
\hline Escritorios & 12 & 360 & 3,660 & 659 & 4,319 \\
Sillas Giratorias & 12 & 170 & 1,728 & 311 & 2,039 \\
Mesa para sala de reuniones & 1 & 800 & 678 & 122 & 800 \\
Mobiliario de oficina(muebles, & 3 & 230 & 584 & 105 & 690 \\
estantes, otros) & 2 & 500 & 847 & 153 & 1,000 \\
Otros muebles varios & 8 & 1,499 & 10,163 & 1,829 & 11,992 \\
Computadoras & 3 & 599 & 1,523 & 274 & 1,797 \\
Impresoras & 1 & 2,130 & 1,805 & 325 & 2,130 \\
Fotocopiadoras & & & $\mathbf{2 0 , 9 8 8}$ & $\mathbf{3 , 7 7 8}$ & $\mathbf{2 4 , 7 6 6}$ \\
\hline Total Mobiliario & & & & & \\
\hline
\end{tabular}

Elaboración propia. 
Tabla 79.

Unidades de Distribución y Venta

\begin{tabular}{lcrrrr}
\hline Concepto & Cantidad & $\begin{array}{l}\text { Precio } \\
\text { Unitario }\end{array}$ & Total Neto & IGV & Precio Total \\
\hline Camión 2 toneladas & 2 & 6,400 & 44,746 & 8,054 & 52,800 \\
\hline $\begin{array}{l}\text { Total Unidades de } \\
\text { Distribución y Venta }\end{array}$ & & & $\mathbf{4 4 , 7 4 6}$ & $\mathbf{8 , 0 5 4}$ & $\mathbf{5 2 , 8 0 0}$ \\
\hline
\end{tabular}

Elaboración propia.

Tabla 80.

Consolidado - Total Inversión Tangible.

\begin{tabular}{lccc}
\hline Concepto & Total Neto & IGV & Precio Total \\
\hline Total Máquinas y Equipos & 108,542 & 19,538 & 128,080 \\
Total Mobiliario & 20,988 & 3,778 & 24,766 \\
Total Unidades de Distribución y Venta & 44,746 & 8,054 & 52,800 \\
Total Inversión Tangible (S/.) & 174,277 & 31,370 & 205,646
\end{tabular}

Elaboración propia.

d. La inversión Activo Diferido, conformada por el pago adelantado de alquileres y sus respectivas garantías. La inversión intangible asciende a S/ 31,185 soles

Tabla 81.

Activos Diferidos

\begin{tabular}{lc}
\hline Administrativos & Total en S/. \\
\hline Alquiler de local (2 meses de garantía y 1 adelanto) & 31,185 \\
\hline Total Inversión Activo Diferido (S/.) & 31,185 \\
\hline Elaboración propia. &
\end{tabular}

\subsubsection{Gastos Pre-operativos}

Los gastos están relacionados a las compras de insumos, sueldos, salarios y servicios durante la etapa pre-operativa, los cuales ascienden a S/. 213,169 soles. 
Tabla 82.

Compras de Insumos

\begin{tabular}{lc}
\hline Concepto & AÑO 0 \\
\hline Papel (pack x 10 unidades) 37.5 grms & 164,209 \\
Bolsa serigrafiada & 238 \\
Caja de cartón (50 packs /caja) & 7,526 \\
SUBTOTAL PRODUCCIÓN META & 171,972 \\
IGV & 30,955 \\
\hline Total Presupuesto de Compras & $\mathbf{1 7 1 , 9 7 2}$ \\
\hline
\end{tabular}

Elaboración propia.

Tabla 83.

Sueldos y Salarios

\begin{tabular}{lc}
\hline Asignación de Sueldos y Salarios & AÑO 0 \\
\hline Sueldos y Salarios & 8,150 \\
Essalud & 734 \\
\hline Total Sueldos y Salarios (S/) & $\mathbf{8 , 8 8 4}$
\end{tabular}

Elaboración propia.

Tabla 84.

Servicios.

Alquiler de local

10,395

Servicio de energía eléctrica

Servicio de agua y desagüe

254.24

Servicio de Trío (Internet, Cable, Teléfono)

160.17

Servicio de Limpieza - 01 personal

Servicio de Vigilancia - 02 personal

2,400

Servicio de rpc celulares

93.22

Servicio de contabilidad

1,000

Servicio de reclutamiento - $\mathrm{RRHH}$

Servicio de asesoría legal

500

Servicio de sistemas

500

Subtotal

IGV

Total Servicios (S/.)

18,427

Elaboración propia. 
Tabla 85.

Total Gastos Pre-operativos.

\begin{tabular}{lc}
\hline Concepto & AÑO 0 \\
\hline Total Compra de Insumos & 171,972 \\
Total Sueldos y Salarios & 8,884 \\
Total Servicios & 18,427 \\
Gastos de Marketing ( Sampling) & 13,886 \\
Total Gastos Pre-operativos (S/.) & 213,169
\end{tabular}

Elaboración propia.

\subsubsection{Inversión en capital de trabajo}

La inversión en capital de trabajo está considerada por las necesidades para el financiamiento de la materia prima y los gastos relacionados con la fuerza de trabajo y pago de otros servicios, necesarios para que el proyecto se mantenga en funcionamiento.

El capital de trabajo se determina a través del déficit acumulado mediante el método del déficit acumulado, con esta metodología el capital mínimo necesario asciende a S/ 549,768 en el Quinto mes.

Para determinarlo es necesario contar con la siguiente información:

Tabla 86

Flujo de efectivo de los primeros 5 meses:

\begin{tabular}{|c|c|c|c|c|c|c|c|c|}
\hline Concepto & MES 1 & MES 2 & AÑO 0 & MES 1 & MES 2 & MES 3 & MES 4 & MES 5 \\
\hline \multicolumn{9}{|l|}{ INGRESOS DE EFECTIVO } \\
\hline Cobros a los clientes & & & & & & 237,304 & 237,304 & 237,304 \\
\hline Saldo de efectivo anterior & 552,876 & & 552,876 & & & & & \\
\hline Total de efectivo disponible & 552,876 & & 552,876 & & & 237,304 & 237,304 & 237,304 \\
\hline \multicolumn{9}{|l|}{ EGRESOS DE EFECTIVO } \\
\hline Compras & $-101,464$ & $-101,464$ & $-202,927$ & $-101,464$ & $-101,464$ & $-101,464$ & $-101,464$ & $-101,464$ \\
\hline Sueldos y Salarios & $-8,884$ & $-8,884$ & $-17,767$ & $-30,284$ & $-32,210$ & $-32,210$ & $-32,210$ & $-49,669$ \\
\hline Servicios/Gastos Fijos & $-17,202$ & $-17,202$ & $-34,403$ & $-18,812$ & $-18,812$ & $-18,812$ & $-18,812$ & $-18,812$ \\
\hline Pago de IGV & & & & & & & & \\
\hline Gastos de Marketing & $-13,886$ & & $-13,886$ & $-102,494$ & $-102,494$ & $-102,494$ & $-86,494$ & $-92,196$ \\
\hline \multirow{2}{*}{\multicolumn{9}{|c|}{$\begin{array}{l}\text { Pago de IR a cuenta } \\
\text { Renta Anual ( } 29.5 \%) \\
\text { Saldo mínimo de efectivo } \\
\text { deseado }\end{array}$}} \\
\hline & & & & & & & & \\
\hline Egresos Totales & $-141,435$ & $-127,549$ & $-268,984$ & $-253,053$ & $-254,979$ & $-254,979$ & $-238,979$ & $-262,140$ \\
\hline Flujo Operativo & 411,441 & $-127,549$ & 283,893 & $-253,053$ & $-254,979$ & $-17,675$ & $-1,675$ & $-24,836$ \\
\hline Flujo Acumulado & 411,441 & 283,893 & 283,893 & 30,839 & $-224,140$ & $-241,815$ & $-243,490$ & $-268,326$ \\
\hline
\end{tabular}

Elaboración propia. 
Tabla 87

Máximo déficit acumulado

\begin{tabular}{|c|c|c|c|c|c|c|c|c|}
\hline INVERSIONES & MES 1 & MES 2 & AÑO 0 & MES 1 & MES 2 & MES 3 & MES 4 & MES 5 \\
\hline $\begin{array}{l}\text { Inversión Preoperativo } \\
\text { Inversión en }\end{array}$ & $-26,016$ & & $-26,016$ & & & & & \\
\hline Intangibles & $-18,595$ & & $-18,595$ & & & & & \\
\hline $\begin{array}{l}\text { Inversión en AF } \\
\text { Inversión en Activo }\end{array}$ & $-205,646$ & & $-205,646$ & & & & & \\
\hline Diferido & $-31,185$ & & $-31,185$ & & & & & \\
\hline TOTAL INVERSIONES & $-281,442$ & & $-281,442$ & & & & & \\
\hline FLUJO ECONÓMICO & 129,999 & $-127,549$ & 2,450 & $-253,053$ & $-254,979$ & $-17,675$ & $-1,675$ & $-24,836$ \\
\hline Flujo Acumulado & 129,999 & 2,450 & 2,450 & $-250,603$ & $-505,582$ & $-523,257$ & $-524,932$ & $-549,768$ \\
\hline & & & & & \multicolumn{3}{|c|}{ MAXIMO DEFICIT ACUMULADO } & $-549,768$ \\
\hline
\end{tabular}

Elaboración propia.

Tabla 88.

Resumen Capital de Trabajo

\begin{tabular}{cc}
\hline Ingresos de Efectivo & $\mathbf{1 , 2 6 4 , 7 8 8}$ \\
Compras & $-710,246$ \\
Sueldos y Salarios & $-194,348$ \\
Servicios/Gastos Fijos & $-128,463$ \\
Gastos de Marketing & $-500,058$ \\
Inversiones & $-281,442$ \\
\hline Total Capital de Trabajo & $\mathbf{- 5 4 9 , 7 6 8}$ \\
\hline
\end{tabular}

Elaboración propia.

Sin embargo, al realizar el financiamiento a través de una entidad financiera, es necesario incrementar el mínimo necesario del déficit acumulado más Gastos adicionales. Considerando estas observaciones el préstamo a través de una entidad financiera asciende a $S / 572,779.26$, lo cual nos generaría un flujo financiero positivo. El cual se detalla a continuación:

Tabla 89

Préstamo a solicitar a una entidad financiera

\begin{tabular}{cr}
\hline Concepto & Importe S/ \\
\hline Máximo Déficit Acumulado & $549,768.00$ \\
TEA & $46.00 \%$ \\
CTEA & $47.24 \%$ \\
Seguro de desgravamen & $8,689.06$ \\
Monto financiado & $572,779.26$ \\
\hline
\end{tabular}

Elaboración propia. 


\subsubsection{Costo del proyecto}

La inversión necesaria para todo el proyecto es de $\mathrm{S} / .1,102,644$ que serán solventadas una parte por aporte de capital de los socios y la diferencia será adquirida como préstamo en el sector financiero. Todas las inversiones pre-operativas serán asumidas por los socios y este asciende a S/.552,876 y la diferencia de S/. 549,768 será tomado del sistema financiero. A continuación, se muestra un cuadro consolidando cifras sobre los aportes y préstamos.

Tabla 90.

Inversión Total en Soles

\begin{tabular}{lccc}
\hline \multicolumn{1}{c}{ Concepto } & Total & Aporte de Capital & Préstamo \\
\hline Total Pre operativo & 26,016 & 26,016 & \\
Total Intangible & 18,595 & 18,595 & \\
Total Activo Fijo & 205,646 & 205,646 & \\
Activo diferido (garantías y adelantos & & 31,185 & \\
alquiler) & 31,185 & 271,434 & \\
Gastos Pre operativos & 271,434 & & 549,768 \\
Capital de Trabajo & 549,768 & $\mathbf{5 5 2 , 8 7 6}$ & $\mathbf{5 4 9 , 7 6 8}$ \\
\hline Total en S/. & $\mathbf{1 , 1 0 2 , 6 4 4}$ & $\mathbf{5 0 . 1 4 \%}$ & $\mathbf{4 9 . 8 6 \%}$ \\
\hline Participación & $\mathbf{1 0 0 . 0 0 \%}$ & & \\
\hline
\end{tabular}

Elaboración propia.

\subsection{Financiamiento}

\subsubsection{Endeudamiento y condiciones}

En La Tabla 88 se muestran las características financieras vigentes en los diferentes bancos del sistema financiero nacional para créditos en M.N. para Pequeñas Empresas a 360 días.

Tabla 91.

Condiciones Financieras

\begin{tabular}{ll}
\hline Entidad & TEA \\
\hline BIF & $42,00 \%$ \\
\hline Continental & $41,20 \%$ \\
\hline Crédito & $40,00 \%$ \\
\hline Financiero & $46,50 \%$ \\
\hline Interbank & $45,00 \%$ \\
\hline Scotiabank & $45,00 \%$ \\
\hline Mi Banco & $46,00 \%$ \\
\hline
\end{tabular}

Elaboración propia. 


\section{Criterios de Selección de las Fuentes de Financiamiento}

Para la elección de las fuentes de financiamiento se tomaron en cuenta siguientes criterios:

- Tasas de interés de los bancos.

- Plazo máximo del préstamo.

- Cantidad de requisitos y dificultad para obtener el préstamo.

- Rapidez en la atención de la solicitud de financiamiento

- Solidez y experiencia de la entidad bancaria.

La evaluación determinó la elección de la entidad financiera Mi Banco, esta empresa cuenta con líneas de crédito para capital de trabajo. Este tipo de entidades enfocadas en el segmento de pequeña empresa muestran menos dificultades 0 requerimientos para el financiamiento de proyectos, que las otras entidades del sistema financiero. Sin embargo, la tasa anual que ofrecen se encuentra por encima de la mayoría de entidades financieras.

\section{Financiamiento}

La estructura de financiamiento involucra obtener recursos en capital de trabajo, lo cual suma un porcentaje equivalente al $49.86 \%$ del requerimiento respectivo de inversión para el proyecto.

En la Tabla 93 se muestra el desagregado de la estructura financiera diseñada para la implementación del proyecto.

Tabla 92.

Financiamiento de Rubros Inversión Nuevos S/.

\begin{tabular}{llll}
\hline Concepto & Total & Aporte de Capital & Préstamo \\
\hline Total en S/. & $1,102,644$ & 552,876 & 549,768 \\
\hline Participación & $100.00 \%$ & $50.14 \%$ & $49.86 \%$ \\
\hline
\end{tabular}

Elaboración propia.

Es evidente que alguien que no tiene historia crediticia o garantías podrá requerir un financiamiento a un Banco. Para empresas nuevas el banco requiere una fianza 
solidaria, la cual avala el importe a solicitar como financiamiento, esta garantía tiene la finalidad de reducir los riesgos de no cumplir con la devolución del préstamo

\section{Cuadro de Amortización de la Deuda}

La deuda con el Banco Mi Banco sería amortizada a lo largo de 60 meses, a una CTEA de $47,24 \%$

Tabla 93.

Definición de cuota.

\begin{tabular}{lcr}
\hline Concepto & Unid & Monto \\
\hline Préstamo & $\mathrm{S} /$. & $\mathrm{S} / .549,768$ \\
Plazo & Meses & 60 \\
CTEA & $\%$ & $47,24 \%$ \\
Cuota Mensual & $\mathrm{S} /$ & $\mathrm{S} / 18,493.40$ \\
\hline
\end{tabular}

Elaboración propia.

En la Tabla 93 se presenta el detalle de la amortización de la deuda, respectivamente.

Tabla 94.

Amortización de la Deuda en Soles

\begin{tabular}{cccccccc}
\hline$N^{\circ}$ & $\begin{array}{c}\text { FECHA } \\
\text { PAGO }\end{array}$ & SALDO & CAPITAL & INTERESES & $\begin{array}{c}\text { CUOTA SIN } \\
\text { ITF }\end{array}$ & ITF & CUOTA \\
\hline & & $572,779.26$ & & & & & \\
1 & $01 / 04 / 2016$ & $570,342.27$ & $2,436.99$ & $16,055.51$ & $18,492.50$ & 0.90 & $18,493.40$ \\
2 & $02 / 05 / 2016$ & $567,824.56$ & $2,517.71$ & $15,974.79$ & $18,492.50$ & 0.90 & $18,493.40$ \\
3 & $01 / 06 / 2016$ & $564,702.70$ & $3,121.86$ & $15,370.64$ & $18,492.50$ & 0.90 & $18,493.40$ \\
4 & $01 / 07 / 2016$ & $561,480.82$ & $3,221.88$ & $15,270.62$ & $18,492.50$ & 0.90 & $18,493.40$ \\
5 & $01 / 08 / 2016$ & $558,669.58$ & $2,811.24$ & $15,681.26$ & $18,492.50$ & 0.90 & $18,493.40$ \\
6 & $01 / 09 / 2016$ & $555,765.22$ & $2,904.36$ & $15,588.14$ & $18,492.50$ & 0.90 & $18,493.40$ \\
7 & $03 / 10 / 2016$ & $553,272.84$ & $2,492.38$ & $16,000.12$ & $18,492.50$ & 0.90 & $18,493.40$ \\
8 & $02 / 11 / 2016$ & $549,684.76$ & $3,588.08$ & $14,904.42$ & $18,492.50$ & 0.90 & $18,493.40$ \\
9 & $01 / 12 / 2016$ & $545,481.19$ & $4,203.57$ & $14,288.93$ & $18,492.50$ & 0.90 & $18,493.40$ \\
10 & $02 / 01 / 2017$ & $542,636.99$ & $2,844.20$ & $15,648.30$ & $18,492.50$ & 0.90 & $18,493.40$ \\
11 & $01 / 02 / 2017$ & $538,708.15$ & $3,928.84$ & $14,563.66$ & $18,492.50$ & 0.90 & $18,493.40$ \\
12 & $01 / 03 / 2017$ & $533,676.68$ & $5,031.47$ & $13,461.03$ & $18,492.50$ & 0.90 & $18,493.40$ \\
\hline
\end{tabular}




\begin{tabular}{|c|c|c|c|c|c|c|c|}
\hline 13 & 03/04/2017 & $530,913.33$ & $2,763.35$ & $15,729.15$ & $18,492.50$ & 0.90 & $18,493.40$ \\
\hline 14 & 02/05/2017 & $526,128.69$ & $4,784.64$ & $13,707.86$ & $18,492.50$ & 0.90 & $18,493.40$ \\
\hline 15 & 01/06/2017 & $521,670.94$ & $4,457.75$ & $14,034.75$ & $18,492.50$ & 0.90 & $18,493.40$ \\
\hline 16 & 03/07/2017 & $518,012.17$ & $3,658.77$ & $14,833.73$ & $18,492.50$ & 0.90 & $18,493.40$ \\
\hline 17 & 01/08/2017 & $512,828.18$ & $5,183.99$ & $13,308.51$ & $18,492.50$ & 0.90 & $18,493.40$ \\
\hline 18 & 01/09/2017 & $508,405.35$ & $4,422.83$ & $14,069.67$ & $18,492.50$ & 0.90 & $18,493.40$ \\
\hline 19 & 02/10/2017 & $503,836.01$ & $4,569.34$ & $13,923.16$ & $18,492.50$ & 0.90 & $18,493.40$ \\
\hline 20 & $02 / 11 / 2017$ & $499,115.32$ & $4,720.69$ & $13,771.81$ & $18,492.50$ & 0.90 & $18,493.40$ \\
\hline 21 & 01/12/2017 & $493,346.39$ & $5,768.93$ & $12,723.57$ & $18,492.50$ & 0.90 & $18,493.40$ \\
\hline 22 & 02/01/2018 & $488,718.60$ & $4,627.79$ & $13,864.71$ & $18,492.50$ & 0.90 & $18,493.40$ \\
\hline 23 & 01/02/2018 & $483,062.27$ & $5,656.33$ & $12,836.17$ & $18,492.50$ & 0.90 & $18,493.40$ \\
\hline 24 & 01/03/2018 & $476,368.58$ & $6,693.69$ & $11,798.81$ & $18,492.50$ & 0.90 & $18,493.40$ \\
\hline 25 & 02/04/2018 & $471,159.97$ & $5,208.61$ & $13,283.89$ & $18,492.50$ & 0.90 & $18,493.40$ \\
\hline 26 & 02/05/2018 & $464,941.08$ & $6,218.89$ & $12,273.61$ & $18,492.50$ & 0.90 & $18,493.40$ \\
\hline 27 & 01/06/2018 & $458,522.94$ & $6,418.14$ & $12,074.36$ & $18,492.50$ & 0.90 & $18,493.40$ \\
\hline 28 & 02/07/2018 & $452,301.28$ & $6,221.66$ & $12,270.84$ & $18,492.50$ & 0.90 & $18,493.40$ \\
\hline 29 & 01/08/2018 & $445,478.18$ & $6,823.10$ & $11,669.40$ & $18,492.50$ & 0.90 & $18,493.40$ \\
\hline 30 & 03/09/2018 & $439,601.54$ & $5,876.64$ & $12,615.86$ & $18,492.50$ & 0.90 & $18,493.40$ \\
\hline 31 & 01/10/2018 & $431,609.62$ & $7,991.92$ & $10,500.58$ & $18,492.50$ & 0.90 & $18,493.40$ \\
\hline 32 & 02/11/2018 & $424,869.76$ & $6,739.86$ & $11,752.64$ & $18,492.50$ & 0.90 & $18,493.40$ \\
\hline 33 & 03/12/2018 & $417,533.36$ & $7,336.40$ & $11,156.10$ & $18,492.50$ & 0.90 & $18,493.40$ \\
\hline 34 & 02/01/2019 & $409,596.33$ & $7,937.03$ & $10,555.47$ & $18,492.50$ & 0.90 & $18,493.40$ \\
\hline 35 & 01/02/2019 & $401,405.01$ & $8,191.32$ & $10,301.18$ & $18,492.50$ & 0.90 & $18,493.40$ \\
\hline 36 & 01/03/2019 & $392,272.10$ & $9,132.91$ & $9,359.59$ & $18,492.50$ & 0.90 & $18,493.40$ \\
\hline 37 & 01/04/2019 & $383,855.92$ & $8,416.18$ & $10,076.32$ & $18,492.50$ & 0.90 & $18,493.40$ \\
\hline 38 & 02/05/2019 & $375,160.96$ & $8,694.96$ & $9,797.54$ & $18,492.50$ & 0.90 & $18,493.40$ \\
\hline 39 & 03/06/2019 & $366,489.94$ & $8,671.02$ & $9,821.48$ & $18,492.50$ & 0.90 & $18,493.40$ \\
\hline 40 & 01/07/2019 & $356,314.07$ & $10,175.87$ & $8,316.63$ & $18,492.50$ & 0.90 & $18,493.40$ \\
\hline 41 & 01/08/2019 & $346,706.81$ & $9,607.26$ & $8,885.24$ & $18,492.50$ & 0.90 & $18,493.40$ \\
\hline 42 & 02/09/2019 & $337,062.34$ & $9,644.47$ & $8,848.03$ & $18,492.50$ & 0.90 & $18,493.40$ \\
\hline 43 & 01/10/2019 & $326,277.13$ & $10,785.21$ & $7,707.29$ & $18,492.50$ & 0.90 & $18,493.40$ \\
\hline 44 & 04/11/2019 & $316,452.22$ & $9,824.91$ & $8,667.59$ & $18,492.50$ & 0.90 & $18,493.40$ \\
\hline 45 & 02/12/2019 & $304,781.66$ & $11,670.56$ & $6,821.94$ & $18,492.50$ & 0.90 & $18,493.40$ \\
\hline 46 & 02/01/2020 & $293,467.42$ & $11,314.24$ & $7,178.26$ & $18,492.50$ & 0.90 & $18,493.40$ \\
\hline 47 & 03/02/2020 & $282,001.58$ & $11,465.84$ & $7,026.66$ & $18,492.50$ & 0.90 & $18,493.40$ \\
\hline 48 & 02/03/2020 & $269,301.93$ & $12,699.65$ & $5,792.85$ & $18,492.50$ & 0.90 & $18,493.40$ \\
\hline 49 & 01/04/2020 & $256,615.73$ & $12,686.20$ & $5,806.30$ & $18,492.50$ & 0.90 & $18,493.40$ \\
\hline 50 & 04/05/2020 & $244,072.49$ & $12,543.24$ & $5,949.26$ & $18,492.50$ & 0.90 & $18,493.40$ \\
\hline 51 & 01/06/2020 & $230,239.84$ & $13,832.65$ & $4,659.85$ & $18,492.50$ & 0.90 & $18,493.40$ \\
\hline 52 & 01/07/2020 & $216,302.13$ & $13,937.71$ & $4,554.79$ & $18,492.50$ & 0.90 & $18,493.40$ \\
\hline 53 & 03/08/2020 & $202,335.87$ & $13,966.26$ & $4,526.24$ & $18,492.50$ & 0.90 & $18,493.40$ \\
\hline 54 & 01/09/2020 & $187,380.25$ & $14,955.62$ & $3,536.88$ & $18,492.50$ & 0.90 & $18,493.40$ \\
\hline 55 & 01/10/2020 & $172,069.37$ & $15,310.88$ & $3,181.62$ & $18,492.50$ & 0.90 & $18,493.40$ \\
\hline 56 & $02 / 11 / 2020$ & $156,450.38$ & $15,618.99$ & $2,873.51$ & $18,492.50$ & 0.90 & $18,493.40$ \\
\hline 57 & 01/12/2020 & $140,074.40$ & $16,375.98$ & $2,116.52$ & $18,492.50$ & 0.90 & $18,493.40$ \\
\hline 58 & $04 / 01 / 2021$ & $123,474.02$ & $16,600.38$ & $1,892.12$ & $18,492.50$ & 0.90 & $18,493.40$ \\
\hline
\end{tabular}




\begin{tabular}{lllccccc}
\hline 59 & $01 / 02 / 2021$ & $106,038.93$ & $17,435.09$ & $1,057.41$ & $18,492.50$ & 0.90 & $18,493.40$ \\
60 & $01 / 03 / 2021$ & $88,075.45$ & $17,963.48$ & 536.59 & $18,500.07$ & 0.90 & $18,500.97$ \\
& & & $484,703.81$ & $624,853.76$ & $1,109,557.57$ & & $1,109,611.57$ \\
\hline
\end{tabular}

Nota: Adaptado de "Fuente de Mi banco 2016", por Mi Banco 2016.

\subsubsection{Capital y costo de oportunidad}

Al respecto, cabe indicar lo siguiente:

a. Tasa Libre de Riesgo (TLR): "Asociada a la rentabilidad de un bono emitido por un Banco Central. Se puede tomar como referencia la tasa de rentabilidad de un bono a 5 años (3,576\%) o una obligación a 10 años (5,446\%) emitidos por el tesoro público". (EmpresaActual.com, 2016).

b. Rendimiento de Mercado (RM): "es la covarianza de los rendimientos del activo con respecto a los rendimientos del mercado". (Lira, 2011).

c. Beta: "determina el riesgo de mercado de un activo, en función, de la coyuntura y fluctuación del mercado. Este riesgo no puede eliminarse, ya que es inherente a la actividad operacional y financiera de la empresa". (EmpresaActual.com, 2016)

d. Tasa de Descuento 1 - Tasa Nominal USA: Calculada con la fórmula siguiente: T.D. $1=\mathrm{TLR}+\left((\mathrm{RM}-\mathrm{TLR})^{\star}\right.$ Beta $)$

e. Inflación USA: Tasa estimada en $1.50 \%$. Se obtuvo un promedio de los últimos 5 años de la inflación de EEUU.

f. Tasa de Descuento $2=\left((1+\text { Tasa de Descuento } 1)^{*}(1+\right.$ Inflación USA $\left.)\right)-1$

g. Riesgo País: 280 puntos -Dato BCRP- Ámbito Financiero.

h. Tasa de Descuento $3=$ Tasa de Descuento $2+$ Riesgo País

i. Inflación Perú: Tasa estimada en $3.50 \%$. Se obtuvo un promedio de los últimos 5 años de la inflación de Perú

j. $\quad$ Tasa de Descuento $4=\left((1+\text { Tasa de Descuento } 3)^{\star}(1+\right.$ Inflación Perú $\left.)\right)-1$

COK = T.L.R. +((Rendimiento de Mercado - T.L.R. $)^{\star}$ Beta $)+$ Riesgo País 


\subsubsection{Costo de Capital promedio ponderado}

Definimos el WACC para el financiamiento del proyecto, el cual garantizará el retorno solicitado por los socios, y el interés cobrado por el financiamiento bancario.

Tabla 95.

Costo de Capital Promedio Ponderado

\begin{tabular}{ll}
\hline Concepto & Valores \\
\hline Peso del Aporte - We & $50,14 \%$ \\
Peso de la Deuda -Wd & $49,86 \%$ \\
COK & $18.24 \%$ \\
TEA & $47,24 \%$ \\
Impuesto a la Renta & $29,50 \%$ \\
WAAC & $25.75 \%$ \\
\hline
\end{tabular}

Elaboración propia.

Al respecto, cabe indicar lo siguiente:

a. Peso del aporte - We: Corresponde al porcentaje de dinero aportado por lo socios del proyecto. (Tabla $\mathrm{N}^{\circ}$ ).

b. Peso del aporte - Wd: Corresponde al porcentaje de dinero obtenido con financiamiento de una institución bancaria. (Tabla $N^{\circ}$ 93).

c. Costo de oportunidad - COK: Corresponde a la rentabilidad del proyecto.

d. Tasa efectiva anual - TEA: Corresponde a la tasa del financiamiento bancario.

e. Impuesto a la renta: Corresponde a la tasa establecida por la SUNAT para los ingresos por ventas.

\subsection{Presupuestos base}

A continuación, se muestra la tabla consolidada con todos los presupuestos que se han desarrollado para la ejecución del proyecto.

Antes de mostrar la tabla de presupuestos totales, se muestra el comportamiento de las ventas del primer año, en el que se observa que la proyección de las mismas se realiza de manera gradual, tomando un criterio de gradualidad y estacionalidad, este criterio es asumido para todos los años. 
Tabla 96.

\begin{tabular}{|c|c|c|c|c|c|c|c|c|c|c|c|c|c|}
\hline Concepto & MES 1 & MES 2 & MES 3 & MES 4 & MES 5 & MES 6 & MES 7 & MES 8 & MES 9 & MES 10 & MES 11 & MES 12 & $\begin{array}{c}\text { TOT } \\
\text { AÑN } 1\end{array}$ \\
\hline $\begin{array}{l}\text { Ventas de packs } \\
\text { (10 unidades) } \\
\text { SOLES }\end{array}$ & 237,304 & 237,304 & 237,304 & 316,405 & 316,405 & 316,405 & 316,405 & 316,405 & 395,507 & 395,507 & 435,057 & 435,057 & $3,955,068$ \\
\hline TOTAL & 237,304 & 237,304 & 237,304 & 316,405 & 316,405 & 316,405 & 316,405 & 316,405 & 395,507 & 395,507 & 435,057 & 435,057 & $3,955,068$ \\
\hline
\end{tabular}

Presupuesto Totales.

\begin{tabular}{|c|c|c|c|c|c|c|}
\hline Concepto & AÑO 0 & AÑO 1 & AÑO 2 & AÑO 3 & AÑO 4 & AÑO 5 \\
\hline Presupuesto de Ventas & & $3,955,068$ & $4,147,305$ & $4,348,886$ & $4,560,265$ & $4,781,918$ \\
\hline $\begin{array}{l}\text { Presupuesto de Costos de } \\
\text { Producción }\end{array}$ & & $1,292,993$ & $1,343,115$ & $1,364,677$ & $1,404,738$ & $1,427,689$ \\
\hline Presupuesto de Compras & 171,972 & $1,031,834$ & $1,047,827$ & $1,064,069$ & $1,080,562$ & $1,097,311$ \\
\hline $\begin{array}{l}\text { Presupuesto de Costos de } \\
\text { Ventas }\end{array}$ & & $2,304,190$ & $2,318,767$ & $2,435,840$ & $2,492,503$ & $2,539,552$ \\
\hline $\begin{array}{l}\text { Presupuesto de Gastos } \\
\text { Administrativos }\end{array}$ & 56,612 & 189,536 & 195,137 & 199,629 & 204,264 & 209,045 \\
\hline $\begin{array}{l}\text { Presupuesto de Gastos de } \\
\text { Marketing y Ventas }\end{array}$ & 13,886 & 763,470 & 620,344 & 688,917 & 755,266 & 788,518 \\
\hline $\begin{array}{l}\text { Presupuesto de Gastos } \\
\text { Financieros }\end{array}$ & & 221,910 & 221,910 & 221,910 & 221,910 & $221,917.57$ \\
\hline
\end{tabular}

Elaboración propia.

\subsubsection{Presupuesto de ventas}

Las ventas del proyecto se inician en el primer mes del año uno y son consideradas como ventas de la totalidad de lo producido el mes anterior.

Tabla 97.

Presupuesto de ventas.

\begin{tabular}{|c|c|c|c|c|c|c|}
\hline Concepto & AÑO 0 & AÑO 1 & AÑO 2 & AÑO 3 & AÑO 4 & AÑO 5 \\
\hline $\begin{array}{l}\text { Ventas de packs (10 } \\
\text { unidades) SOLES }\end{array}$ & - & $3,955,068$ & $4,147,305$ & $4,348,886$ & $4,560,265$ & $4,781,918$ \\
\hline TOTAL & - & $3,955,068$ & 4147,305 & $4,348,886$ & $4,560,265$ & $4,781,918$ \\
\hline
\end{tabular}

Elaboración propia.

\subsubsection{Presupuesto de costos de producción}

Para este presupuesto se ha considerado que los insumos son importados de China, por lo cual existe una demora de 60 días en su transporte y trámites aduaneros para que se encuentre en planta el día 01 del tercer mes del pre operativo. Lo que 
significa que se produce el cuarto mes del pre operativo para poder vender el primer mes del año uno del proyecto. Siguiendo con este concepto los gastos de personal durante los primeros tres meses del pre operativo son solo de los jefes y a partir del cuarto mes incluye operaciones.

Asimismo, se ha considera una participación del $80 \%$ en los gastos correspondientes a alquileres y servicios. $Y$ también las cargas sociales de personal del área.

Tabla 98.

Presupuesto Costos de Producción - Soles.

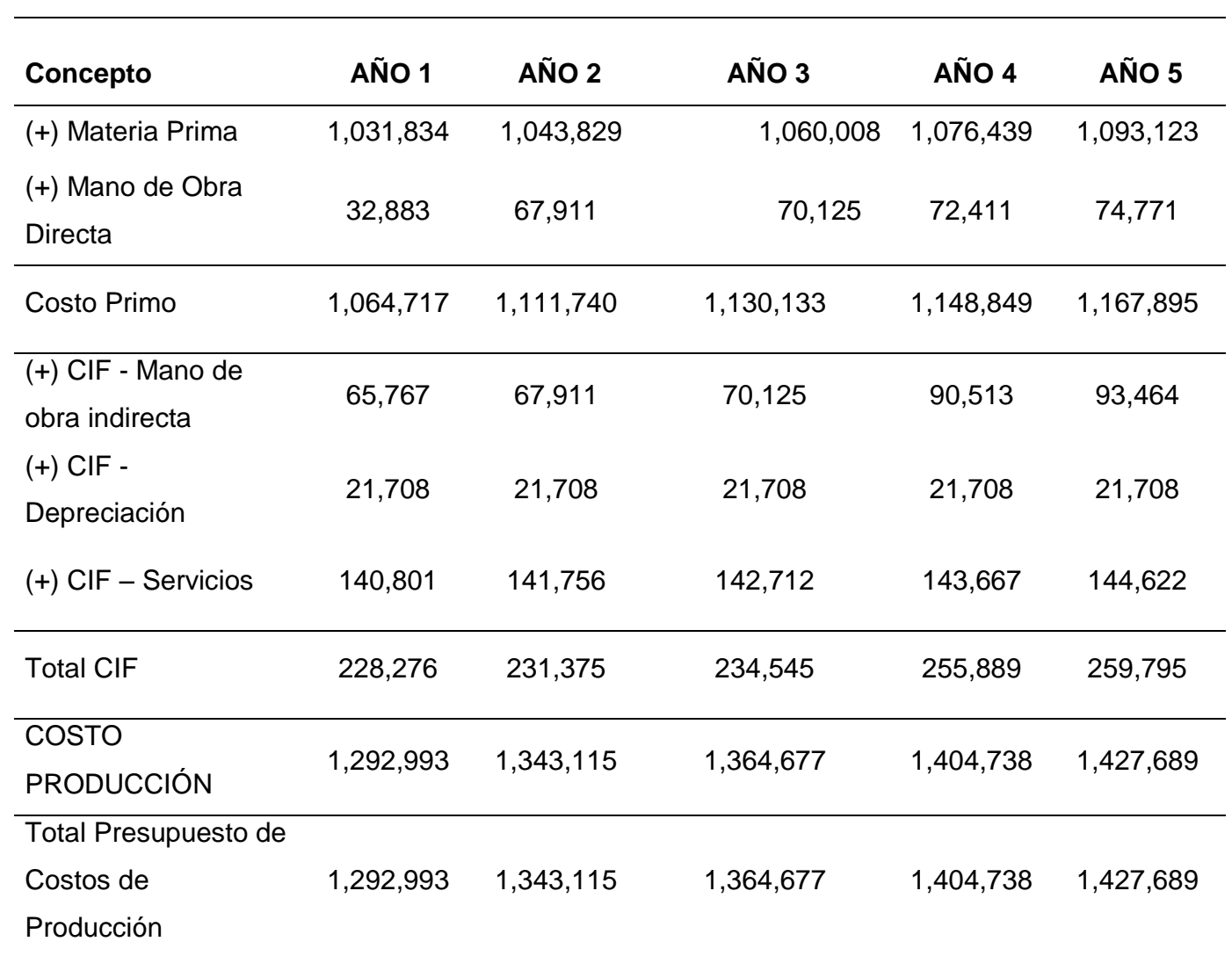

Elaboración propia.

\subsubsection{Presupuesto de compras}

Las compras se realizan a partir del primer mes el pre operativo, debido a que el insumo es importado y demora en llegar a planta 60 días. Por ello todo el proceso de compras se realiza con dos meses de anticipación. 
Tabla 99.

Presupuesto de Compras - Soles.

\begin{tabular}{|c|c|c|c|c|c|c|}
\hline Concepto & AÑO 0 & AÑO 1 & AÑO 2 & AÑO 3 & AÑO 4 & AÑO 5 \\
\hline $\begin{array}{l}\text { Papel (pack x } 10 \\
\text { unidades) } 37.5 \text { grms }\end{array}$ & 164,209 & 985,251 & $1,000,523$ & $1,016,031$ & $1,031,779$ & $1,047,772$ \\
\hline Bolsa serigrafiada & 238 & 1,425 & 1,447 & 1,470 & 1,492 & 1,516 \\
\hline $\begin{array}{l}\text { Caja de cartón ( } 50 \\
\text { packs /caja) }\end{array}$ & 7,526 & 45,157 & 45,857 & 46,568 & 47,290 & 48,023 \\
\hline $\begin{array}{l}\text { Total Presupuesto de } \\
\text { Compras }\end{array}$ & 171,972 & $1,031,834$ & $1,047,827$ & $1,064,069$ & $1,080,562$ & $1,097,311$ \\
\hline
\end{tabular}

Elaboración propia.

\subsubsection{Presupuesto de costo de ventas}

Este presupuesto considera lo vendido, lo cual significa que lo que se produce se vende, restándolo los gastos incurridos en la producción de sampling.

Tabla 100.

Presupuesto de Costo de ventas - Soles.

\begin{tabular}{|c|c|c|c|c|c|}
\hline Concepto & AÑO 1 & AÑO 2 & AÑO 3 & AÑO 4 & AÑO 5 \\
\hline (+) Inventario Inicial de PT & $1,011,197$ & 975,652 & $1,071,163$ & $1,087,766$ & $1,111,868$ \\
\hline (+) Costos de Producción & $1,292,993$ & $1,343,115$ & $1,364,677$ & $1,404,738$ & $1,427,689$ \\
\hline (-) Inventario Final de PT & $-48,152$ & & & & \\
\hline $\begin{array}{l}\text { Total Presupuesto de } \\
\text { Costo de Ventas }\end{array}$ & $2,304,190$ & $2,318,767$ & $2,435,840$ & $2,492,503$ & $2,539,552$ \\
\hline
\end{tabular}

Elaboración propia.

\subsubsection{Presupuesto de gastos administrativos}

Como se mencionó, durante los tres primeros meses del pre operativo se considera los sueldos de los jefes. A partir del cuarto mes del pre operativo y en adelante en los meses del proyecto, se le paga a todo el personal del área administrativa.

Asimismo, se han considerado las cargas sociales inherentes a los sueldos del personal.

Por otro lado, se ha considerado un $10 \%$ de participación en los gastos correspondientes a Servicios y alquileres para esta área de la empresa. 
Tabla 101.

Presupuesto de Gastos administrativos - Soles.

\begin{tabular}{lllllll}
\hline Concepto & AÑO 0 & AÑO 1 & AÑO 2 & AÑO 3 & AÑO 4 & AÑO 5 \\
Sueldos & 22,209 & 129,889 & 134,124 & 138,496 & 143,011 & 147,673 \\
Servicios & 34,403 & 49,208 & 49,328 & 49,447 & 49,566 & 49,686 \\
Depreciación & & 4,198 & 4,198 & 4,198 & 4,198 & 4,198 \\
Amortización & & 6,241 & 7,489 & 7,489 & 7,489 & 7,489 \\
\hline Total de Presupuestos de & $\mathbf{5 6 , 6 1 2}$ & $\mathbf{1 8 9 , 5 3 6}$ & $\mathbf{1 9 5 , 1 3 7}$ & $\mathbf{1 9 9 , 6 2 9}$ & $\mathbf{2 0 4 , 2 6 4}$ & $\mathbf{2 0 9 , 0 4 5}$ \\
Gastos Administrativos & & & & &
\end{tabular}

Elaboración propia.

\subsubsection{Presupuesto de marketing y ventas}

El área de marketing ha diseñado un plan de publicidad y marketing de dos años, dichos gastos se han ingresado en su presupuesto: sampling, agencia de publicidad, revistas, otros, como estrategia de lanzamiento. Por otro lado, para los siguientes años se continúa con inversión de publicidad como estrategia de mantenimiento y penetración en nuevos canales de ventas

Así como, a las otras áreas de la empresa, el área de marketing tiene una participación de $10 \%$ en los gastos correspondientes a servicios y alquileres. 
Tabla 102.

Presupuesto de Marketing y Ventas - Soles.

\begin{tabular}{|c|c|c|c|c|c|c|}
\hline Concepto & AÑO 0 & AÑO 1 & AÑO 2 & AÑO 3 & AÑO 4 & AÑO 5 \\
\hline Sueldos & & 158,662 & 163,834 & 210,374 & 259,773 & 268,242 \\
\hline Servicios & & 20,327 & 20,446 & 21,125 & 15,651 & 16,889 \\
\hline Depreciación & & 8,949 & 8,949 & 8,949 & 8,949 & 8,949 \\
\hline SAMPLING & 13,886 & 41,658 & - & - & - & - \\
\hline $\begin{array}{l}\text { Gastos logísticos } \\
\text { Derecho de }\end{array}$ & & 6,000 & 6,300 & 6,615 & 6,946 & 7,293 \\
\hline Supoermercadios & & 30,000 & 30,000 & 30,000 & 30,000 & 30,000 \\
\hline Agencia publicidad digital & & 170,000 & 180,000 & 190,500 & 201,525 & 213,101 \\
\hline $\begin{array}{l}\text { Revistas aviso } 1 / 2 \text { página } \\
-12 \text { avisos } \\
\text { Folletos } A-4-200,000 x\end{array}$ & & 48,000 & 50,400 & 52,920 & 55,566 & 58,344 \\
\hline $\begin{array}{l}\text { S/. } 0.20 \mathrm{c} / \mathrm{u} \\
\text { Afiches } 2,000 \times \mathrm{S} / .2 .50\end{array}$ & & 40,000 & 40,006 & 42,007 & 44,107 & 46,312 \\
\hline $\begin{array}{l}\text { c/u } \\
\text { Jalavistas }-500 \times \text { S/. }\end{array}$ & & 2,500 & 2,506 & 2,632 & 2,763 & 2,901 \\
\hline $\begin{array}{l}10.00 \mathrm{c} / \mathrm{u} \\
\text { Agencia impulsadoras }-50\end{array}$ & & 2,500 & 2,506 & 2,632 & 2,763 & 2,901 \\
\hline x S/. 2,198.00 & & 109,900 & 115,395 & 121,165 & 127,223 & 133,584 \\
\hline $\begin{array}{l}\text { Total Presupuesto de } \\
\text { Gastos de Marketing y } \\
\text { Ventas }\end{array}$ & 13,886 & 763,470 & 620,344 & 688,917 & 755,266 & 788,518 \\
\hline
\end{tabular}

Elaboración propia.

\subsubsection{Presupuesto de gastos financieros}

Como se mencionó en el punto relacionado a Financiamiento, se ha conseguido un préstamo de S/. 549,768 con Mi Banco, especializado en pequeñas empresas. Este financiamiento es a 60 meses.

El desembolso se realiza al primer mes del pre operativo y la amortización e intereses se comienzan a pagar a partir del mes dos del pre operativo.

Tabla 103

Presupuesto de Gastos Financieros - Soles.

\begin{tabular}{lccrrrr}
\hline $\begin{array}{l}\text { SERVICIO DE } \\
\text { DEUDA }\end{array}$ & AÑO 0 & AÑO 1 & AÑO 2 & AÑO 3 & AÑO 4 & AÑO 5 \\
\hline Amortización & $59,102.58$ & $57,308.10$ & $84,096.48$ & $122,970.17$ & $181,226.48$ \\
Interés & $182,807.42$ & $164,601.90$ & $137,813.52$ & $98,939.83$ & $40,691.09$ \\
\hline TOTAL SERVICIO & - & $\mathbf{2 2 1 , 9 1 0 . 0 0}$ & $\mathbf{2 2 1 , 9 1 0 . 0 0}$ & $\mathbf{2 2 1 , 9 1 0 . 0 0}$ & $\mathbf{2 2 1 , 9 1 0 . 0 0}$ & $\mathbf{2 2 1 , 9 1 0 . 0 0}$ \\
DE LA DEUDA & & & &
\end{tabular}

Elaboración propia. 


\subsection{Presupuestos de resultados}

Las principales premisas usadaspara el desarrollo de las proyecciones son las siguientes:

a. El horizonte de evaluación es 5 años.

b. Los niveles de venta que tendría el proyecto corresponden a los resultados obtenidos en el Estudio de Mercado.

c. Los precios asignados al producto se encuadran en los establecidos por la Encuesta y los que registran los productos similares.

d. El proyecto se implementaría en los distritos de Lima Moderna.

e. Los costos y requerimientos técnicos para la realización del plan han sido obtenidos de entrevista a profesionales del sector e investigaciones de campo.

f. El costo del personal involucra 12 sueldos, 2 gratificaciones y los beneficios sociales de ley. Asimismo, un incremento de los sueldos del personal en 10\% a partir del tercer año y un crecimiento de personal en el área de ventas y operaciones por el ingreso a nuevos canales de distribución.

g. El Impuesto a la Renta es del $29.5 \%$.

h. Estado de ganancias y pérdidas proyectado.

i. El estado de ganancias y pérdidas muestra la eficiencia en las actividades de la empresa en la obtención de utilidades en cada año del ejercicio del proyecto.

Tabla 104.

Estado de Ganancias y Pérdidas Proyectado.

\begin{tabular}{|c|c|c|c|c|c|c|}
\hline EERR & AÑO 0 & AÑO 1 & AÑO 2 & AÑO 3 & AÑO 4 & AÑO 5 \\
\hline VENTAS & - & $3,955,068$ & $4,147,305$ & $4,348,886$ & $4,560,265$ & $4,781,918$ \\
\hline (- ) COSTO DE VENTA & - & $2,304,190$ & $2,318,767$ & $2,435,840$ & $2,492,503$ & $2,539,552$ \\
\hline UTILIDAD BRUTA & - & $1,650,877$ & $1,828,538$ & $1,913,046$ & $2,067,761$ & $2,242,366$ \\
\hline (-) GASTOS ADMINISTRATIVOS & 56,612 & 190,784 & 195,137 & 199,629 & 204,264 & 209,045 \\
\hline (-) GASTOS MKT Y VENTAS & 13,886 & 763,470 & 620,344 & 688,917 & 755,266 & 788,518 \\
\hline UTILIDAD OPERATIVA & 70,498 & 696,624 & $1,013,056$ & $1,024,499$ & $1,108,231$ & $1,244,803$ \\
\hline $\begin{array}{l}\text { (-) GASTOS FINANCIEROS } \\
\text { UTILIDAD ANTES DE }\end{array}$ & - & 182,807 & 164,602 & 137,814 & 98,940 & 40,691 \\
\hline IMPUESTOS & 70,498 & 513,816 & 848,455 & 886,686 & $1,009,291$ & $1,204,112$ \\
\hline (-) IMPUESTO A LA RENTA 29.5\% & & 151,576 & 250,294 & 261,572 & 297,741 & 355,213 \\
\hline UTILIDAD NETO DEL EJERCICIO & $-70,498$ & 362,240 & 598,160 & 625,113 & 711,550 & 848,899 \\
\hline
\end{tabular}

\footnotetext{
Elaboración propia.
} 


\subsubsection{Balance Proyectado}

Tabla 105. Balance General Proyectado.

\begin{tabular}{|c|c|c|c|c|c|c|}
\hline & AÑO 0 & AÑO 1 & AÑO 2 & AÑO 3 & AÑO 4 & AÑO 5 \\
\hline Efectivo y equivalente de efectivo & $1,102,644$ & $-73,328$ & 821,195 & $1,686,282$ & $2,483,461$ & $3,288,790$ \\
\hline Inventario MP & & $1,031,834$ & $1,047,827$ & $1,064,069$ & $1,080,562$ & $1,097,311$ \\
\hline Activo Diferido & & 521,455 & 244,504 & 137,773 & 86,857 & 65,435 \\
\hline Total Activo Corriente & $1,102,644$ & $1,479,961$ & $2,113,526$ & $2,888,124$ & $3,650,880$ & $4,451,535$ \\
\hline Activo Fijo & & 174,277 & 174,277 & 174,277 & 174,277 & 174,277 \\
\hline Depreciación Acumulada & & $-34,855$ & $-69,711$ & $-104,566$ & $-139,421$ & 174,277 \\
\hline Intangible & & 15,758 & 15,758 & 15,758 & 15,758 & 15,758 \\
\hline Amortización Acumulada & - & $-7,489$ & $-14,977$ & $-22,466$ & $-29,955$ & 37,443 \\
\hline Total Activo No Corriente & - & 147,691 & 105,347 & 63,003 & 20,659 & 21,685 \\
\hline TOTAL ACTIVO & $1,102,644$ & $1,627,652$ & $2,218,873$ & $2,951,127$ & $3,671,539$ & $4,429,850$ \\
\hline \multicolumn{7}{|l|}{ PASIVO Y PATRIMONIO } \\
\hline Sueldos y Contraprestaciones & & 66,345 & 142,327 & 226,102 & 323,254 & 423,143 \\
\hline IGV & & 49,603 & 39,918 & 42,416 & 45,136 & 47,894 \\
\hline IR & & 85,922 & 69,993 & 174,957 & 206,916 & 259,974 \\
\hline Total Pasivo Corriente & & 201,870 & 252,238 & 443,475 & 575,307 & 731,010 \\
\hline Deuda LP & 549,768 & 510,666 & 453,358 & 369,261 & 246,291 & - \\
\hline Total Pasivo No Corriente & 549,768 & 510,666 & 453,358 & 369,261 & 246,291 & - \\
\hline TOTAL PASIVO & 549,768 & 712,536 & 705,595 & 812,736 & 821,598 & 731,010 \\
\hline Capital & 552,876 & 552,876 & 552,876 & 552,876 & 552,876 & 552,876 \\
\hline Utilidades Acumuladas & & - & 362,240 & 960,401 & $1,585,514$ & $2,297,065$ \\
\hline Utilidad del Ejercicio & & 362,240 & 598,160 & 625,113 & 711,550 & 848,899 \\
\hline TOTAL PATRIMONIO & 552,876 & 915,117 & $1,513,277$ & $2,138,391$ & $2,849,941$ & $3,698,840$ \\
\hline $\begin{array}{l}\text { TOTAL PASIVO Y } \\
\text { PATRIMONIO }\end{array}$ & $1,102,644.46$ & $1,627,652$ & $2,218,873$ & $2,951,127$ & $3,671,539$ & $4,429,850$ \\
\hline
\end{tabular}

\footnotetext{
Elaboración propia.
} 


\subsubsection{Flujo de caja proyectado}

Tabla 106. Flujo de caja Proyectado.

\begin{tabular}{|c|c|c|c|c|c|c|}
\hline Flujos de Efectivo & AÑO 0 & AÑO 1 & AÑO 2 & AÑO 3 & AÑO 4 & AÑO 5 \\
\hline Ingresos por cobranzas & & $3,084,953$ & $4,312,378$ & $4,314,617$ & $4,524,330$ & $4,744,237$ \\
\hline Total Ingresos & & $3,084,953$ & $4,312,378$ & $4,314,617$ & $4,524,330$ & $4,744,237$ \\
\hline Compras & $-202,927$ & $-1,217,564$ & $\begin{array}{c}-\overline{1} \\
1,236,436\end{array}$ & $\begin{array}{c}- \\
1,255,601\end{array}$ & $\begin{array}{c}- \\
1,275,063\end{array}$ & $-1,294,826$ \\
\hline Sueldos y Salarios & $-17,767$ & $-419,506$ & $-493,619$ & $-545,593$ & $-631,479$ & $-652,496$ \\
\hline Servicios/Gastos Fijos & $-36,854$ & $-225,743$ & $-227,152$ & $-229,221$ & $-224,031$ & $-226,760$ \\
\hline Pago de IGV & 0 & $-244,433$ & $-438,094$ & $-453,422$ & $-483,266$ & $-513,610$ \\
\hline Gastos de Marketing & $-13,886$ & $-763,470$ & $-620,344$ & $-688,917$ & $-470,893$ & $-494,438$ \\
\hline Pago de IR a cuenta & & $-65,654$ & $-180,301$ & $-86,615$ & $-90,825$ & $-95,239$ \\
\hline Impuesto a la Renta Anual & & & & 62,528 & $-167,129$ & \\
\hline Total Egresos & $-271,434$ & $-2,936,370$ & $\begin{array}{c}- \\
3,195,946 \\
\end{array}$ & $\begin{array}{c}- \\
3,196,841 \\
\end{array}$ & $\begin{array}{c}- \\
3,342,686 \\
\end{array}$ & $-3,277,370$ \\
\hline Flujo Operacional & $-271,434$ & 148,582 & $1,116,432$ & $1,117,776$ & $1,181,645$ & $1,466,867$ \\
\hline Inversión Pre operativo & $-26,016$ & & & & & \\
\hline Inversión en Intangibles & $-18,595$ & & & & & \\
\hline $\begin{array}{l}\text { Inversión en AF } \\
\text { Inversión en Activo } \\
\text { Diferido }\end{array}$ & $\begin{array}{l}-205,646 \\
-31,185\end{array}$ & & & & & \\
\hline Capital de Trabajo & $-549,768$ & & & & & \\
\hline Flujo Económico & $-1,102,644$ & 148,582 & $1,116,432$ & $1,117,776$ & $1,181,645$ & $1,466,867$ \\
\hline Préstamo LP & 549,768 & & & & & \\
\hline Amortización de deuda & & $-39,103$ & $-57,308$ & $-84,096$ & $-122,970$ & $-181,226$ \\
\hline Intereses & & $-182,807$ & $-164,602$ & $-137,814$ & $-98,940$ & $-40,691$ \\
\hline Flujo Financiero & $-552,876$ & $-73,328$ & 894,522 & 895,866 & 959,735 & $1,244,950$ \\
\hline Flujo Acumulado & & $-73,328$ & 821,195 & $1,717,060$ & $2,676,795$ & $3,921,745$ \\
\hline
\end{tabular}




\section{CAPITULO IX: EVALUACION ECONOMICO FINANCIERA}

\subsection{Evaluación Económica}

La evaluación Económica implica que el proyecto sea financiado al $100 \%$ por los socios utilizando un COK de $18.24 \%$, obteniéndose los siguientes resultados:

Tabla 107.

Evaluación Económica

\begin{tabular}{cc}
\hline VANE & $1,736,672.40$ \\
TIRE & $60.98 \%$ \\
PRKE & 1 año 10 meses \\
B/CE & 2.58 \\
\hline
\end{tabular}

\section{Valor Actual Neto Económico (VANE)}

\begin{tabular}{|c|c|c|c|c|c|c|}
\hline Flujos de Efectivo & AÑO 0 & AÑO 1 & AÑO 2 & AÑO 3 & AÑO 4 & AÑO 5 \\
\hline Inversión Preoperativo & $-26,016$ & - & - & - & - & - \\
\hline Inversión en Intangibles & $-18,595$ & - & - & - & - & - \\
\hline Inversión en AF & $-205,646$ & - & & & - & - \\
\hline Inversión en Activo Diferido & $-31,185$ & - & - & - & - & - \\
\hline Capital de Trabajo & $-549,768$ & & & & & \\
\hline Flujo Económico & $-1,102,644$ & 148,582 & $1,116,432$ & $1,117,776$ & $1,181,645$ & $1,466,867$ \\
\hline
\end{tabular}

Valor Actual Neto Económico (VANE S/.1,736,672.40 > 0). Esto implica que los beneficios generados son superiores a los costos incurridos, por lo tanto se acepta el estudio y se puede recomendar su ejecución.

\section{Tasa Interna de Retorno Económico (TIRE)}

La tasa Interna de Retorno es la mayor que la tasa de interés mínima aceptable $(60.98 \% \%>18.24 \%)$.

\section{Periodo de Recuperación Económica (PRKE)}

Los inversionistas recuperarán el monto de lo invertido en 1 año 10 meses 


\section{Relación Beneficio - Costo Económico (B/CE)}

Relación Beneficio / costo Económica $=2.58>1$; Esto quiere decir que los beneficios que se generan al invertir el $100 \%$ de capital en el negocio son mayores a los costos por lo cual se dice que el proyecto es aceptable por lo que se recomienda su ejecución.

\subsection{Evaluación Financiera}

\begin{tabular}{lcccccc}
\hline Flujos de Efectivo & AÑO 0 & AÑO 1 & AÑO 2 & AÑO 3 & AÑO 4 & AÑO 5 \\
\hline Inversión Preoperativo & $-26,016$ & - & - & - & - & - \\
Inversión en Intangibles & $-18,595$ & - & - & - & - & - \\
Inversión en AF & $-205,646$ & - & & & - & - \\
Inversión en Activo Diferido & $-31,185$ & - & - & - & - & - \\
Capital de Trabajo & $-549,768$ & & & & & \\
\hline Flujo Económico & $\mathbf{- 1 , 1 0 2 , 6 4 4}$ & $\mathbf{1 4 8 , 5 8 2}$ & $\mathbf{1 , 1 1 6 , 4 3 2}$ & $\mathbf{1 , 1 1 7 , 7 7 6}$ & $\mathbf{1 , 1 8 1 , 6 4 5}$ & $\mathbf{1 , 4 6 6 , 8 6 7}$ \\
\hline Préstamo LP & 549,768 & - & - & - & - & - \\
Amortización de deuda & - & $-39,103$ & $-57,308$ & $-84,096$ & $-122,970$ & $-181,226$ \\
Intereses & - & $-182,807$ & $-164,602$ & $-137,814$ & $-98,940$ & $-40,691$ \\
\hline Flujo Financiero & $\mathbf{- 5 5 2 , 8 7 6}$ & $\mathbf{- 7 3 , 3 2 8}$ & $\mathbf{8 9 4 , 5 2 2}$ & $\mathbf{8 9 5 , 8 6 6}$ & $\mathbf{9 5 9 , 7 3 5}$ & $\mathbf{1 , 2 4 4 , 9 5 0}$ \\
\hline
\end{tabular}

Nota: Tabla elaborada por equipo de investigación.

La evaluación Financiera, implica que el financiamiento del proyecto es con un porcentaje de aporte de accionistas $(50.14 \%)$ y otro porcentaje con financiamiento bancario (49.86\%), utilizando la tasa WACC del 25.75\%., Obteniéndose los siguientes resultados:

Tabla 108.

Evaluación Financiera

\begin{tabular}{cc} 
VANF & $1,184,621.18$ \\
\hline TIRF & $79.29 \%$ \\
\hline PRKF & 1 año 8 meses \\
\hline B/CF & 3.16 \\
\hline
\end{tabular}

Elaboración propia.

\section{Valor Actual Neto Financiero (VANF)}

Valor Actual Neto Financiero (VANF 1, 184,621.18> 0). Esto implica que los beneficios generados son superiores a los costos incurridos, a pesar de tener financiamiento externo por lo tanto se acepta el estudio y se puede recomendar su ejecución obteniendo parte de la inversión a través de terceros. 


\section{Tasa Interna de Retorno Financiero (TIRF)}

La tasa Interna de Retorno es la mayor que la tasa de interés mínima aceptable $(79.29 \% \%>25.75 \%)$.

Esto quiere decir que la rentabilidad que genera el proyecto tanto económica como financiera es superior al rendimiento mínimo aceptable, en este caso el proyecto es aceptable por lo que se recomienda su ejecución

\section{Periodo de Recuperación Financiero (PRKF)}

El financiamiento del negocio con parte de aporte bancario recuperará el monto de lo invertido en 1 año 8 meses.

\section{Relación Beneficio - Costo Financiero (B/CF)}

Relación Beneficio / costo Financiera $=3.16>1$; Esto quiere decir que los beneficios que se generan al financiar parte del capital con recursos de terceros son mayores a los costos por lo cual se dice que el proyecto es aceptable por lo que se recomienda su ejecución.

\subsection{Ratios}

Tabla 109.

\section{Ratios}

\begin{tabular}{lllllll}
\hline \multirow{2}{*}{ LIQUIDEZ } & LIQUIDEZ CORRIENTE & 7.33 & 8.38 & 6.51 & 6.35 & 6.09 \\
& PRUEBA ÁCIDA & 7.33 & 8.38 & 6.51 & 6.35 & 6.09 \\
\hline \multirow{5}{*}{ SOLVENCIA } & ENDEUDAMIENTO DEL ACTIVO & 0.44 & 0.32 & 0.28 & 0.22 & 0.17 \\
& ENDEUDAMIENTO PATRIMONIAL & 0.78 & 0.47 & 0.38 & 0.29 & 0.20 \\
& APALANCAMIENTO & 1.78 & 1.47 & 1.38 & 1.29 & 1.20 \\
& APALANCAMIENTO FINANCIERO & 1.31 & 1.23 & 1.19 & 1.17 & 1.16 \\
\hline \multirow{5}{*}{ GESTIÓN } & ROTACIÓN DE ACTIVO FIJO & 22.69 & 23.80 & 24.95 & 26.17 & 27.44 \\
& ROTACIÓN DE VENTAS & 2.43 & 1.87 & 1.47 & 1.24 & 1.08 \\
& IMPACTO GASTOS ADM.Y VENT. & 0.24 & 0.20 & 0.20 & 0.21 & 0.21 \\
& IMPACTO DE LA CARGA & & & & & \\
& FINANCIERA & 0.05 & 0.04 & 0.03 & 0.02 & 0.01 \\
\hline \multirow{5}{*}{ RENTABILIDAD NETA DEL } & & & & & \\
& ACTIVO - DU PONT & $22.26 \%$ & $26.96 \%$ & $21.18 \%$ & $19.38 \%$ & $19.16 \%$ \\
& MARGEN BRUTO & $41.74 \%$ & $44.09 \%$ & $43.99 \%$ & $45.34 \%$ & $46.89 \%$ \\
& MARGEN OPERACIONAL & $17.61 \%$ & $24.43 \%$ & $23.56 \%$ & $24.30 \%$ & $26.03 \%$ \\
& RENTABILIDAD VENTAS - & & & & \\
& MARGEN NETO & $9.16 \%$ & $14.42 \%$ & $14.37 \%$ & $15.60 \%$ & $17.75 \%$ \\
& RENTABILIDAD OPERACIONAL & & & & & \\
& DE PATRIMONIO & $76.12 \%$ & $66.94 \%$ & $47.91 \%$ & $38.89 \%$ & $33.65 \%$ \\
& RENTABILIDAD FINANCIERA & $29.20 \%$ & $33.11 \%$ & $25.30 \%$ & $22.74 \%$ & $22.20 \%$ \\
\hline
\end{tabular}

Elaboración propia. 
La empresa muestra indicadores Financieros Favorables ya que tanto el rendimiento sobre la inversión como el rendimiento sobre los activos, la rentabilidad de las ventas y el ratio Dupont se muestran favorables durante los años proyectados, siendo también favorables los ratios de liquidez, gestión de solvencia.

\subsection{Análisis de riesgo}

\subsubsection{Análisis de punto de equilibrio.}

Tabla 110. Análisis Punto de Equilibrio

\begin{tabular}{|c|c|c|c|c|c|}
\hline Concepto & AÑO 1 & AÑO 2 & AÑO 3 & AÑO 4 & AÑO 5 \\
\hline Precio unitario & 1.93 & 1.99 & 2.05 & 2.12 & 2.19 \\
\hline $\begin{array}{l}\text { Unidades producidas } \\
\text { Costo de producción }+\end{array}$ & $2,052,607.26$ & $2,084,422.67$ & $2,116,731.22$ & $2,149,540.56$ & $2,182,858.43$ \\
\hline Costos de Adm + Costo Mkt & $2,245,998.56$ & $2,158,596.07$ & $2,253,224.15$ & $2,364,268.03$ & $2,425,252.53$ \\
\hline $\begin{array}{l}\text { Punto de equilibrio en } \\
\text { unidades }\end{array}$ & $1,165,631.88$ & $1,084,903.73$ & $1,096,710.75$ & $1,114,428.71$ & $1,107,083.63$ \\
\hline$\%$ de las ventas & $56.79 \%$ & $52.05 \%$ & $51.81 \%$ & $51.84 \%$ & $50.72 \%$ \\
\hline $\begin{array}{l}\text { Punto de equilibrio en } \\
\text { Soles }\end{array}$ & $2,245,998.56$ & $2,158,596.07$ & $2,253,224.15$ & $2,364,268.03$ & $2,425,252.53$ \\
\hline
\end{tabular}

\subsubsection{Análisis de sensibilidad.}

En el presente acápite se presenta los diferentes índices de rentabilidad y cobertura de la deuda que registraría el proyecto ante una eventual variación de algunas variables de entrada, que podrían considerarse críticas en el desarrollo del proyecto.

\section{Variación del Precio}

a. Reducción en el precio del producto del orden del $5.0 \%$.

Tabla 111.

Reducción del Precio en $5.0 \%$

\begin{tabular}{lccc}
\hline Concepto & Unidades & Económico & Financiero \\
\hline VAN & $\mathrm{S} /$. & $1,103,178.04$ & $651,241.76$ \\
TIR & $\%$ & $46.07 \%$ & $55.40 \%$ \\
Período de Recuperación de la & años & 3 años 9 meses & 3 años 9 meses \\
Inversión/Aporte de capital & veces & 2.00 & 2.19 \\
Beneficio/Costo & & \\
\hline
\end{tabular}

Elaboración propia. 
b. Reducciónen el precio del producto del orden $10 \%$.

Tabla 112

Reducción del Precio en $10 \%$.

\begin{tabular}{lccc}
\hline Concepto & Unidades & Económico & Financiero \\
\hline VAN & $\mathrm{S} /$. & $469,683.67$ & $117,862.34$ \\
TIR & $\%$ & $30.49 \%$ & $31.22 \%$ \\
Período de Recuperación de la & años & 3 años 2 meses & 3 años 1 mes \\
Inversión/Aporte de capital & veces & 1.43 & 1.22 \\
Beneficio/Costo & & &
\end{tabular}

Elaboración propia.

c. Reducción en el precio del producto del orden $13.707 \%$.

Tabla 113.

Reducción del Precio en $13.707 \%$.

\begin{tabular}{lccc}
\hline Concepto & Unidades & Económico & Financiero \\
VAN & S/. & 0.00 & $-277,593.70$ \\
TIR & $\%$ & $18.24 \%$ & $12.56 \%$ \\
$\begin{array}{l}\text { Período de Recuperación de la Inversión/Aporte de } \\
\text { capital }\end{array}$ & años & 3 años 7 meses & 4 años 2 meses \\
Beneficio/Costo & veces & 1.00 & 0.50 \\
\hline
\end{tabular}

Elaboración propia.

Las tablas 111,112 y 113 muestran que el negocio es muy sensible ante cambios en los precios determinándose que cuando el precio se reduce en $13.707 \%$ el VAN=0, la $\mathrm{TIRE}=\mathrm{COK}$ y razón $\mathrm{B} / \mathrm{C}=1$ y los indicadores Financieros se muestran desfavorables.

\section{Variación del Costo de la Materia Prima}

a. Aumento en los costos del orden del $15,0 \%$.

Tabla 114.

Aumento del Costo de Materia prima en 15,0\%

\begin{tabular}{lccc}
\hline Concepto & Unidades & Económico & Financiero \\
\hline VAN & $\mathrm{S} /$. & $1,143,638.11$ & $679,011.41$ \\
TIR & $\%$ & $46.37 \%$ & $55.56 \%$ \\
Período de Recuperación de la & & 3 años 9 meses & 3 años 9 meses \\
Inversión/Aporte de capital & años & 2.03 & 2.26 \\
Beneficio/Costo & veces & &
\end{tabular}

Elaboración propia. 
b. Aumento en los costos del orden del $30 \%$.

Tabla 115.

Aumento del Costo de Materia prima en $30 \%$

\begin{tabular}{|c|c|c|c|}
\hline Concepto & Unidades & Económico & Financiero \\
\hline VAN & $\mathrm{S} /$. & $570,896.56$ & $193,694.36$ \\
\hline TIR & $\%$ & $32.51 \%$ & $34.23 \%$ \\
\hline $\begin{array}{l}\text { Período de Recuperación de la } \\
\text { Inversión/Aporte de capital }\end{array}$ & años & 2 años 9 meses & 2 años 11 meses \\
\hline Beneficio/Costo & veces & 1.52 & 1.36 \\
\hline
\end{tabular}

c. Aumento en los costos del orden del $44.6914 \%$.

Tabla 116.

Aumento del Costo del Papel en 44.6914\%

\begin{tabular}{lccc}
\hline Concepto & Unidades & Económico & Financiero \\
\hline VAN & $\mathrm{S} /$. & 0.00 & $-291,575.71$ \\
\hline TIR & $\%$ & $18.24 \%$ & $13.04 \%$ \\
\hline $\begin{array}{l}\text { Período de Recuperación de la } \\
\text { Inversión/Aporte de capital }\end{array}$ & años & 3 años 7 meses & 4 años 2 meses \\
\hline \begin{tabular}{l} 
Beneficio/Costo \\
\hline
\end{tabular} & veces & 1.00 & 0.48 \\
\hline
\end{tabular}

Elaboración propia.

Las tablas 114,115 y 116 muestran que el negocio es muy sensible ante cambios en los precios determinándose que cuando el precio se reduce en $13.707 \%$ el VAN=0, la $\mathrm{TIRE}=\mathrm{COK}$ y razón $\mathrm{B} / \mathrm{C}=1$ y los indicadores Financieros se muestran desfavorables.

\subsubsection{Análisis de Escenarios.}

Para analizar los tres tipos de escenarios: pesimista, moderado y optimista se consideró variaciones en las ventas y en los costos de la materia prima de esas variaciones, con diferentes porcentajes, se generaron efectos en el TIRF y el VANF que se muestran a continuación: 
Tabla 117.

Análisis de escenarios.

\begin{tabular}{lccc}
\hline Concepto & Pesimista & Inicial & Optimista \\
\hline Variaciones en Precios & $\mathbf{- 1 0 \%}$ & $\%$ & $\mathbf{- 5 \%}$ \\
\hline VANE & $469,683.67$ & $1,736,672.40$ & $1,103,178.04$ \\
VANF & $117,862.34$ & $1,184,621.18$ & $651,241.76$ \\
TIRE & $30.49 \%$ & $60.98 \%$ & $46.07 \%$ \\
TIRF & $31.22 \%$ & $79.29 \%$ & $55.40 \%$ \\
PRKE & 3 años 2 meses & 1 año 10 meses & 3 años 9 meses \\
PRKF & 3 años 1 mes & 1 año 8 meses & 3 años 9 meses \\
B/CE & 1.43 & 2.58 & 2.00 \\
B/CF & 1.22 & 3.16 & 2.19 \\
\hline Variaciones en costos de Materia Prima & $\mathbf{+ 3 0 \%}$ & $\%$ & $\mathbf{+ 1 5 \%}$ \\
\hline VANE & $570,896.56$ & $1,736,672.40$ & $1,143,638.11$ \\
VANF & $193,694.36$ & $1,184,621.18$ & $679,011.41$ \\
TIRE & $32.51 \%$ & $60.98 \%$ & $46.37 \%$ \\
TIRF & $34.23 \%$ & $79.29 \%$ & $55.56 \%$ \\
PRKE & 2 años 9 meses & 1 año 10 meses & 3 años 9 meses \\
PRKF & 2 años 11 meses & 1 año 8 meses & 3 años 9 meses \\
B/CE & 1.52 & 2.58 & 2.03 \\
B/CF & 1.36 & 3.16 & 2.26 \\
\hline
\end{tabular}

Elaboración propia.

La tabla anterior, nos muestra que el proyecto es muy sensible ante cambios en los precios y costos de materia prima. 


\section{CAPITULO X: CONCLUSIONES Y RECOMENDACIONES}

\subsection{Conclusiones}

a. La presente investigación ha determinado que la fabricación y comercialización de un cobertor sanitario para inodoros, es una gran oportunidad de negocio lo cual se evidencia en los resultados de los estados financieros proyectados.

b. La escasa existencia en el mercado peruano de un cobertor sanitario para inodoro, se convierte en una oportunidad para desarrollar el mercado de salud e higiene personal y generar cultura en los usuarios.

c. El mercado Objetivo para el presente negocio, está constituido por Mujeres de Lima Moderna entre 20 y 54 años del NSE A; B y C, obteniéndose en el estudio de mercado que existe disposición de compra del producto.

d. La inversión inicial para la implementación del negocio es de S/. 1, 102,644 con una estructura de financiamiento distribuida de la siguiente forma: aporte propio con un $50.14 \%$ de la inversión inicial y préstamo de la banca con un $49.86 \%$ de la inversión.

e. La evaluación económica y Financiera del negocio, permitió determinar que se considera un COK de 18.24\% para la obteniéndose un VANE de 1,736,672.4, TIRE de 60.98\% un PRKE de 1 Año 10 meses y una relación B/CE de 2.58 asimismo para la evaluación Financiera se utiliza una tasa WACC de $25.75 \%$, Obteniéndose un VANF del 1,184,621.18, un TIRF de 79.29\%, un PRKF de 1 Año 8 meses y una relación B/CF de 3.17 , mostrándose con ello que el $n$

\subsection{Recomendaciones}

a. Ejecutar la fabricación y comercialización del cobertor sanitario basado en los resultados de la investigación de mercado e indicadores financieros.

b. Analizar nuevos Mercados, con la finalidad de expandirse a todos los distritos de Lima metropolitana y Provincias.

c. Diseñar plan de marketing que permitan ampliar mercados. 


\section{REFERENCIAS BIBLIOGRÁFICAS}

Adam, E. (1991). Administración de la producción y las operaciones: conceptos, modelos y funcionamiento (cuarta edición). México, D.F. Prentice-Hall Hispanoamericana.

Alibaba (2015). Productos. Recuperado de www.alibaba.com.

Amaris, G. (2016). Los peligros de usar baños públicos: Emedemujer.com Recuperado de https://ve.emedemujer.com/bienestar/salud/los-peligros-de-usar-banospublicos/

APEIM (2013). Nivel socioeconómico. Recuperado de http://www.apeim.com.pe/wpcontent/themes/apeim/docs/nse/APEIM-NSE-2013.pdf

APEIM (2014). Distribución de hogares según nivel socioeconómico. Recuperado de http://www.apeim.com.pe/wp-content/themes/apeim/docs/nse/APEIM-NSE2013.pdf

Arellano, A. (2017). Los seis estilos de vida. Recuperado https://www.arellano.pe/losseis-estilos-de-vida/

Asociación Interamericana de la Propiedad Intelectual (2018). Vinculación del derecho de la moda, regulación sanitaria y propiedad intelectual: aplicación práctica de casos cosméticos y perfumes. Recuperado de http://www.cosmoprof.com/wpcontent/uploads/2015/11/www.cosmoprof.com/Peru Beauty-report.pdf

Asociación Nacional de Empresarios de Colombia (2014). Informe Estadístico Sector Período $2000 \quad$ - 2013.2 Recuperado de http://www.andi.com.co/cica/Documents/Informe\%20Estadistico\%202014\%20co mpleto.pdf

Banco central de reserva del Perú (2016). Estadísticas. Recuperado de https://estadisticas.bcrp.gob.pe/estadisticas/series/mensuales/tasas-de-interes

Barber B Conable (1986) III Cumbre Social Andina

Cailun Machine (2015). Lista de productos. Recuperado de https://www.made-inchina.com/products/catlist/listsubcat/132/00/mic/Machinery.html?gclid=EAlalQob ChMI98H69anf4AIVwrAChOWzwZbEAAYASAAEgllTfD BwE

Cassamassina, E., Vivas, A. \& Ojeda, J. (2016). Cinco fuerzas de Porter Matriz de Ansoff $y$ estrategias Genéricas de Porter. Recuperado de http://covpublicistasucv.blogspot.es/1463669172/cinco-fuerzas-de-porter-matriz-de-ansoffy-estrategias-genericas-de-porter/

Cosmoprof (2013). Como hacer negocios en el sector cosméticos e higiene. Recuperado de http://www.cosmoprof.com/wpcontent/uploads/2013/11/www.cosmoprof.com/Peru Beauty-report.pdf

Chávez, J. (2013). Cadena de valor, estrategias genéricas y competitividad. Recuperado de http://www.eumed.net/libros-gratis/2013b/1345/1345.pdf 
Datosperú (2015). Comercio exterior de termoencogibles en el Perú. Recuperado de http://www.datosperu.org/comercio-exterior-de-termoencogibles-del-peru-sa20100448123-en-la-partida-48.php (2015)

David, F. (2012). Conceptos de Administración Estratégica (14² Edición). México D.F. Editorial ADDISON-WESLEY.

Decreto Legislativo № 713, Descansos remunerados de los trabajadores sujetos a régimen laboral de la actividad privada. Decreto Supremo 012-92-TR (03 de diciembre de 1992). Diario Oficial "El Peruano". Lima: Congreso de la República.

Decreto Supremo № 011-2010-TR. Incremento de la remuneración mínima vital. (11 de noviembre del 2000). En: Diario el Peruano. Lima: Congreso de la República.

Diashabiles (2016). Calendarios laborales. Recuperado de http://www.diashabiles.com/ (2016).

EmpresaActual (2018). Qué es el WACC y para qué sirve. Recuperado de https://www.empresaactual.com/el-wacc/.

ESAN (2016). Evaluación económica y financiera de proyectos.Recuperado dehttps://www.esan.edu.pe/apuntes-empresariales/2016/09/evaluacioneconomica-y-financiera-de-proyectos/.

ESAN (2016). Costos de inversión y de operación en la formulación de un proyecto. Recuperado de https://www.esan.edu.pe/apuntes-empresariales/2016/06/costosde-inversion-y-de-operacion-en-la-formulacion-de-un-proyecto/

ESAN (2016). La importancia de construir los flujos de caja de un proyecto. Recuperado de https://www.esan.edu.pe/apuntes-empresariales/2016/09/laimportancia-de-construir-los-flujos-de-caja-de-un-proyecto/

Gitman, L. (2012). Principios de administración financiera (12ª ed.). México D.F. Editorial Pearson.

Gonzales, A., Blanco, J. (2011).Propuesta metodológica para la aplicación de la planeación sistemática de Layout (SLP) en el Sector vitivinícola de la Rioja. (Tesis Doctoral).Universidad de Rioja

Hayes, R. \& Wheelwright, S. (1984). Restoring our competitive Edge. Recuperado de https://www.hbs.edu/faculty/Pages/item.aspx?num=47196

INEI (2017). Índice - temático. Recuperado de http://www.inei.gob.pe/estadisticas/indice-tematico/economia/.

KMC Internacional SAC (2016). Producto. Recuperado de http://www.kmcint.com/productos.html

Kotler, P. y Armsyrong,G. (2008). Fundamentos de Marketing. (8 $8^{\mathrm{a}}$ ed.) México D.F.Editorial Pearson. 
Landin, P. (2013). Papel tissue, ¿de fibra virgen o de fibra reciclada?. Recuperado de http://pelandintecno.blogspot.com/2013/06/papel-tissue-de-fibra-virgen-o-defibra.html

Ley de la consolidación de beneficios sociales, Decreto Legislativo № 688 (05 de Noviembre de 1991). En: Normas Legales, № 25327. Diario Oficial "El Peruano". Lima: Congreso de la República.

Ley General de Sociedades, Ley № 26887. (05 de Diciembre del 1997) En: Diario el Peruano. Lima: Congreso de la República.

Ley de Asignación familiar, Ley № 25129. (06 de Diciembre de 1989). En: Diario el Peruano. Lima: Congreso de la República.

Ley Marco de Licencia de Funcionamiento, Ley № 28976. (05 de febrero del 2007). En: Diario el Peruano. Lima: Congreso de la República.

Ley que regula el otorgamiento de las gratificaciones para los trabajadores del régimen laboral de la actividad privada en Fiestas Patrias y Navidad. Ley № 27735 (28 de Mayo del 2002) con su Decreto Supremo № 005-2002-TR. En: Diario el Peruano. Lima: Congreso de la República.

Ley de Rotulados de Productos Industriales Manufacturados, Ley № 28405. (30 de Noviembre del 2004). En: Diario el Peruano. Lima: Congreso de la República.

Ley de Seguridad de Salud en el Trabajo, Ley № 29783 y su D.S. 005-2012-TR. (25 de Abril del 2012). En: Diario el Peruano. Lima: Congreso de la República.

Landin, P. (2013). Papel tissue, ¿de fibra virgen o de fibra reciclada?. Recuperado de http://pelandintecno.blogspot.com/2013/06/papel-tissue-de-fibra-virgen-o-defibra.html

Lira, P. (2012). Un modelo financiero: el CAPM. Recuperado de https://gestion.pe/blog/deregresoalobasico/2011/12/un-modelo-financiero-elcapm.html

Muther, R.(1961). Distribución En Planta, Planificación Sistemática de la Distribución (4ta Edición). Editorial Hispano Europea.

Manufacturing \& Processing Machinery (2016). Productos. Recuperado de http://cninnovo.en.made-in-china.com/product/MSImDnEPsqhL/China-CombinedType-Paper-Folder-Machine-ZX360-6-1-.html

Marcelo Ferrando, M. (2008). Los productos biodegradables: La república. Recuperado de http://quecomoquien.republica.com/actualidad/los-productosbiodegradables.html

Median Interactive Goup (2013). Las 10 grades ventajas de la publicidad online. Recuperada de http://www.mediainteractivegroup.com/blog/las-10-grandesventajas-de-la-publicidad-online/

Ministerio de la Producción (2014). Anuario Estadístico Industrial, Mipyme y Comercio Interno 2014. Recuperado de http://www.produce.gob.pe/documentos/estadisticas/anuarios/anuarioestadistico-mype-2014.pdf 
Ministerio del ambiente (2013). Ley General del Ambiente Nro. 28611. Recuperado de http://www.minam.gob.pe/wp-content/uploads/2013/06/ley-general-del-

ambiente.pdf

Ministerio de Salud (2009). Ambiente Saludable. Recuperado de http://www.minsa.gob.pe/servicios/serums/2009/dgps para serums 2009ii/docu mentos generales/eje tematico de higiene y ambiente.pdf

Ministerio de Salud (2012). Ley General de Salud. Recuperado de http://www.digemid.minsa.gob.pe/UpLoad/UpLoaded/PDF/LEYN26842.pdf

Morales, P., O'Connor, J., Rivera, J. \& Suárez, M. (2017). Planeamiento Estratégico de la Industria Peruana de Cosméticos. (Tesis de maestría). Pontificia universidad católica del Perú. Recuperado de http://tesis.pucp.edu.pe/repositorio/bitstream/handle/123456789/8996/MORALES O\%27CONNOR PLANEAMIENTO COSMETICOS.pdf?sequence $=3$

Murcia, J. (2012). La participación de la descarga del inodoro en la distribución de patógenos y su contribución en el incremento del riesgo de enfermedades. (Tesis de pregrado). Universidad Piloto de Colombia. Recuperado de http://docplayer.es/16226314-La-participacion-de-la-descarga-del-inodoro-en-ladistribucion-de-patogenos-y-su-contribucion-en-el-incremento-del-riesgo-deenfermedades.html.

Osinerg (2016). Tarifas de servicio eléctrico. Recuperado de http://www2.osinerg.gob.pe/Tarifas/Electricidad/PliegosTarifariosUsuarioFinal.as px?ld=15.

Parlamento Andino (2017). Medioambiente y desarrollo sostenible. Recuperado de https://parlamentoandino.org/csa/documentos-de-trabajo/informes-ejecutivos/29medioambiente-y-desarrollo-sostenible.html

Pérez, P. (2008). Metodologías para la resolución de problemas de distribución en planta. Recuperado de https://www.monografias.com/trabajos65/resoluciondistribucion-planta/resolucion-distribucion-planta2.shtml

Pickers, S. (2015). ¿Cómo determinar el tamaño de una muestra?: psyma. Recuperado de http://www.psyma.com/de/unternehmen/news/message/comodeterminar-el-tamano-de-una-muestra.

Plasticosguma (2016). Bolsas de polietileno. Recuperado de http://plasticosguma.com/bolsa-natural-100-virgen-polietileno

Porter, M. (1997). Ventaja Competitiva. México D.F. México: Ed. Continental.

Prado, A. (2010). Cambia tendencia, ahora hay más hombres que mujeres en Perú: Gestión. Recuperado de https://archivo.gestion.pe/noticia/610636/cambiatendencia-ahora-hay-mas-hombres-que-mujeres-peru.

Proexport Colombia (2003). Estudio de productos de aseo personal en Perú. Recuperado de http://docplayer.es/5478791-Estudio-de-mercado-productos-de$\underline{\text { aseo.html }}$ 
Qzxinda (2015). Productos. Recuperado de www.qzxinda.en.made-in-china.com

Ramírez, A. (2017). ¿Qué es sampling y cómo utilizarlo?: Informabtl revista. Recuperado de https://www.informabtl.com/que-es-sampling-y-como-utilizarlo/

Reglamento Técnico Andino. Requisitos y Guía de Inspección para el funcionamiento de establecimientos que fabrican productos de Higiene Doméstica y productos absorbentes de higiene personal. Decisión 721

RPP Noticias (2017). Gráfica - Más de 7 millones de mujeres conforman la fuerza laboral del país. Recuperado de http://rpp.pe/peru/actualidad/mas-de-7-millonesde-mujeres-conforman-la-fuerza-laboral-del-pais-noticia-1035495

Sánchez, F., Moreno, J. \& Sánchez, M. (2012). Desarrollo, Producción y Comercialización del Aislante Sanitario Desechable (Tesis de pregrado). Universidad EAN Facultad de Estudios en Ambientes Virtuales. Bogotá D. C. Recuperado de https://repository.ean.edu.co/bitstream/handle/10882/2947/SanchezFrancy2012. pdf? sequence $=4 \&$ is Allowed $=y$

SBS (2016). Tasa diaria para pequeña empresa. Recuperado de http://www.sbs.gob.pe/app/stats/TasaDiaria 7A.asp

SUNAT (s.f). Consulta de RUC. Recuperado de http://www.sunat.gob.pe/cl-tiitmrconsruc/jcrS00Alias.

SUNAT (2016) Tipo de cambio oficial. Recuperado de http://www.sunat.gob.pe/cl-atittipcam/tcS01Alias

Termoencogible (2015). Línea termoencogible. Recuperado de http://www.termoencogibles.com/home.htm

Thompson, I. (2014). Las ventas personales: Promonegocio. Recuperado de https://www.promonegocios.net/venta/ventas-personales.html

Torres, F. (2018). Niveles de los canales de distribución: canal directo y canal indirecto. Recuperado de https://franciscotorreblanca.es/niveles-de-los-canalesde-distribucion/

T.U.O. de la Ley de compensación por tiempo de servicios, Decreto Supremo № $001-$ 97-TR (01 de marzo de 1997). En: Diario el Peruano. Lima: Congreso de la República.

T.U.O. de la Ley de jornada de trabajo, horario y trabajos en sobretiempos. Decreto Supremo № 007-2002-TR (04 de julio del 2002). En: Diario el Peruano. Lima: Congreso de la República.

Universidad Autónoma de México. Facultad de Contaduría y Administración (2012). Investigación de Mercados: Cosméticos Naturales - 2012. Recuperado de https://investigacion-2257-2012-

2.wikispaces.com/file/view/TRABAJO+FINAL+CON+INDICE+Y+PORTADA.pdf 
Universidad de Castilla-La Mancha. Facultad de Ingeniería Rural. (2009). Distribución de Planta.Recuperado https://previa.uclm.es/area/ing rural/AsignaturaProyectos/Tema\%205.pdf

\section{ANEXOS}

\section{CAPITULO II}

Decisión 706

Decisión 706 - Armonización de Legislaciones en materia de productos de higiene doméstica y productos absorbentes de higiene personal, medidas que adoptan los Países Miembros de la Comunidad Andina el cual integra Perú.

PERIODO CIENTO UNO DE SESIONES ORDINARIAS DE LA COMISION

9-10 de diciembre de 2008

LIMA - PERÚ

LA COMISIÓN DE LA COMUNIDAD ANDINA,

VISTOS: Los Artículos 3 literales a) y b), 22 y 72 del Acuerdo de Cartagena;

CONSIDERANDO:

Que las Autoridades Sanitarias de los Países Miembros necesitan mecanismos ágiles, eficientes, eficaces, seguros y armonizados para desarrollar sus actividades de control y vigilancia en el mercado para los productos de higiene doméstica y productos absorbentes de higiene personal;

Que es necesario asegurar que las medidas que adopten los Países Miembros para la comercialización de productos de higiene doméstica y productos absorbentes de higiene personal, se apliquen de forma tal que no se constituyan en un obstáculo técnico innecesario al comercio intra subregional y con terceros países;

Que la aplicación de la Decisión 516 de la Comunidad Andina, armonización de legislaciones en materia de productos cosméticos, permitió la facilitación y el incremento del comercio, por lo que se considera pertinente utilizar el mismo mecanismo de Notificación Sanitaria Obligatoria para los productos de higiene doméstica y productos absorbentes de higiene personal, dado el bajo riesgo que tienen estos productos para la salud humana;

Que los productos de higiene doméstica y los productos absorbentes de higiene personal son considerados de bajo riesgo sanitario, y que el fabricante o importador es el responsable de la seguridad del producto, las Autoridades Sanitarias de los Países Miembros acordaron armonizar sus legislaciones y permitir el uso del mecanismo de Notificación Sanitaria Obligatoria para autorizar la comercialización de este tipo de productos en la Comunidad Andina; 
Que, el Grupo de Expertos Gubernamentales para la armonización de las legislaciones sanitarias, en su Reunión celebrada el 12 de noviembre de 2008, recomendó la adopción del proyecto de Decisión sobre armonización de legislaciones en materia de productos de higiene doméstica y productos absorbentes de higiene personal;

Normatividad para productos de aseo, higiene y limpieza o productos de desinfección y esterilización

El desarrollo de los servicios personales de estética facial, corporal y ornamental está relacionado con el uso de productos para aseo, higiene, limpieza, desinfección o esterilización.

Estos productos se utilizan para la implementación de técnicas de asepsia en cada uno de los elementos de trabajo según su riesgo, así como con las técnicas de higiene de manos, según se establece en la Resolución 2827 de 2006, por la cual se establece el manual de bioseguridad para establecimientos que desarrollen actividades cosméticas o con fines de embellecimiento facial, capilar, corporal y ornamental.

Estos productos se encuentran reglamentados para sus regímenes sanitarios, de control de calidad y vigilancia sanitaria en relación con la producción, procesamiento, envasado, expendio, importación, almacenamiento y comercialización.

Para entender cuál es la normatividad aplicable para cada uno de los productos de aseo, higiene, limpieza, desinfección o esterilización se requiere diferenciar aquellos de uso doméstico de los de uso industrial:

Producto de aseo, higiene y limpieza de uso industrial:

Es aquella formulación cuya función principal es remover la suciedad y propender por el cuidado de la maquinaria industrial e instalaciones, centros educativos, hospitalarios, etc., que cumple los siguientes requisitos:

Mercado: No está dirigido a productos de aseo, higiene y limpieza de uso doméstico.

Sistema de distribución y comercialización: Esta dirigido única y exclusivamente al sector industrial.

Composición: La cantidad de ingrediente activo es diferente en cuanto a concentración, con respecto a los productos de aseo, higiene y limpieza de uso doméstico.

Uso del producto: Se realiza única y exclusivamente a través de máquinas, equipos o personal especializados.

Tomado de: Circular Externa DG-0100-284 del 23/10/2002 - Dirección General INVIMA 
Estos productos no se encuentran regulados dentro de un régimen de registros sanitarios, siempre y cuando se cumplan todas las 4 características anteriores.

Producto de higiene doméstica:

La Decisión 706 de 2008 de la Comunidad Andina de Naciones, CAN, estableció la Armonización de Legislaciones en Materia de Productos de Higiene Doméstica y Productos Absorbentes de Higiene Personal.

¿Qué es un producto de higiene doméstica?

La Decisión 706 de 2008 establece en su artículo 2 la definición de producto de higiene doméstica de la siguiente manera:

"Es aquella formulación cuya función principal es remover la suciedad, desinfectar, aromatizar el ambiente y propender el cuidado de utensilios, objetos, ropas o áreas que posteriormente estarán en contacto con el ser humano independiente de su presentación comercial.

Esta definición no incluye aquellos productos cuya formulación tiene por función principal el remover la suciedad, desinfectar y propender el cuidado de la maquinaria e instalaciones industriales y comerciales, centros educativos, hospitalarios, salud pública y otros de uso en procesos industriales".

¿Qué se considera producto de higiene doméstica?

La Decisión 706 de 2008 estableció en su anexo No.1 la lista indicativa de grupos de productos de higiene doméstica y productos absorbentes de higiene personal:

- Jabones y detergentes.

- Productos lavavajillas y pulidores de cocina.

- $\quad$ Suavizantes y productos para prelavado y pre planchado de ropa.

- Ambientadores.

- Blanqueadores y quitamanchas.

- Productos de higiene doméstica con propiedad desinfectante.

- Limpiadores de superficies.

- Productos absorbentes de higiene personal (toallas higiénicas, pañales desechables, tampones, protectores de flujos íntimos, pañitos húmedos) siempre y cuando no declaren propiedades cosméticas ni indicaciones terapéuticas.

Los demás que determine la Secretaría General de la Comunidad Andina mediante Resolución, por solicitud y consenso de las Autoridades Sanitarias de los Países Miembros.

¿Cuáles son los requisitos que deben cumplir los productos de higiene doméstica?

La Decisión 706 de 2008 estableció en su artículo $5^{\circ}$ que: "Los productos a los que se refiere la presente Decisión requieren, para su comercialización y/o importación, de 
la Notificación Sanitaria Obligatoria (NSO) presentada ante la Autoridad Nacional Competente del primer País Miembro de comercialización."

¿Qué se entiende por Notificación Sanitaria Obligatoria?

"Es la comunicación en la cual se informa a las Autoridades Nacionales Competentes, mediante declaración jurada, que un producto regulado por la presente Decisión, será comercializado por el interesado."

Tomado de: Artículo 2 - Decisión 706 de 2008.

Productos para desinfección y/o esterilización de aparatología estética:

Todo producto o equipo que se utilice para desinfección y/o esterilización de aparatología de uso en estética se considera también como dispositivo médico y por lo tanto se encuentra regulado por el Decreto 4725 de 2005

Productos para higiene de manos:

Según la técnica escogida para efectuar higiene de manos (Hipervínculo a glosario donde se defina higiene de manos) en los servicios personales de belleza, los productos utilizados para ello caen dentro de diferentes categorías:

Productos cosméticos

En ellos se incluyen jabones o geles convencionales o antibacteriales que declaren propiedades cosméticas. Se encuentran catalogados como "Cosméticos para el aseo e higiene corporal" y se encuentran regulados por la Decisión 516 de 2002 de la Comunidad Andina de Naciones, CAN.

Ley General del Medio Ambiente № 28611

Ley General del Ambiente Nro. 28611 - Publicada el 15 de Octubre del 2005

Del derecho y deber fundamental.

Toda persona tiene el derecho irrenunciable a vivir en un ambiente saludable, equilibrado y adecuado para el pleno desarrollo de la vida, y el deber de contribuir a una efectiva gestión ambiental y de proteger el ambiente, así como sus componentes, asegurando particularmente la salud de las personas en forma individual y colectiva, la conservación de la diversidad biológica, el aprovechamiento sostenible de los recursos naturales y el desarrollo sostenible del país.

Del derecho de acceso a la justicia ambiental.

Toda persona tiene el derecho a una acción rápida, sencilla y efectiva, ante las entidades administrativas y jurisdiccionales, en defensa del ambiente y de sus componentes, velando por la debida protección de la salud de las personas en forma individual y colectiva, la conservación de la diversidad biológica, el aprovechamiento 
sostenible de los recursos naturales, así como la conservación del patrimonio cultural vinculado a aquellos.

Se puede interponer acciones legales aun en los casos en que no se afecte el interés económico del accionante. El interés moral leg Artículo V.

Del principio de sostenibilidad.

La gestión del ambiente y de sus componentes, así como el ejercicio y la protección de los derechos que establece la presente Ley, se sustentan en la integración equilibrada de los aspectos sociales, ambientales y económicos del desarrollo nacional, así como en la satisfacción de las necesidades de las actuales y futuras generaciones.

Del principio de prevención.

La gestión ambiental tiene como objetivos prioritarios prevenir, vigilar y evitar la degradación ambiental. Cuando no sea posible eliminar las causas que la generan, se adoptan las medidas de mitigación, recuperación, restauración o eventual compensación, que correspondan.

Del principio precautorio.

Cuando haya peligro de daño grave o irreversible, la falta de certeza absoluta no debe utilizarse como razón para postergar la adopción de medidas eficaces y eficientes para impedir la degradación del ambiente.

De conformidad con el Artículo 2 de la Ley $N^{\circ}$ 29050, publicada el 24 junio 2007, se adecúa el texto del presente Artículo, y el de todo texto legal que se refiera al "criterio de precaución", "criterio precautorio" o "principio de precaución" a la definición del Principio Precautorio que se establece en el artículo 5 de la Ley № 28245, modificado por el artículo 1 de la citada Ley . 


\section{CAPÍTULO III}

\section{INVESTIGACIÓN CUALITATIVA}

\section{A) Entrevista de Profundidad}

\section{PERFILES DE EXPERTOS}

\section{Ingeniero Civil Carlos Jiménez}

Profesional de la Universidad Villarreal con más de 10 años de experiencia en la industria de la construcción, edificaciones menores y proyectos de mejora de edificaciones. Contratos con el estado en la elaboración de expedientes técnicos de carreteras, puentes y obras de redes de agua y desagüe. Trabajo en Invercomsa y Ocaxa como Jefe de Proyectos, actualmente se desempeña como Jefe de Proyecto de la Nueva Sede Institucional del SINEACE.

\section{Ingeniero Industrial David Oliva Aragón}

Profesional en Ingeniería industrial con experiencia de 10 años en el sector retail, manufactura, energía y servicios. Desarrollando actividades de pensamiento estratégico, negociación, cadena de abastecimiento, logística, compras, almacenes, distribución y transporte. En empresas como Corporación Wong y APC.

\section{Licenciado en Marketing Christian Marky Bertarelli}

Profesional con Licenciatura en Marketing con más de 15 años de experiencia en Marketing, Ventas y Trade marketing. En empresas relacionadas a productos de consumo masivo y en cargos jefaturales. Actualmente se desempeña como Jefe de Marketing Tissue en la empresa Papelera Nacional S.A. (PANASA)

\section{Ingeniero Químico Carlos Bullón}

Profesional en Ingeniería Química de la Universidad Nacional del Callao, con experiencia en procesos productivos de empresas nacionales y transnacionales del rubro papelero, como Papelera Atlas, Protisa Perú, Protisa Colombia, actualmente se desempeña como Gerente de producción en la empresa Papelera Paramonga y consultor en implementación de Plantas papeleras para la firma Rickard-Italia.

\section{Enfermera Maritza García Riveros}

Profesional con Licenciatura en enfermería de la Universidad Villarreal, con especialización en Educación con mención en docencia universitaria e investigación pedagógica. Se desempeñó como enfermera en el Hospital Central del Ejército, teniendo la oportunidad de realizar trabajos de campo a nivel latinoamericano para la aplicación de Cirugía Plástica Reconstructiva. Actualmente se desempeña como Coordinadora 
Nacional de Instituciones Educativas y consultora independiente en temas sanitarios y de salud pública.

\section{Ingeniero Industrial Jorge Sifuentes Canales}

Profesional en Ingeniería Industrial de la Universidad de Lima. Se desempeñó como ejecutivo comercial en el sector inmobiliario y durante los últimos tres años como ejecutivo comercial de demanda de productos en Hipermercados Tottus

\section{ENTREVISTAS DE PROFUNDIDAD}

\section{Entrevista de Profundidad 001 con el Ingeniero Civil Carlos Jiménez}

El objetivo de la entrevista con el especialista técnico era conocer los aspectos positivos y negativos en el uso del cobertor sanitario y cómo podría afectar a las edificaciones.

1. Presentación del Cobertor sanitario para baños y su uso, el especialista índico que sería una buena opción para mantener la salud de las personas. Sin embargo su primer cuestionamiento era si el producto es $100 \%$ biodegradable. Puesto que, indicaba que a pesar de esta cualidad, podrían permanecer remanentes del papel que pueden asentarse en las tuberías de desagüe, y en el futuro generar un atoro.

2. Definiendo los tipos de edificación, las edificaciones nuevas son aquellas que han utilizado tuberías de PVC, las cuales de empezaron usar a partir del año 1995. Mientras que las edificaciones antiguas, tiene tuberías de fierro y la tubería del desagüe es de concreto.

3. De la caja de ingreso de agua, el especialista indicó que SEDAPAL los oferta en medidas de $1 / 2,3 / 4$ y 1 ". Lo tradicional en viviendas es el ingreso de $1 / 2$ ", esto indica el diámetro del tubo y por lo tanto el flujo de ingreso del agua a la vivienda. De lo cual determinó que la potencia depende del ancho del tubo y la presión con la que ingresa el agua. En edificaciones nuevas: edificios, centros comerciales; el ingreso es de mayor ancho, ingreso de $1 \frac{1}{2}$ hacia una bomba distribuidora, para evitar o disminuir el riesgo de atoros, debido a la afluencia y frecuencia de uso de sus inodoros.

4. De los desagües, indicó que las casas tradicionales expulsan sus desechos por tuberías de 4" y estos tubos son hechos de concreto o cemento, y que por su porosidad y cara interna no lisa, es más fácil que cualquier material se adhiera y sedimente, generando un atoro futuro debido a la acumulación de desechos. En edificaciones modernas se usan tubos de PVC que por su carácter liso permiten el flujo de los desechos con mayor facilidad y si son edificios están tuberías tienen un diámetro de 6".

5. De los inodoros de las casas, la distribución de agua en las viviendas es, por lo general, con tubos de $1 / 2$ " lo que podría afectar la potencia al momento de expulsar los 
desechos al desagüe. Sucede que, en algunos lugares de Lima la potencia no es la suficiente: construcción con las tuberías con medida inadecuada sumada a la poca presión del agua.

6. De los inodoros de edificios, centros comerciales, oficinas y otras edificaciones nuevas; en estos casos se toman las previsiones para que los sistemas no colapsen por desabastecimiento, por lo cual las tuberías son más anchas y los sistemas, en algunos casos, contemplan el uso de bombas hidroneumáticas. Estas últimas, garantizan que se tenga la fuerza suficiente en las cañerías para poder trasladar el agua y eliminar los desechos por el desagüe.

7. Cómo se podría solucionar la falta de potencia, esta dificultad se podría superar mediante una solución que aumente la presión del agua: ingreso de 1/2 y distribución de 3/4 y salida de $1 / 2$, esta fórmula aumenta la presión del flujo de agua en las casas y contribuye a evitar atoros en los desagües. Otra solución es solicitar a SEDAPAL un ingreso de agua mayor, lo cual determina un mayor costo del suministro. Otra forma de solucionarlo es aumentar la presión de la bomba interna de los inodoros para que cargue más agua. En toso estos casos, no hay un mayor gasto en agua pues el consumo lo determina el usuario, solo se ha brindado una solución de mayor potencia.

8. El producto funcionaría en las casas de Lima, si en el caso de viviendas con construcción moderna es decir con cañerías de PVC para facilitar el flujo de los desechos al desagüe. En el caso de viviendas con tuberías de fierro y concreto no se recomendaría porque podrían producirse atoros en sus instalaciones.

\section{Conclusiones}

1. Las viviendas con construcción moderna, cañerías de PVC, no deberían tener ningún problema para el desecho del producto.

2. Para las viviendas con construcción antigua, no es recomendable el uso del producto debido a que podrían generar un atoro de las cañerías.

3. El uso del producto en centros comerciales y edificios no representaría ningún problema para el uso del producto.

4. El producto es una buena opción para mantener la salud de las personas.

Entrevista de Profundidad 002 con el Ingeniero Industrial David Oliva Aragón Ejecutivo de Logística de Compras - Corporación Wong - Centro Comercial Plaza Norte.

El objetivo de la entrevista con el Ejecutivo de logística de compras, era conocer los aspectos relacionados con los motivos y condiciones de compra del cobertor sanitario al 
proveedor KMC International y que oportunidades de negocio identifica a nuestro producto parte de la investigación.

1. El Cobertor sanitario como producto y su utilidad para el uso en los baños públicos, el ejecutivo comentó que es una buena alternativa para proteger la salud de las personas. Como es el que tiene a su cargo la gestión de compras del producto tiene conocimiento claro de los atributos y los beneficios de su uso.

2. Conociendo el motivo de la compra inicial del cobertor para baño: por recomendación del proveedor o por estrategia del Grupo Wong, se tomó la decisión de compra por un tema estratégico, pensando en lograr una diferenciación en cuanto a la calidad en el servicio para los clientes al momento de tener la necesidad de utilizar los baños en el centro comercial.

3. Analizando la evolución de las compras del cobertor por Corporación Wong, El ejecutivo comentó que las compras se iniciaron en el año 2012 y que comparando las compras anuales del último año 2015 vs. 2012 se cuadruplicaron, a continuación la evolución:

$$
\begin{aligned}
& 2012 \rightarrow 746 \text { cajas } \\
& 2013 \rightarrow 1,111 \text { cajas } \\
& 2014 \rightarrow 2,210 \text { cajas } \\
& 2015 \rightarrow 3,180 \text { cajas. }
\end{aligned}
$$

4. Presentando el producto, precio y condiciones de venta, El Ing. Oliva comunicó que los cobertores sanitarios vienen en caja de 20 paquetes por 250 unidades. El precio de compra es S/. 23.36 incluido IGV la caja por 5,000 unidades, el proveedor es KMC International quien importa el producto desde China con la marca Safe-t-gard, es $100 \%$ biodegradable.

5. Con referencia al cobro a los clientes que hacen uso del servicio de los baños, indicó que actualmente cobran S/.0.50 a cada cliente por el uso del servicio de los baños, al inicio tuvieron algunos problemas por el cobro del servicio, cuando en otros centros comerciales no cobran por este concepto, pero actualmente los clientes han identificado la diferenciación del servicio por la limpieza constante e higiene, además de todo el kit parte del servicio: jabón líquido, papel higiénico, cobertor sanitario, papel toalla.

6. Analizando la posibilidad de dejar de cobrar por el uso de los baños y la estrategia de diferenciación en la calidad del servicio de limpieza constante e higiene, El ejecutivo fue claro en comentar que la única forma de lograr esta diferenciación de servicio es cobrando S/. 0.50 por el ingreso, ya que es alto el costo del kit: jabón líquido, papel higiénico, cobertor sanitario, papel toalla. Esta inversión mensual promedio de estos productos es aproximadamente de S/. 50,000.00, más el pago de mano de obra del 
personal de limpieza. En resumen, si no cobraran por el ingreso no invertirían por el kit completo, de tal manera que la estrategia de diferenciación tiene relación directa con el cobro de ingreso a los baños.

7. Viendo las oportunidades de uso del cobertor en los baños por los clientes del centro comercial, El ejecutivo considera que en este tema si existe una gran oportunidad ya que según su percepción existe un gran porcentaje de personas que no tienen un conocimiento claro para qué sirve el cobertor sanitario y sus beneficios de uso, en cada uno de los baños se encuentran ubicados en un dispensador el modo de uso pero no los beneficios del producto, también cree que hay una gran oportunidad por un tema cultural y que en todo caso lo valoran más las damas que los caballeros.

8. Si es que tiene alguna información de por qué no utilizan los cobertores en los baños de otros centros comerciales, indicó que no posee información concluyente pero piensa que es porque la inversión en el kit completo es contar con un gran presupuesto mensual y en todo caso depende si su estrategia es mantener el ingreso gratuito o comenzar a cobrar por el servicio de uso de los baños, desde el punto de vista del consumidor considera que existe un alto porcentaje de consumidores que todavía no tienen el hábito y costumbre del uso del cobertor y sus beneficios.

9. Finalmente,qué opina del producto, El Ing. Oliva comenta que el cobertor lo ve como una gran oportunidad de negocio, lo considera de una gran alternativa para proteger la salud, ya que prácticamente el producto no tiene presencia en nuestro país y que además cuenta con un alto potencial. Pero cree que el gran reto es cambiar el tema cultural en los consumidores, así como los hábitos y costumbres, cree que en la primera etapa debe de estar dirigido al segmento de damas.

\section{Conclusiones}

1. El motivo de compra de los Cobertores sanitarios como parte del kit en el centro comercial es por un tema estratégico de diferenciación en la calidad del servicio para el uso de los baños, donde la limpieza e higiene constante son 2 atributos importantes.

2. Que Corporación Wong están dispuestos a seguir invirtiendo en el kit de aseo e higiene donde los cobertores sanitarios son uno de los productos, solo si siguen cobrando por el servicio.

3. El precio de compra de los cobertores está muy por debajo del otro competidor el precio unitario incluido IGV es de S/.0.005.

4. Que actualmente el consumidor que hace uso de los baños del centro comercial, no muestra ninguna molestia, porque si les genera valor el pago con relación al servicio brindado en el uso de los baños. 
5. Existe una gran oportunidad de mejorar la comunicación de los beneficios en el uso del cobertor cuando los clientes requieren de los servicios de los baños en el centro comercial, solo existe modo de uso.

6. El cobertor sanitario se presenta como una gran oportunidad de negocio y de alto potencial, prácticamente no existe en el mercado peruano.

7. El reto es cambiar la cultura, así como los hábitos y costumbres de los peruanos en el cuidado e higiene de la salud, cuando hacen uso de los baños públicos.

\section{Entrevista de Profundidad 003 con el Licenciado en Marketing Christian Marky} Bertarelli, Jefe de Marketing, División Institucional - Productos Tissúe del Perú

\section{S.A.- PROTISA.}

El objetivo de la entrevista con el especialista en marketing del canal institucional era conocer los motivos del porqué Protisa no comercializa en Perú los cobertores sanitarios, o tener conocimiento de alguna experiencia de comercialización del producto en nuestro País.

1. El Cobertor sanitario como producto y su utilidad para el uso en los baños públicos, el ejecutivo comentó que si conoce muy bien al cobertor sanitario, que incluso lo comercializaron no hace mucho tiempo en Perú en el canal institucional con muy malos resultados.

2. Hablando de la experiencia de comercialización del cobertor sanitario por Protisa en el Perú, el producto lo importamos regionalmente desde Protisa Chile, lo comercializamos en los años 2013 y 2014, solo a través del canal institucional los resultados fueron de los peores, incluso quedó algo para el 2015, al final terminamos destruyendo el saldo que quedó.

3. El canal institucional como alternativa de comercialización, El especialista comentó que como estrategia de comercialización el producto fue direccionado solo al canal institucional en una primera etapa, el cual se dirige a empresas, instituciones, centros comerciales, hoteles, restaurants cadenas y de categoría, etc., pero tuvieron muchos problemas desde un primer momento para la venta y colocación, en los clientes que se llegó a vender en muchos casos ya no hubo recompra de cobertores, los centros comerciales, hoteles y restaurants de categoría no querían comprar para sus clientes.

4. Identificando los problemas principales por el fracaso de la comercialización de cobertores en el Perú, indicó que considera al cobertor como un producto de muy nicho, que existe un problema de falta de cultura de higiene y asepsia para proteger la salud de parte de los peruanos cuando utilizan baños públicos fuera de casa, a diferencia de Brasil donde es todo un éxito ya que el brasileño si considera al cobertor como una necesidad 
parte de sus hábitos y costumbres de cuidado e higiene, entonces el consumidor peruano al no exigir el producto como parte del servicio, las instituciones no compran, no invierten, también se debe considerar el factor precio ya que era un producto caro, el paquete de 75 unidades costaba S/. 60.00 , en Chile tampoco se vende mucho, pero mejor que en Perú.

5. De la estrategia del portafolio de productos del canal, con el resto del portafolio de productos si nos va muy bien pero la competencia es fuerte con Kimberly, en papel toalla, papel higiénico, servilletas, etc., decidimos traer los cobertores no pensando en que fuera una alternativa del mix de rentabilidad, el motivo de traerlo fue por protección del portafolio, ya que la competencia también lo tenía anteriormente.

6. Con respecto al uso del producto en favor de la ecología, el especialista indicó de que a pesar de que el producto es $100 \%$ biodegradable, al menos en nuestro País no debe recomendarse arrojarlos al inodoro el sistema de conexión a desagües no está preparado para arrojar por esta vía los cobertores ya que al momento de mezclarse con el agua y la celulosa crean una crema que luego genera atoros, debe de arrojarse al tacho pero al final genera más basura.

7. Con referencia a la comercialización del cobertor sanitario en nuestro país, el ejecutivo comentó que él no recomienda al producto como una oportunidad para un plan de negocio en el canal institucional, al menos ahora no, tiene que pasar varios años para que el consumidor peruano cambie su cultura pensando en proteger su salud, hábitos y costumbres con referencia al uso de baños fuera de casa. Sin embargo, sugirió que la estrategia se dirija al consumidor final a través del canal moderno.

\section{Conclusiones}

1. Si comercializó Protisa en nuestro País el cobertor sanitario para inodoro, los resultados según el especialista fueron pésimos, incluso destruyeron producto, por tal motivo lo descontinuaron y retiraron del portafolio del canal.

2. Que el consumidor peruano todavía no incorpora dentro de su cultura la importancia de proteger su salud a través de un mayor cuidado, higiene y aseo cuando tiene la necesidad de hacer uso de baños fuera de casa, por tal motivo no exige el uso de cobertores sanitarios.

3. El precio de venta de los cobertores por Protisa era muy caro, casi S/. 1.00 cada uno, un factor importante a considerar para la inversión de parte de las empresas e instituciones.

4. Que en otros países de Sud América si tienen un mejor consumo de los cobertores, ejemplo Brasil. 
5. Según el especialista de Protisa los cobertores no deben arrojarse al inodoro, al contrario deben de arrojarse al tacho, nuestro sistema de conexión a desagüe no está preparado puede producir atoro.

6. No recomiendan al cobertor sanitario como una gran oportunidad de negocio en el canal institucional en nuestro País, que la estrategia debería ser orientada al consumidor final a través del canal moderno.

\section{Entrevista de Profundidad 004 con el ingeniero Químico Carlos Bullón}

El objetivo de la entrevista con el especialista en Producción era conocer si conoce de algún impedimento operativo para la producción de los cobertores sanitarios en Perú ya sea desde el aspecto de compras de suministros, manejo de inventarios, almacenamiento, transporte o distribución.

1. Cómo aprecia la respuesta de los proveedores en la venta de insumos para la fabricación de papel a base de celulosa, desde que el mundo se encuentra globalizado las importaciones son cada vez más ágiles y la confianza en los proveedores asiáticos cada vez es más grande, debe tenerse mucho énfasis en estandarizar los criterios de compra para que el proveedor no cambie su calidad y se pueda ofrecer al mercado peruano un producto bueno.

2. Acá en Colombia se fabrica el protector sanitario, cómo lo percibe el consumidor de este país, la respuesta del consumidor colombiano es diferente, tienen un mercado de salud e higiene más desarrollado que el peruano, el producto en Colombia no es caro, no lo produce Protisa, pero si Kimberly Clark porque es parte de su portafolio.

3. El proceso de fabricación es complicado, No, su proceso de fabricación es sencilla y no requiere de mucha inversión ni especialización, pero no es un producto del portafolio de Protisa Colombia y Perú.

4. Consideras que la calidad de la materia prima es importante para la fabricación del cobertor sanitario que entra en contacto con la piel, si bien es cierto que el consumidor peruano aún está creciendo ya se nota que existe cierta exigencia por el cumplimiento de estándares de calidad, el proveedor asiático es bueno siempre se le entregue especificaciones claras de producción de insumos.

5. Respecto a los niveles de inventario dentro de los almacenes recomiendas algún tipo de especificación o recomendación, el principal enemigo del papel es la humedad de Lima, hace que pierda color y gane peso, son pocos los sitios donde no haya humedad, sin embargo recomendaría más tener una posición céntrica con bajos niveles de stock para evitar deterioro del insumo y/o producto terminado. 
6. Al ser un producto nuevo del mercado, las máquinas tienen alta capacidad de respuesta en producción en caso haya alta demanda, las máquinas convertidoras tienen un sistema hidráulico casi con cero mantenimiento que les permite trabajar 24/365 y con un alto desempeño del $85 \%$ de su capacidad nominal.

7. Recomendarías tener 2 convertidoras y 2 embolsadoras/empacadoras, me concentraría en estructurar estrategias de captura de mercado orientadas a la cultura de higiene en el usuario.

8. El producto funcionaría en las casas de Lima, el papel con el cual está desarrollado el cobertor sanitario no es igual al papel higiénico, no recomendaría que éste sea desechado por el desagüe, hay que ser muy específicos con esto en el empaque.

9. Qué opinas del producto en sí, me parece una buena alternativa para mejorar la salud de las personas, además que al no ser un producto caro en su costo de fabricación podría aprovecharse la ventaja de ser el primero en el mercado.

Conclusiones

1. Desarrollar en el consumidor peruano la cultura de higiene y protección de la salud.

2. No debe arrojarse el cobertor sanitario al inodoro, deben de arrojarse al tacho, nuestro sistema de conexión a desagüe no está preparado y puede producir atoro.

3. Lima de por sí es una ciudad húmeda por su ubicación geográfica, debe mantenerse el mínimo stock necesario de insumo y producir solamente lo que se venderá.

4. Las máquinas de conversión son de alto rendimiento por lo que inversión en éstos debe ser lo necesario.

5. No es ningún impedimento que el insumo sea de origen asiático mientras las especificación de fabricación del papel sea controlado.

\section{Entrevista de Profundidad 005 con la Enfermera Maritza García Riveros}

El objetivo de la entrevista está relacionado a obtener información sobre los baños públicos y su incidencia en la salud de las personas.

1. Presentación del Cobertor sanitario para baños y su uso, la experta indicó que dependiendo de las características del producto, este podría disminuir el riesgo de contraer enfermedades al contacto del cuerpo con el inodoro de los baños públicos. Pues en su experiencia de uso y conocimiento del producto, la dificultad que encontró es que era muy acotado con respecto al inodoro lo que podría causar que se mueva y se produzca un contacto con la piel. 
2. De los baños públicos, la experta indicó que si usa los baños públicos pero de ciertos establecimientos que le generan confianza o por que evidencia que hay personal de limpieza que constantemente está atendiendo el mantenimiento de dichos baños. Entre los baños públicos que usa indicó los siguientes: el baño de su oficina, de hoteles de calidad comprobada y el de la casa de sus familiares. En todo caso, indico que para evitar el uso de baño públicos, baño diferente al de su domicilio, trata de no consumir muchos líquidos. Por otro lado, comento que los baños que utilizan pastillas desinfectantes, aquellas que vuelven el agua azul, es una garantía de prevención ante la posibilidad de contraer alguna enfermedad y que ello le genera confianza en el uso de dicho espacio.

3. En relación con la salud, el uso de baños públicos si puede generar el contraer alguna enfermedad. En el caso de los hombres y mujeres se podrían contraer enfermedades en las vías urinarias, al defecar o miccionar. Por otro lado, en el sector femenino es más probable el contraer enfermedades por la exposición del aparato urinario, directamente con los inodoros, como es el caso de la Cistitis. La Cistitis es la inflamación de la vejiga, la cual puede ser ocasionada por varios tipos de bacterias, dentro de ellas la más conocida es la Escherichia Coli. Asimismo, indicó que esta enfermedad, en el caso de las mujeres, se puede dar por dos vías: al contraer una bacteria al contacto con el baño o por el evitar orinar

4. De la forma de uso, las mujeres, en su mayoría, no se sientan en los inodoros de los baños públicos, justamente porque podrían enfermarse al contraer algún virus o bacteria. Por ello, la forma de uso al no sentarse, como forma natural de uso del baño, produce que orinen paradas y esta posición con los años puede producir enfermedades en ellas. La enfermedad, directamente relacionada con la forma de uso es el Prolapso, que es un debilitamiento de los músculos del piso pélvico y que soportan los órganos internos. Sin embargo, también puede ser ocasionado por los partos, estreñimiento, factores genéticos, entre otros. Pero si se puede afirmar que la posición al ser incorrecta podría contribuir al desarrollo de dicha enfermedad.

Finalmente, la experta indicó que existen estudios que relacionan el uso de baños públicos con la posibilidad de contraer enfermedades

\section{Conclusiones}

1. El producto puede disminuir el riesgo de enfermedades asegurando una forma y tamaño adecuado. Pero, una mayor seguridad se puede generar con una limpieza correcta de los baños y con el uso de productos de calidad. 
2. Los baños públicos si pueden generar enfermedades. Asimismo, la forma inadecuada de la acción de miccionar, en las mujeres, podría generar enfermedades. En ambos casos, existen estudios que soportan estas afirmaciones.

\section{Entrevista de Profundidad 006 con el Ingeniero Industrial Jorge Sifuentes} Canales, Jefe de Compras de Productos de Gran Consumo - Hipermercados Tottus

El objetivo de la entrevista con el especialista en compras del canal supermercados, es ver la viabilidad de compra del cobertor sanitario para comercializarlo a través del canal intermediario en el ámbito de Lima Metropolitana.

1. El Cobertor sanitario como producto y su utilidad para el uso en los baños públicos, el ejecutivo comentó que, si tiene conocimiento del uso del cobertor sanitario. La primera vez que tuvo contacto con el producto fue en Estados Unidos y luego en Colombia.

2. Comentando de la importancia del cobertor sanitario como producto, lo consideró muy importante para proteger la salud y evitar el contacto directo de los usuarios con la tapa de los sanitarios los cuales contienen diferentes tipos de microbios y bacterias. También indicó que este producto está dirigido, principalmente, a un público femenino.

3. Hablando de las posibilidades de compra de productos propuestos por los proveedores, normalmente Hipermercados Tottus compra productos de las diferentes categorías, previo análisis de las diferentes propuestas, utilizando como herramienta los estudios de mercado de la empresa CCR y, también, investigación comercial que manejan internamente en la empresa.

4. Conversando acerca de las posibilidades de entrada y compra de nuevos productos, el especialista indicó que primero los productos pasan por un proceso de evaluación, teniendo como resultado 2 posibilidades que decidan comprar el producto o no. En el caso de que decidan comprar un producto nuevo se dan considerando 2 escenarios:

a. Productos diferenciados, cuando viajan los Gerentes de Compras y Comercial al exterior, donde identifican productos que comienzan a romper mercado, realizan las negociaciones para traerlos y comercializarlos en nuestro País.

b. Productos rentables con buena tendencia, analizan los productos nuevos propuestos por los proveedores y lo importante es que lograr una buena negociación de margen comercial que resulte un negocio atractivo para la cadena. Además de ello, el supermercado solicita una inversión inicial la cual fluctúa entre S/. 30,000 a S/. 60,000 dependiendo la categoría, en el caso del cobertor debe de estar en el nivel de 
inversión de S/. 40,000 a S/. 50,000.00 soles, este derecho puede financiarse y fraccionarse de acuerdo a negociación.

5. De la presencia de un cobertor sanitario del competidor con la marca Queen 12 unidades a S/. 4.00 la caja, nos dijo que si tenía conocimiento del producto, pero que el no vio lo referente a su negociación inicial, también comentó que ya tenía algunos años en la cadena y que si tenía reposición.

6. Luego de presentar el cobertor sanitario parte de nuestra propuesta, conversamos referente a la posibilidad de poder ser comercializado por la cadena en una presentación de 10 unidades a un precio de S/. 2.50; nos comentó que tendría que pasar por un proceso de evaluación, pero dada la tendencia del consumidor actual con mayor énfasis el femenino en proteger su salud y como ya existe el producto en tienda, él nos sugiere vayamos por la alternativa de negociación de productos rentables con tendencia de inversión.

7. Preguntando acerca de la posibilidad de compra del cobertor sanitario por parte de Cencosud y Supesa - Plaza Vea, nos comentó que, si un supermercado ya tiene el producto como parte de su oferta, es más acordar su venta con las otras cadenas.

8. Referente a las proyecciones de venta y partiendo del escenario de trabajar con la cadena pensamos que podemos vender a todas las tiendas de Lima Metropolitana; Jorge Sifuentes manifestó que normalmente para este tipo de productos no se puede vender en todas sus tiendas, inicialmente se considera a las tiendas segmentadas y dada las características del producto lo orientaría a las tiendas en los sectores del NSE A,B y C en un gran porcentaje compuesto por Lima Moderna.

9. Como manejan las condiciones de ventas; pago con factura a 60 días, margen comercial mínimo de 30\% el cual incluye distribución 5\%, mercaderismo $1.5 \%$ y software B2B $0.5 \%$

10. Con referencia al reparto del cobertor sería por tienda o a un almacén central de la cadena; el reparto en función a la programación de pedidos se centraliza la entrega en nuestro Centro de Distribución y luego nosotros nos encargamos del reparto a las diferentes tiendas, el costo es el $5 \%$ del total de la facturación y está incluido en el margen comercial.

11. Que otros tipos de pagos se consideran en el margen comercial, hay otros pagos adicionales $0.5 \%$ por utilizar nuestro software B2B donde pueden ver los stocks por tienda y el requerimiento de pedidos, $1,5 \%$ por mercaderismo el cual lo asumen todos los proveedores, ambos ya están incluidos en el margen de 30\%, basado en margen front, margen back. 
12. Respecto a las promociones como se llevan a cabo, la cadena ya no trabaja con promociones como por ejemplo paga 2 lleva 3, ahora están enfocados en la estrategia lower Price, teniendo en cuenta el punto de precio.

13. Como se realiza la reposición de pedidos, en la cadena se calcula los pedidos a los diferentes proveedores teniendo como herramienta al sistema ASR, el cual considera como variables: promedios, stock de seguridad, lead time (ciclo de la orden de compra).

14. Con respecto a la visibilidad, ubicación en góndola, categoría y exhibición del cobertor sanitario; primero lo define el comprador teniendo en cuenta la evaluación catman, el layout final en cuanto a espacios está a cargo del category Management.

15. Con respecto a la ubicación del competidor Queen en la categoría limpieza; actualmente yo veo compras de productos de gran consumo, pero si me dices que está ubicado en limpieza me parece que no está en la ubicación correcta, porque tiene que ver con el cuidado y protección femenina.

16. Pensando en la ubicación en góndola del cobertor sanitario en la categoría de cuidado y protección femenina, teniendo en cuanta la ruta de consumo de productos personales como toallas higiénicas, tampones, etc.; me parece que sería la ubicación correcta porque se incluiría como parte de los productos que no faltan en el bolso de las mujeres jóvenes y adultas para la higiene y protección femenina, finalmente se coordina con el comprador pero hay que proponerlo porque en la medida que se venda y rote más, ganamos todos.

17. Se puede hacer uso en tienda de material publicitario como jalavistas por ser un producto nuevo, en este caso no hay problema pero se coordina con el comprador.

18. Con el cobertor sanitario necesitamos generar la cultura de la importancia de que el segmento femenino cuide su salud cuando utilizan los baños públicos al salir fuera del hogar, pero es importante darlo a conocer, que sugieres para ejecutar el sampling; es de vital importancia que consideren dentro del presupuesto un lote de producto para que el target lo conozca, pienso que debería ser los 3 primeros meses, sugiero 2 alternativas primero entrega de muestras programando mercaderistas por horas en las diferentes tiendas con una hoja $1 / 2 \mathrm{~A} 4$, que describa los atributos y beneficios del producto, segundo entregarlo como estrategia de cruzadito que su producto acompañe un producto de alta rotación para el segmento femenino, y claro la entrega es gratis.

19. Respecto a visibilidad como definen los espacios de los productos por categoría, cuál sería la medición en góndola para el cobertor sanitario; lo definimos por número de facing, es decir caras visibles, finalmente lo determinan comprador y catman, para este tipo de productos nuevos no creo que sean más de 3 facing de ancho $\times 5$ packs 
verticales, hacia arriba y hasta 6 de fondo. De acuerdo al tamaño de un pack de pañitos de limpieza.

20. Con respecto al primer pedido estimado por tienda, normalmente nosotros hacemos pedidos iniciales por tienda de 2 pallets, que para este tipo de producto pienso que debe estar entre 70 a 90 cajas x 50 packs de cobertor sanitario para inodoros, luego vamos viendo cómo se comporta la rotación para los pedidos futuros utilizando la herramienta de sistema ASR.

\section{Conclusiones}

1. Si hay alternativa de poder comercializar en la cadena Tottus el cobertor sanitario, pero tendría que ser bajo el escenario de productos rentables con buena tendencia, el cual viene acompañado de inversión inicial.

2. Luego de cerrar la negociación con Tottus, según lo comentado por Jorge y teniendo en cuenta su experiencia podemos cerrar las negociaciones con las otras 2 cadenas Cencosud y Supesa.

3. No es posible vender a todas las tiendas que involucra los diferentes distritos de Lima Metropolitana, solo se sugiere iniciar con los distritos de Lima Moderna, donde hay una mayor concentración del NSE A, B y C.

4. La entrega y reparto de los productos se realiza solo en el centro de distribución de la cadena, luego se encargan de distribuir a cada una sus tiendas, para esto se asume un costo del $5 \%$ del total de la venta, el cual está incluido en el margen comercial.

5. El pack x 10 unidades del cobertor sanitario y al precio de S/. 2.50, lo aprecia como una gran alternativa para el segmento femenino ya que el competidor lo oferta con un precio $60 \%$ más elevado, pero en caja de 12 unidades.

6. Como políticas comerciales trabajan con pago de factura a 60 días, con un margen comercial mínimo de 30\%, el cual debe incluir 5\% por distribución, $1.5 \%$ por mercaderismo.

7. De acuerdo a la negociación con el comprador, el cobertor sanitario puede ir ubicado en la categoría de protección femenina. 


\section{B) Filtro de NSE}

\section{FILTRO PARA DETERMINAR NSE}

Nombre:

Edad:

Dirección:

Promedio de Ingreso Familiar:

N1. ¿Cuál es el último año o grado de estudios y nivel que aprobó el jefe de hogar? (ACLARAR “COMPLETA O INCOMPLETA")

\begin{tabular}{|c|c|c|}
\hline Sin educación/ Educación inicial & $\begin{array}{l}\text { Superior Técnico } \\
\text { Completa }\end{array}$ & $\begin{array}{c}\text { Post- } \\
\text { Grado Universitario }\end{array}$ \\
\hline Primario / /Secundaria completa & $\begin{array}{l}\text { Superior Univ. } \\
\text { Incompleta }\end{array}$ & \\
\hline $\begin{array}{l}\text { Secundaria completa/ Superior } \\
\text { Técnico completo }\end{array}$ & $\begin{array}{l}\text { Superior Univ. } \\
\text { Completa }\end{array}$ & \\
\hline
\end{tabular}

N2. El jefe de hogar se encuentra afiliado a un:

\begin{tabular}{|c|c|c|}
\cline { 2 - 3 } \multicolumn{1}{c|}{} & NO & SI \\
\hline $\begin{array}{c}\text { Seguro de salud privado o } \\
\text { EPS }\end{array}$ & 0 & 4 \\
\hline
\end{tabular}

N3. ¿Cuál de estos bienes tiene en su hogar que está funcionando?

\begin{tabular}{|l|r|r|}
\cline { 2 - 3 } \multicolumn{1}{c|}{} & NO & SI \\
\hline $\begin{array}{l}\text { Computadora, laptop en } \\
\text { funcionamiento }\end{array}$ & 0 & 2 \\
\hline Lavadora en funcionamiento & 0 & 2 \\
\hline $\begin{array}{l}\text { Horno microondas en } \\
\text { funcionamiento }\end{array}$ & 0 & 2 \\
\hline $\begin{array}{l}\text { Refrigeradora/ congeladora en } \\
\text { funcionamiento }\end{array}$ & 0 & 2 \\
\hline \multicolumn{1}{|c|}{ SUMAR } & & \\
\hline
\end{tabular}

N4. ¿Cuál de estos servicios tiene en su hogar?

\begin{tabular}{|l|l|l|}
\cline { 2 - 3 } \multicolumn{1}{c|}{} & O & I \\
\hline Teléfono fijo & & \\
\hline Televisión por cable & & \\
\hline Internet (sin compartir por el celular) & & \\
\hline SUMAR & & \\
\hline
\end{tabular}

\begin{tabular}{|c|c|}
\hline & $\begin{array}{ll} & \text { PTJ } \\
\text { E } & \end{array}$ \\
\hline Ningún servicio & 0 \\
\hline 1 de 3 & 2 \\
\hline 2 de 3 & 4 \\
\hline 3 de 3 & 7 \\
\hline
\end{tabular}

N5. ¿Cuáles de los siguientes bienes o servicios tiene en su hogar que se encuentren funcionando?

Auto y/o camioneta para uso particular

Servicio doméstico en el hogar pagado (MINIMO QUE VAYA AL HOGAR UNA

VEZ POR SEMANA) 


\begin{tabular}{|l|c|c|}
\hline Internet (sin compartir por el celular) & 0 & 4 \\
\hline \multicolumn{2}{|c|}{ SUMAR } & \\
\hline
\end{tabular}

N6. ¿Cuál es el material predominante en los pisos de su vivienda? (CONSIDERAR AREA CONSTRUIDA RESPUESTA UNICA)

\begin{tabular}{|l|l|l|}
\hline $\begin{array}{l}\text { Tierra / Otro material (arena y } \\
\text { tablones sin pulir) }\end{array}$ & $\begin{array}{l}\text { Laminas asfálticas o similares/ vinílicos, mosaico o similares/ } \\
\text { Laminado tipo madera. }\end{array}$ & \\
\hline Madera (entablados) /tapizón & & Losetas/ terrazas, mayólicas, cerámicas. \\
\hline Cemento sin pulir o pulido & & O madera pulida y similares: porcelanato, alfombra, mármol \\
\hline
\end{tabular}

N7. ¿El material predominante de las paredes es ladrillo o bloque de cemento?

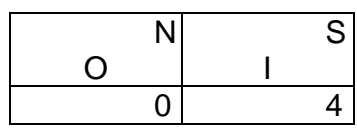

N8. ¿El baño o servicio higiénico que tiene en su hogar está CONECTADO a:

\begin{tabular}{|l|c|}
\hline No tiene baño/ No está conectado a una red publica & 0 \\
\hline $\begin{array}{l}\text { Baño compartido fuera de su vivienda (Ejem: quintas, corralosos, cuartos con } \\
\text { baño compartido, etc). }\end{array}$ & 1 \\
\hline Baño dentro de la vivienda & 4 \\
\hline \multicolumn{2}{c|}{ SUMAR } \\
\hline
\end{tabular}

\begin{tabular}{|c|l|}
\hline N1 & \\
\hline N2 & \\
\hline N3 & \\
\hline N4 & \\
\hline N5 & \\
\hline N6 & \\
\hline N7 & \\
\hline N8 & \\
\hline Total & \\
\hline
\end{tabular}

\begin{tabular}{|l|l|l|}
\hline 12 puntos o menos & NSE E & 8 \\
\hline De 13 a 19 puntos & NSE D & 7 \\
\hline De 20 a 22 puntos & NSE C2 & 6 \\
\hline De 23 a 28 puntos & NSE C1 & 5 \\
\hline De 29 a 33 puntos & NSE B2 & 4 \\
\hline De 34 a 39 puntos & NSE B1 & 3 \\
\hline De 40 a 47 puntos & NSE A2 & 2 \\
\hline 48 puntos a más & NSE A1 & 1 \\
\hline
\end{tabular}


C)Focus Group

LISTA DE PARTICIPANTES DE LOS FOCUS GROUP

Focus Group 01

SEGMENTO FEMENINO DE 20 A 54 AÑOS DE EDAD - 08 PARTICIPANTES

\begin{tabular}{|c|c|c|c|c|c|}
\hline № & PARTICIPANTE & $\begin{array}{l}\text { LUGAR DE } \\
\text { RESIDENCIA }\end{array}$ & EDAD & NSE & PROFESIÓN \\
\hline 1 & $\begin{array}{l}\text { FLAVIA ALIAGA } \\
\text { NALDOS }\end{array}$ & $\begin{array}{l}\text { SAN JUAN DE } \\
\text { MIRAFLORES }\end{array}$ & 23 & C & $\begin{array}{l}\text { ASISTENTE DE } \\
\text { OFICINA }\end{array}$ \\
\hline 2 & $\begin{array}{l}\text { AMALIA ROSA } \\
\text { BARRETO } \\
\text { PENADILLO }\end{array}$ & $\begin{array}{l}\text { VILLA MARIA } \\
\text { DEL TRUNFO }\end{array}$ & 29 & C & CONTADORA \\
\hline 3 & $\begin{array}{l}\text { CLAUDIA LÓPEZ } \\
\text { DEL ÁGUILA }\end{array}$ & SAN BORJA & 27 & $A$ & SECRETARIA \\
\hline 4 & $\begin{array}{l}\text { CLAUDIA } \\
\text { CORDERO } \\
\text { GARCÍA }\end{array}$ & CHORRILLOS & 34 & B & ADMINISTRADORA \\
\hline 5 & $\begin{array}{l}\text { SILENIA } \\
\text { RODRIGUEZ } \\
\text { CORDOVA }\end{array}$ & LINCE & 34 & C & PROFESORA \\
\hline 6 & $\begin{array}{l}\text { VANESA } \\
\text { COLLANTES } \\
\text { FUENTES }\end{array}$ & LOS OLIVOS & 35 & $B$ & TRADUCTORA \\
\hline 7 & $\begin{array}{l}\text { GISELL FONSECA } \\
\text { FALLA }\end{array}$ & LA MOLINA & 28 & $A$ & DISEÑADORA \\
\hline 8 & $\begin{array}{l}\text { MERILEY } \\
\text { SHAPIAMA DE } \\
\text { TIMOTEO } \\
\text { HIDALGO }\end{array}$ & SAN MIGUEL & 33 & B & CONTADORA \\
\hline
\end{tabular}

Fuente: Elaboración propia 


\section{Focus Group 02}

\section{SEGMENTO FEMENINO DE 20 A 54 AÑOS DE EDAD - 08 PARTICIPANTES}

\begin{tabular}{cl|cccc}
\hline No & \multicolumn{1}{c}{ PARTICIPANTE } & $\begin{array}{c}\text { LUGAR DE } \\
\text { RESIDENCIA }\end{array}$ & EDAD & NSE & PROFESIÓN \\
\hline 1 & $\begin{array}{l}\text { JENNIFER DE LA } \\
\text { CRUZ SANTOS }\end{array}$ & LOS OLIVOS & 42 & C & INVESTIGADORA \\
\hline 2 & $\begin{array}{l}\text { LIZ KEHUARUCHO } \\
\text { RAIREZ }\end{array}$ & LA MOLINA & 38 & A & ECONOMISTA \\
\hline 3 & $\begin{array}{l}\text { YVONNE RUIZ } \\
\text { ZEGARRA }\end{array}$ & SURCO & 43 & B & PSICOLOGA \\
\hline 4 & $\begin{array}{l}\text { VALIA VENEGAS } \\
\text { MEJÍA }\end{array}$ & JESUS MARÍA & 39 & B & PERIODISTA \\
\hline 5 & $\begin{array}{l}\text { MILAGROS } \\
\text { CARRASCO } \\
\text { LOYOLA }\end{array}$ & SURQUILLO & 48 & B & CIRUJANO \\
\hline 6 & $\begin{array}{l}\text { JULIA MARLY } \\
\text { HERNÁNDEZ } \\
\text { TERRONES }\end{array}$ & $\begin{array}{l}\text { SAN MARTIN } \\
\text { DE PORRES }\end{array}$ & 47 & A & EDUCADORA \\
\hline 7 & $\begin{array}{l}\text { BETTY ZARATE } \\
\text { AGUILAR }\end{array}$ & LOS OLIVOS & 48 & B & EDUCADORA \\
\hline CECILIA ROMAINA
\end{tabular}

Fuente: Elaboración propia

Focus Group 03

SEGMENTO FEMENINO DE 20 A 54 AÑOS DE EDAD - 08 PARTICIPANTES

\begin{tabular}{|c|c|c|c|c|c|}
\hline № & PARTICIPANTE & $\begin{array}{c}\text { LUGAR DE } \\
\text { RESIDENCIA }\end{array}$ & EDAD & NSE & PROFESIÓN \\
\hline 1 & $\begin{array}{l}\text { EVELYN EUGENIA } \\
\text { CASTILLO } \\
\text { FONSECA }\end{array}$ & LOS OLIVOS & 40 & B & ADMINISTRADORA \\
\hline 2 & $\begin{array}{l}\text { MARLY } \\
\text { HERNANDEZ } \\
\text { TERRONES }\end{array}$ & SURCO & 55 & A & $\begin{array}{l}\text { LICENCIADA EN } \\
\text { EDUCACIÓN }\end{array}$ \\
\hline 3 & $\begin{array}{l}\text { KATHERINE } \\
\text { PINEDO }\end{array}$ & SAN LUIS & 31 & A & SECRETARIA \\
\hline 4 & $\begin{array}{l}\text { MARTHA FUENTEA } \\
\text { RIOJA }\end{array}$ & PUEBLO LIBRE & 55 & B & AMA DE CASA \\
\hline 5 & $\begin{array}{l}\text { DANIELA } \\
\text { MAUCAILLE ROJAS }\end{array}$ & CHORRILLOS & 25 & C & PROFESORA \\
\hline 6 & $\begin{array}{l}\text { VERÓNICA GIANI } \\
\text { SANDOVAL } \\
\text { MAURICCI }\end{array}$ & LA MOLINA & 35 & B & EMPRESARIA \\
\hline 7 & $\begin{array}{l}\text { KARIZZA WILSON } \\
\text { FUENTES }\end{array}$ & $\begin{array}{l}\text { INDEPENDENC } \\
\text { IA }\end{array}$ & 45 & C & INDEPEDIENTE \\
\hline 8 & $\begin{array}{l}\text { FIORELA PONCE } \\
\text { BENITES }\end{array}$ & SAN MIGUEL & 33 & B & ECONOMISTA \\
\hline
\end{tabular}

Fuente: Elaboración propia 


\section{GUÍA DE PAUTAS PARA EL FOCUS GROUP}

\section{I.- INTRODUCCION}

El moderador se presenta a los invitados y define las características y mecánica del desarrollo de la investigación, asimismo establece pautas y les comunica que toda la entrevista será grabada.

\section{PRESENTACIÓN Y ESTABLECIMIENTO DE LAS NORMAS}

Buenos días (buenas tardes) mi nombre es veo el nombre de cada uno de ustedes en sus solaperos, eso va a facilitar la comunicación. Me gustaría saber es su edad y el lugar de donde vienen...

La presente reunión tiene como objetivo determinar el uso de baños públicos y la y frecuencia de dicho uso; asimismo sobre el lanzamiento de una nueva marca de cobertores de sanitarios para por tal razón les solicito que sean totalmente honestos en sus respuestas y que no se dejen influenciar por nadie, asimismo deben saber que no existen respuestas incorrectas todas son respuestas igualmente válidas.

También quisiera solicitarles autorización para grabar estasesión ya que sus opiniones son importantes y no quisiera olvidar alguna información útil que me puedan proporcionar durante la sesión.

\section{SOBRE LOS HABITOS}

1.- ¿Cuándo está fuera de su hogar y tiene una necesidad utiliza baños públicos?, si no los utiliza cual es el principal motivo de que no lo utiliza

2.- Si tuviéramos que indicar la cantidad de veces a la semana que los utiliza ¿Cuántas serían en promedio?

4.- Si tuviera que calificar la experiencia de uso ¿Cómo la calificaría?

\section{III.- ESTUDIO EN PROFUNDIDAD}

SOBRE EL COBERTOR PARA SANITARIOS

1.- ¿Conoce algún producto que permite evitar que su piel tenga contacto directo con su piel al momento de utilizar un baño público?

2. Si su respuesta fue Sí, ¿ha utilizado este tipo de productos?

3. Si su respuesta fue sí estaría dispuesto a comprar un producto de este tipo con una nueva marca' 
4.- Si su respuesta fue No lo conoce, estaría dispuesto a utilizar este tipo de producto si se lanzara una marca nueva al mercado?

4.- ¿Dónde les gustaría encontrar el producto?

5.- ¿Cuál sería la presentación que preferiría si se ofrecen paquetes de 5, 10, o 15 unidades?

6.- ¿Cuantos estaría dispuesto a comprar por mes?

7. ¿Cuánto estaría dispuesto a pagar por Pack?

8.- ¿Cómo le gustaría saber del producto? ¿En qué medios publicitarios?

9. ¿Considera importante que existan expendedores de estos productos en los baños públicos?

\section{CIERRE}

Hacer un resumen de los resultados

El Focus Group se desarrolló de forma amigable con los participantes, como se mencionó participaron 8 personas, con una duración de 50 minutos aproximadamente, en su primera parte tuvo una duración de 25 minutos y en el desenlace 25 minutos.

\section{RESULTADO DE LOS FOCUS GROUP}

\section{Focus Group 001}

La reunión de investigación se desarrolló con ocho participantes con edades que fluctuaban entre los 20 a 54 años de edad, de sexo femenino y de la ciudad de Lima.

1. Sobre el uso de baños públicos, en todos los casos indicaron que si los usaban. Y que el principal problema estaba relacionado con la limpieza y la posibilidad de contraer enfermedades. Y sobre todo relacionado con la salud de sus hijos.

2. Sobre la frecuencia de uso, en la mayoría de los casos se coincidió que lo usaban casi todos los días de la semana. Sin embargo, dos de ellas indicaron que lo frecuentaban más debido a su alto consumo de agua por ser deportistas, asistían a los gimnasios.

3. Sobre la existencia del producto, 4 de las participantes conocían el producto pero solo dos las usaban ya que les daba mayor confianza a realizar sus necesidades en los baños públicos.

4. Sobre la utilización del producto, solo 6 personas manifestaron que utilizarían el producto las otras dos manifestaron que lo consideraban que era un gasto 
innecesario, pues no estaban convencidos que su salud estaría garantizada con su uso.

5. Sobre la presentación, el pack de 10 unidadesles pareció el más conveniente, porque era una opción parecida a la de los protectores diarios y que se podía transportar a todos lados y que incluso se lo podrían dar a sus hijos

6. Sobre el precio y lugares de venta, con respecto al precio estarían dispuestas a pagar entre S/. 2.00 a S/. 3.00, debido a que consideran que la salud es muy importante. Con respecto al punto de venta de preferencia es en los supermercados, pues ahí realizan sus compras del hogar.

7. Sobre la comunicación, indicaron que sería por televisión en programas especializados, revistas, paneles e internet.

8. Sobre la colocación de expendedores en baños públicos, la idea fue aceptada, sobretodo que les permitía acceder al producto en situaciones no previstas cuando no lo tuvieran en su cartera. Pero siempre con la salvedad de que el precio no se incremente muy por encima del precio propuesto en supermercados.

\section{Focus Group 002}

La reunión de investigación se desarrolló con ocho participantes con edades que fluctuaban entre los 20 a 54 años de edad, de sexo femenino y de la ciudad de Lima.

10.2.1.1.1 Sobre el uso de baños públicos, en todos los casos indicaron que si los usaban ya que permanece fuera de casa mayormente por motivos laborales, sin embargo manifiestan que en muchas ocasiones no están muy limpios y están preocupadas por su salud.

2 Sobre la frecuencia de uso, en la mayoría de los casos se coincidió que lo usaban diariamente, pues permanecían fuera de casa muchas horas, ya sea por temas laborales o por la realización de diligencias personales.

3. Sobre la existencia del producto, solo 2 de las participantes conocían el producto y lo usaban, pues los baños que utilizaban cotidianamente no eran muy limpios y estaban preocupadas por contraer alguna enfermedad.

4. Sobre la utilización del producto, solo 3 personas manifestaron que utilizarían el producto por la protección de su salud, las cinco restantes manifestaron que no lo utilizarían por ser un gasto innecesario.

5. Sobre la presentación, el pack de 10 unidades les pareció el más conveniente, ya que así se presentan por lo general los productos de higiene personal. 
6. Sobre el precio manifestaron que estarían dispuestas a pagar entre S/. 2.01 a $\mathrm{S} / 3.00$, pues consideran que la prevención de enfermedades es crucial para su vida.

7. Con respecto al punto de venta de preferencia es en los supermercados, pues en dichos lugares habían comprado o habían visto el producto.

8. Sobre la comunicación, indicaron que sería por redes sociales, programas de salud en televisión, revistas médicas.

9. Sobre la colocación de expendedores en baños públicos, la idea les pareció excelente pero solicitando que el precio unitario no sea diferente al que se obtiene por paquete.

\section{Focus Group 003}

La reunión de investigación se desarrolló con ocho participantes con edades que fluctuaban entre los 20 a 54 años de edad, de sexo femenino y de la ciudad de Lima.

1. Sobre el uso de baños públicos, en todos los casos indicaron que si los usaban. Si bien el uso de estos es imprescindible por las horas que se permanece fuera de casa, la preocupación de contraer enfermedades es latente, ya que generalmente se encuentran desaseados y en mal estado de conservación.

1. Sobre la frecuencia de uso, en la mayoría de los casos se coincidió que lo usaban a diario, pues es inevitable ingerir comidas y bebidas durante el día, lo que posteriormente origina la necesidad del uso de los baños públicos.

10. Sobre la existencia del producto, 3 de las participantes conocían el producto y lo usaban ya que consideran que con este evitan el contacto directo con el inodoro y por ende, protegen su salud.

11. Sobre la utilización del producto, solo 5 personas manifestaron que utilizarían el producto por la protección de su salud, las tres restantes manifestaron que su uso no garantiza la prevención de enfermedades que pueden contraerse en baños públicos, por lo que es un gasto que no harían.

12. Sobre la presentación, el pack de 10 unidades les pareció el más conveniente, ya que es un empaque de tamaño apropiado de fácil transporte en bolsos, carteras y maletas de trabajo, por lo que podrá usarlo todos los miembros de la familia.

13. Sobre el precio y lugares de venta, con respecto al precio estarían dispuestas a pagar de S/. 3.00 a más, pues consideran que la prevención de enfermedades es 
crucial para su vida. Con respecto al punto de venta de preferencia es en los supermercados, pues ahí realizan sus compras de útiles de higiene del hogar.

14. Sobre la comunicación, indicaron que sería por redes sociales, programas de salud en televisión, revistas médicas.

15. Sobre la colocación de expendedores en baños públicos, la idea fue aceptada, previendo que el producto se les agote en el transcurso del día. Se enfatizó en que el precio unitario no exceda mucho, en base al precio en paquete que se expenden en los supermercados.

\section{INVESTIGACIÓN CUANTITATIVA}

\section{ENCUESTA}

Estimada Sra. (ita), la presente encuesta ha sido elaborada para fines académicos y determinar la viabilidad de lanzar al mercado un cobertor Sanitario para inodoro, que es un producto que evita el contacto de la piel con los WC de baños públicos.

Agradezco anticipadamente su participación en la misma

1. ¿Utiliza baños públicos?

A. Muy frecuente

B. Frecuentemente

C. Ocasionalmente

D. Raramente

E. Nunca

\section{2. ¿Con qué frecuencia usa los baños públicos?}
A. 1 vez por semana
B. 2 veces por semana
C. 3 veces por semana
D. 4 veces por semana

3. ¿Usted cree que el estado de los baños podría afectar su salud?
A. Niños
B. Mujeres
C. Hombres
D. Ancianos
A. Conozco totalmente
B. Conozco parcialmente
C. Indeciso
D. Desconozco
E. Desconozco totalmente

4. ¿Conoce algún producto que le permita evitar el contacto de su piel con el inodoro al usar los baños públicos? 
5. ¿Ha Utilizado este tipo de productos?
A. Muy frecuente
B. Frecuentemente
C. Ocasionalmente
D. Raramente
E. Nunca

6. Si su respuesta a la pregunta 4 fue Indeciso, Desconozco o Desconozco totalmente, Nos gustaría conocer las razones de su respuesta
A. Desconocía la existencia del producto
B. No lo considero necesario
C. Considero que puede tener un precio alto
D. Desconozco donde lo venden
E. Otros

7. ¿Qué marcas de cobertor sanitario para inodoro ha visto en el mercado?
A. Flushables
B. Wc Protect
C. Coversit
D. Protector sanitario maxilimpio
E. Producto en plaza norte
F. Producto encontrado en totus

8. De las marcas mencionadas en la pregunta anterior, ¿Que marca de cobertor sanitario para inodoro es la que Ud. Utiliza actualmente?
A. Flushables
B. Wc Protect
C. Coversit
D. Protector sanitario maxilimpio

9. Regularmente, cuando hace uso de un baño público, en qué lugares utiliza el cobertor sanitario para inodoros.
A. En su centro de trabajo
B. En restaurantes
C. En supermercados
D. En su centro de estudios
E. En centros comerciales y otros 
10. Si se ofrece un nuevo cobertor sanitario para inodoro que presenta los siguientes atributos, Garantiza el cuidado de su salud, calidad por encima de los productos de la competencia, precios adecuados y que se encuentren en puntos de ventas accesibles¿Qué tan importante le parecen los atributos del producto?
A. Muy importante
B. Importante
C. Indeciso
D. No lo considera importante
E. No tiene ningún grado de competencia

11. De los atributos mencionados ¿Cuál considera más importante?
A. Cuidado de la salud
B. Calidad del producto
C. Puntos de ventas accesibles
D. Precio competitivo

12. ¿Cuál es la presentación del cobertor sanitario para inodoro que sería de su preferencia?
A. Pack con 05 unidades
B. Pack con 10 unidades
C. Pack con 15 unidades

13. En qué punto de venta le gustaría encontrar el pack del cobertor
A. Supermercados
B. Mercados
C. Farmacias
D. Tiendas de conveniencia

14. ¿En el punto de venta en que área le gustaría encontrar el pack del cobertor sanitario para inodoros?
A. Belleza
B. Cuidado personal
C. Higiene

15. ¿Cuál esla frecuencia con la que compra el producto o estaría dispuesto a comprarlo?
A. 4 veces por mes
B. 3 veces por mes
C. 2 veces por mes
D. 1 vez al mes 
16. ¿Cuantos paquetes del cobertor sanitario para inodoro compra o compraría?
A. 1 paquete
B. 2 paquetes
C. 3 paquetes
D. Más de tres paquetes

17. ¿Cuánto estaría Usted dispuesto a pagar por un pack de acuerdo a su elección de contenido?
A. Entre $S / .1 .50$ y $S / 2.00$
B. Entre S/. 2.01 y S/2.50
C. De $S / 2.51$ a más

18. Luego de la presentación e introducción de los atributos del nuevo cobertor sanitario para inodoros ¿Ud. Estaría dispuesto a comprarlo?
A. Definitivamente si
B. Probablemente si
C. Indiferente
D. Probablemente no
E. Definitivamente no

19. Si su respuesta fue "Indiferente", "Probablemente No" y definitivamente No, ¿Nos gustaría conocer las razones? En el caso de que el encuestado responda esta pregunta se finaliza su encuesta.
A. Uso complicado del producto
B. No me parece atractiva la presentación
C. Uso los baños públicos esporádicamente
D. No considero que necesariamente cuide la salud

20. ¿Qué medio de comunicación considera el más importante para realizar la publicidad del cobertor sanitario para inodoros?
A. Tv
B. Radio
C. Revistas
D. Redes sociales
E. Páginas web
F. Vallas
G. Otros 


\section{DATOS DE CONTROL}

1.Edad:

$20-24$

25 a 35

36 a 45

46 a 54

2. Distrito donde vive:

3 Grado de Instrucción ( )

Primaria ( ) Secundaria ( ) Superior Técnica Superior Universitaria ( ) Postgrado

4 Servicio de Salud

Publico ( ) Privado ( )

5 Vivienda

Propia ( ) Alquilada ( )

6 Material predominante en la vivienda

Madera (entablados)/ tapizón ( ) Cemento sin pulir o pulido ( ) Láminas asfálticas o similares/ vinílicos, mosaico o similares/ Laminado tipo madera ( ) Losetas / terrazos, mayólicas, cerámicos ( ) Parquet o madera pulida y similares; porcelanato, alfombra, mármol ( )

7 Servicios con los que cuenta

Teléfono fijo ( ) Televisión por cable () Internet (sin compartir por el celular) ( )

8 Bienes o servicios tiene en su hogar que esté funcionando

Auto y/o camioneta para uso particular ( )

Servicio doméstico en el hogar pagado (Mínimo que vaya al hogar una vez por semana) ( ) 


\section{Entrevista a Funcionario de Mi banco}

Nombre

Cargo

Sucursal.

Tiempo que labora en la Institución

1. ¿Qué tipo de proyectos de Negocios Financia Mi banco?

2. ¿Es fácil obtener financiamiento en la Institución Financiera?

3. ¿Cuáles son los requisitos para obtener Financiamiento?

4. ¿Considera que las tasas de Interés son competitivas con las tasas de otras Instituciones Financieras?

5. ¿Mi Banco Financia emprendimientos?

6. ¿Cuáles son los requisitos que solicita la Institución para el financiamiento de emprendimientos?

7. ¿Qué tasas de Interés se manejan para este tipo de negocios?

8. ¿Si se pretende lanzar al mercado una nueva marca de Cobertor sanitario para inodoros, considera que es una buena alternativa para financiar? 


\section{CAPÍTULO $v$}

\section{MANUAL DE BUENAS PRACTICAS DE MANUFACTURA}

El presente manual se rige a las especificaciones planteadas en el Reglamento Técnico Andino relativo a los Requisitos y Guía de Inspección para el funcionamiento de establecimientos que fabrican Productos de Higiene Doméstica y Productos Absorbentes de Higiene Personal. DECISION 721. El presente reglamento lo podemos descargar del siguiente link:

intranet.comunidadandina.org > Documentos > decisiones > DEC721 